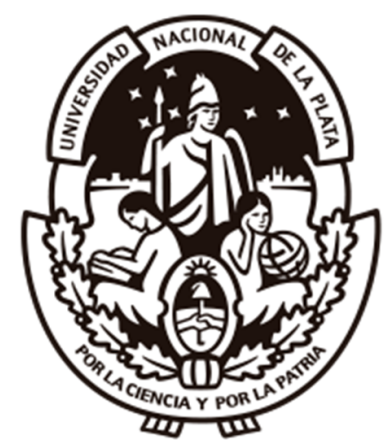

UNIVERSIDAD NACIONAL DE LA PLATA

FACULTAD DE CIENCIAS EXACTAS

DEPARTAMENTO DE QUÍMICA

Trabajo de Tesis Doctoral

\title{
MATERIALES BASADOS EN HETEROPOLIÁCIDOS TIPO KEGGIN Y SU APLICACIÓN EN REACCIONES DE ESTERIFICACIÓN PARA LA VALORIZACIÓN DE DERIVADOS DE BIOMASA
}

Angélica María Escobar Caicedo

Directores:

Dr. Gustavo P. Romanelli

Dr. Luis R. Pizzio 


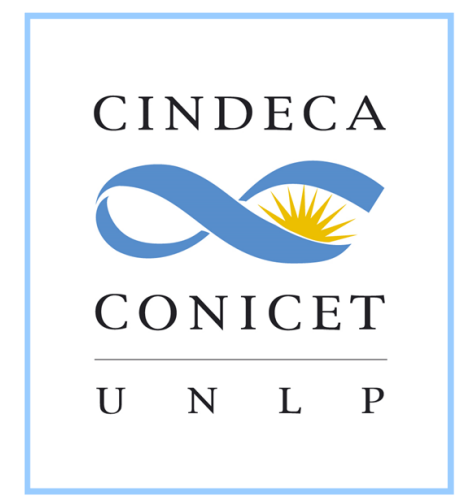

Este trabajo fue realizado en el

Centro de Investigación y Desarrollo en Ciencias

Aplicadas

“Dr. Jorge J. Ronco", CINDECA.

Dependiente del Departamento de Química de la Facultad de Ciencias Exactas de la U.N.L.P. y del CCT La Plata-CONICET. 
OS Leonardo y Cebastián, los amores de mi vida.

OM mis padres, a quienes debo todo lo que say. OM mis hermanos por su cariño y apayo incondicional. (9) a Diospor permitirme cumplir un sueño más en la vida. 
La presente Tesis Doctoral se ha concretado gracias a la guía, colaboración y apoyo de muchas personas a las cuales quiero agradecerles.

En primer lugar se encuentran mis directores, Gustavo Romanelli y Luis Pizzio, a quienes les agradezco la oportunidad que me dieron de trabajar en su grupo de investigación, su guía, su apoyo, sus enseñanzas y el tiempo dedicado a mi formación durante estos años. De igual forma quiero hacer una mención especial a la Dra. Mirta Blanco quien me acompañó y guió durante los primeros años de doctorado. A ustedes, mi admiración y respeto.

Agradezco al Consejo Nacional de Investigaciones Científicas y Técnicas (CONICET) por haberme otorgado la beca doctoral.

También agradezco a todo el personal del CINDECA: secretarias, contadoras, investigadores, personal de apoyo y becarios, por su colaboración y compañerismo. En especial quiero mencionar a Lilian Osiglio, a quien le agradezco por su tiempo, sus enseñanzas en la síntesis de los catalizadores, pero sobre todo, por la gran calidez humana y amistad que siempre sentí a su lado.

De igual forma, agradezco a los Drs. José Martínez y Jairo Cubillos del Grupo de Catálisis de la Universidad Pedagógica y Tecnológica de Colombia (UPTC), donde tuve la posibilidad de realizar una estancia, gracias por los conocimientos compartidos y el trato acogedor con el que me recibieron.

También, a la Dra. Miriam Pérez y Mónica García del Laboratorio de Incrustaciones Biológicas del CIDEPINT, por los ensayos de actividad biológica de los furoatos en pinturas antiincrustantes. 
Quiero agradecerle a Leo, mi esposo, por su constante apoyo y animarme en los momentos difíciles. Le agradezco por ser un gran compañero de vida. A nuestro hijo Sebastián, que viene en camino y quien en estos momentos es la motivación más grande para culminar mi doctorado. Así mismo, agradezco a mis padres, Nora y Manuel, y a mis hermanos Juan Manuel y Jorge Luis por apoyarme en todas las decisiones que he tomado y acompañarme aun en la distancia.

Y finalmente pero no menos importante, quiero agradecer a mis compañeros de laboratorio que se volvieron mis grandes amigos, a Romina, Omar y Eliana, con los que compartimos tantos buenos e inolvidables momentos, por su apoyo, su calidez y todas las risas compartidas. Su amistad hizo de mi estadía aquí una experiencia hermosa e inolvidable.

A cada persona que ha colaborado y me ha acompañado, le agradezco. 


\section{ÍNDICE}

LISTA DE ABREVIATURAS Y ACRÓNIMOS. .....................................................................

ÍNDICE DE FIGURAS. ..........................................................................................................ii

ÍNDICE DE TABLAS .....................................................................................................................vi

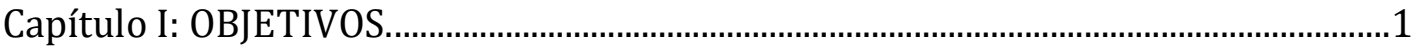

1.1. OBJETIVO GENERAL …………………………………………………….....

1.2. OBJETIVOS ESPECÍFICOS .............................................................................

Capítulo II: INTRODUCCIÓN.....................................................................................................

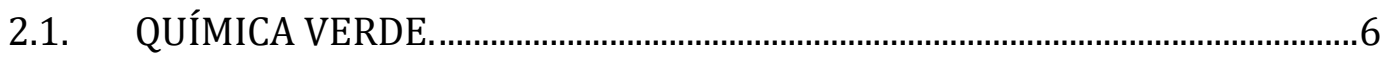

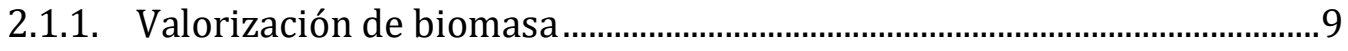

2.1.2. Deshidratación de monosacáridos a furfural. .........................................18

2.1.2.1. Ácido furoico................................................................................................19

2.1.2.2. Furoatos de alquilo como posibles compuestos antifoulling.............22

2.1.3. La deshidratación de pentosas a 5-hidroximetilfurfural. .......................26

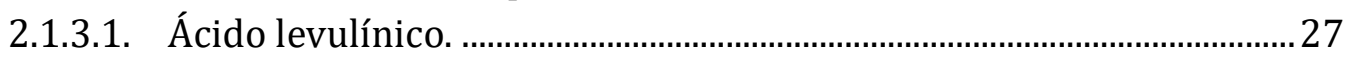

2.1.3.2. Levulinatos de alquilo............................................................................29

2.2. CATÁLISIS HETEROGÉNEA: TECNOLOGÍA VERDE Y SOSTENIBLE. ........35

2.2.1. Catalizadores basados en heteropoliácidos. ....…………………………..36

2.2.1.1. Propiedades generales de los heteropoliácidos tipo Keggin................39

2.2.2. Catálisis heterogénea por heteropoliácidos.............................................. 44

2.2.3. Heteropoliácidos soportados sobre óxido de zirconia.............................52

2.2.4. Heteropoliácidos soportados sobre óxido de titanio................................56

2.2.5. Catalizadores magnéticos.......................................................................59

2.2.5.1. Propiedades magnéticas de las nanopartículas.....................................59

2.2.5.2. Estructura y propiedades de los óxidos de hierro..................................64

2.2.5.3. Síntesis de las nanopartículas magnéticas.............................................66

2.2.5.4. Método de co-precipitación. ……………………………………………....68

2.2.5.5. Encapsulación de NPMs en esferas de óxido de silicio $\left(\mathrm{SiO}_{2}\right)$...........70

Capítulo III: METODOLOGÍA Y DESARROLLO EXPERIMENTAL....................................73

3.1. ASPECTOS GENERALES. ..............................................................................

3.2. REACTIVOS. ............................................................................................

3.2.1. Reactivos utilizados en la preparación de los catalizadores..................75

3.2.2. Reactivos utilizados en las reacciones orgánicas......................................75

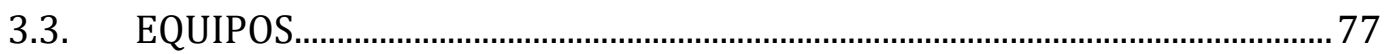

3.3.1. Caracterización de los catalizadores ............................................................77 
3.3.2. Reacciones orgánicas y caracterización de compuestos.

3.4. SÍNTESIS DE CATALIZADORES GRUPO I. ÁCIDO TUNGSTOFOSFÓRICO SOPORTADO SOBRE ZIRCONIA.

3.5. SÍNTESIS DE CATALIZADORES GRUPO II. HETEROPOLIÁCIDOS SOPORTADOS SOBRE TITANIA.

3.6. SÍNTESIS DE CATALIZADORES GRUPO III. ÁCIDO TUNGSTOFOSFÓRICO SOPORTADO SOBRE MAGNETITA ENCAPSULADA EN ÓXIDO DE SILICIO. ...................... 80

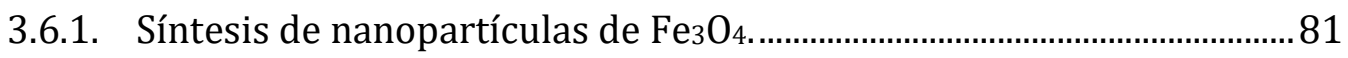

3.6.2. Preparación de revestimientos de sílice sobre $\mathrm{Fe}_{3} \mathrm{O}_{4}\left(\mathrm{Fe}_{3} \mathrm{O}_{4} @ \mathrm{SiO}_{2}\right) . .82$

3.6.3. Inmovilización de TPA sobre $\mathrm{Fe}_{3} \mathrm{O}_{4} @ \mathrm{SiO}_{2}$.

3.7. TÉCNICAS DE CARACTERIZACIÓN FISICOQUÍMICA APLICADAS A LOS CATALIZADORES.

3.8. EVALUACIÓN CATALÍTICA..............................................................................90

3.8.1. Reacciones de esterificación del ácido 2-furoico con n-butanol catalizadas por los materiales del Grupo I. ................................................................ 90

3.8.2. Procedimiento general para la síntesis de 2-furoatos de alquilo. .......91

3.8.3. Ensayos biológicos de los furoatos de alquilo como compuestos

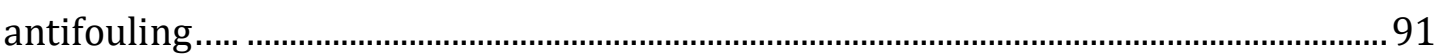

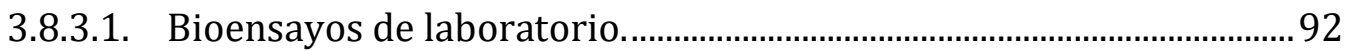

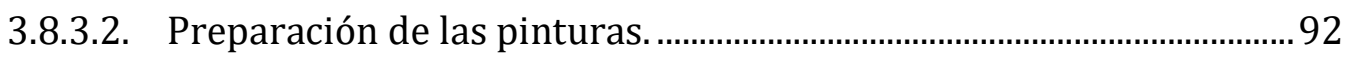

3.8.3.3. Pruebas de campo................................................................................ 93

3.8.4. Reacciones de esterificación del ácido 2-furoico con 2-fenoxietanol catalizadas por los materiales.

3.8.5. Reacciones de esterificación del ácido levulínico con n-butanol catalizadas por los materiales del Grupo III. 96

3.8.6. Reutilización de los catalizadores..........................................................97

Capítulo IV: ANÁLISIS DE RESULTADOS. ..................................................................98

4.1. CARACTERIZACIÓN DE LOS MATERIALES DE LOS GRUPOS I Y II............99

4.1.1. Espectrometría de absorción atómica (EAA)..........................................99

4.1.2. Microscopía de barrido electrónico (SEM)................................................. 99

4.1.3. Isotermas de adsorción- desorción de nitrógeno. ................................... 101

4.1.4. Resonancia magnética nuclear de giro de ángulo mágico

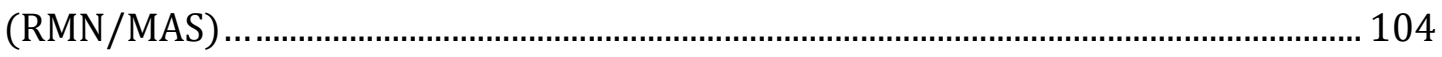

4.1.5. Fuerza ácida por titulación potenciométrica con n-butilamina........ 108

4.1.6. Espectroscopia Infrarrojo por Transformada de Fourier (IR-TF)... 111

4.1.7. Espectroscopía RAMAN....................................................................... 114

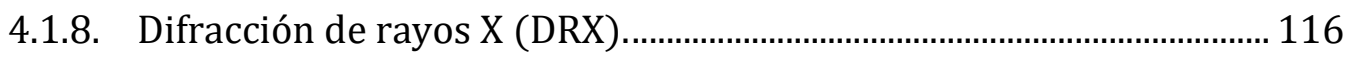

4.2. CARACTERIZACIÓN DE LOS MATERIALES DEL GRUPO III. ..................... 118

4.2.1. Microscopía de barrido electrónico (SEM)............................................. 118

4.2.2. Isotermas de adsorción- desorción de nitrógeno. ................................. 126 
4.2.3. Espectroscopia Infrarroja con Transformada de Fourier acoplada a Reflectancia Total Atenuada (FTIR-ATR) ................................................................... 128

4.2.4. Difracción de Rayos X (DRX) ............................................................ 129

4.2.5. Estudio por magnetometría de vibración. ............................................. 131

4.2.6. Fuerza ácida por titulación potenciométrica con n-butilamina........ 133

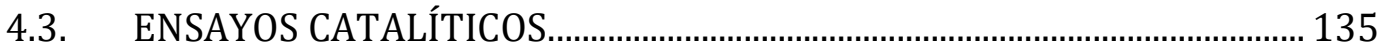

4.3.1. Evaluación catalítica de los catalizadores del Grupo I......................... 135

4.3.1.1. Prueba de reutilización de los catalizadores del Grupo I. ................ 142

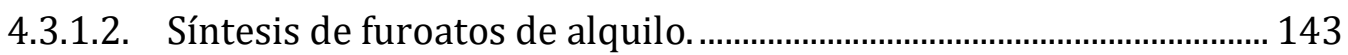

4.3.2. Resultados de las pruebas antifouling................................................. 147

4.3.2.2. Pruebas de campo................................................................................... 148

4.3.3. Evaluación catalítica de los catalizadores del Grupo II........................ 151

4.3.3.1. Prueba de reutilización del catalizador............................................. 156

4.3.4. Evaluación catalítica de los catalizadores del Grupo III....................... 158

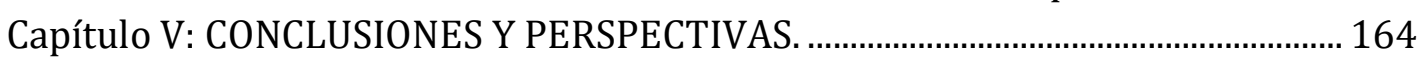

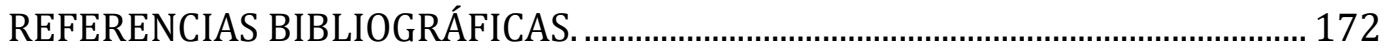




\section{LISTA DE ABREVIATURAS Y ACRÓNIMOS.}

- $\quad$ AAS: Espectrometría de absorción atómica.

- AF: Antifluling.

- $\quad$ CG/EM: Cromatografía de gases acoplado a un espectrómetro de masas.

- CG/FID: Cromatografía de gases acoplado a un detector de ionización de llama.

- DRX: Difracción de rayos X.

- 5-HMF: 5-Hidroximetil furfural.

- HPA: Heteropoliácido, HPAs: Heteropoliácidos.

- IRFT: Espectroscopía infrarroja con transformada de Fourier.

- IUPAC: Unión Internacional de Química Pura y Aplicada.

- $\quad$ kt: Kilotonelada.

- $\quad$ Mt: Megatonelada.

- $\quad$ NPMs: Nanopartículas magnéticas.

- $\quad$ ONU: Organización de las Naciones Unidas.

- PEG: Polietilenglicol.

- POMs: Polioxometalatos.

- RMN: Resonancia magnética nuclear.

- $\quad \mathrm{S}_{\mathrm{BET}}$ : Área superficial BET.

- SEM: Microscopía electrónica de barrido.

- TEOS: Tetraetilortosilicato.

- $\quad$ TPA: Ácido tungstofosfórico.

- TSA: Ácido tungstosilísico.

- VSM: Magnetómetro de muestra vibratoria. 


\section{ÍNDICE DE FIGURAS.}

Figura 1. Esquema que representa cómo está conformada la lignocelulosa dentro de las células vegetales

Figura 2. Esquema de la variedad de productos que se pueden obtener en una biorrefinería..

Figura 3. Esquema general de la síntesis de ácido levulínico y 2-furoico a partir de material lignocelulósico 17

Figura 4. Productos primarios obtenidos por transformación directa de furfural. ..........20 Figura 5. Esquema de la reacción de esterificación de Fischer del ácido 2-furoico y un alcohol y diferentes ejemplos de ésteres que se pueden obtener

Figura 6. Ejemplos de biofouling marino. Áreas susceptibles de biofouling en un barco típico

Figura 7. Estructura química del metabolito ácido (1'E, 5'E)-2-(2', 6'-dimetilocta-1', 5', 7'-trienil)-4-furoico. 26

Figura 8. Productos primarios obtenidos por transformación directa del ácido levulínico 28

Figura 9. Rutas sintéticas del ácido levulínico. 29

Figura 10. Rutas de síntesis para la obtención de levulinatos de alquilo.

Figura 11. Posibles rutas de reacción en la obtención de levulinatos de alquilo a partir de glucosa. 33

Figura 12. Estructura $\alpha$-Keggin en su presentación poliédrica y atómica. 38

Figura 13. Estructuras primaria, secundaria y terciaria del anión Keggin 39

Figura 14. Tres tipos de catálisis para POMs sólidos .44

Figura 15. Esquema del proceso sol-gel 49

Figura 16. Conformaciones estructurales del óxido de zirconia .53

Figura 17. Representación de las estructuras cristalinas del óxido de titania .57

Figura 18. Diferentes tipos de comportamiento magnético 60

Figura 19. Evolución de la estructura multidominio hasta la situación de monodominio de un material magnético según el tamaño de partícula. 
Figura 20. Representación del movimiento de la pared de dominio bajo la aplicación de un campo magnético externo $(\mathrm{H})$.

Figura 21. Curvas de magnetización de un material ferri o ferromagnético 63

Figura 22. Estructura cristalina de los óxidos de hierro. .66

Figura 23. Representación simplificada de la hidrólisis y condensación de TEOS sobre NPMs en el proceso Stöber. 71

Figura 24. Reacciones que rigen la síntesis sol-gel de sílice con TEOS como precursor 72

Figura 25. Esquema de la síntesis de los catalizadores magnéticos 80

Figura 26. Reacción test: esterificación de ácido 2-furoico con n-butanol para sintetizar 2-furoato de n-butilo. 90

Figura 27. Reacción test: esterificación del ácido 2-furoico con 2-fenoxietanol para sintetizar 2-furoato de 2-fenoxietilo.

Figura 28. Reacción test: esterificación del ácido levulínico con n-butanol para

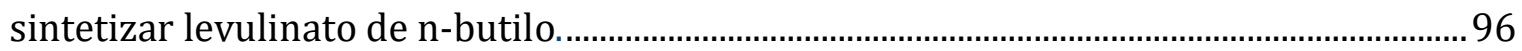

Figura 29. Imágenes SEM de las muestras del Grupo I........................................................ 100

Figura 30. Imágenes SEM de las muestras del Grupo II 101

Figura 31. Isotermas de adsorción-desorción a la temperatura del nitrógeno líquido de los Grupos I y II. 102

Figura 32. Espectros RMN/MAS de ${ }^{31} \mathrm{P}$ de los catalizadores del Grupo I .......................... 106

Figura 33. Espectros RMN/MAS de ${ }^{31} \mathrm{P}$ y ${ }^{29} \mathrm{Si}$ de los catalizadores del Grupo II............. 108

Figura 34. Curvas de titulación potentiométrica del Grupo I............................................... 110

Figura 35. Curvas de titulación potentiométrica del Grupo II............................................... 111

Figura 36. Espectros FT-IR de los catalizadores del Grupo I.................................................. 113

Figura 37. Espectros FT-IR de los materiales del Grupo II ................................................. 114

Figura 38. Espectros Raman de las muestras del Grupo II ................................................. 116

Figura 39. Espectros DRX de las muestras del Grupo I. ........................................................... 117

Figura 40. Espectros DRX de las muestras del grupo II. ….................................................. 117

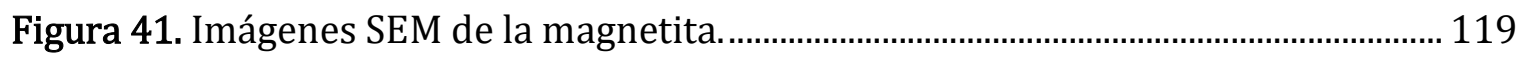

Figura 42. Imágenes SEM de la magnetita ............................................................................. 119

Figura 43. Imágenes SEM a diferentes aumentos de la muestra $\mathrm{Fe}_{3} \mathrm{O}_{4} @ \mathrm{SiO}_{2}$, sintetizada

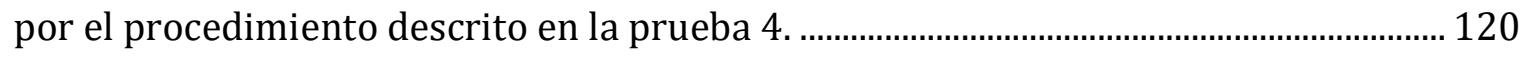


Figura 44. Imágenes SEM de las muestras variando la relación $\mathrm{Fe}_{3} \mathrm{O}_{4} / \mathrm{SiO}_{2}$.

Figura 45. Diagrama de barra de las conversiones alcanzadas durante los diferentes ciclos de reutilización de los materiales del grupo III 123

Figura 46. Imágenes SEM a diferentes aumentos del catalizador $\mathrm{Fe}_{3} \mathrm{O}_{4} @ \mathrm{SiO}_{2} @ \mathrm{SiO}_{2} / \mathrm{TPA}$

Figura 47. Isotermas de adsorción-desorción a la temperatura del nitrógeno líquido de las diferentes fases durante la síntesis de los catalizadores del Grupo III. 128

Figura 48. Espectros IRFT-ART de las muestras del Grupo III.

Figura 49. Espectros DRX de las muestras del Grupo III.

Figura 50. Curvas de magnetización para los materiales magnéticos en las diferentes etapas de síntesis del catalizador.

Figura 51. Curvas de titulación potentiométrica para los materiales del Grupo III...... 134 Figura 52. Conversión del ácido 2-furoico en función del tiempo para los diferentes catalizadores del Grupo I. 136

Figura 53. Porcentaje de conversión (\%) del ácido 2-furoico a 2-furoato de n-butilo en función de la temperatura.

Figura 54. Porcentaje de conversión (\%) de ácido 2-furoico a 2-furoato de n-butilo en función de la cantidad de catalizador 140

Figura 55. Ensayo de toxicidad de los furoatos a diferentes concentraciones contra Artemia sp 147

Figura 56. Cobertura de los paneles pintados luego de 30 días de inmersión en el mar (puerto de Mar del Plata) 149

Figura 57. Conversión del ácido 2-furoico en función del tiempo para los diferentes catalizadores del Grupo II. 151

Figura 58. Porcentaje de conversión (\%) del ácido 2-furoico a 2-furoato de 2fenoxietilo en función del tiempo para a) Relación molar ácido 2-furoico/2fenoxietanol. b) Temperatura. 154

Figura 59. Desaparición del ácido 2-fuórico y formación de 2-furoato de 2-fenixietilo bajo prueba catalítica en las condiciones óptimas. 156 Figura 60. Influencia de la cantidad de catalizador en la conversión del ácido levulínico a levulinato de n-butilo con $\mathrm{Fe}_{3} \mathrm{O}_{4} @ \mathrm{SiO}_{2} @ \mathrm{SiO}_{2} / \mathrm{TPA}_{400 \mathrm{~N}}$ como catalizador. 161 
Figura 61. Influencia de la temperatura en la conversión de AL a levulinato de n-butilo con $\mathrm{Fe}_{3} \mathrm{O}_{4} @ \mathrm{SiO}_{2} @ \mathrm{SiO}_{2} / \mathrm{TPA}_{400 \mathrm{~N}}$ como catalizador 162 Figura 62. Influencia de la relación molar de reactivos en la conversión de levulinato de n-butilo con $\mathrm{Fe}_{3} \mathrm{O}_{4} @ \mathrm{SiO}_{2} @ \mathrm{SiO}_{2} / \mathrm{TPA}_{400 \mathrm{~N}}$ como catalizador. 163 


\section{ÍNDICE DE TABLAS.}

Tabla 1. Constantes de disociación de HPAs y ácidos convencionales en acetona a $25^{\circ} \mathrm{C}$.

Tabla 2. Cantidades utilizadas en la síntesis de $\mathrm{Fe}_{3} \mathrm{O}_{4} / \mathrm{SiO}_{2}$ con diferentes relaciones de reactivos.

Tabla 3. Composición de las pinturas expresadas como \% en peso. 93

Tabla 4. Área superficial específica (SBET), superficie específica de microporos (SMicro) y diámetro promedio de poro $\left(\mathrm{D}_{\mathrm{p}}\right)$ para las familias de catalizadores de zirconia y titania.

Tabla 5. Fuerza de acidez según el potencial medido 109

Tabla 6. Resultados de las pruebas EDX y SвET para las 3 relaciones $\mathrm{Fe}_{3} \mathrm{O}_{4} / \mathrm{SiO}_{2}$ 121

Tabla 7. Conversiones alcanzadas durante los diferentes ciclos de reutilización de los materiales del grupo III. 124

Tabla 8. Área superficial específica $\left(\mathrm{S}_{\mathrm{BET}}\right)$ y diámetro promedio de poro $\left(\mathrm{D}_{\mathrm{p}}\right)$ para los materiales del Grupo III. 127

Tabla 9. Propiedades ácidas $(\mathrm{mV})$ y conversiones de reacción (\%) para el blanco de reacción y los catalizadores del Grupo I.

Tabla 10. Efecto del radio molar ácido 2-furoico/n-butanol.

Tabla 11. Síntesis de 2-furoato de n-butilo utilizando ZrTPA30PEGT100 como catalizador, variando las condiciones de reacción. $24 \mathrm{~h}$. 142

Tabla 12. Efecto de la naturaleza del alcohol sobre la conversión alcanzada en la esterificación del ácido 2-furoico. 145

Tabla 13. Concentración letal cincuenta para cada compuesto. 148

Tabla 14. Actividad catalítica en la conversión (\%) de ácido 2-furoico en 2-furoato de 2fenoxietilo bajo diferentes condiciones experimentales para los catalizadores del Grupo II. 155

Tabla 15. Prueba de reutilización del catalizador. Conversiones obtenidas para cada ciclo de reacción. 157 
Tabla 16. Resultados catalíticos durante la esterificación del ácido levulínico con nbutanol sobre el catalizador $\mathrm{Fe}_{3} \mathrm{O}_{4} @ \mathrm{SiO}_{2} @ \mathrm{SiO}_{2} / \mathrm{TPA}_{400 \mathrm{~N} 2}$ en diferentes condiciones de reacción durante $7 \mathrm{~h}$ 160 
Capítulo I: OBJETIVOS. 
Capítulo I. Objetivos.

\subsection{OBJETIVO GENERAL}

Sintetizar y caracterizar catalizadores basados en heteropoliácidos con estructura tipo Keggin inmovilizados sobre óxido de zirconio $\left(\mathrm{ZrO}_{2}\right)$, óxido de titanio $\left(\mathrm{TiO}_{2}\right)$ y materiales magnéticos $\left(\mathrm{Fe}_{3} \mathrm{O}_{4}\right)$ encapsulados en óxido de silicio $\left(\mathrm{SiO}_{2}\right)$, y evaluarlos en reacciones de esterificación de los ácidos 2-furoico y levulínico (los cuales pueden obtenerse a partir de biomasa vegetal) con diferentes alcoholes, para la obtención de compuestos de alto valor agregado.

Desarrollo de una metodología sintética que involucre el menor impacto ambiental posible, de modo de cumplir con la mayor cantidad de postulados de la Química Verde. Para ello se propone el reemplazo de los catalizadores convencionales como ácidos sulfúrico y clorhídrico por heteropoliácidos, la utilización de catalizadores soportados para una fácil recuperación y reutilización, y llevar a cabo las reacciones preferentemente en ausencia de solvente para aumentar la eficiencia atómica del proceso.

Desarrollar una metodología que conduzca a la obtención de una variedad de ésteres de los ácidos 2-furoico y levulínico, los cuales son reactivos que se pueden obtener de biomasa y de este modo dar un valor agregado a los desechos de la misma. De modo que la investigación propuesta permitirá realizar aportes en las áreas de materiales, catálisis, reacciones eco-eficientes y valorización de biomasa. 
Capítulo I. Objetivos.

\subsection{OBJETIVOS ESPECÍFICOS}

- Sintetizar materiales basados en ácido tungstofosfórico (TPA) inmovilizado sobre zirconia $\left(\mathrm{ZrO}_{2}\right)$ mesoporosa, obtenida mediante el método sol-gel partiendo de propóxido de circonio como precursor y polietilenglicol (PEG) como agente formador de poros. Se estudiará como la cantidad de TPA soportada sobre la zirconia y el orden en que se agrega tanto el TPA como el PEG afectan las propiedades fisicoquímicas y catalíticas de los materiales. Se evaluará su actividad catalítica en la reacción de esterificación del ácido 2-furoico con nbutanol. Una vez optimizadas las condiciones de reacción, se procederá a variar la estructura del alcohol para sintetizar diferentes ésteres de interés farmacológico e industrial. El seguimiento de las reacciones se llevará a cabo por cromatografía de gases (CG/FID) y los productos serán caracterizados mediante cromatografía de gases acoplada a espectrometría de masas (CG/EM) y resonancia magnética nuclear (RMN de $\left.{ }^{1} \mathrm{H} \mathrm{y}^{13} \mathrm{C}\right)$.

- Sintetizar materiales basados en heteropoliácidos (HPA) soportados sobre óxido de titanio $\left(\mathrm{TiO}_{2}\right)$ mediante el método sol-gel. Los HPA utilizados serán el ácido tungstofosfórico (TPA) y el tungstosilísico (TSA); como precursor se usará isopropóxido de titanio y urea como agente formador de poros. Se estudiará cual HPA presenta mejor actividad en la reacción de esterificación del ácido 2-furoico con 2-fenoxietanol. El seguimiento de las reacciones se llevará a cabo por cromatografía de gases (CG/FID) y el producto será caracterizado mediante cromatografía de gases acoplada a espectrometría de masas (CG/EM), RMN de ${ }^{1} \mathrm{H}$ $\mathrm{y}^{13} \mathrm{C}$ y determinación del punto de fusión.

- Sintetizar materiales basados en ácido tungstofosfórico (TPA) soportados sobre magnetita obtenida por el método de coprecipitación de sales de hierro y recubiertas con sílice mediante el método Stöber a partir de tetraetilortosilicato (TEOS) como precursor. Se estudiarán dos formas de soportar el TPA, incluyéndolo durante la síntesis de la sílice o por impregnación. Los materiales 
Capítulo I. Objetivos.

serán evaluados en la reacción de esterificación del ácido levulínico con n-butanol y se determinarán las condiciones óptimas de reacción.

- Caracterizar textural y fisicoquímicamente los catalizadores, mediante difracción de rayos $\mathrm{X}$ para determinar la presencia de fases cristalinas y sus cambios durante el proceso, microscopia electrónica de barrido para estudiar su morfología, espectroscopia infrarroja y resonancia magnética nuclear para conocer las especies presentes, adsorción de nitrógeno a baja temperatura para determinar las características texturales y titulación potenciométrica con nbutilamina para el análisis de la acidez de los sólidos. En el caso de los materiales magnéticos también se analizarán sus propiedades magnéticas mediante estudio por magnetometría de vibración. 


\section{Capítulo II:}

\section{INTRODUCCIÓN.}




\section{Capítulo II. Introducción.}

\subsection{QUÍMICA VERDE.}

En las últimas cinco décadas se ha generado una serie de cambios y avances científicos y tecnológicos sin precedentes en la historia de la humanidad que han mejorado en muchos aspectos la forma de vida, pero a la vez, ha tenido un impacto negativo para el medio ambiente.

En estas décadas la Química ha jugado un papel importante, donde sus logros han mejorado las condiciones de vida mediante el desarrollo de muchos de sus campos de acción, como la síntesis de nuevos fármacos, la producción de alimentos, la agricultura, el desarrollo de energías alternativas, entre muchos otros, pero a su vez, estos cambios han traído consigo consecuencias indeseables desde el punto de vista del consumo de energía y la degradación ambiental, que se expresan en la contaminación del aire, el calentamiento global, la contaminación de ríos, aguas subterráneas y suelos, y la alteración de diferentes ecosistemas, y lo más preocupante es que en muchos casos estos daños son irreversibles.

Esto hizo que la imagen de la industria química ante la sociedad sea desfavorable, tanto así que a menudo la clasifican junto a industrias tan impopulares como la industria nuclear y las tabacaleras. Esta mala imagen se inició en los años 60 con la publicación del libro "Primavera silenciosa" escrito por Rachel Carson ${ }^{1}$, el cual fue uno de los primeros libros de divulgación científica que advertía sobre los efectos negativos de los pesticidas para el medio ambiente, centrando su denuncia en el pesticida Dicloro-difenil-tricloroetano (DDT) y sus efectos perjudiciales, especialmente en las poblaciones de aves y culpando directamente a la industria química de la creciente contaminación.

Tiempo después este polémico debate llegó a como los pesticidas organoclorados podían afectar la salud humana generando cáncer y malformaciones congénitas a futuras generaciones. Estas denuncias y muchos otros eventos desafortunados, bastante documentados especialmente por la prensa, hicieron que las personas sean más conscientes de los errores de la industria química que de los muchos beneficios 
Capítulo II. Introducción.

que reciben. En la actualidad se tiene una gran calidad de vida gracias a las mejoras y desarrollo de nuevos medicamentos, alimentos, prendas de vestir y demás bienes de consumo y nadie está dispuesto a ceder dicha calidad, al contrario, la demanda de producción industrial sigue en crecimiento de forma proporcional al aumento de la población, pero al tiempo, hay una presión económica, social y ambiental sin precedentes que exige que la industria química sea más limpia, o en otras palabras, compatible con el medio ambiente ${ }^{2}$.

En respuesta a esta preocupación y presión pública, nace un gran desafío para la industria química: replantear todos sus procesos de producción, y generar nuevos diseños que sean ecológicos sin que esto comprometa las necesidades de las generaciones futuras, a esto se le denominó sustentabilidad. Así, en la década de 1990, la iniciativa "Química Verde" cobra fuerza gracias al libro "Química Verde: Teoría y Práctica" donde sus autores, Paul Anastas (Oficina de Prevención de la Contaminación y Tóxicos, EE.UU. EPA) y John Warner (Docente de la Universidad de Massachusetts, Boston) la definen de la siguiente forma: "La Química Verde es el diseño, desarrollo y aplicación de productos químicos y procesos para reducir o eliminar el uso y producción de sustancias peligrosas para la salud humana y el medio ambiente"3.

En dicho libro, los objetivos de la Química Verde se dividen en doce principios, encaminados todos a contribuir al concepto fundamental de que es más fácil prevenir la creación de material peligroso y contaminante que tratar de limpiar los desechos. De esta forma, se cubren dos aspectos importantes: prevenir la contaminación y reducir los costos de producción al eliminar pasos como separación, purificación y manejo de residuos, favoreciendo tanto al medio ambiente, como a la economía de las industrias.

Aunque el principal objetivo de la Química Verde es desafiar a los innovadores a que diseñen y utilicen la materia y la energía de una manera tal que aumente el rendimiento y el valor mientras que protege la salud humana y el medio ambiente, su alcance va mucho más allá de solo reducir los residuos y prevenir la contaminación, ya que sus doce principios son un enfoque novedoso, que considera la totalidad del ciclo de vida del proceso en sus tres etapas principales: materia prima, fabricación y uso, y 
Capítulo II. Introducción.

destino final del producto, y guía las pautas necesarias para diseñar nuevos procesos de producción o rediseñar los ya existentes, evaluando cada una de estas etapas teniendo en cuenta aspectos como la procedencia de las materias primas, la eficiencia energética, la toxicidad de los solventes, reactivos, productos y subproductos, el almacenamiento, empaque y transporte, hasta el final de la vida útil del producto, de tal forma que todo el proceso sea sustentable.

Es tal la importancia y el alcance de la Química Verde, que otras áreas han adoptado sus principios, como es el caso de la medicina, la industria alimentaria, empresas energéticas, productos de hogar y limpieza, la industria automotor y electrónica y una amplia gama de bienes de consumo que demuestran la universalidad de sus principios y la eficacia de la Química Verde como una herramienta para la sustentabilidad 4 .

Los 12 principios son:

1- Prevención. Es preferible evitar la producción de un residuo que tratar de eliminarlo una vez que se ha formado.

2- Economía de átomos. Se deben diseñar métodos de síntesis de manera que incorporen al máximo, en el producto final, los materiales empleados durante el proceso.

3- Reacciones con compuestos de baja toxicidad. Siempre que sea posible, los métodos de síntesis deben diseñarse para utilizar y generar sustancias que tengan poca o nula toxicidad, tanto para el hombre como para el medio ambiente.

4- Desarrollo de compuestos seguros. Los productos químicos deben ser diseñados de manera que mantengan, en simultáneo, la eficacia y una baja o nula toxicidad.

5- Disminución del uso de solventes y auxiliares. Debe evitarse el uso de sustancias que no sean imprescindibles y, en caso de ser necesarias, deberán ser tan inocuas como sea posible. 


\section{Capítulo II. Introducción.}

6- Eficiencia energética. Debe reducirse el uso de energía en los procesos de síntesis, minimizando así el impacto ambiental y económico. Se prefieren los procesos a presión y temperatura ambiente.

7- Uso de sustancias renovables. Siempre que sea técnica y económicamente viable, debe emplearse sustancias y fuentes de energía renovables.

8- Evitar la derivatización. Se debe evitar la formación de derivados por medio de protección/desprotección de grupos funcionales, por bloqueo de los mismos y por modificación temporaria mediante procesos físico-químicos.

9- Catálisis. Se debe emplear catalizadores selectivos en lugar de reactivos estequiométricos, siendo de especial interés los materiales reutilizables.

10-Desarrollo de compuestos degradables. Los productos químicos deben diseñarse de manera tal que al finalizar su función no persistan en el medio ambiente, sino que se transformen en productos inocuos mediante su degradación.

11-Análisis en tiempo real para la prevención de la contaminación. Los procesos deben desarrollarse de manera tal que permitan un monitoreo y control en tiempo real de la posible formación de sustancias peligrosas.

12-Química segura para la prevención de accidentes. Los materiales empleados en un proceso químico deben ser escogidos de manera tal que minimicen riesgos de siniestros, incluyendo emanaciones, explosiones e incendios.

\subsubsection{Valorización de biomasa}

El principio 7 de la Química Verde dice que es preferible usar materias primas renovables siempre que sea técnica y económicamente rentable, sin embargo, en la actualidad, el 90\% de los productos orgánicos generados por la industria química son derivados de compuestos fósiles, que, primero, no son renovables y segundo, generan grandes cantidades de desechos contaminantes. Por esta razón, la Química Verde desvió su mirada hacia la biomasa, pues así como a principios de 1990, la atención se centró en prevenir la producción de residuos, ahora el foco se centra en la explotación de los residuos que no se pueden evitar generar, como por ejemplo los desechos de biomasa ${ }^{5}$. 


\section{Capítulo II. Introducción.}

Los desechos de biomasa abarcan cualquier material orgánico aparte de la materia prima para lo cual fueron sembrados, por ejemplo, los desechos de hojas y bagazo de la caña durante la producción de azúcar o papel o las cascaras y semillas de frutas en la industria alimentaria. Así, nacen las biorrefinerías, las cuales van adquiriendo cada vez un mayor protagonismo en el área de las nuevas tecnologías sostenibles y se definen como una instalación industrial que emplea un amplio rango de procesos tecnológicos (mecánicos, físicos y bio o termoquímicos) capaces de separar las materias primas renovables en sus constituyentes principales (carbohidratos, proteínas, triglicéridos, etc.), para producir combustibles, energía, calor y productos químicos de valor agregado de forma análoga a como las refinerías de petróleo procesan el crudo para producir productos químicos especializados, pero procurando que la cantidad de residuos sea mínima, mejorando así la sostenibilidad de la planta.

Por lo tanto, la definición de biorrefinería es análoga a la de una refinería de petróleo convencional, con la diferencia de que se utiliza biomasa como materia prima en lugar de petróleo. A nivel nacional, regional y mundial, hay tres factores principales para el uso de la biomasa (la cual es abundante, de bajo costo y hasta el momento, la única fuente de carbono renovable en la tierra) en biorrefinerías para la producción de bioenergía, biocombustibles y productos bioquímicos, éstos son el cambio climático, la seguridad energética y el desarrollo rural, esperando que se alivie gradualmente la actual dependencia de los recursos fósiles ${ }^{6,7}$.

Hace unos años nadie hubiese imaginado que los desechos orgánicos pudieran ser una fuente de energía y generar grandes dividendos, un ejemplo de ello es como en 2012 se autorizó el transporte de aproximadamente 200.000 toneladas/año de residuos domésticos desde Nápoles Italia a Rotterdam para su uso como materia prima en centrales eléctricas holandesas, donde son quemados en dos incineradoras cuyo calor generado se utiliza para calentar los hogares y generar energía. Estos desechos enviados desde Italia representan solo el 3\% de los residuos incinerados en Holanda y es una muestra de cómo se pueden aprovechar los desechos orgánicos ${ }^{8}$. 


\section{Capítulo II. Introducción.}

Pero el principal reto del uso de la biomasa, no es usarla para generar energía y calor a través de ser incinerada, sino pasar de la petroquímica, la cual en la actualidad es el sector industrial más estable, hacia una industria química basada en recursos renovables, donde se abra la puerta a numerosas oportunidades de investigación de una nueva química que incluye la extracción benigna de productos químicos valiosos de la biomasa (por ejemplo, usando fluidos supercriticos ${ }^{9}$ ), valorizar los polímeros más abundantes de la naturaleza como almidón, celulosa, quitina, etc., y convertir los desechos de biomasa en moléculas plataforma para la síntesis de nuevos compuestos químicos de interés industrial, farmacéutico y comercial, en las cuales conseguir un valor agregado y utilidad de los residuos ${ }^{10}$.

Debido a que las fuentes de residuos son tan diversas, se hace necesario clasificarla en cuatro fuentes independientes, según su constitución: polisacáridos, lignina, triglicéridos (a partir de grasas y aceites) y proteínas. El pretratamiento de los polisacáridos, proteínas y triglicéridos conduce a sus constituyentes básicos, monosacáridos, aminoácidos y ácidos grasos más glicerol, respectivamente, y aunque las perspectivas de usar biomasa en sustitución del petróleo son buenas, se ha generado un importante debate internacional debido a los costes de producción, viabilidad del proceso y la competencia con los alimentos.

Es por esto que de todas las biorrefinerías industriales, la que tiene mayores perspectivas de éxito es la basada en lignocelulosa. Algunas de las principales fuentes de biomasa lignocelulósica son la madera, maderas de crecimiento rápido, residuos forestales y residuos de la industria del papel, la paja y alimentos, los cuales están compuestos principalmente por hidratos de carbono, que representan aproximadamente el $75 \%$ de la biomasa renovable, que equivale a unos 200 millones de toneladas anualmente. De este valor, sólo un 4\% aproximadamente es utilizado por el hombre, y el resto se degrada siguiendo las vías naturales. Además, desarrollar tecnologías de aprovechamiento de la lignocelulosa permitiría también integrar la biorrefinería con la producción de alimentos mediante el aprovechamiento de los residuos generados por la industria alimentaria ${ }^{11}$. 
Capítulo II. Introducción.

La mayor parte de los hidratos de carbono corresponden a polisacáridos, su utilización no alimentaria se limita a las industrias textil, papel, y de revestimiento, ya sea como tal o en forma de ésteres simples y éteres. Sin embargo, por lo general, los productos químicos orgánicos son moléculas simples de bajo peso molecular, por lo que es más convenientemente obtenerlos a partir de hidratos de carbono que a partir de macromoléculas como los polisacáridos. En consecuencia, las materias primas de carbohidratos reales para ser usadas como bloques de construcción en Química Fina terminan siendo la mínima fracción que se repite de estos polisacáridos, como por ejemplo la Glucosa, mínima fracción de la celulosa y el almidón, la cual es de bajo costo y disponibles en escala de varias toneladas ${ }^{12}$.

Una ventaja adicional de usar como materia prima la biomasa, es que algunas de las transformaciones en el material de partida de la industria petroquímica, implica la introducción de grupos funcionales que contengan oxígeno y nitrógeno, hecho que genera una demanda de reactivos y energía. La biomasa en cambio, ya contiene diferentes grupos funcionales, evitando estos pasos adicionales y permitiendo su utilización directa como plataforma de reacción.

Así mismo, la enorme cantidad de residuos convierten a la biomasa en un recurso potencial, ya que se calcula un valor aproximado de cientos de megatoneladas al año [> $10^{8} \mathrm{t}$ ] alrededor del mundo. Se estima que los desechos de biomasa lignocelulósica supera $\operatorname{los} 2 \times 10^{11} \mathrm{t} / \mathrm{año}$ en todo el mundo ${ }^{13}$. Para hacer una estimación de lo que esto significa, un ejemplo son los cultivos de arroz, donde el $20 \%$ de su producción corresponde a cascaras, y de los 120 Mt de cascaras de arroz que se producen por año, solo 20 Mt tienen una utilidad, dejando 100 Mt que podrían ser convertidos en combustible o en productos químicos de utilidad ${ }^{14}$.

Otro ejemplo más común en nuestra región es el cultivo de caña, sus desechos mejor conocidos como bagazo, son los derivados de la caña luego de ser exprimida y que tiene un valor aproximado al $26 \%$ de cada tonelada cultivada. La caña de azúcar es uno de los principales cultivos en Sudamérica, con un área plantada que supera los 8 millones de hectáreas y una producción del orden de 635 millones de toneladas que 


\section{Capítulo II. Introducción.}

corresponden al 41\% de la producción mundial y que generan cerca de 165 millones de toneladas de bagazo. En la actualidad, el principal uso que se le da a estos desechos es el de generar energía quemándolos en grandes calderas, el vapor producido por la combustión se destina hacia la producción de energía mecánica o eléctrica y energía térmica para los requerimientos del proceso tecnológico de la producción del azúcar, alcohol u otros derivados ${ }^{15}$, sin embargo, el bagazo, por su composición lignocelulósica, puede ser aprovechado para la obtención de productos de alto valor agregado aumentando la sostenibilidad de la industria.

En la Figura 1 se representa un esquema de cómo está conformada la lignocelulosa, la cual está compuesta principalmente de dos polisacáridos, celulosa y hemicelulosa, y de lignina que conforman un material estructurado jerárquicamente.

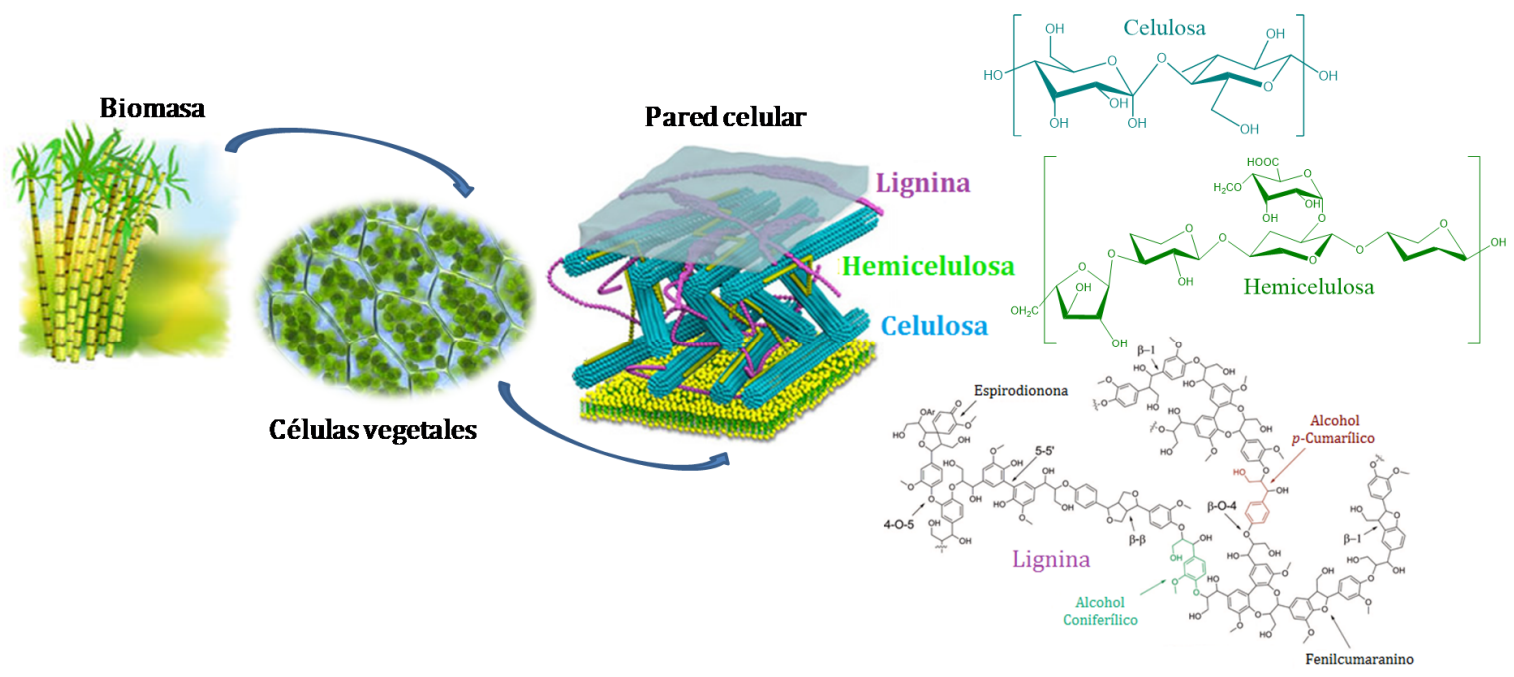

Figura 1. Esquema que representa cómo está conformada la lignocelulosa dentro de las células vegetales. (Imagen adaptada de Stephen K. Ritter ${ }^{16}$ ).

La celulosa es un polisacárido insoluble en agua relativamente homogéneo, constituido por varios miles de moléculas de D-glucosa $\left(\mathrm{C}_{6} \mathrm{H}_{10} \mathrm{O}_{5}\right)$ n unidas por enlaces $\beta$-1,4-glucosídicos no ramificados con un grado de polimerización alrededor de 9000 y 15000 en madera nativa y plantas; que junto con la hemicelulosa, cumplen la función de dar dureza y soporte a las plantas, siendo el componente principal de la pared 
Capítulo II. Introducción.

celular de las plantas correspondiente a una fracción cercana al 50\%, además de ser el biopolímero más abundante sintetizado por la naturaleza ${ }^{17}$.

Por su parte, la hemicelulosa (también llamada poliosa) no es tan uniforme, representa aproximadamente el $25-30 \%$ en peso de la biomasa, abarca todos los polisacáridos basados en hexosanos (polímeros formados por hexosas, fundamentalmente glucosa, manosa y galactosa) y petonsanos (polímeros basados en pentosas, fundamentalmente la xilosa o arabinosa, siendo la D-xilosa la más abundante de todos ellos), su grado de polimerización es de aproximadamente 100 a 200 y es por lo tanto de tamaño significativamente menor que la celulosa ${ }^{18}$.

La lignocelulosa contiene además entre un 15-20\% de lignina y otros compuestos extractables. La lignina tiene una estructura muy diferente a la celulosa y hemicelulosa, ya que es una red polimérica amorfa, tridimensional y termoplástica que actúa como pegamento esencial en las plantas, dando lugar a su estructura integral y rígida. Está conformada por subunidades de fenilpropileno (monómeros aromáticos), concretamente los alcoholes cumarílico, coniferílico y sinapílico, conectados mediante diferentes tipos de enlaces para formar una red final tridimensional que constituye las paredes de las células vegetales.

La lignina se asocia normalmente con la celulosa y hemicelulosa para formar la lignocelulosa, y se encuentra recubriendo todo el conjunto, siendo muy inerte químicamente, por lo que otorga al material una alta resistencia a los ataques químicos y/o biológicos ${ }^{19}$. Esto explica porqué para el aprovechamiento de los azúcares contenidos en la lignocelulosa es necesario pretratamientos físico-químicos que permitan romper la barrera que supone el recubrimiento de lignina alrededor de la celulosa y hemicelulosa para facilitar así el acceso a estos compuestos, ya que a diferencia del almidón en los granos de cereales y los aceites en las semillas oleaginosas, estos biopolímeros son difíciles de extraer. Éstos métodos incluyen procesos biológicos, mecánicos o físicos y químicos, o una combinación de ellos que se describen a continuación ${ }^{20,21}$. 
Capítulo II. Introducción.

Pre-tratamientos físicos: Consiste en el procesamiento mecánico de la biomasa para reducir su tamaño y facilitar la extracción de las moléculas de interés en los pasos posteriores. Incluye métodos como la molienda, radiaciones con microondas, extrusión, entre otros. Este paso mejora los resultados de la hidrólisis, debido a la reducción de la cristalinidad y se mejoran las características de transferencia de masa por la reducción del tamaño de las partículas.

Pre-tratamientos físico-químicos: Combinan tanto los procesos físicos como químicos, los más importantes son: explosión con vapor que puede ser catalizada por $\mathrm{H}_{2} \mathrm{SO}_{4}$ y $\mathrm{CO}_{2}$ donde se forma ácido carbónico, o con amoniaco (explosión de fibra de amoniaco, AFEX por sus siglas en inglés). También se puede hacer una auto-hidrólisis, donde los ácidos presentes en la lignocelulosa como el ácido acético y el ácido fórmico se liberan catalizando el proceso. Cada uno de estos tratamientos puede dar lugar a diferentes propiedades físicas y químicas en los sólidos obtenidos, pero en general permiten un acceso más fácil a la hemicelulosa que se encuentra parcialmente hidrolizada. En todos los casos, tanto los ácidos como el amoniaco deben ser recuperados y tratados para su desecho o reutilización según sea el caso ${ }^{22}$

Uno de los métodos más limpios y amigables con el medio ambiente es el empleo de agua líquida caliente (Liquid hot water LHW) y altas presiones. Se ha demostrado que este pretratamiento es muy adecuado para aumentar la digestibilidad de la celulosa, la extracción de azúcares y la recuperación de las pentosas. Se puede hacer una adaptación con microondas siendo más efectivo que el método convencional ya que acelera las reacciones durante el proceso.

Pre-tratamientos químicos: Se han usado extensamente para romper la cubierta protectora alrededor de la celulosa y hacer las hemicelulosas más accesibles a la hidrólisis, ya que éstas tienen una estructura amorfa fácilmente hidrolizable por ácidos o bases, comparada con la estructura cristalina fuerte y rígida resistente a la hidrólisis que presenta la celulosa. Estos pre-tratamientos pueden ser ácidos (siendo el $\mathrm{H}_{2} \mathrm{SO}_{4}$ el más usado), básicos (hidróxido de sodio, potasio, calcio y amonio) o tratamientos con disolventes (líquidos iónicos) ${ }^{23}$. 


\section{Capítulo II. Introducción.}

Pre-tratamientos biológicos: Emplean microorganismos degradantes de la madera tales como hongos y bacterias, que modifican la composición química y/o estructura de la biomasa lignocelulósica permitiendo tratamientos enzimáticos posteriores más fáciles y eficientes ${ }^{19}$.

Una vez que la lignocelulosa ha sido tratada mediante algunos de estos procedimientos y sus azúcares están más disponibles, es el momento de procesarlos selectivamente mediante métodos químicos o biológicos para despolimerizar los polisacáridos en los azúcares que los componen y transformarlos en productos químicos de interés como por ejemplo: derivados de furano, ácidos, principalmente ácido acético, ácido fórmico y levulínico; compuestos fenólicos que incluyen alcoholes, aldehídos, cetonas y ácidos entre otros ${ }^{24}$, estos derivados y otros se presentan resumidos en la Figura 2, la cual es una de las múltiples propuestas que ejemplifica la importancia del aprovechamiento integral de la lignocelulosa en una biorrefinería.

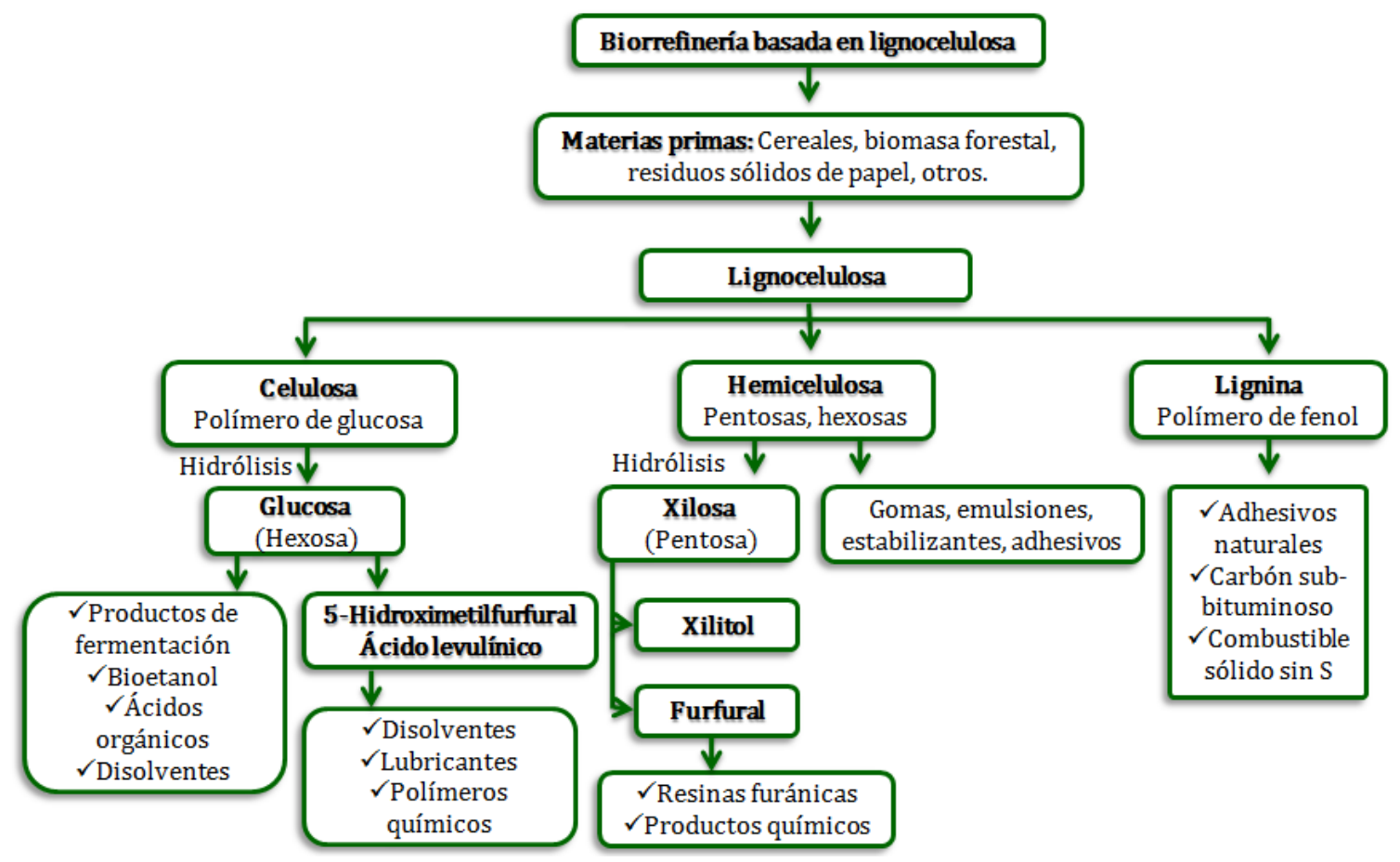

Figura 2. Esquema de la variedad de productos que se pueden obtener en una biorrefinería. 


\section{Capítulo II. Introducción.}

Uno de los componentes más importantes de la lignocelulosa como bloque de construcción es la xilosa, la cual es la pentosa más representativa de la hemicelulosa debido a que es la más barata, fácilmente accesible y de la cual se obtiene el furfural mediante catálisis ácida acuosa, donde el pentosano se hidroliza a pentosa, que a su vez se deshidrata a furfural en un proceso unificado, del cual luego se puede obtener alcohol furfurílico, ácido furoico, furano, tetrahidrofurano, 2-metiltetrahidrofurano, y resinas relacionadas.

Otro componente importante que se puede obtener por transformaciones químicas de las hexosas es el 5-hidroximetilfurfural (HMF) llamado comúnmente "el gigante del sueño" debido a su rica química y potenciales transformaciones, donde, tanto su oxidación como su reducción, ofrecen acceso a numerosos bloques de construcción, como el ácido levulínico ${ }^{25}$. Estos dos procesos se muestran en la Figura 3.

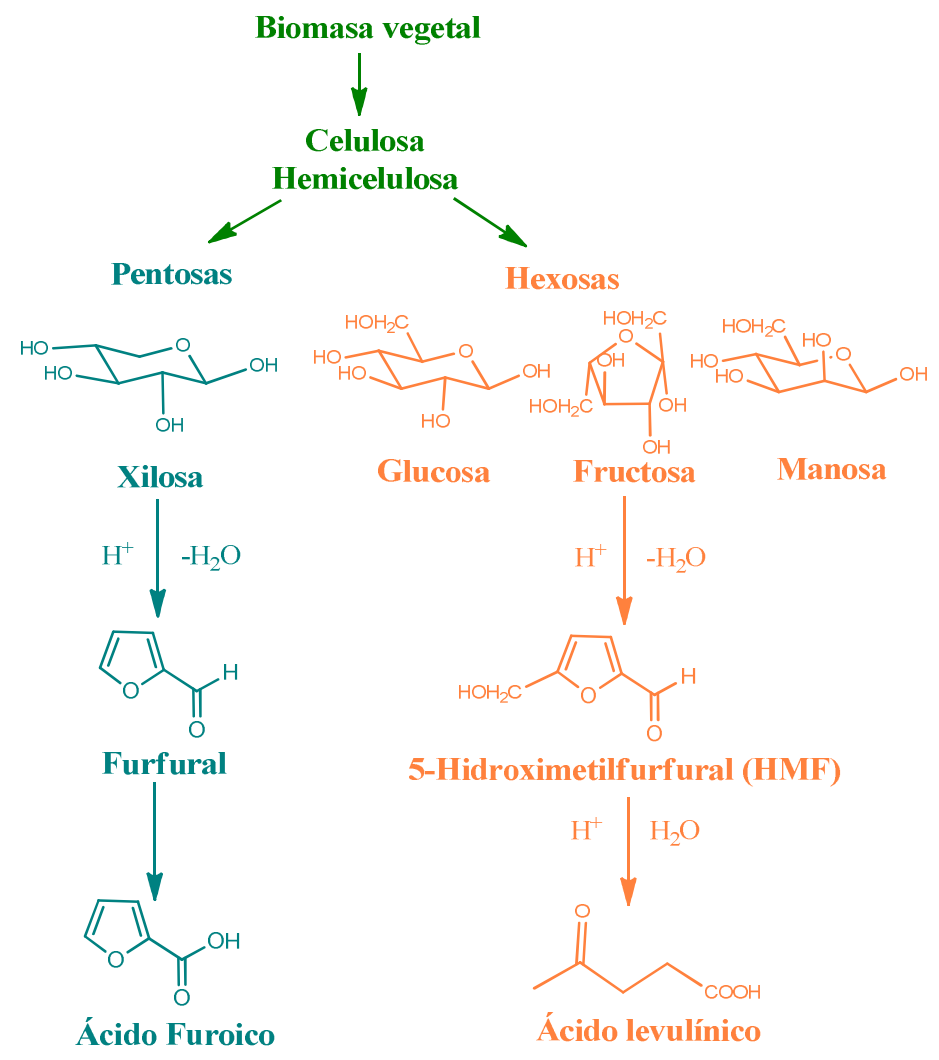

Figura 3. Esquema general de la síntesis de ácido levulínico y 2-furoico a partir de material lignocelulósico. 
Capítulo II. Introducción.

Estas moléculas plataforma cumplen con varios requisitos para ser considerados como bloques de construcción: conservan una razonable porción de su estructura original, son estables para ser almacenadas y transportadas y tienen la reactividad esencial para transformarse en otros productos químicos, por esto, son los compuestos más interesantes que pueden obtenerse en una biorrefinería ${ }^{26,27}$.

\subsubsection{Deshidratación de monosacáridos a furfural.}

La demanda mundial de furfural en el año 2013 fue de $300 \mathrm{kt}$ y se espera que llegue a 652,5 kt en el 2020, creciendo a una tasa anual de 11,9\% desde 2014 hasta 2020 correspondiendo a USD 1'200.900 millones, según un estudio realizado por Grand View Research, Inc ${ }^{28}$, lo que demuestra el creciente interés en este compuesto y sus múltiples aplicaciones.

El primer proceso comercial para la producción de furfural, que, de hecho, aún en la actualidad es el más usado, fue desarrollado por la compañía Quaker Oats Co. en 1922. Esta compañía tenía unas ollas a presión de un antiguo proceso en desuso y querían darle una utilidad y aprovechar las cantidades masivas de cáscaras de avena que sobraban de sus procesos. Por lo tanto, el diseño del reactor y el procedimiento para la producción de furfural fue el resultado de un intento de aprovechar aparatos y materias primas disponibles y no de un estudio de optimización, ya que la cinética de formación del furfural no se estableció sino hasta muchos años más tarde. Por eso es más notable que este proceso aún se use en estos tiempos, aunque ha sido sometido a algunos cambios y ha alcanzado un alto grado de sofisticación ${ }^{29}$.

En la actualidad hay dos tipos de tecnologías para producir furfural. La primera es una técnica en una sola etapa, donde la despolimerización de pentosanos en xilosa y su deshidratación en furfural ocurren simultáneamente. La segunda es una tecnología de dos etapas, una disolución y despolimerización de pentosanos se producen en condiciones suaves, seguido por la deshidratación de pentosa en furfural. 
Capítulo II. Introducción.

La ventaja de la tecnología de dos etapas se basa en el hecho de que la lignocelulosa residual es casi inalterada y se puede utilizar para la conversión a otros productos químicos (glucosa, etanol, fenol, etc.) en una etapa posterior; además, el rendimiento de furfural aumenta notablemente ${ }^{30}$.

Cualquiera de los dos procesos utiliza ácidos minerales convencionales tales como ácido sulfúrico y ácido fosfórico como catalizador, lo que significa grandes inconvenientes relacionados con el uso de sustancias altamente corrosivas y tóxicas, la dificultad en la separación y el reciclaje y que debido a que es una reacción que conlleva varios pasos y reacciones secundarias, resulta en bajos rendimientos, razones por las cuales, muchos estudios se centran en mejorar la tecnología y el rendimiento de este procedimiento, como por ejemplo, usar como catalizador los mismos ácidos generados durante la hidrólisis de la lignocelulosa (ácido fórmico, ácido acético, ácido levulínico, entre otros) ${ }^{30}$, el uso de catalizadores heterogéneos como las zeolitas ${ }^{31}$, MCM-41 sulfonada ${ }^{32}$ y sílice sulfonada soportados sobre materiales magnéticos ${ }^{33}$, o una combinación de técnicas como catalizadores de $\mathrm{CrCl}_{3}$, extracción con líquidos iónicos y calentamiento asistido con microondas ${ }^{34}$.

\subsubsection{1. Ácido furoico.}

La química del furfural está bien desarrollada y documentada 35,36 , son diversos los derivados que se pueden obtener a partir de éste bloque de construcción. En la Figura 4 se muestran algunas de las familias más importantes, donde uno de ellos es el ácido furoico, el cual es un producto importante utilizado como materia prima en síntesis orgánica y como un intermediario en la síntesis de medicamentos, perfumes y agroquímicos. 
Capítulo II. Introducción.

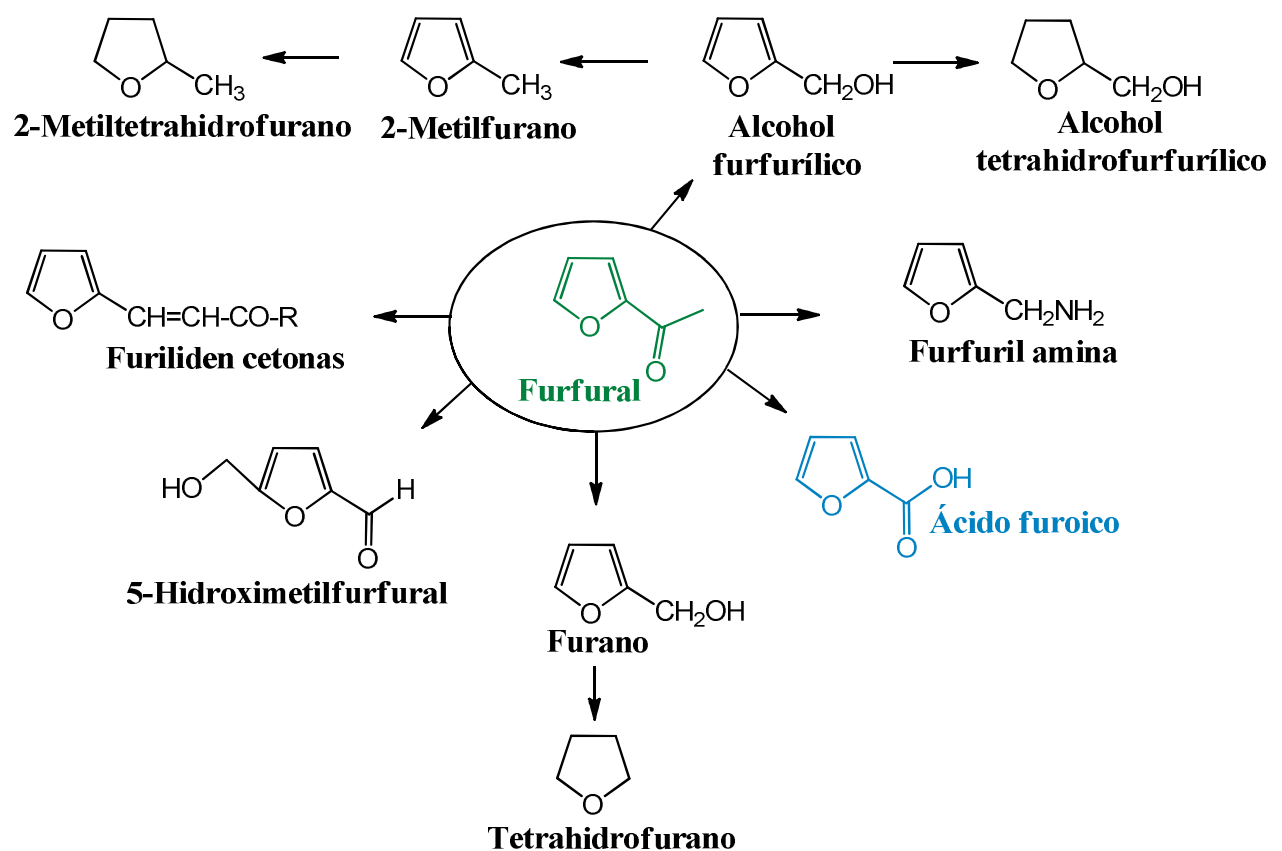

Figura 4. Productos primarios obtenidos por transformación directa de Furfural.

Algunos métodos informados para su obtención implican la reacción de Cannizaro en solución acuosa de $\mathrm{NaOH}$, donde se produce alcohol furfurílico y furoato de sodio, luego se requiere la adición de ácido sulfúrico para neutralizar la solución y para obtener finalmente el ácido furoico, en consecuencia se forma bisulfato de sodio en una reacción altamente exotérmica ${ }^{37}$; y la oxidación de furfural utilizando oxidantes tales como $\mathrm{KMnO}_{4}, \mathrm{MnO}_{2}, \mathrm{Ag}_{2} \mathrm{O}$, o mezclas de óxidos metálicos, tales como hierro, cobre, y platino.

Sin embargo, ninguna de estas síntesis se puede considerar selectivas, los catalizadores en muchos casos son fácilmente envenenados, su regeneración es difícil y ninguna se puede considerar síntesis verde. Por lo tanto, muchas investigaciones se han dirigido a lograr un método selectivo para la oxidación de furfural a ácido furoico con oxidantes menos contaminantes y tóxicos y más baratos, como oxígeno o peróxido de hidrógeno en presencia de bases como aminas secundarias y terciarias, donde se han alcanzado rendimientos entre 40 y $80 \%{ }^{38}$. Estudios más recientes utilizan métodos biológicos mediante síntesis enzimáticas preparando ácido 2-furoico partiendo del 


\section{Capítulo II. Introducción.}

correspondiente aldehído o alcohol, alcanzando rendimientos del 98\% en 21 h cuando el sustrato es el alcohol furfurílico, y del $88 \%$ en 8 h cuando es el furfural ${ }^{39}$.

A menudo se utiliza como material de partida para la producción de ésteres de furoato al reaccionar con diferentes alcoholes. En particular, sus ésteres son derivados importantes con diversas aplicaciones, como por ejemplo agentes aromatizantes de alimentos como es el caso del 2-furoato de n-hexilo y 2-furoato de n-octilo, aceptados por la Organización de las Naciones Unidas para la Alimentación y la Agricultura $(\mathrm{FAO})^{40}$. Otras aplicaciones incluyen saborizantes, fragancias en perfumería, y bioactividades como: anti-bacteriana, anti-fúngica y repelente.

Los métodos tradicionales para su síntesis incluyen la esterificación de Fischer usando catalizadores ácidos en fase homogénea tales como ácido sulfúrico ${ }^{41}$, ácido clorhídrico $^{42}$, ácido $p$-toluensulfónico ${ }^{43}$ y cloruro de tionilo ${ }^{44}$. Si bien, estos catalizadores presentan altos rendimientos, las desventajas de toxicidad y contaminación conocidas por todos que éstos conllevan, son una gran limitación.

Dentro de la catálisis heterogénea se destacan algunos catalizadores como carbonato de potasio ${ }^{45}$ o ácido perclórico inmovilizado sobre sílice gel ${ }^{46}$, entre otros. Otros métodos incluyen la esterificación de furfural usando manganeso (IV) como catalizador oxidativo ${ }^{47}$, la reacción entre cloruro de furoilo y alcoholes ${ }^{48}$ y la transesterificación de furoato de etilo y furoato de metilo con alcoholes de cadena larga catalizada por tamices moleculares $4 \mathrm{~A}^{49}$.

En la Figura 5 se muestra un esquema común de la reacción de esterificación del ácido 2-furoico con alcoholes y algunos de los ésteres que se pueden formar. El interés en esta reacción está en que al tener tantas aplicaciones industriales, se ve la necesidad de optimizar el proceso y hacerlo más benigno para el medio ambiente cumpliendo con la mayor cantidad de los principios de la química verde, y en especial el número 9, que habla del uso de catalizadores heterogéneos. 
Capítulo II. Introducción.

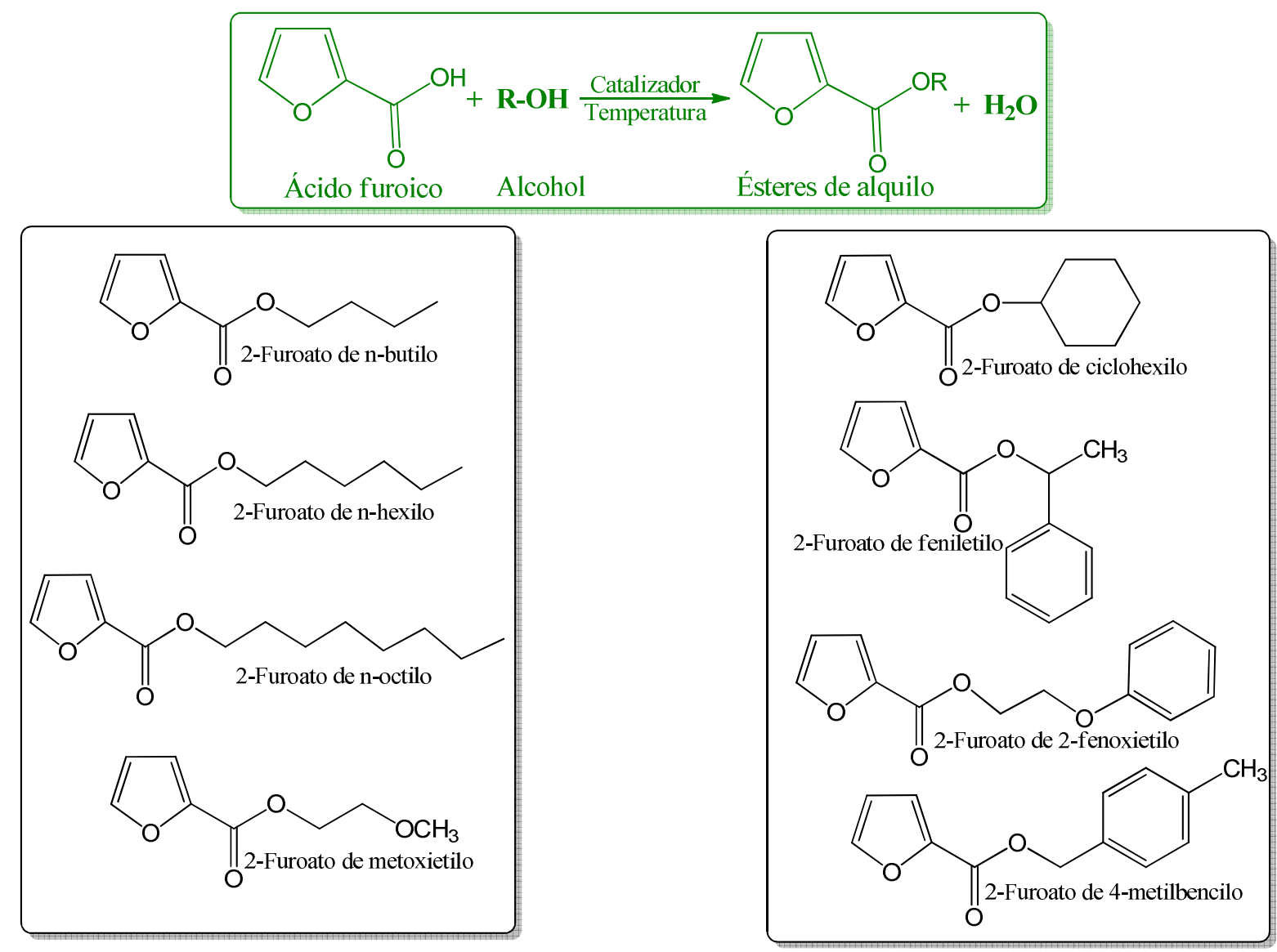

Figura 5. Esquema de la reacción de esterificación de Fischer del ácido 2-furoico y un alcohol y diferentes ejemplos de ésteres que se pueden obtener.

\subsubsection{Furoatos de alquilo como posibles compuestos antifoulling.}

Se denomina biofouling (incrustaciones biológicas) al asentamiento de micro y macroorganismos sobre sustratos duros naturales o artificiales sumergidos en agua, tales como rocas, cascos de barcos y estructuras asociadas como tuberías de agua, pozo de anclaje, etc. Dentro de estos organismos se incluyen algas marinas, cirripedios, mejillones, briozoos, entre otros ${ }^{50}$ (Un ejemplo se muestra en la Figura 6). 


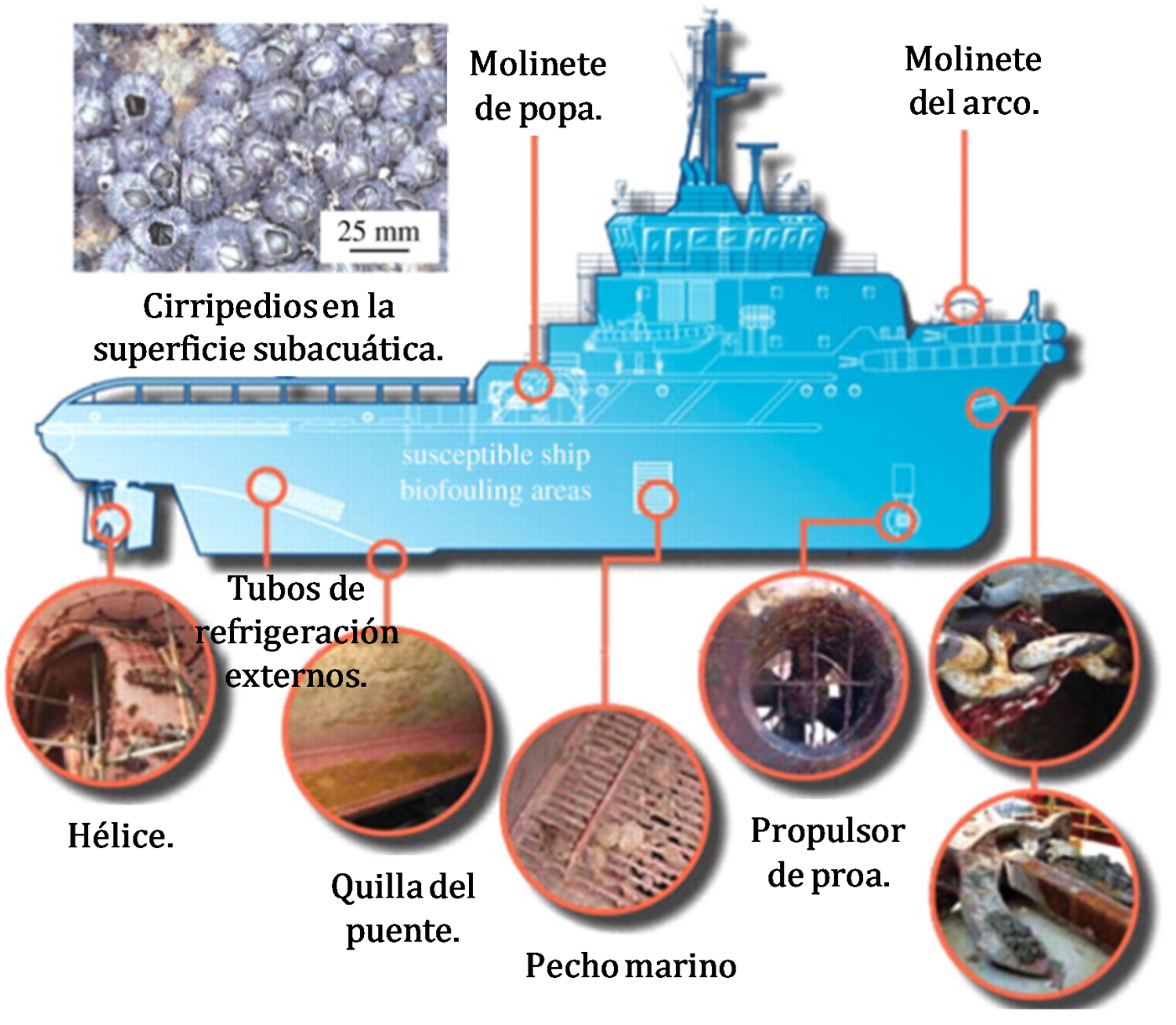

Figura 6. Ejemplos de biofouling marino. Áreas susceptibles de biofouling en un barco típico. (Imagen adaptada de Mermaid Marine Australia, Ltd; Fotografías cortesía de Ashley Coutts, Instituto Cawthron, John Polglaze, URS Australia y Helix ESG ${ }^{51}$ ).

Estos organismos son indeseables en los cascos de los buques y embarcaciones debido a que aumentan la resistencia, generando un aumento en la cantidad de combustible utilizado y reduciendo la velocidad y maniobrabilidad de los buques ${ }^{52,53}$. Además, un análisis realizado por Molnar et al. (2008) ${ }^{54}$, basándose en información de más de 350 bases de datos y otras fuentes, demostró que la contaminación biológica en los buques es la principal fuente de contaminación cruzada y el transporte de especies invasoras a lo largo de las costas del mundo, correspondiente al 69\% de las 329 especies marinas invasoras consideradas, las otras causas posibles son la acuicultura, los canales, el comercio de acuarios y de mariscos vivos. 
Capítulo II. Introducción.

Ante esta problemática, surge la necesidad de buscar soluciones, donde los sistemas antifouling (AF) aparecen, éstos fueron definidos en la Convención Internacional sobre el Control de Sistemas Antifouling Nocivos en los Buques, 2001 (AFS Convention) como "un revestimiento, pintura, tratamiento superficial o dispositivo que se utiliza en un buque para controlar o prevenir el asentamiento de organismos no deseados". Además, dichos revestimientos proporcionan ventajas adicionales tales como proteger las estructuras afectadas no sólo de las especies incrustantes, sino también de la corrosión del agua salada y las fluctuaciones de temperatura ${ }^{55}$. Los sistemas $\mathrm{AF}$, pueden funcionar de una de dos maneras ${ }^{56}$ : i) el revestimiento contiene biocidas o agentes activos que gradualmente se lixivian del revestimiento, matando los organismos marinos asentados; ii) El recubrimiento contiene repelentes que evitan la adherencia exitosa de organismos marinos.

El primer revestimiento AF a ser patentado se remonta a 1625, y consistía en revestimientos con recubrimientos a base de metales pesados como cobre y una variedad de materiales tóxicos (por ejemplo, plomo, mercurio, arsénico). Luego, en la década de 1960, se introdujeron los compuestos orgánicos con estaño como el tributilestaño (TBT), los cuales fueron ampliamente utilizados debido a su eficacia, siendo tóxicos a niveles extremadamente bajos (partes por trillón). Sin embargo, esta alta toxicidad pronto comenzó a causar problemas significativos en una amplia gama de biota marina, en particular a lo largo de las rutas marítimas ${ }^{57}$, siendo uno de los biocidas más tóxicos jamás introducidos, ya que no se degrada fácilmente en el medio ambiente natural y porque no discrimina, actuando tanto en organismos objetivo como sobre organismos no objetivo. Esto hizo que la Organización Marítima Internacional y el Comité de Protección del Medio Marino, prohibieran la producción total de revestimientos a base de TBT desde enero de 2003 y su aplicación en enero de $2008^{58}$.

Después de la prohibición de los productos AF que contienen TBT, se utilizan como alternativa pinturas de cobre y zinc, aunque estos metales son también tóxicos para el medio marino ${ }^{59,60}$. Otras pinturas AF alternativas basadas en biocidas, contienen compuestos tales como Irgarol 1051, Diuron, Sea-Nine 211, Clorotalonil, 
Capítulo II. Introducción.

Diclofluanida y Piritiona de zinc, siendo los biocidas de refuerzo más utilizados en todo el mundo, aunque algunos de ellos también se han acumulado en aguas costeras a niveles que son perjudiciales para los organismos marinos ${ }^{58,61}$.

Esto ha generado un interés creciente en el desarrollo de compuestos AF ambientalmente aceptables y libres de biocidas, centrando la atención en los invertebrados marinos, los cuales son fuentes ricas de compuestos bioactivos y su potencial biotecnológico atrae interés científico y económico a nivel mundial. Hasta la fecha, muchos de los productos naturales que se han descubierto a partir de organismos marinos como bacterias, algas, esponjas, corales, etc. desempeñan un papel ecológico para sus especies de origen en el medio marino y en muchos casos actúan como AF naturales ${ }^{62-64}$.

Las duras condiciones químicas y físicas en el medio ambiente han sido importantes impulsores para la producción de una variedad de moléculas con características estructurales únicas. Estas moléculas marinas presentan diversos tipos de actividades biológicas y se dividen ampliamente en terpenos y no terpenos ${ }^{65,66}$. Sin embargo, la producción de estas sustancias bioactivas a gran escala a partir de fuentes marinas es un gran desafío para la tecnología AF, ya que hasta la fecha la mayoría de estos metabolitos se han aislado con bajos rendimientos (por ejemplo entre el $2 \%$ y el $5 \%$ en esponjas) y organismos marinos de crecimiento lento, tales como corales, esponjas y otros invertebrados que no pueden ser cosechados a escala comercial sin dañar el medio ambiente67. Además, muchos de los compuestos aislados son estructuralmente complejos, haciendo que su producción por una ruta sintética sea comercialmente poco realista para la mayoría de estos compuestos.

Un estudio realizado por Michael Stewart et al. (2009) ${ }^{68}$ sugiere que la actividad AF de estos productos naturales terpenoides se debe al resto correspondiente $\gamma$ hidroxibutenólida de los anillos de furanos. Similarmente, Yong-Xin Li et al. (2013)69 compararon la relación que existía entre la estructura y la actividad AF de 49 productos naturales marinos contra larvas de amphitrite cyprid, encontrando que los compuestos que tienen una fracción de furano y furanona mostraban una actividad 


\section{Capítulo II. Introducción.}

significativa $\mathrm{AF}$, mientras que los compuestos sin resto de estos dos anillos no exhibieron tal actividad. Estos resultados apoyan la hipótesis de que el grupo furano y furanona son importantes farmacóforos en la actividad AF y hace considerar más factible la síntesis de compuestos más simples que contengan tales estructuras.

Esta idea se vio reforzada por el hallazgo de un sesquiterpeno con una estructura más sencilla y una ruta sintética conocida llamado ácido (1'E, 5'E)-2-(2', 6'-dimetilocta1', 5', 7'-trienil)-4-furoico (Figura 7)70, el cual abrió una nueva línea de búsqueda. Basados en que este compuesto presenta propiedades AF y baja toxicidad, se está investigando la posibilidad de encontrar compuestos análogos más sencillos y fáciles de sintetizar como los furoatos de alquilo.

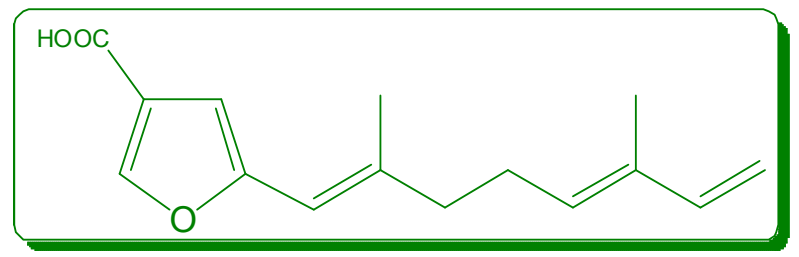

Figura 7. Estructura química del metabolito ácido (1'E, 5'E)-2-(2', 6'-dimetilocta-1', 5',

$$
\text { 7'-trienil)-4-furoico. }
$$

De esta forma, como un estudio adicional a los objetivos planteados inicialmente en esta Tesis Doctoral, se realizó un estudio para evaluar la actividad como agentes AF usados en pinturas de tres compuestos sintetizados durante este trabajo, los cuales son: 2-furoato de n-butilo, 2-furoato de n-hexilo y 2-furoato de n-octilo, presentándose como una alternativa altamente amigable con el medio ambiente y las especies marinas, ya que se pueden sintetizar directamente en el laboratorio y a gran escala, además, como materia prima se puede utilizar biomasa, siendo un ejemplo potencial de valorización de desechos de biomasa y catálisis heterogénea. Adicionalmente, no son tóxicos ya que los furoatos de n-butilo, n-hexilo y n-octilo son compuestos seguros utilizados en la industria alimentaria como saborizantes ${ }^{40}$.

\subsubsection{La deshidratación de pentosas a 5-hidroximetilfurfural.}




\section{Capítulo II. Introducción.}

Como bien se ha dicho, el 5-HMF es otra de las moléculas usadas como bloques de construcción más importantes, y ha sido de interés desde la última década del siglo 19 cuando en 1895 Düll y Kiermeyer trabajando de forma independiente, publicaron un método de sintetizarlo y lo llamaron "oximetilfurfurol", desde ese momento han sido numerosas las publicaciones sobre su síntesis, derivados y aplicaciones.

La síntesis es bastante compleja, se basa en la triple deshidratación de hexosas donde también se generan varias reacciones secundarias como isomerización, fragmentación y condensación que conducen a numerosos subproductos como polímeros y ácidos húmicos y si la deshidratación de 5-HMF continúa, se produce ácido levulínico; estos subproductos afectan en gran medida la eficiencia del proceso ${ }^{71}$. En la literatura se reportan dos hipótesis alternativas para el mecanismo de la deshidratación de la fructosa a 5-HMF: (1) una secuencia de reacciones en la que se mantiene intacto el anillo de fructofuranosa, y (2) una sucesión de reacciones que se dan principalmente a través de intermediarios de cadena abierta. La evidencia existente favorece la hipótesis 1, un ejemplo de ello, es el estudio reportado por Antal y col. en el cual encontraron que la formación del catión fructofurfuranosilo como intermediario de la deshidratación de la fructosa en agua a $250{ }^{\circ} \mathrm{C}$, en presencia y ausencia de catalizador ácido, para producir 5-HMF da altos rendimientos, siento más eficiente y selectivo cuando se parte de cetohexosas que de aldohexosas ${ }^{72}$.

\subsubsection{1. Ácido levulínico.}

En el 2004 los investigadores del NREL (Laboratorio Nacional de Energía Renovable) y PNNL (Laboratorio Nacional del Noroeste Pacífico) realizaron un extenso estudio para identificar los bloques de construcción más valiosos a base de los azúcares de la biomasa lignocelulósica ${ }^{73}$. De 300 candidatos seleccionados inicialmente, se obtuvo una lista de treinta productos químicos interesantes, la cual, luego de la evaluación de los mercados potenciales de los bloques de construcción y sus derivados y la complejidad de las vías de síntesis, se redujo a doce. Uno de estos top-doce bloques de construcción prometedores es el ácido levulínico, también conocido como ácido 4-oxopentanoico; en el 2010 fue reconfirmado en el top 10, luego 


\section{Capítulo II. Introducción.}

de una evaluación actualizada de posibles bloques de construcción donde se evaluaron los avances de la tecnología que llevó a la inclusión de un compuesto en el primer listado $^{74}$. En la Figura 8 se muestran algunos de los subproductos que pueden obtenerse a partir del ácido levulínico.

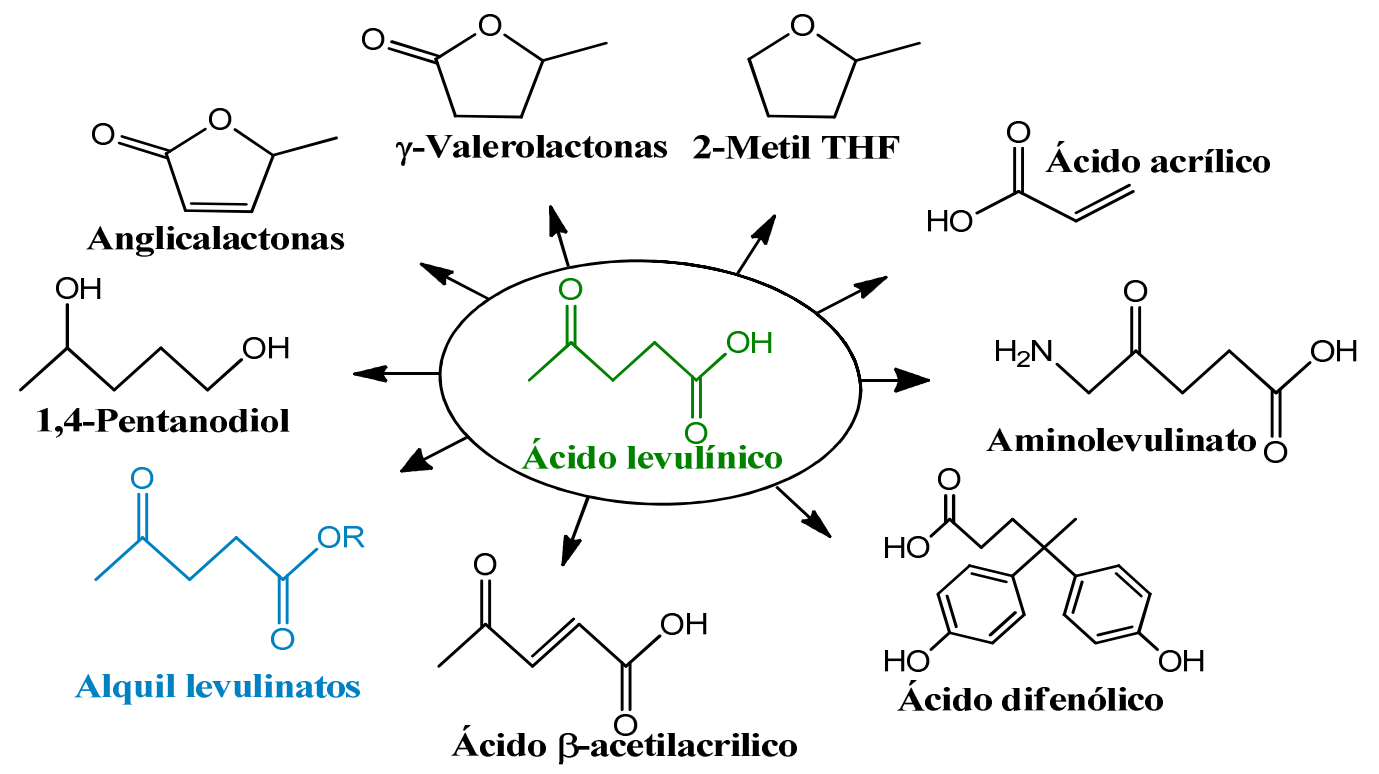

Figura 8. Productos primarios obtenidos por transformación directa del ácido levulínico.

El ácido levulínico está conformado por una cetona y un grupo carboxílico, que le confieren propiedades altamente reactivas que permiten un gran número de transformaciones sintéticas. Se sintetiza mediante dos rutas posibles (Figura 9): 1) deshidratación ácida de hexosas, tales como glucosa, fructosa, manosa o galactosa a través de la formación de 5-hidroximetilfurfural y su posterior hidratación, y 2) tratamiento ácido de pentosas tales como xilosa y arabinosa para producir furfural, seguido de reducción catalítica a alcohol furfurílico y posterior apertura del anillo en agua. 


\section{Capítulo II. Introducción.}

1)

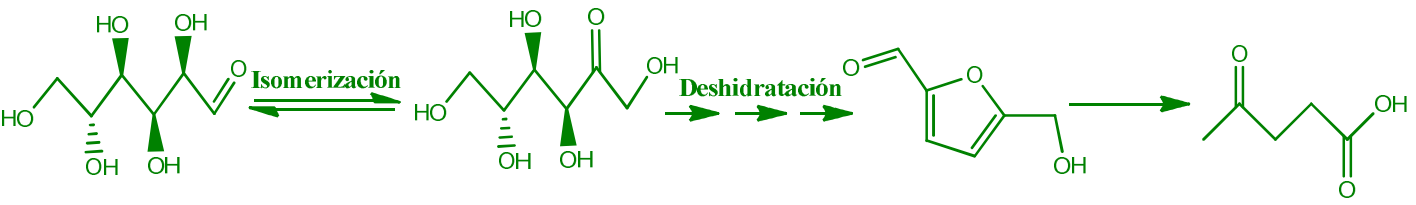

Glucosa

Fructosa

5-HMF

Ácido levulínico

2)

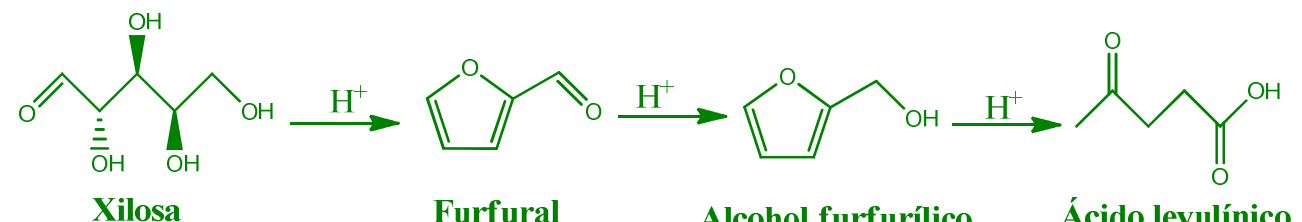

Figura 9. Rutas sintéticas del ácido levulínico.

Es un ácido carboxílico de bajo peso molecular del cual, sus usos como disolvente, agente saborizante en alimentos, material de partida para una variedad de compuestos farmacéuticos e industriales, resinas, plastificante, textil, alimentación animal y anticongelante, entre otros han sido reportados ${ }^{75}$. El ácido levulínico es fácilmente soluble en agua, etanol, éter di-etílico, acetona y muchos otros disolventes orgánicos ${ }^{76}$.

Según un estudio realizado por Grand View Research en 201577, la demanda global de ácido levulínico fue de 2,606 toneladas en 2013 y se prevé que aumente a 3,820 toneladas en 2020 , esto debido a menores costos de las materias primas, avances en la tecnología de producción y al incremento de sus aplicaciones, especialmente en el campo de los pesticidas, disolventes, productos farmacéuticos, cosméticos y las industrias que lo perfilan cada vez más como un sustituto de sus equivalentes sintéticos.

\subsubsection{Levulinatos de alquilo.}

Hay numerosos compuestos útiles derivados del ácido levulínico, entre ellos los levulinatos de alquilo, de los cuales se conoce desde finales de 1800 cuando se empezaron a publicar una serie de estudios que describían la formación de levulinato de metilo y propilo a partir de ácido levulínico purificado y el alcohol respectivo, en presencia de ácido sulfúrico y clorhídrico diluido ${ }^{78,79}$. Posteriormente, se publicaron 
Capítulo II. Introducción.

estudios que describían el método de preparación y algunas propiedades físicas como puntos de fusión y presiones de vapor ${ }^{80,81}$.

Estos compuestos químicos tienen gran potencial para diversas aplicaciones, sustituyendo productos químicos actuales producidos a partir de rutas petroquímicas, lo que ha despertado el interés en ellos, haciendo que la literatura sobre estos compuestos haya aumentado considerablemente en los últimos años, reseñando rutas de preparación de vanguardia donde se destaca su obtención con altos rendimientos y selectividades de productos simples como el ácido levulínico o el alcohol furfurílico; y sus principales campos de aplicación que incluyen su uso como saborizantes, disolventes, plastificantes, aditivos en biocombustibles y materiales de partida en síntesis química, gracias a que los cetoésteres resultantes sirven como sustratos para una variedad de reacciones de condensación y adición en el grupo éster o ceto ${ }^{82}$.

Entre los numerosos compuestos, se destacan los ésteres producidos a partir de metanol o etanol, los cuales tienen un potencial significativo como componentes en las formulaciones de diesel ya que son similares a los ésteres metílicos de ácidos grasos del biodiesel pero sin los inconvenientes que estos presentan como solidificación a bajas temperaturas y formación de gomas, además, cumple el estándar de combustible diesel de la norma ASTM D-975. Hace varios años, la empresa Biofine Corporation desarrolló un proceso para obtener ácido levulínico a partir de la celulosa ${ }^{83}$, del cual sintetizan diferentes derivados, entre ellos levulinato de etilo. Biofine junto con Texaco producen diesel con una formulación 21:79, que consiste en 20\% de levulinato de etilo, $1 \%$ de co-aditivo y $79 \%$ de diesel, y puede ser utilizado en motores diesel regulares. El contenido de oxígeno en el levulinato de etilo es de 33\% en peso, dando un contenido de oxígeno de $6,9 \%$ en peso en la mezcla, lo que resulta en un combustible significativamente más limpio y una mejor combustión, con la ventaja adicional sobre los bioésteres convencionales que no hay co-producción de glicerol, el cual, si bien tiene muchas aplicaciones industriales y farmacéuticas, a la escala en que se produce el biodiesel, la cantidad de este sub producto es superior a la que se requiere, siendo un inconveniente a largo plazo ${ }^{84}$. 


\section{Capítulo II. Introducción.}

En particular, los levulinatos están actualmente en el centro de múltiples iniciativas de $\mathrm{I}+\mathrm{D}$ debido a su accesibilidad directa desde el ácido levulínico. Así, otro éster del ácido levulínico importante es el levulinato de n-butilo, el cual puede encontrar aplicaciones como disolventes verde alternativo, plastificante polimérico o sabor y fragancia aprobado por la $\mathrm{FAO}^{85}$. Otros levulinatos de alquilo tienen potencial como reemplazo de queroseno como combustible para calefacción y para la cocción directa de turbinas de gas para generación de electricidad ${ }^{86}$. Por consiguiente, el desarrollo de nuevas rutas para la producción de levulinatos a partir de moléculas plataformas ha atraído cada vez más atención.

Los esfuerzos de las investigaciones más recientes se centran en el desarrollo de catalizadores heterogéneos eficientes y reciclables que hagan más rentable el procedimiento, y compatible con el medio ambiente.

Los ésteres se pueden obtener por una reacción de esterificación directamente a partir de ácido levulínico (Figura 10.a), en la cual, debido a que la formación del éster es una reacción de equilibrio limitado, se mejoran los rendimientos eliminando el agua que se genera mediante un reactor de destilación catalítica desplazando así el equilibrio hacia la formación del éster. Entre los catalizadores ácidos, los heteropoliácidos (HPAs) y las zeolitas ${ }^{87}$ son las opciones preferidas. Para superar sus bajas superficies específicas, los HPAs han sido soportados en óxidos de altas superficies específicas como montmorillonita $\mathrm{K} 10^{88}, \mathrm{ZSM}-5^{89}, \mathrm{SiO}_{2}{ }^{90}, \mathrm{ZrO}_{2}{ }^{91}$.

Otro método de síntesis reportado es la obtención de levulinatos de alquilo a partir de la formación de $\alpha$-angelicolactonas por calentamiento del ácido levulínico a temperaturas entre 150 a $175{ }^{\circ} \mathrm{C}$ y presiones de $17-50 \mathrm{~mm}$ en ausencia de catalizador. Estas lactonas son muy reactivas hacia alcoholes y en presencia de un catalizador ácido o básico se obtienen altas conversiones al levulinato de alquilo correspondiente (Figura 10.b). Se han usado catalizadores como Amberlyst-15, 20\% Li(acetato)/ $\mathrm{SiO}_{2}$, $20 \% \mathrm{Ba}$ (acetato) $)_{2} / \mathrm{SiO}_{2}$ y $\mathrm{Na}_{2} \mathrm{CO}_{3}{ }^{92}$. 
Capítulo II. Introducción.

También se han sintetizado a partir de la mezcla de ácido levulínico con olefinas tales como etileno, propileno, buteno, penteno, o cualquier otra no mayor a 22 carbonos, en presencia de un catalizador ácido, el cual puede ser ácidos inorgánicos tales como ácido sulfúrico, ácido clorhídrico, y ácido nítrico, o mezclas de los mismos; ácidos orgánicos como ácido p-toluenensulfónico o catalizadores heterogéneos como zeolitas, alúmina fluorada, sílice y arcillas tratadas con ácido, heteropoliácidos soportados y zirconia sulfatada. Como resultado se obtiene una mezcla de ésteres de alquilo lineales y ramificados (Figura 10.c) ${ }^{93}$.

Un cuarto método incluye la formación de ésteres del ácido levulínico a partir del alcohol furfurílico, el cual se obtiene fácilmente por hidrogenación del furfural y posterior esterificación ácida con el alcohol respectivo (Figura 10.d). Entre los catalizadores ácidos reportados se encuentran metil imidazol butilsulfato fosfotungsteno ([MIMBS $\left.]_{3} \mathrm{PW}_{12} \mathrm{O}_{40}\right)$ con el que se obtienen rendimientos alrededor del 90\% cuando el alcohol es primario y disminuye el rendimiento significativamente con alcoholes secundarios y terciarios ${ }^{94}$, resinas de intercambio iónico y zeolitas ${ }^{95}$, sílice, carbón y resinas de poliestireno funcionalizados con grupos sulfónicos ${ }^{96}$ entre otros.

a)

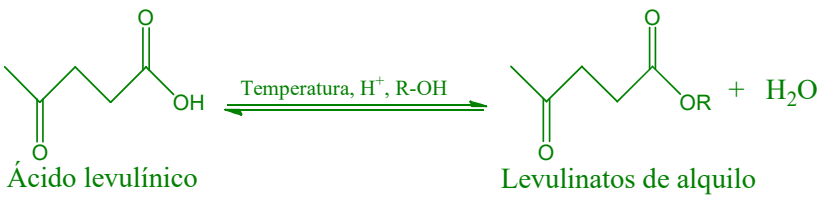

b)
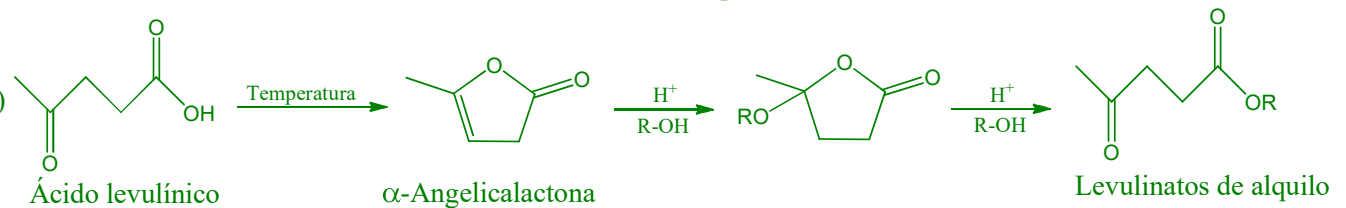

c)
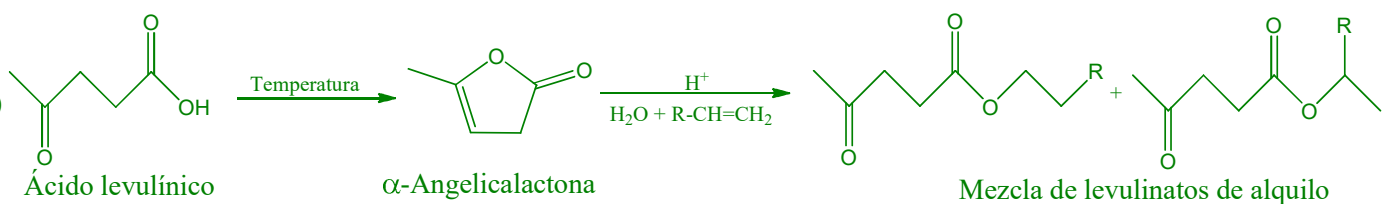

Mezcla de levulinatos de alquilo

d)
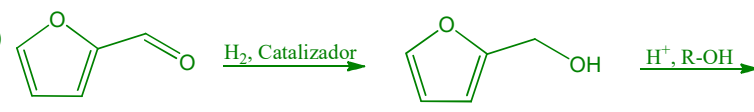

Furfural

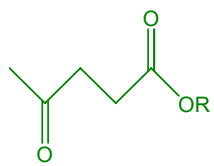

Levulinatos de alquilo

Figura 10. Rutas de síntesis para la obtención de levulinatos de alquilo. 


\section{Capítulo II. Introducción.}

Por otro lado, debido a que el ácido levulínico se deriva de carbohidratos de la biomasa, se ha estudiado la posibilidad de sintetizar levulinatos de alquilo directamente partiendo de polisacáridos. En el caso de materiales lignocelulósicos, la estabilidad e insolubilidad de los reactivos en solventes como agua, añadido a los pasos necesarios de despolimerización, solvólisis, y deshidratación para obtener los respectivos monosacáricos, hacen que el proceso global requiera condiciones drásticas (temperaturas entre 120 y $200{ }^{\circ} \mathrm{C}$, mayores relaciones molares ácido/alcohol y largos tiempos de reacción ${ }^{97-99}$ ), de lo contrario, conducirá inevitablemente a una baja selectividad y rendimiento, obteniendo polímeros como subproductos. Sin embargo, Xun $\mathrm{Hu}$ y $\mathrm{col}^{100}$, determinaron que en las reacciones que implican carbohidratos en solventes como metanol y en presencia de un catalizador ácido, los grupos hidroxilo y carbonilo de la glucosa, 5-HMF o el furfural se protegen mediante eterificación y acetalización, previniendo reacciones de polimerización no deseadas, aumentando significativamente la formación de levulinatos de alquilo (Figura 11).

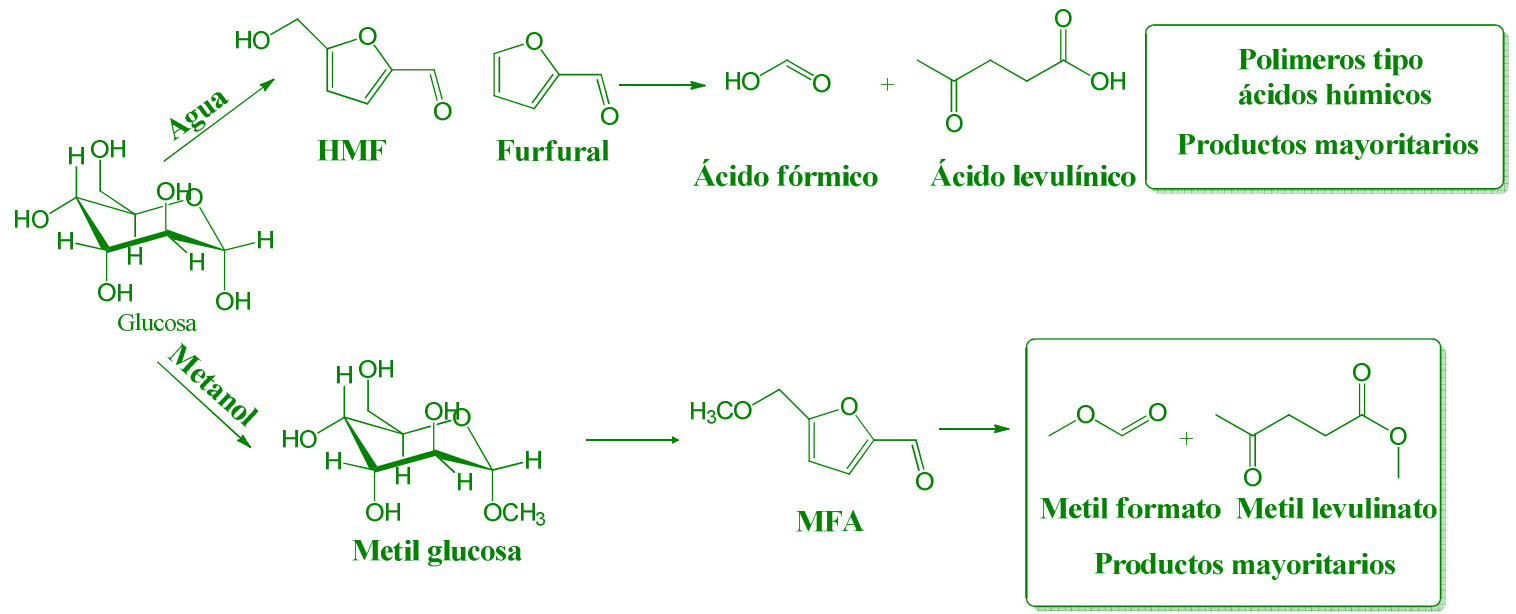

Figura 11. Posibles rutas de reacción en la obtención de levulinatos de alquilo a partir de glucosa. La primera en un medio rico en agua que incluye la transformación a ácido levulínico a través de la formación de 5-HMF seguido por una esterificación final, y la segunda en un medio rico en alcohol (para este ejemplo metanol) donde se forman especies de éteres o acetales que luego sufren deshidratación/rehidratación hasta formar el éster final. Definición de las abreviaturas en la figura: HMF: 5-(hidroximetil) furfural, MFA: 5-(metoximetil) 2-furancarboxadehído. 


\section{Capítulo II. Introducción.}

Otra desventaja de trabajar con condiciones tan severas de reacción, además de los altos costos de producción, es que estas condiciones son más favorables para que se dé la deshidratación del alcohol formando inevitablemente el di-alquil éter correspondiente. Esto plantea problemas para la comercialización de los levulinatos de alquilo sintetizados así, no sólo por un mayor consumo de alcohol, sino también por dificultades para reciclar, separar y eliminar los residuos del proceso. Sin embargo, la formación de di-alquil éteres se puede limitar utilizando catalizadores sólidos como $\mathrm{SO}_{4}{ }^{2-} / \mathrm{ZrO}_{2}, \quad \mathrm{SO}_{4}{ }^{2-} / \mathrm{TiO}_{2}$, y $\mathrm{SO}_{4}{ }^{2-} / \mathrm{ZrO}_{2}-\mathrm{Al}_{2} \mathrm{O}, \quad$ o catálisis homogénea mediante soluciones con concentraciones muy bajas de ácido ${ }^{99}$. 
Capítulo II. Introducción.

\subsection{CATÁLISIS HETEROGÉNEA: TECNOLOGÍA VERDE Y SOSTENIBLE.}

Como ya se ha mencionado a lo largo de este escrito, en la mayoría de los procesos industriales para la obtención de furfural y sus derivados, hasta llegar a los ésteres del ácido furoico y el ácido levulínico, se emplea normalmente ácido sulfúrico concentrado como catalizador, y en menor medida ácido clorhídrico en diferentes rangos de concentraciones. El problema se centra en que estos ácidos son extremadamente corrosivos, altamente tóxicos y difíciles de manipular y sufren de los serios inconvenientes encontrados en los procesos catalíticos homogéneos, tales como dificultad en la separación y reciclado del ácido mineral, contaminación del producto, y riesgos medioambientales muy severos, entre otros, que hacen que la búsqueda de catalizadores heterogéneos sea de vital importancia, ya que son más seguros y medioambientalmente sostenibles de acuerdo con el principio 7 de la Química Verde. De hecho, el número de patentes que emplean catálisis heterogénea en la deshidratación de los monosacáridos ha crecido vertiginosamente durante los últimos años, lo que ha hecho que la búsqueda de catalizadores heterogéneos adecuados para estos procesos sea un aspecto de especial relevancia tendiendo a tecnologías verdes y sostenibles.

Los catalizadores son herramientas indispensables para la industria química, pero sólo tienen sentido útil si sus aplicaciones son prácticas. En otras palabras, puede ser una tecnología sostenible clave solamente si se demuestra su utilidad en la sociedad mediante las mejoras del bienestar humano y del medio ambiente. Sus aportes pueden ser de dos maneras: (i) catalizadores que sean respetuosos del medio ambiente, o sea, minimizando su toxicidad y contaminación, y disminuyendo los peligros de los procesos, y (ii) catalizadores que eliminen o disminuyan los compuestos peligrosos generados.

En este sentido, la continuación de los esfuerzos para innovar en nuevos materiales catalíticos son muy importantes para el progreso de la ciencia química y de nuevas tecnologías ecocompatibles. Un ejemplo de ello, son los catalizadores basados en heteropoliácidos, los cuales han demostrado sus propiedades como catalizadores 
Capítulo II. Introducción.

verdes, llegando a ser usados en procesos industriales, haciéndolos más rentables y disminuyendo drásticamente el uso de otros catalizadores contaminantes como ácidos minerales y metales nobles como Pd, Pt y $\mathrm{Rh}^{101}$.

\subsubsection{Catalizadores basados en heteropoliácidos.}

La catálisis por HPAs y compuestos relacionados de polioxometalatos (POMs, especies heteropolianiónicas) es un campo de gran importancia debido a sus ventajas que los postulan como catalizadores económicos y ecológicos. El primer informe de lo que llamamos un polioxometalato se remonta a 1826 cuando J. J. Berzelius halló que acidificando soluciones que contienen molibdato y fosfato se formaba un precipitado cristalino amarillo que resultó ser $\left(\mathrm{NH}_{4}\right)_{3}\left[\mathrm{PMo}_{12} \mathrm{O}_{40}\right]^{102}$. Estos compuestos prestaron significativos aportes conceptuales y retos experimentales a Werner y los fundadores de la química de coordinación y a muchos investigadores desde entonces.

Sólo años después, con el avance de la tecnología y las técnicas de caracterización se pudo conocer más sobre la química fundamental de estos compuestos y desde entonces, su estudio y aplicación ha ido en crecimiento dando grandes aportes a la química, física y ciencias de los materiales. Por un lado, los HPAs presentan una acidez Bronsted muy fuerte, acercándose a la región de un superácido (Siguiendo la definición de Gillespie ${ }^{103}$, los superácidos son ácidos más fuertes que el $\mathrm{H}_{2} \mathrm{SO}_{4}$ al 100\%; ellos tienen la función de acidez de Hammett Ho menor que -12), por otro lado, son eficientes oxidantes, que exhiben rápidas transformaciones redox bajo condiciones bastante suaves.

Pocos compuestos pueden ser tan ampliamente modificados, ya que prácticamente todas las propiedades moleculares que impactan la utilidad de una clase de compuestos en la catálisis y ciencia de los materiales puede ser alterada en los POMs, estas propiedades incluyen la composición molecular, donde la mayoría de los elementos de la tabla periódica se pueden incorporar en el marco estructural de estos compuestos, también se puede modificar su tamaño, estructura, densidad de carga, potenciales redox, acidez y la solubilidad ${ }^{104}$. 


\section{Capítulo II. Introducción.}

La primer estructura caracterizada y la más estudiada de los HPAs es la estructura tipo Keggin, estos compuestos son relativamente simples de preparar y poseen acidez Brönsted fuerte que los hace versátiles en una amplia gama de reacciones. Reciben su nombre debido a que en 1933 J. F. Keggin resolvió la estructura del anión $\left[\mathrm{PW}_{12} \mathrm{O}_{40}\right]^{3-}$ mediante difracción de rayos $\mathrm{X}$, representando tanto los aniones $\alpha$-Keggin hidratados, como los deshidratados sin necesidad de un cambio estructural significativo ${ }^{105}$.

En los años posteriores fueron descubiertas otras estructuras fundamentales más complejas como por ejemplo la del ion Wells-Dawson ${ }^{106}$, la de Anderson-Evans ${ }^{107}$ o la de Dexter Silverton ${ }^{108}$.

Típicamente, la estructura primaria de los HPAs Keggin está representada por la fórmula $\left[\mathrm{XM}_{12} \mathrm{O}_{40}\right]^{x-8}$, donde $\mathrm{X}$ es el átomo central (para este trabajo, será $\mathrm{P}^{5+} \mathrm{o} \mathrm{Si}^{4+}$ correspondientes al ácido tungstofosfórico TPA y tungstosilísico TSA, respectivamente), $x$ es su estado de oxidación y $M$ es el ion metálico (para este caso, $\mathrm{W}^{6+}$ ). Uno o varios iones $\mathrm{M}^{6+}$ pueden ser sustituidos por otros iones metálicos, por ejemplo, $\mathrm{Mo}^{6+}, \mathrm{V}^{5+}, \mathrm{Co}^{2+}, \mathrm{Zn}^{2+}$, etc.

Dicha estructura primaria consiste en un tetraedro céntrico $\mathrm{XO}_{4}$ rodeado por cuatro grupos $\mathrm{M}_{3} \mathrm{O}_{13}$, formados cada uno por 3 octaedros $\mathrm{MO}_{6}$ que comparten un oxígeno en sus aristas, que también se comparte con el grupo $\mathrm{XO}_{4}$ del tetraedro central, el cual puede ser visto como un ligando enlazado a doce unidades (Figura 12)109.

Los aniones Keggin tienen tres tipos de átomos externos de oxígeno como potenciales centros de protonación: oxígenos terminales $\mathrm{M}=0$ y dos tipos de oxigeno puente M-O-M (Figura 12.b). 


\section{Capítulo II. Introducción.}
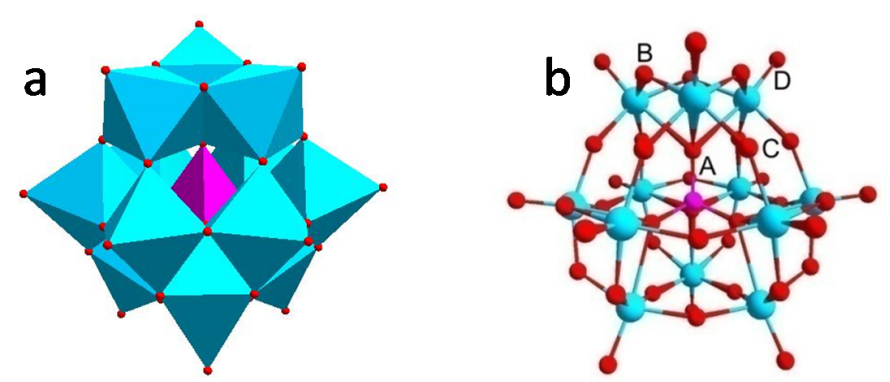

Figura 12. Estructura $\alpha$-Keggin en su presentación a) Poliédrica, b) Atómica. Las letras corresponden a: A) Oxígenos internos que se unen al tetraedro central con las cuatro triadas de octaedros $\left.\mathrm{MO}_{6}, \mathrm{~B}\right)$ Oxígenos que unen a dichos octaedros a través de las aristas para formar las triadas, C) Oxígenos que unen los grupos $\mathrm{M}_{3} \mathrm{O}_{13}$ a través de los vértices y D) Oxígenos terminales. Imágenes tomadas y modificadas de la página web WOW 110 .

La estructura tipo Keggin presenta distintos isómeros posibles, como consecuencia de la rotación de algunos de los grupos $\mathrm{M}_{3} \mathrm{O}_{13}$ en torno a su eje de simetría. Así mismo, en soluciones que poseen un $\mathrm{pH}$ mayor a 2, se forma el anión Keggin lacunar, el cual ha perdido una triada $\mathrm{M}_{3} \mathrm{O}_{13}$, éste es bastante difícil de aislar por su inestabilidad 111,112 .

La estructura secundaria está formada por un arreglo tridimensional de polianiones (estructura primaria), contra-cationes como $\mathrm{H}^{+}, \mathrm{H}_{3} \mathrm{O}^{+}, \mathrm{H}_{5} \mathrm{O}_{2}{ }^{+}$, etc. y moléculas adicionales como el agua de hidratación; correspondiente a la llamada "celda unidad" (Figura 13.b). Ésta estructura es flexible al adoptar diferentes ordenamientos cristalinos que dependen fundamentalmente del contra-catión y de la estructura del polianión. Así, a partir de difracción de rayos X de monocristal, datos de difracción de neutrones ${ }^{113}$ y resonancia magnética nuclear de ${ }^{1} \mathrm{H}^{114}$, se determinó que la estructura cristalina del TPA hexahidratado se forma mediante el empaquetamiento de heteropolianiones en una estructura cúbica centrada en el cuerpo. 


\section{Capítulo II. Introducción.}

En estado sólido, los protones del TPA hexahidrato se representan como iones $\mathrm{H}_{5} \mathrm{O}_{2}{ }^{+}$, donde cada uno de ellos enlaza cuatro heteropolianiones vecinos mediante la formación de enlaces de hidrógeno con el terminal W=0 (Figura 13.a).

La estructura terciaria representa la manera con la cual la estructura secundaria se ensambla dentro de las partículas sólidas y está relacionada a propiedades tales como tamaño de partícula, área superficial, estructura porosa y distribución de sitios ácidos. Esta disposición juega un rol muy importante en sus propiedades como catalizador (Figura 13.c) ${ }^{115,116 .}$

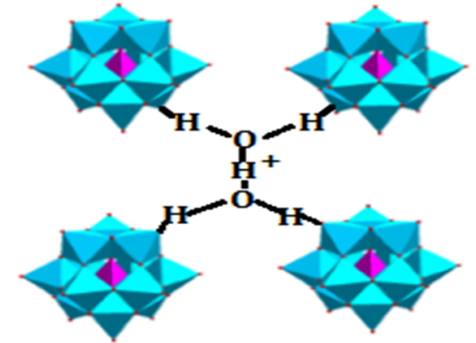

A

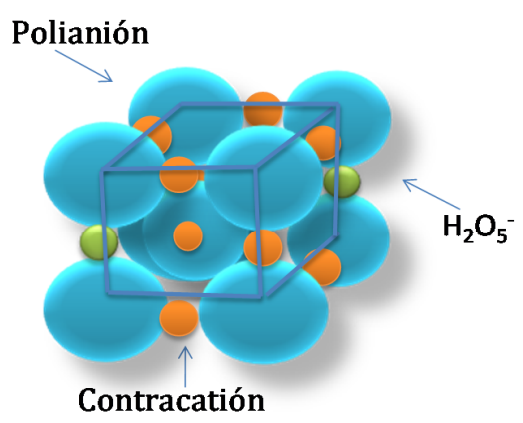

B

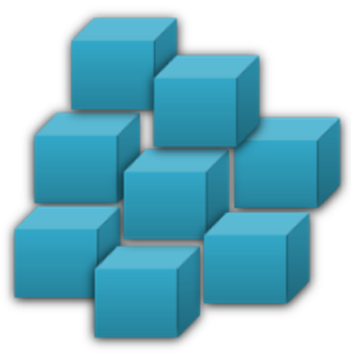

C

Figura 13. Estructuras del anión Keggin a) Estructura secundaria formada entre $\mathrm{H}_{5} \mathrm{O}_{2}{ }^{+}$ y los polianiones, b) Estructura secundaria, c) Estructura terciaria. (Imagen adaptada de Toshio Okuhara et. al ${ }^{116}$ )

\subsubsection{Propiedades generales de los heteropoliácidos tipo Keggin.}

Los polioxometalatos son especies estables en aire y en agua, extremadamente solubles en solventes polares, son de un gran tamaño ( 6 a $25 \AA$ ) y de alto peso iónico (1000-10000). Su estructura cristalina depende de la cantidad de moléculas de agua de hidratación, la cual se puede eliminar fácilmente por calentamiento, con lo que la concentración de ácido se incrementa debido a la deshidratación de los protones. Todas estas características influyen fuertemente en sus propiedades catalíticas y se describen más ampliamente a continuación. 


\section{Capítulo II. Introducción.}

- $\quad$ Estabilidad térmica.

La estabilidad térmica de los HPAs tipo Keggin se define como la temperatura a la que todos los protones ácidos se pierden. Esta propiedad es de suma importancia en catálisis heterogénea, ya que la actividad catalítica se puede perder irreversiblemente por descomposición térmica durante su aplicación, con la consecuente pérdida de su ventaja de reutilización.

Esto hace que sea de vital importancia caracterizar dicha estabilidad mediante diferentes técnicas como Análisis Termogravimétrico (TGA), Análisis Térmico Diferencial (DTA), calorimetría diferencial de barrido, entre otras, y se puede complementar con otras técnicas como Difracción de Rayos X, Resonancia Magnética Nuclear, Infrarrojo, etc. Todas estas técnicas han permitido identificar el comportamiento de estos materiales, encontrando que su descomposición térmica tiene lugar en varias etapas que dependen de la estructura del HPA, siendo los de estructura tipo Keggin los que presentan mayor estabilidad térmica. La temperatura de descomposición decrece según la serie $\mathrm{e}^{117}$ :

$$
\begin{gathered}
\mathrm{H}_{3}-\mathrm{PW}_{12} \mathrm{O}_{40}>\mathrm{H}_{3} \mathrm{PMo}_{12} \mathrm{O}_{40}> \\
\text { que } \mathrm{H}_{4} \mathrm{HiMo}_{6} \mathrm{P}_{2} \mathrm{O}_{40} \mathrm{~W}_{18} \mathrm{O}_{62} \text {. } \mathrm{H}_{3}-\mathrm{PW}_{12} \mathrm{O}_{40} \text { es mucho más estable }
\end{gathered}
$$

Sin embargo, las altas estabilidades térmicas de los HPA son relativas. Por ejemplo, $\mathrm{H}_{3} \mathrm{PW}_{12} \mathrm{O}_{40}$ pierde sus protones de 450 a $470{ }^{\circ} \mathrm{C}$ para formar $\left\{\mathrm{PW}_{12} \mathrm{O}_{38.5}\right\}$, y la estructura está completamente destruida aproximadamente a los $600{ }^{\circ} \mathrm{C}$, ésta última pérdida es prácticamente irreversible, lo que provoca la pérdida de la actividad catalítica, así, la descomposición térmica de $\mathrm{H}_{3} \mathrm{PW}_{12} \mathrm{O}_{40}$ sigue el curso ${ }^{118}$ :

$\mathrm{H}_{3} \mathrm{PW}_{12} \mathrm{O}_{40} \mathrm{nH}_{2} \mathrm{O} \underset{-(\mathrm{n}-6) \mathrm{H}_{2} \mathrm{O}}{\stackrel{<100^{\circ} \mathrm{C}}{\longrightarrow}} \mathrm{H}_{3} \mathrm{PW}_{12} \mathrm{O}_{40} 6 \mathrm{H}_{2} \mathrm{O} \underset{-6 \mathrm{H}_{2} \mathrm{O}}{\stackrel{<200^{\circ} \mathrm{C}}{\longrightarrow}} \mathrm{H}_{3} \mathrm{PW}_{12} \mathrm{O}_{40} \underset{-1.5 \mathrm{H}_{2} \mathrm{O}}{\stackrel{450-547^{\circ} \mathrm{C}}{\longrightarrow}}\left\{\mathrm{PW}_{12} \mathrm{O}_{38.5} \stackrel{\text { ca. } 600^{\circ} \mathrm{C}}{\longrightarrow} 1 / 2 \mathrm{P}_{2} \mathrm{O}_{5}+12 \mathrm{WO}_{3}\right.$ 
Capítulo II. Introducción.

- $\quad$ Solubilidad y estabilidad en solución.

Los heteropolianiones son oxoaniones poliméricos formados por condensación de más de dos oxoaniones diferentes en solución acuosa, según la ecuación:

$$
12 \mathrm{WO}_{4}^{2-}+\mathrm{HPO}_{4}^{2-}+23 \mathrm{H} \rightarrow \mathrm{PW}_{12} \mathrm{O}_{40}^{3-}+12 \mathrm{H}_{2} \mathrm{O}
$$

Estos oxoaniones polimerizan cuando la solución es ácida (bajos pH) y despolimerizan, o en otras palabras, se hidrolizan, cuando el $\mathrm{pH}$ incrementa. Para el caso del $\mathrm{PO}_{4}^{3-} \mathrm{y} \mathrm{WO}_{4}{ }^{2-}$ en una solución acuosa concentrada se producen los siguientes cambios:

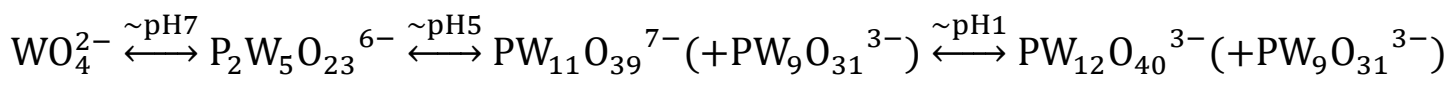

La condensación y la hidrólisis son usualmente rápidas y los polianiones coexisten en diversas especies en equilibrio en función del pH. Este es un proceso reversible que cambia el volumen de la celda unidad. En general, la estabilidad en solución (estructura Keggin) de los HPAs disminuye en función del átomo metálico de la siguiente forma: $\mathrm{W}^{6+}>\mathrm{Mo}^{6+}>\mathrm{V}^{5+}$. Los aniones Keggin son bastante móviles, no sólo en agua, sino también en una gran variedad de moléculas orgánicas polares. Tal flexibilidad estructural de los HPAs es importante cuando se utilizan como catalizadores heterogéneos ${ }^{119}$.

\section{- $\quad$ Acidez}

Los heteropoliácidos con estructura tipo Keggin son ácidos fuertes, generalmente más fuerte que los habituales ácidos minerales $\mathrm{H}_{2} \mathrm{SO}_{4}, \mathrm{HCl}, \mathrm{HNO}_{3}$ (Tabla 1). Ésta fuerte acidez se produce por la baja densidad de carga distribuida entre los muchos átomos de oxígeno del polianión. Los tres protones del ácido $\mathrm{H}_{3} \mathrm{PW}_{12} \mathrm{O}_{40}$ se disocian igualmente en solución acuosa y no se pueden diferenciar por titulación, pero si se pueden diferenciar en disolventes orgánicos como acetona, etanol, y ácido acético. 
Capítulo II. Introducción.

Tabla 1. Constantes de disociación de HPAs y ácidos convencionales en acetona a 25 ${ }^{\circ} \mathrm{C} 109$.

\begin{tabular}{lccl}
\hline \multicolumn{1}{r}{ Ácido } & $\mathrm{pk}_{1}$ & $\mathrm{pk}_{2}$ & \multicolumn{1}{c}{$\mathrm{Pk}_{3}$} \\
\hline $\mathrm{H}_{3} \mathrm{PW}_{12} \mathrm{O}_{40}$ & 1.6 & 3.0 & 4.0 \\
$\mathrm{H}_{4} \mathrm{SiW}_{12} \mathrm{O}_{40}$ & 2.0 & 3.6 & 5.3 \\
$\mathrm{H}_{3} \mathrm{PMo}_{12} \mathrm{O}_{40}$ & 2.0 & 3.6 & 5.3 \\
$\mathrm{H}_{4} \mathrm{SiMo}_{12} \mathrm{O}_{40}$ & 2.1 & 3.9 & 5.9 \\
$\mathrm{H}_{2} \mathrm{SO}_{4}$ & 6.6 & & \\
$\mathrm{HCl}$ & 4.3 & & \\
$\mathrm{HNO}_{3}$ & 9.4 & & \\
\hline
\end{tabular}

Diferentes métodos para determinar acidez como cambios de colores de los indicadores de Hammett, titulación potenciométrica con n-butilamina, desorción termoprogramada de amoniaco, y adsorción de piridina, entre otras, han permitieron determinar que la fuerza ácida de los HPA depende débilmente de su composición obteniendo la siguiente secuencia de fuerza ácida de HPAs anhidros, donde se evidencia que los ácidos de wolframio son marcadamente más fuertes que los de molibdeno ${ }^{120,121}$ :

$$
\mathrm{H}_{3} \mathrm{PW}_{12} \mathrm{O}_{40}>\mathrm{H}_{4} \mathrm{SiW}_{12} \mathrm{O}_{40}>\mathrm{H}_{6} \mathrm{P}_{2} \mathrm{~W}_{18} \mathrm{O}_{62}>\mathrm{H}_{3} \mathrm{PMo}_{12} \mathrm{O}_{40}>\mathrm{H}_{4} \mathrm{SiMo}_{12} \mathrm{O}_{40}
$$

Aunque la fuerza y la actividad catalítica de los ácidos Brönsted se cuantifican mejor en términos de sus constantes de disociación y la función de acidez de Hammett, otras características, como la dureza del ácido o la suavidad de la base correspondiente también han sido estudiadas, ya que estos son parámetros claves de la teoría ácidobase (duro-blanda) relacionada con las polarizabilidades de los ácidos y bases que ayudan a explicar la estabilidad de los compuestos y los mecanismos de reacción. 
Capítulo II. Introducción.

Se aplica el término 'duro' a aquellas especies que son pequeñas, tienen estado de oxidación o carga alta, y son débilmente polarizables. De igual forma, se aplica el término 'blando' a aquellas especies que son grandes, tienen estado de oxidación o carga pequeña, y son fuertemente polarizables ${ }^{122}$. Según Izumi y $\operatorname{col}^{123}$ los aniones Keggin pueden caracterizarse como basicidad blanda y gran suavidad, la cual se cree, mejora la actividad catalítica y la selectividad mediante la estabilización en la reacción de intermedios. El orden de la suavidad de heteropolianiones y otros aniones en solución acuosa sigue el orden:

$$
\mathrm{SiW}_{12} \mathrm{O}_{40} 0^{4-}>\mathrm{GeW}_{12} \mathrm{O}_{40} 0^{4-}>\mathrm{PW}_{12} \mathrm{O}_{40^{3-}}>\mathrm{PMo}_{12} \mathrm{O}_{40} 0^{3-}>\mathrm{SiMo}_{12} \mathrm{O}_{40} 0^{4-}>\mathrm{NO}_{3}->\mathrm{TsO}^{-}>\mathrm{SO}_{4}^{2-}
$$

Por otro lado, basado en la estructura jerárquica y la naturaleza flexible de la estructura sólida (estructura secundaria variable) de los POMs, puede demostrarse que hay tres modos completamente diferentes de catálisis en estado sólido, a saber: catálisis superficial, pseudo-líquida (bulk tipo I) y bulk tipo II (Figura14).

La catálisis de superficie (Figura 14.a) es la catálisis heterogénea ordinaria que tiene lugar sobre la superficie del sólido (campo de reacción bidimensional en la superficie exterior). Pero además de esta forma, Misono y col ${ }^{124}$ demostraron que los HPAs en muchos aspectos se comportan como soluciones. Esto debido al hecho de que estos sólidos tienen estructuras iónicas móviles. Los HPAs sólidos absorben una gran cantidad de moléculas polares, por ejemplo, alcoholes, éteres, aminas, etc., en el enrejado sólido (entre los polianiones, expandiendo a veces el enrejado), formando HPAs solvatados.

Sumado a esto, los HPAs sólidos poseen una movilidad de protones extremadamente alta, por lo que las moléculas polares sufren reacciones catalíticas no sólo en la superficie, sino también en la mayor parte de la red cristalina, haciendo que la reacción no se dé solamente en los protones superficiales. Este fenómeno, inusual para la catálisis ácida heterogénea, se denominó "fase pseudo-líquida". 


\section{Capítulo II. Introducción.}

A diferencia de las moléculas polares, los reactivos no polares (por ejemplo, los hidrocarburos) son incapaces de ser absorbido por el HPA, ellos solo interactúan con la superficie del catalizador. En la Figura 14.b se representa la catálisis de tipo pseudolíquido, donde los campos de reacción son tridimensionales en contraste con la catálisis de tipo superficial.

En otras palabras, el campo de reacción se convierte en tridimensional de igual forma a como ocurre en las reacciones en solución. En la fase pseudo-líquida aparecen los catalizadores como sólidos pero se comportan como líquidos (disolvente). Debido a este comportamiento, los catalizadores de POMs suelen exhibir actividades y selectividades únicas.

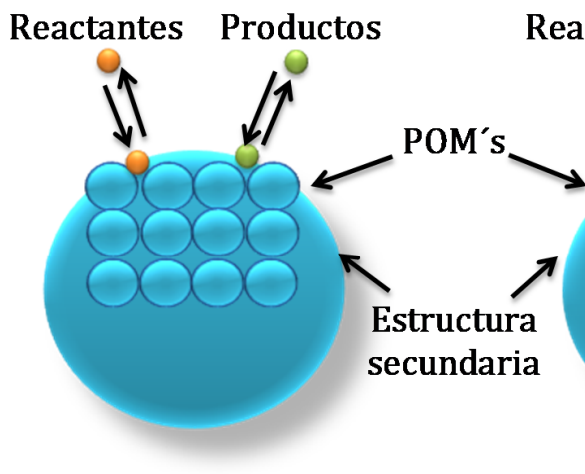

a)
Reactantes Productos

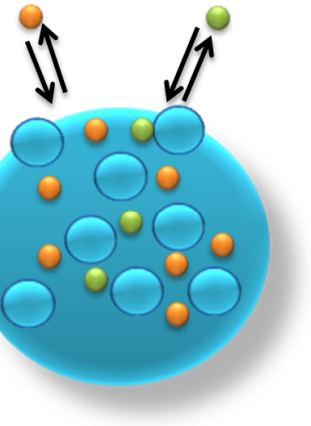

b)

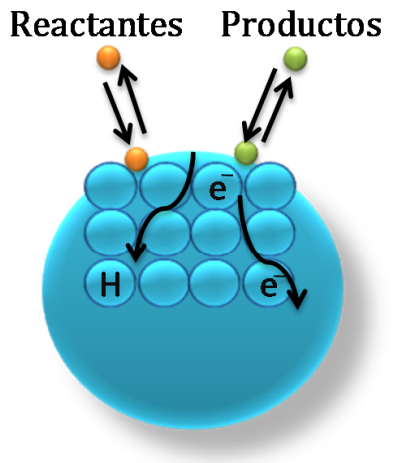

c)

Figura 14. Tres tipos de catálisis para POMs sólidos: a) superficial; b) Bulk tipo I pseudo-líquido; c) Bulk tipo II. (Imagen adaptada de Guixian Li et al124).

\subsubsection{Catálisis heterogénea por heteropoliácidos.}

Como ya se ha mencionado anteriormente, las ventajas que ofrecen los HPAs como su baja volatilidad, baja corrosividad, alta acidez, alta actividad, flexibilidad y estabilidad térmica, los hace atractivos catalizadores usados en diversas reacciones en fase líquida homogénea123,125,126. Por ejemplo, HPAs sólidos tales como $\mathrm{H}_{3} \mathrm{PW}_{12} \mathrm{O}_{40}$ y $\mathrm{H}_{4 \mathrm{si}} \mathrm{W}_{12} \mathrm{O}_{40}$ sin soporte, muestran una actividad muy alta para reacciones de deshidratación de alcoholes a pesar de su pequeña área superficial (Usualmente 1-5 $\mathrm{m}^{2} / \mathrm{g}$ ), debido a que estas reacciones ocurren a través de la catálisis bulk tipo I 


\section{Capítulo II. Introducción.}

(pseudo-líquido) donde todos los protones (tanto los de la superficie, como los internos) pueden tomar parte en la catálisis ácida, haciendo que el área superficial sea un factor menor.

Sin embargo, el rendimiento no es igual para todas la reacciones, sobre todo las que ocurren de forma superficial afectadas por sus bajas áreas. En estos casos, se ve la necesidad de ampliar el área superficial de los HPAs sólidos, utilizando soportes, obteniendo catalizadores activos para una mayor cantidad de aplicaciones y facilitando su separación del medio de reacción, permitiendo su reutilización, donde la acidez y la actividad catalítica va a depender del tipo de soporte, la carga efectiva de fase activa, las condiciones de pretratamiento, etc ${ }^{127}$.

Intentando mejorar la eficiencia y estabilidad de los HPAs se han soportado sobre diferentes materiales, preferiblemente ácidos o neutros, siendo el óxido de silicio $\left(\mathrm{SiO}_{2}\right)$ uno de los más usados ${ }^{90,128-132}$. Entre otros materiales comunes se encuentran: óxido de zirconia $\left(\mathrm{ZrO}_{2}\right)^{133-137}$, óxido de titanio $\left(\mathrm{TiO}_{2}\right)^{138-141}$, carbón activado ${ }^{142}$, SBA$15^{143}$, etc. Logrando áreas superficiales mayores, volumen y diámetro de poro más grandes y mejorando la adsorción, aunque su actividad catalítica a menudo es inferior a la de los catalizadores sólidos bulk, lo que indica una menor acidez en comparación con los catalizadores estándar de los HPAs. Sin embargo, esto es compensado por una mejor estabilidad de rendimiento y facilidad de reutilización de los catalizadores.

Las propiedades catalíticas dependen en gran medida del tipo de soporte, área superficial, tamaño y forma de partícula y de poro y estas características se pueden controlar manipulando las condiciones de síntesis, donde el precursor, tipo de agente surfactante utilizado, método de impregnación, y temperatura de calcinación juegan un papel importante.

Aunque son diversas las formas de síntesis, se pueden clasificar principalmente en dos tipos: 1) Precipitación y 2) Sol-gel. Así mismo, la fase activa suele agregarse bien sea por impregnación ${ }^{144}$, proceso que se lleva a cabo en dos etapas, o incluidos durante la síntesis del soporte ${ }^{145}$, método de una sola etapa, seguido de calcinación a 


\section{Capítulo II. Introducción.}

temperaturas menores o cercanas a $\operatorname{los} 500{ }^{\circ} \mathrm{C}$, es decir, temperaturas menores a la temperatura de descomposición del HPA correspondiente. Estos materiales así sintetizados, han presentado actividad en un amplio rango de reacciones catalizadas con ácido, a menudo con un buen reciclaje del catalizador sin pérdida significativa de actividad en varios ciclos.

\section{- $\quad$ Método de precipitación.}

Como punto de partida para generar el soporte se utiliza un precursor del metal, el cual generalmente es una sal inorgánica, sobre el cual se deposita la fase activa del catalizador. En esta técnica, el crecimiento de partículas del metal es inducido por la sobresaturación de la solución precursora, la precipitación puede ser iniciada por un cambio físico en las condiciones tales como la temperatura, el pH o la evaporación, aunque lo más frecuente es que se dé por cambios químicos, bien sea por la adición de sustancias básicas o ácidas, o la utilización de agentes formadores de complejos; cualquiera sea el método utilizado, da inicio a dos procesos elementales que ocurren simultánea o secuencialmente: (1) nucleación, es decir, formación de partículas elementales más pequeñas de la nueva fase que son estables bajo las condiciones de precipitación; y (2) crecimiento o aglomeración de dichas partículas.

Una nucleación inicial de pequeños cristales que empiezan a crecer sin la formación de nuevos núcleos puede generar partículas pequeñas y bastante monodispersas. Este concepto es conocido como "nucleación explosiva" y no sólo es importante para la precipitación sino también clave en la generación de coloides ya que desempeña un papel en la síntesis de catalizadores por impregnación. La síntesis del soporte puede suceder al tiempo que se agrega la fase activa del catalizador, en un procedimiento conocido como coprecipitación, donde las sales del metal y la fase activa se disuelven y mezclan juntos, de modo que la nucleación y el crecimiento del sólido se combina con la fase activa en una sola etapa. Durante la coprecipitación, se debe tener mucho cuidado para evitar las fluctuaciones locales en las condiciones usadas, como gradientes de temperatura, de concentración o mezcla insuficiente, que pueden causar 
Capítulo II. Introducción.

eventos de nucleación adicionales, patrones de crecimiento diferentes o no homogéneos, o diferentes fases Laplace ${ }^{146}$.

Otro método para soportar la fase activa es por impregnación donde el soporte, luego de ser sintetizado y secado, se pone en contacto con una solución que contiene la fase activa y por atracción de cargas se consigue la adsorción de las moléculas precursoras sobre grupos superficiales del soporte (adsorción de iones) o a través del intercambio de iones, después de lo cual el precursor en exceso es removido. Cuando se requieren cargas mayores, se elimina el paso del lavado y el soporte se seca directamente, de modo que el precursor termina en el soporte impregnado y seco.

Se distinguen dos métodos principales de impregnación, a saber, impregnación en húmedo (IH), que se da en una cantidad de solución en exceso y la impregnación de volumen de poros (PVI), en la que se utiliza una cantidad de solución justa para llenar solo el volumen de poro del soporte, éste último método también se conoce como impregnación de humedad incipiente (IHI) o impregnación en seco (IS), debido a que el material a ser impregnado, mantiene un carácter seco a una escala macroscópica. La absorción del líquido en los poros del soporte se produce debido a un diferencial de presión capilar $\Delta p$ a través de un menisco en un poro con radio $r_{p}$ según la ecuación de Young-Laplace ${ }^{147}$.

$$
\Delta_{p}=\left(2 \gamma_{l v} / r_{p}\right) \cos \theta
$$

Donde $\gamma_{V}$ es la tensión superficial entre el líquido y el vapor y $\theta$ es el ángulo de humectación entre el sólido y el líquido. Sí $\theta<90^{\circ}$, el líquido se considera como humectante y penetra espontáneamente en el soporte, como es el caso del agua en combinación con la mayoría de los soportes oxídicos. Sí el líquido es no humectante $\left(\theta>90^{\circ}\right)$, la presión capilar se vuelve negativa y una presión externa es necesaria para forzar la entrada del líquido en el poro. Esto puede ocurrir para soportes hidrófobos tales como carbono, para los cuales un disolvente menos polar tal como etanol o 2Propanol puede ser más apropiado, aunque esto sucede a expensas de una menor solubilidad del precursor. 


\section{Capítulo II. Introducción.}

De la ecuación 1 es claro que la diferencia de presión es inversamente proporcional al tamaño del poro, de modo que el líquido es succionado preferentemente por los poros más pequeños. La velocidad a la que el líquido llena los poros es generalmente rápida y no se considera a menudo un parámetro crítico para la síntesis del catalizador.

La precipitación es seguida a menudo por un período de envejecimiento, que se refiere al periodo de tiempo durante el cual se deja el precipitado en su líquido madre ya sea bajo las mismas o diferentes condiciones a las que se hizo la precipitación. El precipitado formado inicialmente es a menudo amorfo, y durante el envejecimiento en su líquido madre sufre una conversión a una fase cristalina. Éste proceso se realiza generalmente después de que se completa la precipitación, con agitación del precipitado durante un tiempo en el mismo recipiente de reacción.

Durante este tiempo, ocurren diferentes procesos que pueden llegar a afectar fuertemente las propiedades del material final como la morfología y el tamaño de las partículas que cambian como resultado de la maduración de Ostwald (fenómeno que describe el cambio de una partícula homogénea en el tiempo, la solubilidad aumenta con el tamaño de partícula decreciente, es decir, luego de un periodo, pequeñas partículas comienzan a disolverse y cristales grandes siguen creciendo $^{148}$ ), recristalización no isotérmica, aglomeración o coagulación.

Además, el más importante proceso -con respecto al desempeño del catalizadorque puede ocurrir durante el envejecimiento es la recristalización acompañada por un cambio en la composición química de la fase sólida. Para evitar estos problemas, nuevamente es importante controlar las condiciones de temperatura, $\mathrm{pH}$ y concentraciones ${ }^{149}$. 


\section{Capítulo II. Introducción.}

- $\quad$ Método Sol-Gel.

La técnica Sol-Gel es un tipo de procedimiento para sintetizar materiales sólidos, generalmente inorgánicos como óxidos e hidróxidos a bajas temperaturas (típicamente $\mathrm{T}<100^{\circ} \mathrm{C}$ ) y con la posibilidad de controlar el tamaño, la morfología y la composición de las partículas resultantes. Se forman partiendo de solutos químicos denominados precursores, los cuales se polimerizan estableciendo puentes $\mathrm{M}-\mathrm{OH}-\mathrm{M}$ o $\mathrm{M}-\mathrm{O}-\mathrm{M}$ entre los átomos metálicos M de las moléculas precursoras.

En una primera etapa del proceso, se forman partículas sólidas coloidales independientes (nanopartículas), las cuales, cada una tiene una mayor o menor densidad de reticulación, es decir, una estructura interna diferente. Normalmente dichas partículas se mantienen dispersas en el disolvente, formando una suspensión coloidal denominada sol (Figura 15.a). En una segunda etapa, estas partículas coloidales pueden vincularse entre sí, mientras están todavía en el disolvente, para construir una rejilla abierta tridimensional, denominado gel (Figura 15.b). La transformación de un sol a un gel constituye un proceso de gelificación, y los geles que se obtienen se denominan entonces geles coloidales ${ }^{150}$.

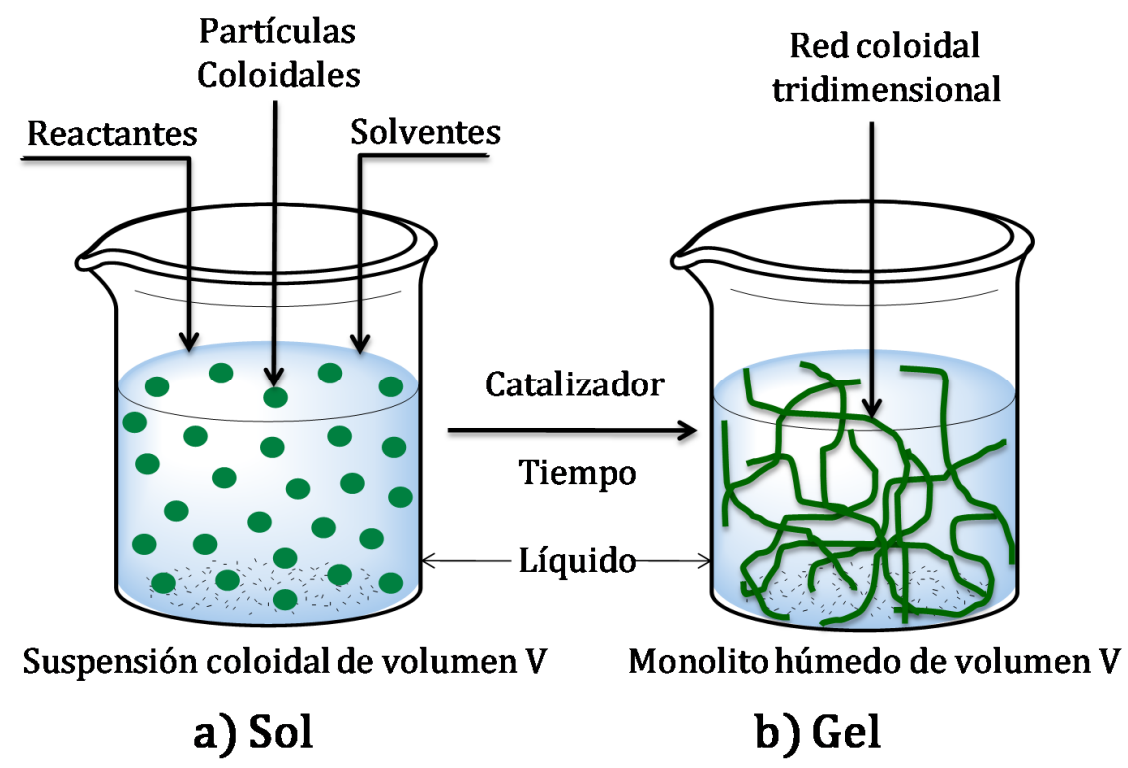

Figura 15. Esquema del proceso sol-gel: (a) sol; (b) gel. 


\section{Capítulo II. Introducción.}

Como fundador de la ciencia coloidal se considera a Thomas Graham ${ }^{151}$, quien estudió las propiedades del ácido silícico y otras sustancias análogas como los ácidos titánico, túngstico y molíbdico y observó que a medida que aumentaba la concentración de ácido silícico disuelto en agua disminuía su solubilidad y en lugar se formaba una sustancia "gomosa" blanca que denominó jalea, determinando que era soluble en proporción a su grado de hidratación y que cuando la jalea se hacía anhidra, resultaba ser absolutamente insoluble y que este comportamiento se repetía con los otros ácidos estudiados.

Posteriormente, diferentes campos de la Química han contribuido al desarrollo y conocimiento del proceso sol-gel, donde se destacan las contribuciones de la fisicoquímica mediante los principios de la estabilización cinética de un sol por interacciones electrostáticas hechas por Derjaguin, Landau, Verwey y Overbeek de acuerdo a la teoría actualmente conocida como la D. L. V. O. la cual dice que las partículas dispersas están sujetas a dos tipos de fuerzas de largo alcance, que influyen en el hecho de que dos partículas que se acercan bajo la acción del movimiento browniano, lleguen a tocarse y permanecer en contacto o no y estas fuerzas son: fuerzas de atracción de London y Van der Waals y fuerzas de repulsión electrostática, producidas por el solapamiento de las dobles capas eléctricas de las interfases que se acercan, en otras palabras, la curva que representa la energía total de interacción entre partículas coloidales, es la suma de las curvas de atracción y repulsión en función de la distancia entre las partículas cargadas ${ }^{152,153 .}$

Por su parte, el fenómeno de la gelificación, se estudió estadísticamente de manera independiente para geles orgánicos por Flory ${ }^{154}$ y Stockmayer ${ }^{155}$. Ellos denominaron cadenas a las moléculas poliméricas de diversos tamaños que inicialmente existen en el sistema las cuales, no tienen que ser necesariamente lineales. En el caso más simple, cada unidad de monómero en una cadena lleva un grupo funcional que puede reaccionar químicamente con otras cadenas de su tipo, con o sin la ayuda de un agregado. Todos los grupos funcionales se supone que son similares y de 
Capítulo II. Introducción.

una misma reactividad, y el término molécula lo reservaron para el agregado que existe después de la unión de varias cadenas.

La teoría de estas reacciones, desarrollada por los autores ya mencionados, permitió predecir el punto de gel para varias policondensaciones estudiadas, estableciendo que cuando la ramificación de las partículas es suficientemente frecuente, las cadenas se vinculan mediante reacciones de polimerización o policondensación, donde las moléculas más grandes tienen una mayor capacidad de crecimiento (debido a su mayor número de grupos terminales que no han reaccionado) conduciendo a la formación de unas estructuras de red con una velocidad tal, que el material cambia de manera bastante rápida de un líquido a un gel.

Los geles secados por simple evaporación del líquido que interpenetra su armazón siempre sufren un encogimiento de los poros que conlleva a una irreversible reducción de su superficie y se los denomina xerogeles. El colapso de la estructura de poros es causado por fuerzas mecánicas debido a la disminución del menisco de agua en los poros. Puede evitarse reemplazando el agua con otro líquido con menor tensión superficial antes de ser secados o por eliminación del vapor de agua a una temperatura superior a su punto crítico generando así los aerogeles, los cuales ciertamente son sorprendentes, ya que éstos retienen, en estado seco, el tipo de red muy abierto, similar al que tenían en el estado húmedo ${ }^{150}$.

Posteriormente la gelación se estudió mediante la teoría de percolación introducidas por Hammersely ${ }^{156}$, así como por el método de simulación de Monte Carlo. Estos nuevos métodos mostraron que el fenómeno de gelificación podría ser descrito como un fenómeno crítico en la termodinámica y también introdujeron el uso de la dimensión fractal para describir la estructura de red del gel, particularmente para los aerogeles. 


\section{Capítulo II. Introducción.}

En el proceso para formar partículas de sol y geles se parte inicialmente de precursores que suelen ser sales metálicas de la forma $\mathrm{M}_{\mathrm{m}} \mathrm{X}_{\mathrm{n}}$ (donde $\mathrm{M}$ es el metal y X el anión) o alcóxidos $\mathrm{M}(\mathrm{OR})_{\mathrm{n}}$ que últimamente son ampliamente utilizados. Estos productos químicos son compuestos formados por la combinación de un metal M con un grupo alcóxido OR, donde $\mathrm{R}$ designa un grupo alquilo. Se caracterizan por la existencia de enlaces covalentes polares M-O en sus moléculas. En la práctica, suelen estar disponibles como complejos polimerizados más o menos pequeños y a menudo se encuentran en una solución con su alcohol de origen.

Su transformación se hace en un disolvente orgánico, generalmente un alcohol y en algunos casos se agrega agua para que controle la reactividad de los alcóxidos. Las reacciones del proceso sol-gel que se dan con estos precursores involucran hidrólisis (ecuación 2), que conducen a la sustitución de ligandos OR por $\mathrm{OH}$, seguido de reacciones de condensación o alcoxilación (ecuación 3), similares a las que se producen con sales metálicas que conducen a la construcción de puentes $\mathrm{M}-\mathrm{OH}-\mathrm{M}$ o puentes M-O-M con eliminación del alcohol correspondiente ${ }^{157}$.

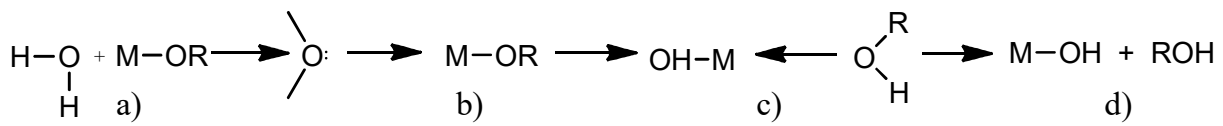

Hidrólisis

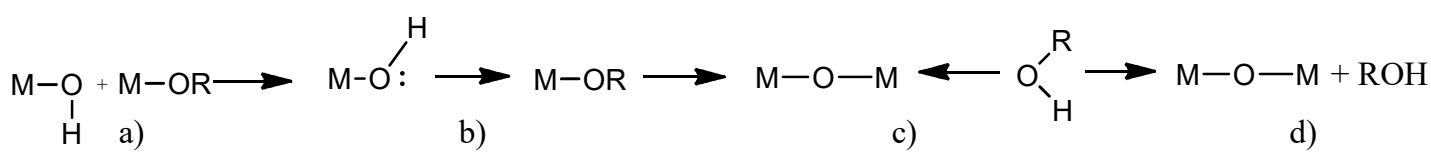

Alcoxolación

\subsubsection{Heteropoliácidos soportados sobre óxido de zirconia.}

Históricamente el zirconio ha sido conocido como una joya de la antigüedad. El nombre del metal, zirconium, viene del árabe Zargón (de color dorado) que a su vez proviene de dos palabras persas Zar (oro) y Gun (color). Por su parte, la zirconia, es el dióxido metálico $\left(\mathrm{ZrO}_{2}\right)$, identificado por primera vez en 1789 por el químico alemán Martin Heinrich Klaproth, siendo el producto de reacción obtenido después de calentar 


\section{Capítulo II. Introducción.}

gemas. Durante mucho tiempo se utilizó mezclado con óxidos de tierras raras como pigmento para cerámica. Gracias a su resistencia al desgaste, se utiliza para fabricar piezas que funcionan en ambientes agresivos, como tintes de extrusión, válvulas portantes para motores de combustión, revestimientos refractarios resistentes a los golpes o fundiciones, entre otros ${ }^{158}$.

Dependiendo de la presión y la temperatura, la zirconia tiene tres conformaciones estructurales (Figura 16): a presión y temperatura ambiente, el $\mathrm{ZrO}_{2}$ existe como un polvo blanco en su fase monoclínica, a temperaturas alrededor de 1170 ${ }^{\circ} \mathrm{C}$, se transforma a su forma tetragonal acompañada por un aumento de la densidad de alrededor del $4-5 \%$, y finalmente se transforma a la estructura cúbica a $2370{ }^{\circ} \mathrm{C}$, hasta cerca de su punto de fusión el cual es de $2710^{\circ} \mathrm{C}^{159}$. Si bien las simetrías del cristal se modifican, su estado de coordinación permanece inalterado. Todas estas trasformaciones son displacivas (sin difusión atómica) y reversibles.

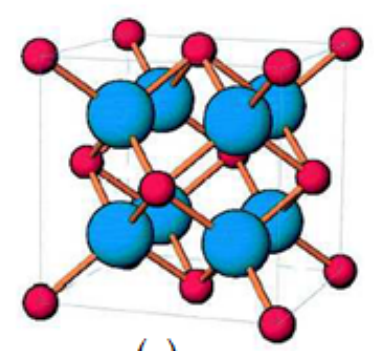

(a)

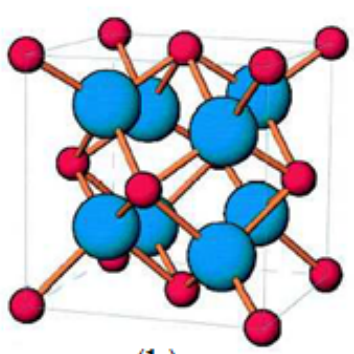

(b)

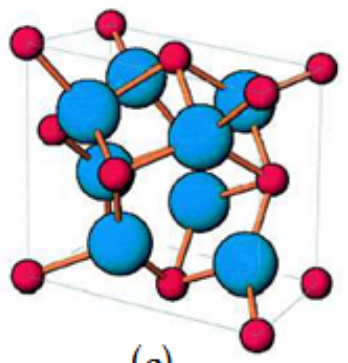

(c)

Figura 16. Conformaciones estructurales del óxido de zirconia. a) Cúbica, b) Tetragonal y c) Monoclínica (Imagen tomada de la página web de la universidad Tuebingen ${ }^{160}$ ).

El óxido de zirconio (zirconia) es un material interesante para ser utilizado como soporte de catalizador debido a propiedades útiles entre las que se destacan su alto punto de fusión, baja conductividad térmica y alta resistencia a la corrosión, además, químicamente, la zirconia es un soporte anfótero similar a la alúmina con capacidades oxidantes y reductoras, y un pH que puede ser modificado por la adición de sustancias catiónicas o aniónicas; por último, es económicamente factible, ampliamente producido y fácil de sintetizar en el laboratorio ${ }^{161 .}$ 
Capítulo II. Introducción.

En particular, se ha estudiado el zirconio sulfatado (SZ), que fue el primero preparado como catalizador heterogéneo, y que fue explorado en la isomerización y alquilación de hidrocarburos en 1962162, sin embargo, estos catalizadores se desactivan rápidamente a altas temperaturas y sí hay agua en el medio de reacción, forma ácido sulfúrico, contaminando los desechos generados.

Otro ion bastante estudiado y prometedor es el tungstato $\left(\mathrm{WO}_{3} / \mathrm{ZrO}_{2}\right)^{163}$, obteniendo materiales con alta acidez utilizados por ejemplo en la producción de biodiesel a partir de ácidos grasos de algas, mostrando una conversión de biodiesel comparable al catalizador homogéneo convencional y una conversión más alta que catalizadores enzimáticos, e incluso presentan mejores rendimientos que los catalizadores SZ en la alquilación de fenoles ${ }^{164}$.

Recientemente se ha estudiado la introducción de HPAs en la matriz de la zirconia, obteniéndose un excelente catalizador con una amplia gama de aplicaciones, donde se destaca su uso en fotocatálisis gracias a que el $\mathrm{ZrO}_{2}$ es un óxido semiconductor de tipo $n$ el cual se ha probado con éxito en la realización de reacciones fotocatalíticas, aunque con una actividad por unidad de superficie mucho menor que la que muestra el óxido de titanio, pero que se mejora con la impregnación de heteropoliácidos tipo Keggin en su superficie ${ }^{137}$.

La actividad de estos catalizadores se estudió en reacciones de degradación de 4nitrofenol (4-NP) acuoso y el colorante azul de metileno (MB) en condiciones aerobias, encontrando que la actividad fotocatalítica de los compuestos fue influenciado por factores tales como estructuras de fase, propiedades de absorción óptica y propiedades fisicoquímicas de la superficie de los compuestos ${ }^{137}$. También se usó como fotocatalizador heterogéneo eficiente para la oxidación aeróbica de alcoholes bencílicos primarios y secundarios a los aldehídos y cetonas correspondientes con altos rendimientos bajo atmósfera de $\mathrm{O}_{2}{ }^{165}$. 
Capítulo II. Introducción.

Así mismo, han presentado aplicaciones en otras reacciones de química fina como reacciones de sustitución aromática electrofílica de indoles con aldehídos para proporcionar los correspondientes bis o tris (indol) metanos con buenos y altos rendimientos, encontrando que la eficacia catalítica del TPA aumentaba después de ser soportado sobre zirconia, y se determinó que era reutilizable sin pérdida significativa de actividad 135 .

Otra aplicación, ha sido en reacciones de esterificación como es el caso de la síntesis de bioadicionantes para biocombustibles a partir de la esterificación de glicerol con ácido acético, trabajo en el cual, sobre la zirconia se soportaron diferentes HPA como $\mathrm{H}_{4} \mathrm{SiW}_{12} \mathrm{O}_{40}, \mathrm{H}_{3} \mathrm{PW}_{12} \mathrm{O}_{40}$ y $\mathrm{H}_{3} \mathrm{PMo}_{12}-\mathrm{O}_{40}$ como compuestos activos. Entre estos catalizadores probados, $\mathrm{H}_{4} \mathrm{SiW}_{12} \mathrm{O}_{40} / \mathrm{ZrO}_{2}$ alcanzó el mejor rendimiento catalítico y presentó actividad consistente durante cuatro reacciones consecutivas ${ }^{166}$.

En nuestro grupo de investigación se han realizado algunos estudios previos sobre este tipo de catalizadores en reacciones multicomponente para sintetizar 14-aril$14 H$-dibenzo[a,j]xantenos ${ }^{134}$ y derivados de quinoxalinas ${ }^{167}$, y por ese motivo continuamos explorando su campo de acción para demostrar su versatilidad.

En el presente trabajo de Tesis Doctoral se evaluó su actividad en reacciones de esterificación del ácido 2-furoico con diferentes alcoholes para valorización de derivados obtenidos de biomasa. Como es conocido, la esterificación del grupo carboxilo es relativamente lenta y necesita la activación ya sea por temperatura, por la presencia de un grupo activante o por un catalizador para lograr la conversión de equilibrio en un tiempo razonable. 


\section{Capítulo II. Introducción.}

\subsubsection{Heteropoliácidos soportados sobre óxido de titanio.}

Durante varias décadas, el dióxido de titanio o titania, $\mathrm{TiO}_{2}$, ha sido ampliamente estudiado por sus interesantes propiedades eléctricas, magnéticas, catalíticas y electroquímicas. Sobre la base de estas propiedades, una amplia gama de aplicaciones se han desarrollado donde su aplicación principal es como pigmento blanco en la producción de pinturas, tintas, colorantes de alimentos, cosméticos, pastas dentífricas, polímeros y otros casos en los que la coloración blanca sea deseada ${ }^{168}$, y en el campo de la catálisis, se destacan sus usos como filtro, adsorbente y soporte de catalizadores.

Desde 1971, cuando Fujishima y Honda reportaron una célula fotoelectroquímica que poseía un ánodo de $\mathrm{TiO}_{2}$ como fotoelectrodo, con la cual transformaron la luz en energía química, el óxido de titanio se convirtió en el material más estudiado dentro de la fotocatálisis, manteniendo una posición dominante, donde es considerado como el fotocatalizador más prometedor dentro de la Química Verde ${ }^{169}$.

El óxido de titanio existe en tres fases cristalinas principales denominadas brokita (ortorrómbico) anatasa y rutilo (tetragonales), sus estructuras se construyen sobre la conexión de octaedros de $\mathrm{TiO}_{6}$, los cuales en la anatasa se unen compartiendo los bordes, y en el rutilo y la brokita tienen una configuración en la que comparten tantos las esquinas como los bordes (Figura 17).

La anatasa y el rutilio son los que desempeñan un papel importante en las aplicaciones industriales, ya que los datos experimentales sobre $\mathrm{TiO}_{2}$ brokita son limitados debido a su rareza y difícil preparación por su metaestabilidad ${ }^{170}$. Por su parte, la anatasa se transforma irreversiblemente en rutilo a temperaturas elevadas. Esta transformación no tiene una temperatura única y los procesos que están implicados en la transformación así como los métodos para inhibir o promover esta transformación no se conocen concretamente hasta la fecha ${ }^{171}$. 


\section{Capítulo II. Introducción.}

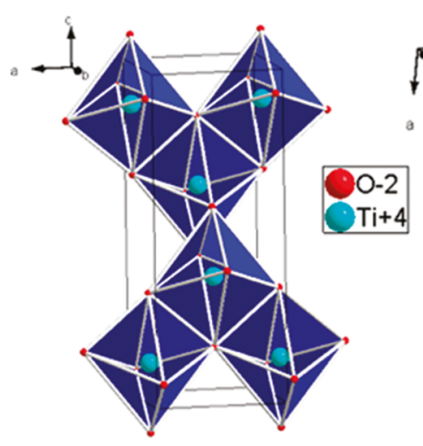

a) Anatasa

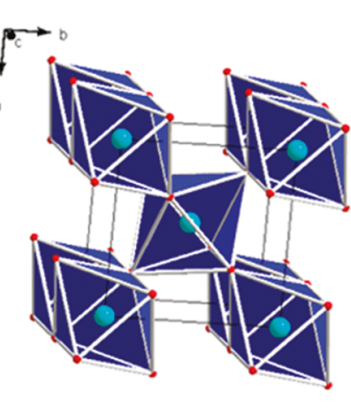

b) Rutilo

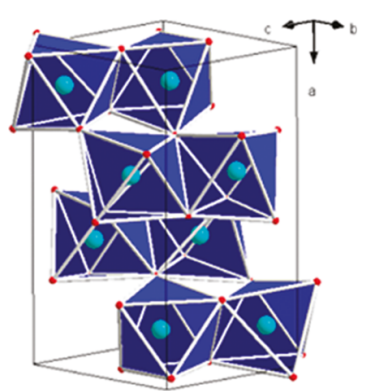

c) Broquita

Figura 17. Representación de las estructuras cristalinas del $\mathrm{TiO}_{2}$ a) anatasa, b) rutilo y c) brokita. (Imagen tomada de Damien Dambournet et.al ${ }^{170}$ ).

Aunque el rutilo es la fase más estable desde un punto de vista termodinámico y generalmente se encuentra en mayor cantidad, los métodos de preparación en fase de solución favorecen la estructura anatasa por dos efectos cinéticos principales: la energía superficial y la química de los precursores, ya que cuando las dimensiones de las partículas son muy pequeñas, la energía superficial es una parte importante de la energía total y se ha encontrado que la energía superficial de la anatasa es inferior a las de rutilo y brookita.

Las propiedades de los materiales de las nanopartículas de $\mathrm{TiO}_{2}$ dependen de la estructura cristalina, el tamaño de las nanopartículas y la morfología, y son fuertemente dependientes del método de síntesis ${ }^{172}$. Así mismo, las aplicaciones dependen también de su estructura cristalina, por ejemplo, mientras que la fase rutilo, debido a su alta constante dieléctrica y alta resistencia eléctrica, es útil en las industrias electrónicas como componente de condensadores, filtros, circuitos de potencia, etc. La fase anatasa se utiliza en fotocatálisis, células solares sensibilizadas por tinte, etc ${ }^{173}$.

El proceso sol-gel se ha convertido en una de las técnicas más exitosas utilizadas para la preparación de materiales de óxido de titanio nanocristalinos, gracias a la posibilidad que brinda de controlar el tamaño y la homogeneidad del material resultante, aunque comprender el mecanismo de formación de las nanopartículas se ha 


\section{Capítulo II. Introducción.}

complicado debido a la multitud de condiciones experimentales reportadas, lo que ha dificultado la comparación de los mecanismos. Dentro de los muchos sistemas de síntesis reportados se destacan el uso de alcóxidos como precursores; partículas en fase anatasa pura con diámetros entre 6 y $30 \mathrm{~nm}$ generalmente se consiguen preparándolas a partir de isopropóxido de titanio (IV) y ácidos débiles como el ácido acético o ácidos más fuertes, muy diluidos ${ }^{174}$.

Muchos estudios han sido dirigidos a preparar titania en polvo con mayor textura y estabilidad estructural y determinar cómo factores como la temperatura y tiempo de calcinación y la concentración del ácido afectan dicha estructura. Por ejemplo, N. Phonthammachai y $\operatorname{col}^{175}$, prepararon dióxido de titanio mesoporoso mediante la técnica sol-gel empleando glicolato de titanio como precursor en solución de $\mathrm{HCl} 1 \mathrm{M}$ a varias relaciones $\mathrm{HCl}: \mathrm{H}_{2} \mathrm{O}$. El análisis DRX indicó que la fase anatasa predomina a temperaturas de calcinación en el rango de $600-800{ }^{\circ} \mathrm{C}$ (sin embargo, las temperaturas de transición reportadas varían en la gama de 400-1200 ${ }^{\circ} \mathrm{C}$, esto debido al uso de diferentes métodos de determinación de las temperaturas de transición, las materias primas y los métodos de síntesis y tratamiento de los materiales $\left.{ }^{171}\right)$.

De igual forma, dedujeron a partir de los tamaños de los granos, que la tasa de nucleación domina la cinética a menor temperatura, y la tasa de crecimiento se convierte en el factor dominante a temperaturas más altas para materiales preparados a relaciones $\mathrm{HCl}: \mathrm{H}_{2} \mathrm{O}$ de 0,28 y 0,33. A volúmenes más altos, la tasa de crecimiento parece ser el factor dominante a todas las temperaturas.

A pesar de que el $\mathrm{TiO}_{2}$ ha sido ampliamente utilizado en el área de la fotocatálisis, en años recientes, ha tomado fuerza doparlo con diferentes elementos para mejorar su capacidad fotoquímica, reduciendo así la banda del $\mathrm{TiO}_{2}$ y extendiendo el rango de absorción de longitud de onda a la región visible, permitiendo de esta manera que sea utilizado con la luz solar. Los polioxometalatos tales como $\mathrm{H}_{3} \mathrm{PW}_{12} \mathrm{O}_{40}$ (TPA) y $\mathrm{H}_{4} \mathrm{SiW}_{12} \mathrm{O}_{40}$ (TSA) resultaron ser grandes fotocatalizadores con actividad en la degradación de colorantes, plaguicidas y otros contaminantes orgánicos debido a su estructura de electrones $\mathrm{d}^{0}$ similar a la del $\mathrm{TiO}_{2}$, de esta forma, materiales con estos dos 
Capítulo II. Introducción.

compuestos combinados presentan significativas mejoras en sus propiedades fotocatalíticas, siendo este el inicio de una nueva línea de investigación en el desarrollo de nuevos materiales ${ }^{176,177}$.

Sin embargo, aunque uno de los principales usos de materiales de $\mathrm{TiO}_{2} / \mathrm{POM}$ ha sido en el área de la fotoquímica, debido a sus propiedades ácidas, se han utilizado también en reacciones que implican procesos catalizados por ácidos como es el caso de las esterificaciones, transesterificaciones ${ }^{178}$ y deshidratación de alcoholes ${ }^{141}$. El rendimiento superior de los materiales conformados por $\mathrm{TiO}_{2} / \mathrm{POM}$ en este tipo de reacciones se explica en términos de una dispersión mayor del POM sobre la superficie del $\mathrm{TiO}_{2}$, proporcionando un mayor número de protones disponibles y mejor distribuidos para participar en las reacciones junto con una mejor accesibilidad de las moléculas reactivas a los protones de la fase activa. Debido a que, en nuestro grupo de trabajo estos materiales han sido bastante estudiados en fotocatálisis, se quiso indagar en un nuevo campo de aplicación: reacciones de esterificación de ácidos derivados de biomasa.

\subsubsection{Catalizadores magnéticos.}

\subsubsection{Propiedades magnéticas de las nanopartículas.}

Los materiales con propiedades magnéticas se encuentran entre los que tienen aplicaciones tecnológicas más interesantes desde tiempos muy remotos. Se destacan sus aplicaciones en los campos de la biomedicina ${ }^{179,180,}$ biotecnología181,182, ingeniería ${ }^{183}$, ciencia de $\operatorname{los}$ materiales ${ }^{184}$, catálisis ${ }^{185}$ y medio ambiente ${ }^{186}$. En la mayoría de los casos, estas partículas magnéticas deben ser encapsuladas con un polímero orgánico/inorgánico o estabilizarlas con un tensioactivo, para protegerlas de posibles oxidaciones, descomposición por el ambiente o por sustancias como los ácidos. En muchos casos, este recubrimiento también se utiliza para funcionalizarlas, por ejemplo, como puntos de anclaje con otras nanopartículas o diversos ligandos, dependiendo de la aplicación deseada, siendo una de las más destacadas su uso como soportes para catalizadores. 


\section{Capítulo II. Introducción.}

Todos los materiales se clasifican por su respuesta a un campo magnético aplicado, siendo cinco los tipos básicos existentes los cuales son: diamagnetismo, paramagnetismo, ferromagnetismo, antiferromagnetismo y ferrimagnetismo (Figura 18) ${ }^{187}$.
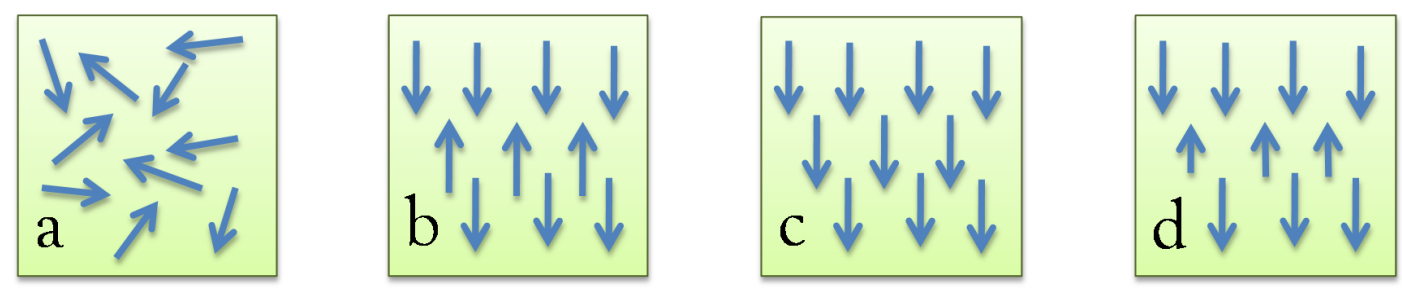

Figura 18. Diferentes tipos de comportamiento magnético. a) Paramagnetismo, b) Antiferromagnetismo, c) Ferromagnetismo y d) Ferrimagnetismo (Imagen adaptada de Daliya S. Mathew et. $\mathrm{al}^{187}$ ).

En presencia de un campo magnético aplicado externamente, la corriente atómica forma bucles creados por el movimiento orbital de los electrones que se oponen al campo aplicado, este tipo de repulsión a un campo magnético se denomina diamagnetismo y ocurre en todos los materiales, sin embargo, el diamagnetismo es muy débil y por lo tanto cualquier otra forma de comportamiento magnético que un material pueda poseer suele dominar prevaleciendo sobre los efectos de los bucles de corriente.

En términos de la configuración electrónica, el diamagnetismo se observa en materiales con subcapas electrónicas llenas donde los momentos magnéticos se cancelan mutuamente. Este tipo de materiales tienen una susceptibilidad negativa $(\chi<0)$ y repelen débilmente un campo magnético. Ejemplos de ello son el cuarzo $\mathrm{SiO}_{2}$ y la calcita $\mathrm{CaCO}_{3}$.

Sin embargo, si el material presenta un momento magnético neto o tiene un orden magnético de largo alcance (decimos que hay orden magnético si todos los espines apuntan en la misma dirección), los efectos de estos bucles de corriente atómica son superados, esto es atribuido, al menos parcialmente, a electrones no 


\section{Capítulo II. Introducción.}

apareados en las capas atómicas, generalmente en las capas 3d o 4f de cada átomo. Así, materiales cuya estructura atómica esta desacoplada, es decir que no tienen un orden de largo alcance y hay una pequeña susceptibilidad magnética positiva $(\chi \approx 0)$ se denominan paramagnéticos (Figura 18.a). Algunos ejemplos son la montmorillonita y la pirita.

Los materiales clasificados como ferromagnéticos, han alineado los momentos atómicos magnéticos de igual magnitud y su estructura cristalina permite el acoplamiento directo entre los momentos, mejorando la densidad de flujo (Fligura 18.c), esto ocurre con los elementos Fe, Ni y Co. Además, ésta alineación puede conferir una espontánea magnetización en ausencia de un campo magnético aplicado.

Materiales que retienen la magnetización permanente en ausencia de un campo aplicado se conocen como imanes duros. Materiales que tienen momentos magnéticos atómicos de igual magnitud, pero antiparalelos, dejando así una magnetización neta cero se clasifican como antiparamagnéticos (Figura 18.b). Ejemplos son la troilita (FeS) y la ilmenita $\left(\mathrm{FeTiO}_{2}\right)$.

Por último, ferrimagnetismo es una propiedad exhibida por materiales cuyos átomos o iones tienden a asumir una posición ordenada en la misma dirección, pero no en el mismo sentido, de modo que se anulan entre sí parcial o completamente, sin embargo, al estar distribuidos de forma aleatoria y al no ser equivalentes, la magnetización no llega a ser cero, presentando así, al igual que los materiales ferromagnéticos, magnetizaciones permanentes y punto de saturación, aunque con valores menores (Figura 18.d). Los ejemplos más importantes dentro de esta clasificación son los óxidos de hierro como la magnetita $\mathrm{Fe}_{3} \mathrm{O}_{4}$.

Por encima de una determinada temperatura (temperatura de Curie, Tc, en los ferromagnéticos y ferrimagnéticos, y temperatura de Néel, $\mathrm{T}_{\mathrm{N}}$, en los antiferromagnéticos), se vencen las fuerzas de acoplamiento de los momentos magnéticos y se comportan como materiales paramagnéticos, con los momentos magnéticos desalineados ${ }^{187}$. 
Capítulo II. Introducción.

Tanto los materiales ferromagnéticos como ferrimagnéticos están divididos en dominios magnéticos, los cuales fueron postulados por primera vez por Pierre Weiss en $1907^{188}$ y se refieren a regiones que engloban momentos magnéticos con una misma orientación, esto significa que los momentos magnéticos de los átomos individuales están alineados uno con el otro y que apuntan en la misma dirección. Dichas regiones están separadas unas de otras por paredes de dominio (Figura 19). En el caso de materiales nanométricos, las partículas de los materiales magnéticos actúan como monodominios dando lugar al efecto conocido como superparamagnetismo, donde cada partícula se comporta como un átomo paramagnético, pero con un gigantesco momento magnético, ya que todavía hay un orden magnético bien definido en cada nanopartícula ${ }^{189}$.

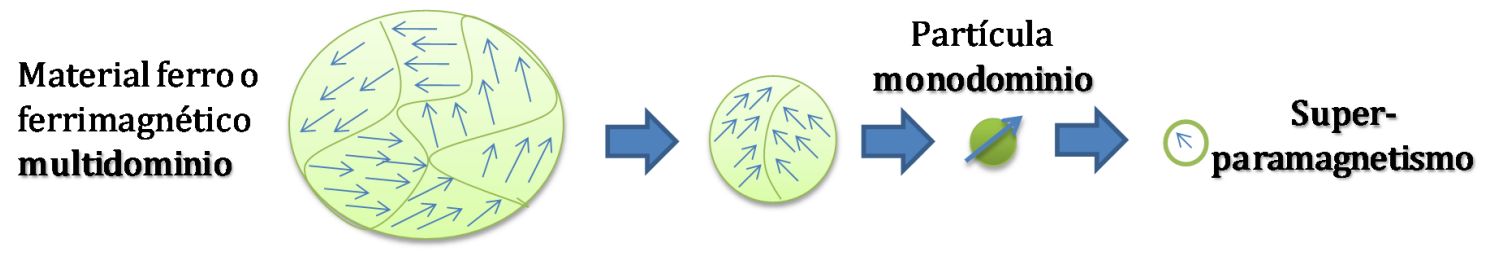

Figura 19. Evolución de la estructura multidominio hasta la situación de monodominio de un material magnético según el tamaño de partícula. Imagen adaptada de R.

$$
\text { Pujales }{ }^{190} \text {. }
$$

En ausencia de un campo magnético, los diferentes dominios están alineados aleatoriamente, tendiendo a anular entre sí la magnetización de unos y otros. Como se muestra en la Figura 20.a la separación entre dos dominios no es abrupta ya que energéticamente no es favorable mantener dos átomos de un material ferromagnético juntos con la magnetización antiparalela, sino que la transición está formada por las paredes de dominios, donde la magnetización va girando progresivamente. Al aplicar un campo magnético (Figura 20.b y c), los momentos magnéticos rotan gradualmente, haciendo que las paredes de dominio se muevan y se produzca un crecimiento de uno de los dominios a expensas de sus vecinos. 


\section{Capítulo II. Introducción.}

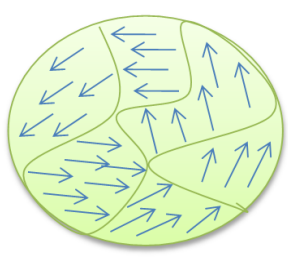

a)
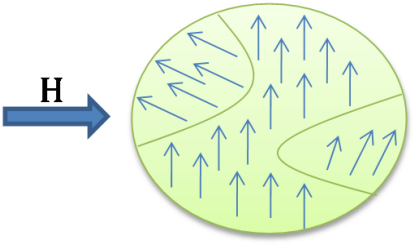

b)

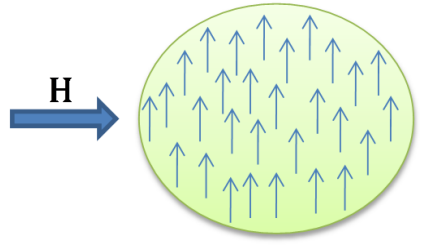

c)

Figura 20. Representación del movimiento de la pared de dominio bajo la aplicación de un campo magnético externo (H). a) Esquema de un material separado en dominios magnéticos; (b) a campo distinto de cero, se desplazan las paredes y los dominios se empiezan a orientar paralelos al campo aplicado y (c) rotación de los dominios hasta orientar totalmente su magnetización paralela al campo aplicado. Imagen adaptada de M. Castellanos ${ }^{191 .}$

El comportamiento magnético de las diferentes sustancias ferromagnéticas y ferrimagnéticas se caracteriza con sus curvas de magnetización. Éstas son gráficas en que se representa la variación de la densidad de flujo magnético (B) o de la magnetización (M), en función del campo magnético aplicado $(H)$, a una temperatura dada. Las curvas de magnetización, presentan el ciclo mostrado en la Figura 21.a:
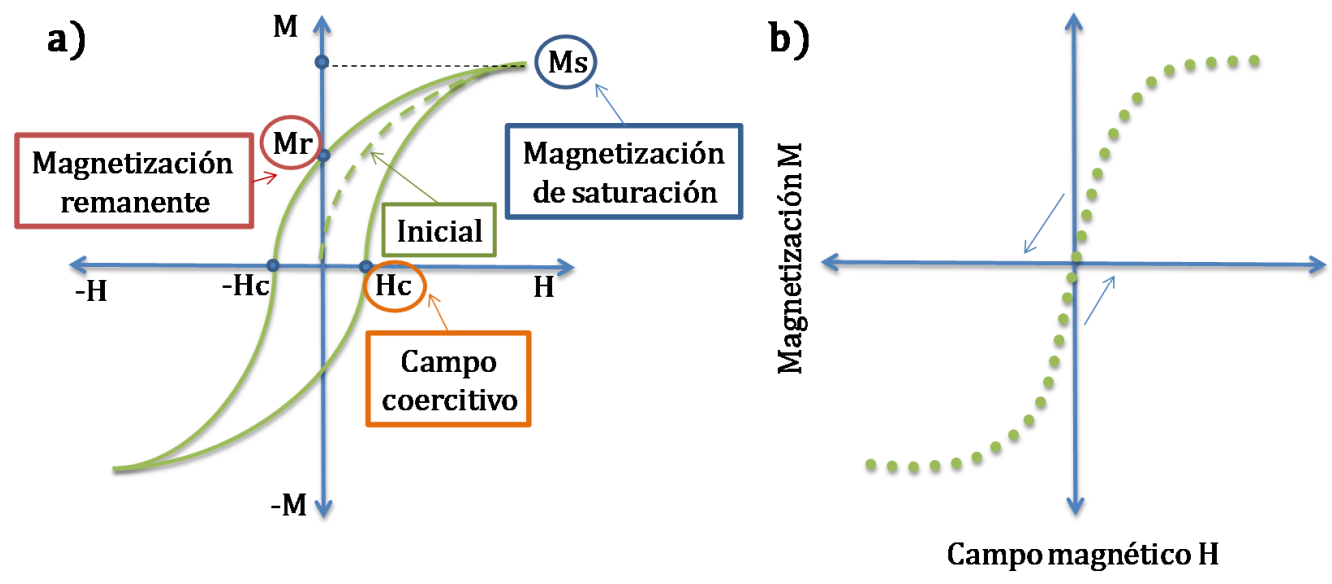

Figura 21. Curvas de magnetización de un material ferri o ferromagnético. a) Parámetros más relevantes de una curva de magnetización. b) Curva de magnetización característica de materiales que presentan comportamiento superparamagnético. Imagen modificada de M. Castellanos ${ }^{191}$. 
Capítulo II. Introducción.

La prueba consiste en aplicar un campo magnético $\mathrm{H}$ a una muestra que inicialmente se encuentra sin magnetizar. A medida que se va aumentando el campo, se registra la variación del magnetismo con éste, hasta alcanzar la magnetización de saturación $\left(\mathrm{M}_{\mathrm{S}}\right)$, que se produce debido a la alineación máxima de los momentos magnéticos con el campo. Al disminuir el campo aplicado, la magnetización disminuye hasta el valor de magnetización remanente $\left(\mathrm{M}_{\mathrm{r}}\right)$, magnetización que presenta un material a campo nulo tras haber estado expuesto a un campo magnético. Al seguir variando el campo a valores negativos, se elimina la magnetización del material. El campo necesario para retirar la magnetización que un material manifiesta después de haber estado sometido a un campo magnético se conoce como campo coercitivo (Hc) y, si se continúa aumentando el campo que se aplica, el material presentará nuevamente una magnetización de saturación de valor contrario al indicado para el campo de sentido opuesto. Si se vuelve a disminuir y modificar el campo magnético, se alcanza el valor de magnetización remanente, de valor inverso al anterior, cerrando así el ciclo de histéresis.

Las curvas de histéresis se producen en materiales que presentan ferromagnetismo o ferrimagnetismo, bien cuando la temperatura es inferior a la temperatura de bloqueo en materiales monodominio, o bien en materiales multidominio. En los materiales multidominio, cuanta mayor resistencia a la movilidad de las paredes de dominio opongan, más anchas serán las curvas. Si la movilidad de las paredes se produce de manera sencilla, las curvas de histéresis serán más estrechas. En el caso de los materiales superparamagnéticos, debido a sus dimensiones por debajo del tamaño de monodominio, las curvas son tan estrechas que no presentan coercitividad o remanencia, es decir pasan siempre por el origen (Figura 21.b).

\subsubsection{Estructura y propiedades de los óxidos de hierro.}

En la actualidad, las nanopartículas magnéticas (NPMs) más estudiadas son las correspondientes a óxidos de hierro, las cuales contienen únicamente hierro como catión metálico, donde se destacan tres tipos, magnetita $\left[\mathrm{Fe}_{3} \mathrm{O}_{4}\right]$, maghemita $\left[\gamma-\mathrm{Fe}_{2} \mathrm{O}_{3}\right]$ y hematita $\left[\alpha-\mathrm{Fe}_{2} \mathrm{O}_{3}\right]$. 


\section{Capítulo II. Introducción.}

La hematita ${ }^{192}$ es el óxido de hierro más estable y un semiconductor tipo $n$ en condiciones ambientales con un ancho de banda de $2.3 \mathrm{eV}$, donde la banda de conducción está compuesta por orbitales $d$ de $\mathrm{Fe}^{3+}$ y la banda de valencia (VB) por orbitales $3 d \mathrm{de} \mathrm{Fe}^{3+}$ con algunas mezcla de los orbitales $2 p$ del $\mathrm{O}$ no vinculante. Como se muestra en la Figura 22.a, presenta una estructura romboédrica donde los iones $\mathrm{Fe}^{3+}$ ocupan dos tercios de los sitios octaédricos que están confinados por la rejilla hexagonal. Es ampliamente utilizado en catalizadores, pigmentos y sensores de gas debido a su bajo coste y alta resistencia a la corrosión. También puede ser utilizada como material de partida para la síntesis de magnetita y maghemita, las cuales han tenido un mayor interés científico por sus aplicaciones tecnológicas en las últimas décadas.

La magnetita y maghemita presentan una estructura diferente a la hematia, ya que son miembros del grupo espinela cúbica (óxidos de fórmula ideal $\mathrm{AB}_{2} \mathrm{O}_{4}$, donde $\mathrm{A}$ es un catión divalente y $\mathrm{B}$ un catión trivalente). El óxido $\mathrm{MgAl}_{2} \mathrm{O}_{4}$, llamado Espinela, da nombre a este tipo de estructuras, que se pueden describir como un empaquetamiento cúbico compacto donde la celdilla elemental cristalográfica (que contienen $8 \mathrm{AB}_{2} \mathrm{O}_{4}$ ) está constituida de la siguiente forma: los 8 átomos de A están rodeados tetraédricamente por 4 átomos de oxígeno y los 16 átomos de $\mathrm{B}$ están rodeados octaédricamente por 6 átomos de oxígeno. En algunos casos, los átomos A y B están dispuestos de forma diferente, donde la mitad de los átomos de B están ocupando el lugar de $\mathrm{A}$, cuando es así, se formulan como $\mathrm{B}(\mathrm{AB}) \mathrm{O}_{4}$ para diferenciarlos del primer grupo y se denominan espinelas "inversas")193. La magnetita es una espinela inversa (Figura 22.b), su fórmula estándar se puede representar como $\mathrm{AB}_{2} \mathrm{O}_{4}$, donde el átomo $\mathrm{A}$ es $\mathrm{Fe}^{2+}$ y el átomo $\mathrm{B}$ es $\mathrm{Fe}^{3+}$.

La maghemita (Figura 22.c) tiene la misma estructura, y puede considerarse como una magnetita deficiente en Fe (II) y se forma por la oxidación topotáctica (sin cambio estructural) de la magnetita ${ }^{194}$. 


\section{Capítulo II. Introducción.}

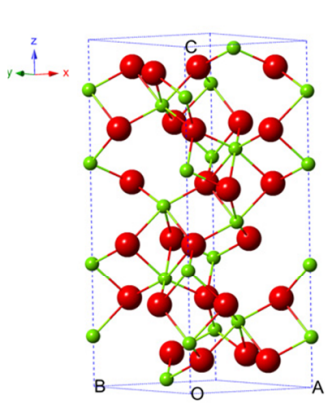

a) Hematita Romboédrica R3c

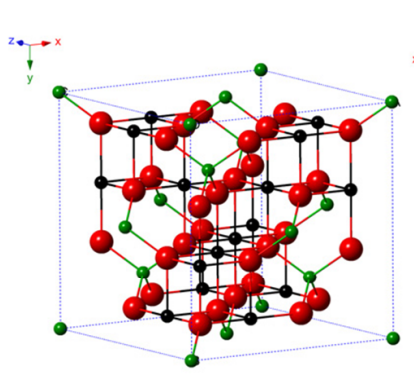

b) Magnetita Cúbica, Fd3m

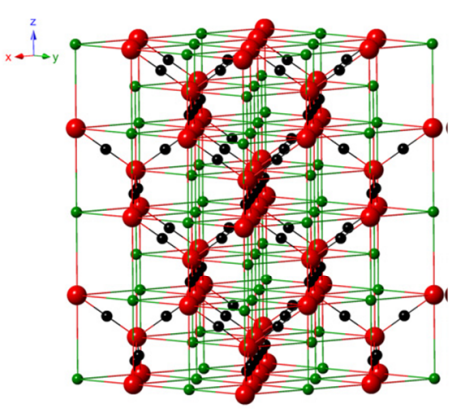

c) Maghemita

Figura 22. Estructura cristalina de los óxidos de hierro. a) hematita, b) magnetita y c) maghemita. (Imagen tomada de Wei Wi y col ${ }^{195}$ )

Las propiedades magnéticas de los tres óxidos de hierro son bastante similares, aunque la magnetita presenta valores algo más elevados de magnetización. A simple vista, se pueden diferenciar fácilmente por el color, ya que la magnetita es de color negro, la maghemita es marrón y la hematita es roja. A pesar de que estas partículas magnéticas de óxidos de hierro exhiben una menor magnetización de saturación, se prefieren frente a otras nanopartículas metálicas, como el níquel, el cobalto y el hierro, debido al bajo costo, relativa facilidad de síntesis, estabilidad frente a la oxidación y a la menor toxicidad que presentan las primeras.

\subsubsection{Sintesis de las nanopartículas magnéticas.}

Una gran parte de los artículos publicados sobre NPMs han sido sobre rutas de síntesis eficientes para alcanzar un tamaño controlado, altamente estable y estrecha distribución de fases y composición. A la fecha, los métodos reportados se pueden clasificar en tres grupo ${ }^{196}$ :

Síntesis en fase líquida: dentro de este grupo se destacan técnicas como coprecipitación, microemulsión, descomposición térmica, sonoquímica, reducción química, métodos con micoondas, síntesis hidrotermal y solvotermal, entre otros, con los que siguiendo algunos principios, se logra una monodispersión con una desviación estándar menor al 5\%. En una síntesis en fase líquida, la precipitación de las partículas 


\section{Capítulo II. Introducción.}

se presenta cuando la concentración aumenta hasta su saturación, alcanzado un punto donde ocurre la nucleación. En este crecimiento de partículas, lo más probable es que se produzca una combinación de los átomos en los núcleos, con una agregación irreversible, así, los principios para conseguir una monodispersión de tamaños son:

(I) La velocidad de nucleación debe ser lo suficientemente alta para que la concentración no continúe subiendo.

(II) La tasa de crecimiento de estos núcleos debe ser lo suficiente para reducir la concentración por debajo de la concentración del punto de nucleación. De esta manera sólo un número limitado de partículas son creadas.

(III) La tasa de crecimiento debe ser lo suficientemente lenta, es decir, que el período de crecimiento debe ser largo comparado con el período de nucleación. Esto generalmente reduce la distribución de tamaños que resulta del período de nucleación finita.

Por lo tanto, al controlar estos factores, se consiguen NPMs monodispersas, sintetizando así tamaños deseados según las condiciones empleadas.

- Síntesis en fase gaseosa: dentro de este grupo se destacan técnicas como deposición química en fase vapor, descarga de arco y pirolisis laser.

- Síntesis en fase sólida: este método de síntesis es utilizado para obtener NPMs recubiertas con carbono, sin embargo, el tamaño y por tanto las propiedades magnéticas de las partículas finales difícilmente pueden controlarse, y partículas superparamagnéticas no se pueden obtener ya que el tamaño de partícula inicial es generalmente mucho mayor del necesario. Dentro de este grupo se destaca la técnica de síntesis por combustión. 
Capítulo II. Introducción.

\subsubsection{Método de co-precipitación.}

En el presente trabajo se empleó el método de coprecitación ${ }^{197}$, el cual es un método en el que la temperatura y el tiempo de reacción son menores comparado con otros métodos como hidrotermal o descomposición térmica ${ }^{198}$. Además, utiliza un solvente respetuoso del medio ambiente (agua) y se consigue un rendimiento de reacción alto y escalable, lo que hace que sea una manera fácil y conveniente de sintetizan NPMs.

La técnica consiste en sintetizar óxidos metálicos y ferritas a partir de soluciones acuosas de sales de hierro, en un medio básico (generalmente se agrega hidróxido de sodio o de amonio) e inerte. La base desprotona los ligandos hidratados que rodean los cationes de hierro y forma ligandos hidroxilo, para posteriormente producirse la condensación y formación del óxido. La reacción de formación puede escribirse según la ecuación 4:

$$
\mathrm{M}^{2+}+2 \mathrm{Fe}^{3+}+8 \mathrm{OH}^{-} \longrightarrow \mathrm{MF}_{2} \mathrm{O}_{4}+4 \mathrm{H}_{2} \mathrm{O}
$$

Donde $\mathrm{M}$ puede ser $\mathrm{Fe}^{2+}, \mathrm{Mn}^{2+}, \mathrm{Co}^{2+}, \mathrm{Cu}^{2+}, \mathrm{Mg}^{2+}, \mathrm{Zn}^{2+}$ y $\mathrm{Ni}^{2+}$.

A pH entre 8 y 14 y libre de oxígeno, se espera una precipitación completa, con una relación estequiométrica de 2:1 $\left(\mathrm{Fe}^{3+} / \mathrm{M}^{2+}\right)$. La magnetita no es muy estable bajo condiciones ambientales y se oxida fácilmente, igualmente ocurre en un medio ácido, donde pasa a ser maghemita, aunque dado que la maghemita también tiene propiedades magnéticas, dependiendo de la aplicación para la que se requiera, este puede ser un problema menor.

Debido a que de los parámetros de síntesis de las NPMs, dependen las propiedades físicas y químicas como el tamaño, cristalización y composición final de las mismas, muchos estudios se han realizado para identificar cuáles son las condiciones que más influyen y de qué modo lo hacen, donde se destacan la naturaleza de las sales utilizadas (por ejemplo, cloruros, sulfatos, o nitratos), relación $\mathrm{M}^{2+} / \mathrm{Fe}^{3+}$, condiciones de reacción como la temperatura y el pH, tipo y cantidad de base, 
Capítulo II. Introducción.

velocidad de mezcla, fuerza iónica de los medios, secuencia de adición y burbujeo de gas inerte ${ }^{197}$.

Un estudio realizado por Lucia Babes y $\operatorname{col}^{199}$ en el que analizan la influencia de diferentes parámetros en el tamaño y composición de nanopartículas de óxido de hierro determinaron que uno de los factores más importantes es la relación molar entre $\mathrm{Fe}^{2+} / \mathrm{Fe}^{3+}$, ya que la formación del núcleo se produce sólo en una relación molar cercana a 0,5, así, en presencia de una sola clase iónica o de una relación inferior a 0,4 se da la formación de coloidales, por ejemplo, si se usa solo $\mathrm{Fe}^{3+}$, conduce a preparaciones parecidas al hierro paramagnético y para valores de esta relación superiores a 0,6, el tamaño medio de las partículas aumenta significativamente.

De igual forma, reportaron que otros factores bastante determinantes en el tamaño de partícula son el pH y la fuerza iónica del medio de precipitación, ya que el tamaño disminuye de forma significativa con el aumento del $\mathrm{pH}$, siendo ideal trabajar a pH entre 11 y 13 y una fuerza iónica en un área entre 1 y $3 \mathrm{M}$ induciendo a una casi estabilidad de los tamaños, explicada por la alta carga inducida que genera una caída superficial de la energía.

Con respecto al pH, Faiyas y $\operatorname{col}^{200}$ concluyeron también que éste influye en el mecanismo de reacción. Ellos analizaron muestras sintetizadas a diferentes pH por espectroscopía de fotoelectrones de rayos X (XPS), encontrando que si se tienen valores de $\mathrm{pH}$ entre 6 y 9, la especie predominante es maghemita y a un valor de pH 11 se produce solo magnetita. El pH adecuado para la rápida formación de $\mathrm{Fe}_{3} \mathrm{O}_{4}$ se logra mediante la adición en exceso de la base. Shen y col $^{201}$ observaron que el producto presentaba un color parduzco, indicación de la presencia de $\mathrm{Fe}_{2} \mathrm{O}_{3}$, sí el $\mathrm{NH}_{4} \mathrm{OH}$ añadido era insuficiente.

Así mismo, el $\mathrm{NH}_{4} \mathrm{OH}$ favorece una mejor cristalinidad y un tamaño más pequeño, con la consecuente mayor magnetización de saturación en comparación a cuando se utiliza $\mathrm{NaOH}$ como base. Otros estudios han demostrado que los valores de magnetización de saturación de las muestras sintetizadas con sales ferrosas y férricas 
Capítulo II. Introducción.

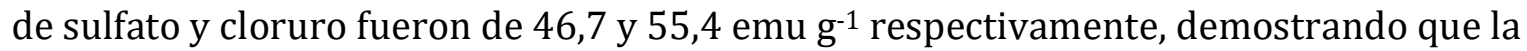
naturaleza de las sales influencia las propiedades del material final. Por otro lado, en la síntesis de $\mathrm{Fe}_{3} \mathrm{O}_{4}$, la precipitación a temperaturas por debajo de $60{ }^{\circ} \mathrm{C}$ produce típicamente un oxihidróxido hidratado amorfo que puede ser fácilmente convertido en $\mathrm{Fe}_{2} \mathrm{O}_{3}$, mientras que a temperaturas de reacción más altas $\left(>80^{\circ} \mathrm{C}\right)$ se favorece la formación de $\mathrm{Fe}_{3} \mathrm{O}_{4}$, como ya se mencionó antes, esto se debe a la eliminación de oxígeno disuelto en el agua evitando la oxidación del hierro.

\subsubsection{Encapsulación de NPMs en esferas de óxido de silicio ( $\left.\mathrm{SiO}_{2}\right)$.}

Las MNPs son muy sensibles a la oxidación si se dejan expuestas al aire del ambiente cambiando drásticamente sus propiedades, esto debido a su tamaño ultra fino y su alta reactividad química, además tienden a aglomerarse por sus interacciones dipolo-dipolo magnético. Esto ha hecho que se vea la necesidad de recubrirlas con una capa bien sea de un óxido, un metal noble, o sustancias como polímeros orgánicos, que las protejan de factores externos o del medio de reacción.

Dentro de los materiales utilizados para encapsular NPMs, el $\mathrm{SiO}_{2}$ ha atraído una atención especial en primer lugar, porque capas de sílice sobre la superficie de las NPMs disminuye la atracción dipolar magnética, lo que favorece su dispersión en medios líquidos y los protege de la lixiviación en un ambiente ácido. En segundo lugar, debido a la existencia de abundantes grupos silanoles, la capa de sílice, sirve de anclaje de diferentes materiales y grupos funcionales y así, inmovilizar, por ejemplo, catalizadores homogéneos. Finalmente, la capa de sílice proporciona una superficie químicamente inerte para ser utilizada en sistemas biológicos. Estas características se pueden modificar a través de la variación del espesor de la capa ${ }^{196}$.

Se han explorado dos técnicas diferentes para recubrir con sílice las superficies de partículas de óxido de hierro. El primero es el método Stöber, reportado por Werner Stöber y Arthur Fink en 1968202, siendo aún el método de síntesis de sílice más utilizado porque permite un tamaño monodisperso de partículas, su bajo costo, condiciones suaves de reacción y libre de surfactantes, entre otras ventajas. Este 


\section{Capítulo II. Introducción.}

método es un ejemplo de un proceso sol-gel en el cual la sílice se forma in situ a través de la hidrólisis y condensación de un precursor (típicamente TEOS) en una solución alcohólica (generalmente metanol o etanol) y amoniaco como catalizador.

Una representación de esta reacción se muestra en la Figura 23. Las moléculas resultantes se unen para formar estructuras más grandes, donde el tamaño se puede controlar dependiendo de las condiciones de reacción (relación molar de reactivos, cantidad de base, velocidad de mezcla, etc) ${ }^{203}$.

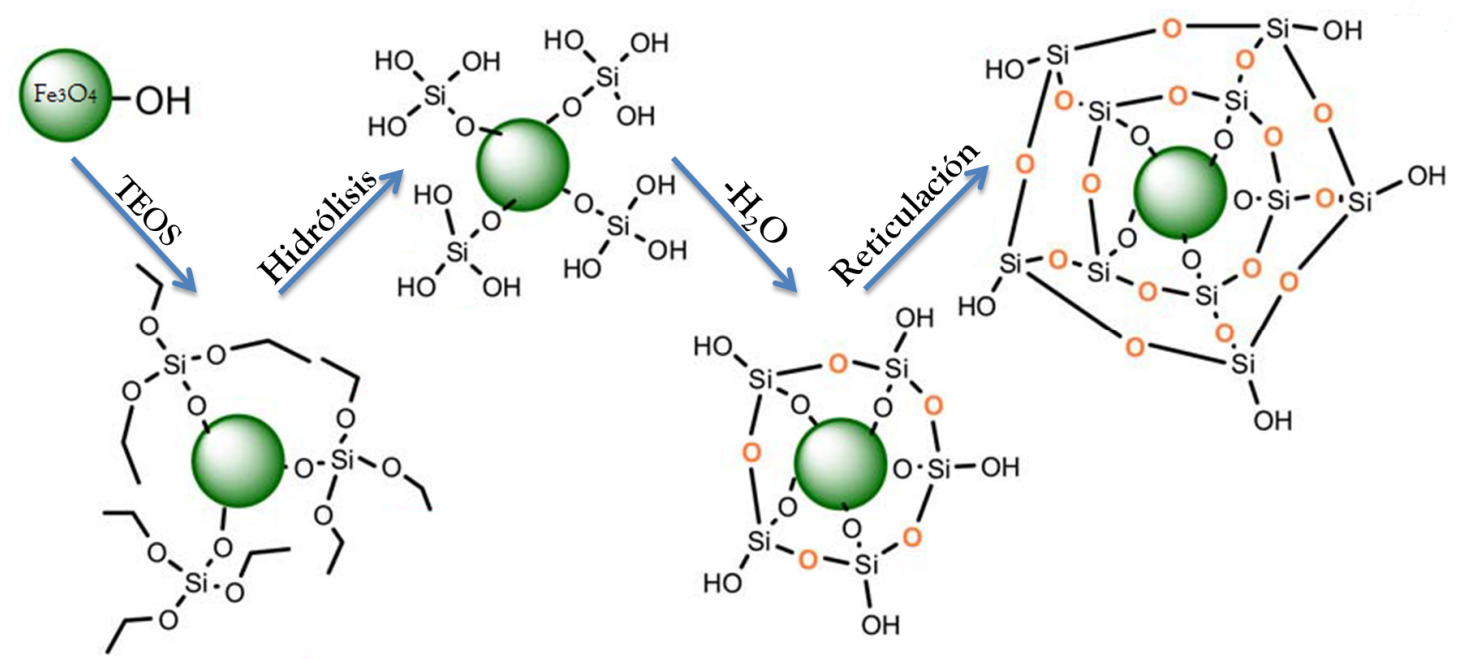

Figura 23. Representación simplificada de la hidrólisis y condensación de TEOS sobre NPMs en el proceso Stöber. (Imagen modificada de G.H. Du et al 2006204).

La reacción consiste en la obtención de soles mediante la hidrólisis de los precursores catalizada por una base para formar especies $=\mathrm{SiOH}$ (Figura 24, ecuación 5) sumamente reactivas. Estas especies continúan reaccionando mediante la alcoxolación (reacción donde se forman puentes oxo Si-0-Si a través de la eliminación de una molécula de alcohol, Figura 24, ecuación 6), o la oxolación (reacción análoga a la alcoxolación, excepto por que la molécula saliente en lugar de alcohol es agua, Figura 24, ecuación 7), estas reacciones también se conocen como condensación. 
Capítulo II. Introducción.

La hidrólisis de los grupos etóxidos y la posterior condensación conduce a la reticulación, el cual es un proceso de una etapa ya que estas dos reacciones ocurren juntas en un único recipiente de reacción ${ }^{205}$.

$$
\begin{aligned}
& \equiv \mathrm{Si}-\mathrm{OCH}_{2} \mathrm{CH}_{3}+\mathrm{H}_{2} \mathrm{C} \underset{\text { Esterificación }}{\stackrel{\text { Hidrólisis }}{\rightleftarrows}} \equiv \mathrm{Si}-\mathrm{OH}+\mathrm{CH}_{3} \mathrm{CH}_{2} \mathrm{OH} \\
& \equiv \mathrm{Si}-\mathrm{OCH}_{2} \mathrm{CH}_{3}+\mathrm{HO}-\mathrm{Si} \equiv \underset{\text { Alcoholisis }}{\stackrel{\text { Alcoxolación }}{\rightleftarrows}} \equiv \mathrm{Si}-\mathrm{O}-\mathrm{Si} \equiv+\mathrm{CH}_{3} \mathrm{CH}_{2} \mathrm{OH} \\
& \equiv \mathrm{Si}-\mathrm{OH}+\mathrm{HO}-\mathrm{Si} \equiv \underset{\text { Hidrólisis }}{\stackrel{\text { Oxolación }}{\rightleftarrows}} \equiv \mathrm{Si}-\mathrm{O}-\mathrm{Si} \equiv+\mathrm{H}_{2} \mathrm{O}
\end{aligned}
$$

Figura 24. Reacciones que rigen la síntesis sol-gel de sílice con TEOS como precursor. (Imagen modificada de Emel I. Goksu es al205).

El segundo método es la microemulsión ${ }^{206}$, basado en un sistema compuesto por agua, aceite, un surfactante y eventualmente un co-surfactante. Comúnmente, las NPMs son previamente recubiertas por un ligando hidrofóbico, dispersados en un medio orgánico. Posteriormente se agrega una solución acuosa alcalina, que contiene el surfactante y la mezcla es tratada con ultrasonido formando así la microemulción. Finalmente un precursor de sílice es agregado, generalmente TEOS y se deja reaccionar durante un determinado tiempo. Así, microsferas de sílice mesoporosa con núcleo magnético son obtenidas, donde el crecimiento, grosor y regularidad de la capa de sílice depende de los parámetros experimentales como la concentración de TEOS, cantidad de agua, tiempo de reacción, tipo de surfactante, entre otros. Como desventaja, este método requiere de un mayor esfuerzo para separar las esferas de sílice, de la gran cantidad de tensioactivos asociados con el sistema de microemulsión.

En la Presente Tesis Doctoral, se estudió la síntesis de NPMs de $\mathrm{Fe}_{3} \mathrm{O}_{4}$, su encapsulación en óxido de silicio mediante el método Stöber y la inmovilización del ácido tungstofosfórico sobre ellas. Se caracterizaron por diferentes técnicas fisicoquímicas y se evaluó su actividad catalítica en la esterificación del ácido levulínico con n-butanol. 


\section{Capítulo III:}

METODOLOGÍA Y

DESARROLLO

EXPERIMENTAL. 


\section{Capítulo III. Metodología y Desarrollo Experimental.}

\subsection{ASPECTOS GENERALES.}

A continuación, se describe la metodología, los equipos, los reactivos utilizados en la síntesis de los catalizadores, las técnicas con las cuales se determinaron sus propiedades fisicoquímicas, la evaluación catalítica de los materiales sintetizados y los métodos analíticos utilizados en el seguimiento y cuantificación de las reacciones tests.

Todos los reactivos fueron de alta pureza o se prepararon de acuerdo a procedimientos descritos en la literatura, o bien, de acuerdo a procedimientos novedosos desarrollados por el grupo de investigación (cada caso es oportunamente indicado). Los solventes fueron grado analítico.

Los catalizadores sintetizados y estudiados durante esta Tesis Doctoral se clasificaron en tres grupos y así serán nombrados durante todo el documento:

$\checkmark \quad$ Grupo I: Ácido tungstofosfórico soportado sobre óxido de zirconia $\left(\mathrm{ZrO}_{2}\right)$.

$\checkmark \quad$ Grupo II: Heteropoliácidos soportados sobre óxido de titanio $\left(\mathrm{TiO}_{2}\right)$.

$\checkmark \quad$ Grupo III: Ácido tungstofosfórico soportado sobre magnetita encapsulada en óxido de silicio $\left(\mathrm{Fe}_{3} \mathrm{O}_{4} @ \mathrm{SiO}_{2}\right)$.

Las reacciones fueron llevadas a cabo en baños calefaccionados de silicona o vaselina líquida con control de temperatura y agitación magnética, hasta que los reactivos se consumieron, o hasta que no se observaron cambios significativos en la composición de la mezcla de reacción. El seguimiento y cuantificación del rendimiento de las reacciones de esterificación se hizo por cromatografía gaseosa (CG/FID), mediante el método de curva de calibración para las reacciones del ácido 2-furoico y por el método de normalización de áreas para las reacciones del ácido levulínico. La identificación de los productos se hizo mediante cromatografía de gases/masas (CG/EM), RMN de ${ }^{1} \mathrm{H}$ y ${ }^{13} \mathrm{C}$ y se determinó su punto de fusión, en los casos en los cuales el producto fue sólido. 
Capítulo III. Metodología y Desarrollo Experimental.

\subsection{REACTIVOS.}

3.2.1. Reactivos utilizados en la preparación de los catalizadores.

- $\quad$ Cloruro de hierro II tetrahidratado $\left(\mathrm{FeCl}_{2} .4 \mathrm{H}_{2} \mathrm{O}\right)$, Sigma Aldrich $99.9 \%$

- $\quad$ Cloruro de hierro III hexahidratado $\left(\mathrm{FeCl}_{3} .6 \mathrm{H}_{2} \mathrm{O}\right)$, Sigma Aldrich 98.0\%

- $\quad$ Óxido de hierro (II, III) $\left(\mathrm{Fe}_{3} \mathrm{O}_{4}\right)$, Sigma Aldrich $95.0 \%$

- $\quad$ Hidróxido de amonio $\left(\mathrm{NH}_{4} \mathrm{OH}\right), 28.0 \%$

- Alcohol etílico anhidro, Anedra

- $\quad$ Tetraetilorotosilicato (TEOS) $\left(\mathrm{C}_{8} \mathrm{H}_{20} \mathrm{O}_{4} \mathrm{Si}\right)$, Sigma Aldrich 98.0\%

- $\quad$ Propóxido de zirconio $\left(\mathrm{Zr}\left(\mathrm{C}_{3} \mathrm{H}_{7} \mathrm{O}\right)_{4}\right)$, Sigma Aldrich

- Isopropóxido de titanio $\left.\left(\mathrm{Ti}\left(\mathrm{C}_{3} \mathrm{H}_{7} \mathrm{O}\right)\right)_{4}\right)$, Sigma-Aldrich $99.0 \%$

- Urea, Sigma Aldrich 99.0\%

- $\quad$ Ácido tungstofosfórico $\left(\mathrm{H}_{3} \mathrm{O}_{40} \mathrm{PW}_{12}\right)$ Fluka p.a.

- $\quad$ Ácido tungstosilícico $\left(\mathrm{H}_{4} \mathrm{O}_{40} \mathrm{PW}_{12}\right)$ Fluka p.a.

- $\quad$ Polietilenglicol (PEG)

\subsubsection{Reactivos utilizados en las reacciones orgánicas.}

- Ácido 2-furoico, Sigma Aldrich 98.0\%

- $\quad$ Ácido levulínico, Sigma Aldrich 98.0\%

- $\quad$ Alcohol n-butílico, Merck 99.5\%

- $\quad$ 2-fenoxietanol, Fluka 99.0\%

- Alcohol metílico

- Alcohol n-pentílico

- Alcohol n-hexílico

- Alcohol n-ciclohexilico

- Alcohol n-octílico

- Alcohol metoxietílico

- Alcohol ter-amílico 
Capítulo III. Metodología y Desarrollo Experimental.

- $\quad$ Alcohol 1-feniletílico

- Alcohol 4-metilbencílico

- Alcohol 4-hidroxibencílico

- Mentol

- Alcohol difenilmetílico

- Alcohol trifenilmetílico 
Capítulo III. Metodología y Desarrollo Experimental.

\subsection{EQUIPOS}

\subsubsection{Caracterización de los catalizadores}

- $\quad$ Espectrómetro de resonancia magnética nuclear (RMN) Bruker Avance T 9.4.

- $\quad$ Espectrómetro de resonancia magnética nuclear (RMN) Bruker Avance II.

- $\quad$ Espectrómetro Raman Horiba Jobin-Yvon T 64000.

- $\quad$ Espectrómetro FTIR Bruker IFS 66.

- $\quad$ Espectrómetro Nicolet S50 FTIR acoplado a reflectancia total atenuada (ATR).

- $\quad$ Espectrómetro de absorción atómica (AAS) Varian AA modelo 240.

- $\quad$ Acelerado de área superficial y porosidad Micromeritics ASAP 2020.

- $\quad$ Titulador potenciométrico, Metrohm 794 Basic Titrino.

- $\quad$ Difracción de rayos X (DRX) Phillips PW- 1732.

- $\quad$ Magnetómetro de muestra vibratoria (VSM) -VersaLab.

- $\quad$ Microscopio de barrido electrónico (SEM-EDX) Philips SEM 505.

\subsubsection{Reacciones orgánicas y caracterización de compuestos.}

- Cromatógrafo de gases (CG) Shimadzu CG2014 con detector FID y columna capilar SPB-1, longitud $30 \mathrm{~m}$, I.D. $32 \mathrm{~mm}$ y diámetro de película $1.00 \mu \mathrm{m}$.

- $\quad$ Cromatógrafo de gases/masas (CG-MS) Perkin Elmer Auto System/Q-Mass 910.

- $\quad$ Espectrómetro de resonancia magnética nuclear (RMN) Brunker Avance II 500

- $\quad$ Equipo para la determinación de punto de fusión Bioamerican Bs 448.

- $\quad$ Balanza analítica Precisa XT220A.

- Campana de extracción C4, modelo C180X.

- $\quad$ Plancha de calentamiento y agitación Corning, modelo PC 420.

- $\quad$ Rotaevaporador Heidolph, modelo Heizbad WB.

- $\quad$ Micropipeta BRAND 20-200 $\mu \mathrm{L}$.

- Deionizador D\&E. Destilador SchottGerate. 
Capítulo III. Metodología y Desarrollo Experimental.

\subsection{SÍNTESIS DE CATALIZADORES GRUPO I. ÁCIDO TUNGSTOFOSFÓRICO SOPORTADO SOBRE ZIRCONIA.}

Los catalizadores se sintetizaron mediante la técnica sol-gel por hidrólisis ácida del alcóxido, siguiendo una metodología desarrollada anteriormente en nuestro grupo de trabajo. Se preparó una solución homogénea disolviendo $25 \mathrm{~mL}$ de propóxido de zirconio en $425 \mathrm{~mL}$ de etanol anhidro mediante agitación, bajo atmósfera de nitrógeno a temperatura ambiente. Posteriormente se añadió lentamente $0,47 \mathrm{~mL}$ de solución acuosa de ácido clorhídrico 0,28M a esta mezcla. Se dejó reposar durante 3 h y luego se añadió una solución de polietilenglicol (PEG)-alcohol-agua en proporción en peso 1:5:1 como agente formador de textura, bajo agitación vigorosa. La cantidad de solución agregada se calculó de modo de obtener una concentración del formador de poros de $10 \%$ en peso respecto a la cantidad teórica de $\mathrm{ZrO}_{2}$ que se obtendría. En otro recipiente se prepararon soluciones de ácido tungstofosfórico (TPA) en etanol cuya concentración se adecuó para obtener contenidos de TPA de 30 y 60\% p/p en el sólido final. Dichas soluciones se agregaron a la síntesis por dos métodos diferentes, 1) junto con la solución que contenía el PEG, los dos catalizadores resultantes se denominaron ZrPEGTPA30T100 y ZrPEGTPA60 100 y 2) se agregaron antes de la adición del PEG, para comparar la influencia del momento de agregar el formador de textura en las propiedades finales de los materiales. Los catalizadores obtenidos de esta forma se denominaron ZrTPA30PEGT100 y ZrTPA60PEGT100 (en los 4 catalizadores los números 30 y 60 se refieren a la carga de TPA en el material y el 100 representa la temperatura a la que fueron secados).

De igual forma, se sintetizó una quinta muestra siguiendo el mismo procedimiento sin la adición de TPA denominada ZrPEGTPA00T100. Las muestras se dejaron reposar hasta sequedad a temperatura ambiente en sus respectivos vasos de precipitados, después se molieron hasta obtener un polvo, se lavaron en tres ocasiones con $500 \mathrm{~mL}$ de agua destilada para eliminar el PEG. Posteriormente, los sólidos fueron secados a $100^{\circ} \mathrm{C}$ durante $24 \mathrm{~h}$. 
Capítulo III. Metodología y Desarrollo Experimental.

\subsection{SÍNTESIS DE CATALIZADORES GRUPO II. HETEROPOLIÁCIDOS SOPORTADOS SOBRE TITANIA.}

Al igual que los materiales del Grupo I, éstos catalizadores también se sintetizaron vía sol-gel mediante hidrólisis ácida siguiendo una metodología desarrollada en nuestro grupo de trabajo, aunque en esta ocasión como agente formador de poros se utilizó urea. Se mezclaron $25 \mathrm{~mL}$ de isopropóxido de titanio en $236 \mathrm{~mL}$ de etanol absoluto y se agitó durante 10 min para obtener una solución homogénea a temperatura ambiente, luego se agregó lentamente 0,33 mL de una solución acuosa de ácido clorhídrico 0,28 M y se dejó en agitación durante $3 \mathrm{~h}$. Transcurrido este tiempo, se añadió una solución de urea-alcohol-agua en relación 1:5:1 en peso, bajo agitación vigorosa. La cantidad de solución agregada se calculó de modo de obtener una concentración del formador de poros de $10 \%$ en peso respecto a la cantidad teórica de $\mathrm{TiO}_{2}$ que se obtendría. Al mismo tiempo se adicionó una solución que contenía $5 \mathrm{~g}$ del heteropoliácido (bien sea ácido tungstofosfórico o ácido tungstosilísico) disuelto en $50 \mathrm{~mL}$ de etanol, para una concentración de $30 \% \mathrm{p} / \mathrm{p}$ en el sólido final. También se sintetizó un tercer material siguiendo el mismo procedimiento pero sin el agregado del heteropoliácido.

Los xerogeles se secaron a temperatura ambiente en un vaso de precipitados. Los sólidos se molieron hasta obtener un polvo y se lavaron en 3 ocasiones con $500 \mathrm{~mL}$ de agua destilada para eliminar la urea. Finalmente, los sólidos se trataron térmicamente a $500{ }^{\circ} \mathrm{C}$ durante $2 \mathrm{~h}$. Las muestras se denominaron $\mathrm{TiO}_{2} / \mathrm{TPA}, \mathrm{TiO}_{2} / \mathrm{TSA}_{\text {y }} \mathrm{TiO}_{2}$. 
Capítulo III. Metodología y Desarrollo Experimental.

\subsection{SÍNTESIS DE CATALIZADORES GRUPO III. ÁCIDO TUNGSTOFOSFÓRICO SOPORTADO SOBRE MAGNETITA ENCAPSULADA EN ÓXIDO DE SILICIO.}

Para la síntesis de los catalizadores del Grupo III, se variaron algunos parámetros buscando evitar la lixiviación del TPA, ya que la reproducción de metodologías reportadas en la literatura llevó a catalizadores que se lavaban. Así, el procedimiento se dividió en tres partes (un esquema de la síntesis se muestra en la Figura 25):

1. Síntesis de las NPMs de magnetita $\left(\mathrm{Fe}_{3} \mathrm{O}_{4}\right)$ por el método de coprecipitación donde se evaluaron diferentes agentes dispersantes, atmósfera inerte y temperatura.

2. Recubrimiento de las NPMs con óxido de silicio $\left(\mathrm{Fe}_{3} \mathrm{O}_{4} @ \mathrm{SiO}_{2}\right)$ por el método Stöber, a partir de TEOS como precursor e hidrólisis básica, donde se variaron condiciones como la relación $\mathrm{Fe}_{3} \mathrm{O}_{4} / \mathrm{SiO}_{2}$, la relación TEOS $/ \mathrm{NH}_{4} \mathrm{OH}$ y el tiempo de reacción.

3. Inmovilización del ácido tungstofosfórico sobre el material $\mathrm{Fe}_{3} \mathrm{O}_{4} @ \mathrm{SiO}_{2}$, para lo cual se evaluaron dos métodos: impregnación e inclusión durante un segundo recubrimiento con óxido de silicio, esta vez mediante hidrólisis ácida y tratamiento térmico a diferentes temperaturas.

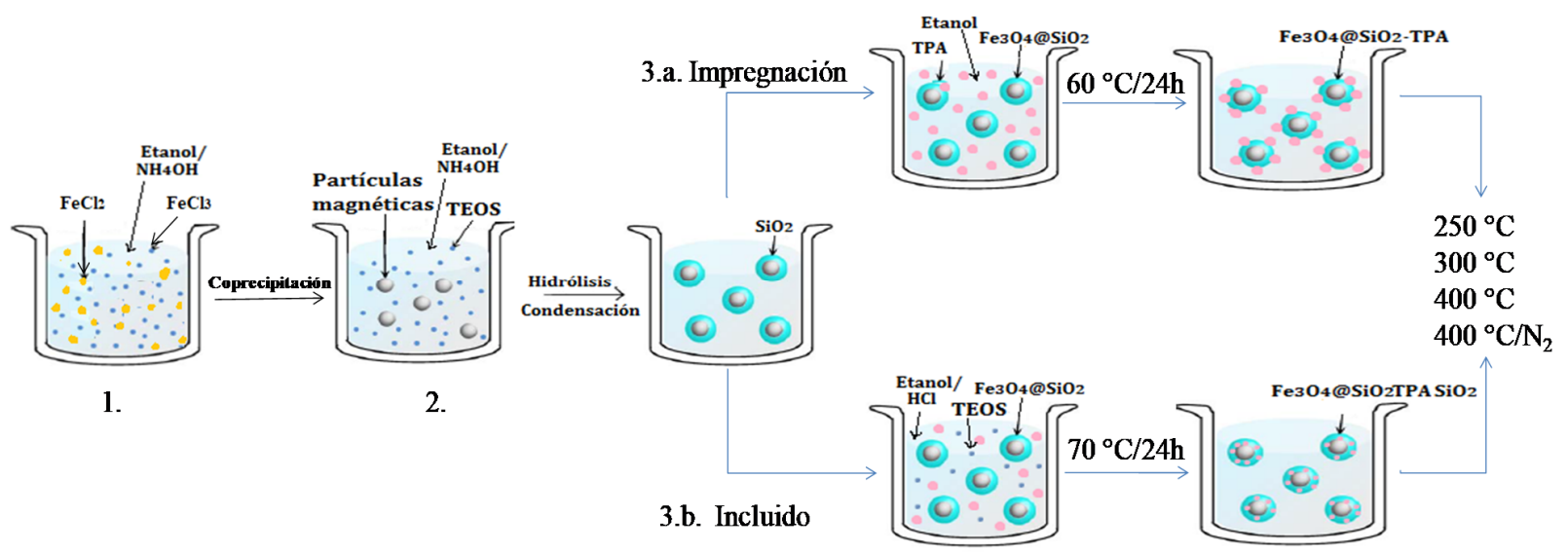

Figura 25. Esquema de la síntesis de los catalizadores magnéticos. 
Capítulo III. Metodología y Desarrollo Experimental.

\subsubsection{Síntesis de nanopartículas de $\mathrm{Fe}_{3} \mathrm{O}_{4}$}

Las NPM de $\mathrm{Fe}_{3} \mathrm{O}_{4}$ se prepararon mediante el método de coprecipitación química, partiendo de iones férricos y ferrosos en una solución alcalina con amoníaco (en todas las pruebas la relación estequiométrica $\mathrm{Fe}^{3+} / \mathrm{Fe}^{2+}$ fue 2:1). Las pruebas fueron:

Prueba 1.

Para este primer ensayo de la síntesis de magnetita, se siguió el procedimiento descrito por Liu y $\mathrm{col}^{207}$. En $400 \mathrm{~mL}$ de agua destilada se disolvió 11,6 g de $\mathrm{FeCl}_{3} 6 \mathrm{H}_{2} \mathrm{O}$ y 4,3 g de $\mathrm{FeCl}_{2} .4 \mathrm{H}_{2} \mathrm{O}$ bajo agitación vigorosa (1000 rpm) con burbujeo de nitrógeno y se calentó a $85^{\circ} \mathrm{C}$. Cuando se alcanzó la temperatura indicada se agregó $15 \mathrm{~mL}$ de $\mathrm{NH}_{4} \mathrm{OH}$ $25 \%$ y 9 mL de ácido oleico gota a gota. La solución se puso de un color negro y se dejó durante $1 \mathrm{~h}$ con calentamiento y agitación constante. Transcurrido el tiempo, las partículas magnéticas se precipitaron con la ayuda de un imán de neodimio, se retiró el sobrenadante y se lavó varias veces con agua hasta $\mathrm{pH}$ neutro (aproximadamente 500 $\mathrm{mL})$, luego con etanol y finalmente con hexano hasta que los desechos de lavado no eran turbios. Finalmente se secaron a temperatura ambiente.

\section{Prueba 2.}

En este ensayo se siguió el procedimiento descrito por Rafiee y $\operatorname{col}^{208}$, el cual tiene varios cambios, entre ellos, no se agrega ácido oleico. Se pesó $5,4 \mathrm{~g}$ de $\mathrm{FeCl}_{3} \cdot 6 \mathrm{H}_{2} \mathrm{O}$ y 2,0 g de $\mathrm{FeCl}_{2} .4 \mathrm{H}_{2} \mathrm{O}$ los cuales se disolvieron en $100 \mathrm{~mL}$ de agua destilada mediante agitación vigorosa (1000 rpm), posteriormente se agregó $200 \mathrm{~mL}$ de una solución 0,6 $\mathrm{M}$ de $\mathrm{NH}_{4} \mathrm{OH}$ y se agitó durante una hora. Posteriormente se agregó $30 \mathrm{~mL}$ de $\mathrm{NH}_{4} \mathrm{OH}$ $25 \%$ y se calentó a reflujo durante una hora más. Transcurrido el tiempo, se precipitaron las NPM con la ayuda de un imán de neodimio, se lavaron en repetidas ocasiones con agua hasta $\mathrm{pH}$ neutro y luego con etanol hasta que los desechos de lavado no eran turbios. La muestra se secó a temperatura ambiente. 


\section{Capítulo III. Metodología y Desarrollo Experimental.}

\section{Prueba 3.}

En el ensayo 3 se siguió el procedimiento descrito por Jang y $\operatorname{col}^{209}$, el cual hace énfasis en la importancia de que el agua esté libre de iones y oxígeno disuelto para prevenir que el hierro se oxide y garantizar la obtención de magnetita en lugar de otros óxidos de hierro posibles, para esto se usa agua destilada, desionizada y burbujeada con nitrógeno y la reacción se lleva a cabo a $80{ }^{\circ} \mathrm{C}$. Se pesó $2,7 \mathrm{~g}$ de $\mathrm{FeCl}_{3} \cdot 6 \mathrm{H}_{2} \mathrm{O}$ y $1,0 \mathrm{~g}$ de $\mathrm{FeCl}_{2} .4 \mathrm{H}_{2} \mathrm{O}$ y se disolvieron en $25 \mathrm{~mL}$ de agua. Al llegar a los $80{ }^{\circ} \mathrm{C}$ se agregó $12 \mathrm{~mL}$ de $\mathrm{NH}_{4} \mathrm{OH} 25 \%$ (de nuestra experiencia concluimos que es importante que se agreguen lo más lentamente posible, ya que esto influye en el tamaño de las partículas). Una vez terminado de agregar el hidróxido, la solución se tornó negra y el precipitado se formó inmediatamente, se continuó agitando durante 20 min y a continuación, las NPMs de $\mathrm{Fe}_{3} \mathrm{O}_{4}$ se precipitaron por aplicación de un campo magnético y se lavaron repetidamente con agua y etanol, hasta que el pH estaba neutro y los desechos no eran turbios.

Se utilizó nitrógeno en todo el proceso para evitar que las partículas se oxidaran. $\mathrm{Al}$ igual que con las muestras anteriores, las NPMs se secaron a temperatura ambiente y se analizaron por microscopía de barrido electrónico para determinar su forma y tamaño. Este procedimiento se repitió hasta obtener $30 \mathrm{~g}$ de magnetita, 5 muestras escogidas aleatoriamente se analizaron por SEM para determinar si eran iguales morfológicamente y así mezclar todos los lotes sintetizados.

\subsubsection{Preparación de revestimientos de sílice sobre $\mathrm{Fe}_{3} \mathrm{O}_{4}\left(\mathrm{Fe}_{3} \mathrm{O}_{4} @ \mathrm{SiO}_{2}\right)$.}

Una vez determinado el mejor método para sintetizar las partículas magnéticas, es decir, que se obtuvieran partículas de tamaño uniforme y a escala de nanómetros, se buscó la mejor forma para recubrirlas. Se escogió hacerlo por el método Stöber descrito por Deng y $\operatorname{col}^{210}$ al que se le hicieron varias modificaciones. Este procedimiento se diseñó originalmente para sintetizar esferas huecas de sílice, pero sirve también para revestir o encapsular materiales como las NPMs. Los ensayos realizados se detallan a continuación en las pruebas 4,5 y 6 . 
Capítulo III. Metodología y Desarrollo Experimental.

Prueba 4. Procedimiento general.

Las capas de sílice sobre las NPMs de $\mathrm{Fe}_{3} \mathrm{O}_{4}$ se obtuvieron usando tetraetilorotosilicato (TEOS) como precursor y posterior hidrólisis básica. $1 \mathrm{~g}$ de las NPMs de $\mathrm{Fe}_{3} \mathrm{O}_{4}$ sintetizadas en la prueba 3 se sometieron a ultrasonido durante 30 minutos en $70 \mathrm{~mL}$ de etanol y $24 \mathrm{~mL}$ de solución de amoníaco $(25 \%$ p/p), (6 mL de amoniaco por cada $\mathrm{mL}$ de TEOS). Posteriormente se calentaron a $45{ }^{\circ} \mathrm{C}$ agitando constantemente. Cuando se alcanzó la temperatura mencionada, $4 \mathrm{~mL}$ de TEOS se añadieron gota a gota a la mezcla (por cada $\mathrm{mL}$ de TEOS se obtiene $300 \mathrm{mg}$ de $\mathrm{SiO}_{2}$ ) y se dejó reaccionar durante $4 \mathrm{~h}$. A continuación, se dejó evaporar el etanol a temperatura ambiente hasta sequedad mientras se mantenía la agitación. Así, se formaron recubrimientos de sílice sobre las $\mathrm{NPMs}$ de $\mathrm{Fe}_{3} \mathrm{O}_{4}$.

Las partículas se separaron con la ayuda de un imán de neodimio y se lavaron en repetidas ocasiones con agua y etanol hasta que la mezcla no era turbia. Las partículas de $\mathrm{Fe}_{3} \mathrm{O}_{4} @ \mathrm{SiO}_{2}$ no mostraron disolución perceptible de $\mathrm{Fe}_{3} \mathrm{O}_{4}$ en la mezcla de ácido clorhídrico y ácido nítrico concentrado durante 24 h. Por lo tanto, los revestimientos de sílice pueden usarse como capas protectoras para inhibir la disolución de núcleos magnéticos de $\mathrm{Fe}_{3} \mathrm{O}_{4}$ en entorno ácido, siendo aptas para incluir posteriormente el heteropoliácido.

Prueba 5. Relación $\mathrm{Fe}_{3} \mathrm{O}_{4}: \mathrm{SiO}_{2}$

Se estudió la influencia de la relación $\mathrm{Fe}_{3} \mathrm{O}_{4} / \mathrm{SiO}_{2}$ sobre la forma, tamaño y propiedades de los materiales, con el objeto de seleccionar aquella que permita obtener el mejor material. Para lo cual se diseñó una serie de experimentos consecutivos para sintetizar los materiales empleando las relaciones 1:0.5, 1:1 y 1:2. El experimento consistió en hacer un primer recubrimiento con una relación 1:0.5 y de esta separar una parte del material obtenido para caracterizarlo y con el resto realizar un nuevo recubrimiento de 0,5 sobre la misma muestra, así sucesivamente hasta llegar a una relación 1:2. Las cantidades utilizadas se muestran en la Tabla 2. 
Capítulo III. Metodología y Desarrollo Experimental.

Tabla 2. Cantidades utilizadas en la síntesis de $\mathrm{Fe}_{3} \mathrm{O}_{4} / \mathrm{SiO}_{2}$ con diferentes relaciones de reactivos.

\begin{tabular}{ccccc}
\hline $\begin{array}{c}\text { Relación } \\
\mathrm{Fe}_{3} \mathrm{O}_{4} / \mathrm{SiO}_{2}\end{array}$ & $\begin{array}{c}\mathrm{Fe}_{3} \mathrm{O}_{4} \\
(\mathrm{~g})\end{array}$ & $\begin{array}{c}\mathrm{TEOS} \\
(\mathrm{mL})\end{array}$ & $\begin{array}{c}\mathrm{NH}_{4} \mathrm{OH} \\
(\mathrm{mL})\end{array}$ & $\begin{array}{c}\text { Etanol } \\
(\mathrm{mL})\end{array}$ \\
\hline $1: 0.5$ & 1.6 & 3.2 & 19 & 64 \\
$1: 1$ & 1.4 & 2.4 & 14.5 & 48 \\
$1: 2$ & 0.4 & 0.8 & 4.8 & 16 \\
\hline
\end{tabular}

Prueba 6. Relación TEOS/ $\mathrm{NH}_{4} \mathrm{OH}$

Buscando las mejores condiciones para el recubrimiento de las $\mathrm{NPMs}$ con $\mathrm{SiO}_{2}$, se estudió la cantidad de amoniaco necesaria por mL de TEOS utilizado. Siguiendo las condiciones del procedimiento general descrito anteriormente, se pesó $1 \mathrm{~g}$ de $\mathrm{Fe}_{3} \mathrm{O}_{4}$, se disolvió en $70 \mathrm{~mL}$ de etanol, se agregaron $4 \mathrm{~mL}$ de amoniaco y 4 de TEOS (relación 1:1). Se hizo una segunda prueba con las mismas cantidades, de magnetita y TEOS pero una relación 3:1 amoniaco/TEOS, y una tercer prueba con una relación 6:1.

\subsubsection{Inmovilización de TPA sobreFe3O4@SiO2.}

Se estudiaron dos formas de soportar el TPA sobre la magnetita recubierta con sílice, una fue por el método de impregnación y la otra incluyéndolo dentro de una segunda capa de óxido de silicio con el fin de lograr que el TPA quede anclado lo más fuerte posible al soporte y no se lixivie durante su uso en reacciones.

\section{Prueba 7. Impregnación.}

Se pesó $1 \mathrm{~g}$ de $\mathrm{Fe}_{3} \mathrm{O}_{4} @ \mathrm{SiO}_{2}$ de la prueba 4, el cual se suspendió en $25 \mathrm{~mL}$ de etanol. Se agregó 0,400 g de TPA para un 30\% de fase activa en el catalizador final, se calentó a $60{ }^{\circ} \mathrm{C}$ y se dejó durante $24 \mathrm{~h}$. Transcurrido este tiempo, el sólido se separó con un imán de neodimio, se retiró el sobrenadante y se dejó secar a temperatura ambiente. Posteriormente el sólido se dividió en 4 fracciones, una de ellas se dejó sin calcinar (SC) y las tres restantes se calcinaron a 200,300 y $400{ }^{\circ} \mathrm{C}$ respectivamente (La 
Capítulo III. Metodología y Desarrollo Experimental.

muestra calcinada a $400{ }^{\circ} \mathrm{C}$ se calcinó en atmósfera de nitrógeno). Las muestras se denominaron $\mathrm{Fe}_{3} \mathrm{O}_{4} @ \mathrm{SiO}_{2} / \mathrm{TPAsc}, \quad \mathrm{Fe}_{3} \mathrm{O}_{4} @ \mathrm{SiO}_{2} / \mathrm{TPA}_{200}, \quad \mathrm{Fe}_{3} \mathrm{O}_{4} @ \mathrm{SiO}_{2} / \mathrm{TPA}_{300}$ y $\mathrm{Fe}_{3} \mathrm{O}_{4} @ \mathrm{SiO}_{2} / \mathrm{TPA}_{400 \mathrm{~N} 2}$

Prueba 8. El TPA se incluye simultáneamente con una segunda capa de $\mathrm{SiO}_{2}$.

Se hace un segundo recubrimiento con $\mathrm{SiO}_{2}$, en el que simultáneamente se agrega el TPA, de tal forma que quede inmovilizado en esta capa y sea más fuerte el anclaje. En esta ocasión se hace mediante una hidrólisis ácida del TEOS catalizada por el mismo TPA. El experimento consistió en suspender $1 \mathrm{~g}$ de las NPMs de $\mathrm{Fe}_{3} \mathrm{O}_{4} @ \mathrm{SiO}_{2}$ de la prueba 4 , en $70 \mathrm{~mL}$ de etanol junto con $1 \mathrm{~g}$ de TPA, la mezcla se calentó a $45^{\circ} \mathrm{C}$, cuando se llegó a esta temperatura, se añadieron $4 \mathrm{ml}$ de TEOS lentamente y se suspendió el calentamiento. La muestra se dejó en agitación hasta sequedad. Después se calcinó a 200, 300 y a $400{ }^{\circ} \mathrm{C}$, ésta última bajo atmósfera de nitrógeno durante $2 \mathrm{~h}$. Los materiales obtenidos se denominaron $\mathrm{Fe}_{3} \mathrm{O}_{4} @ \mathrm{SiO}_{2} @ \mathrm{SiO}_{2} / \mathrm{TPAx}$ (donde $\mathrm{x}=200,300$ y $\left.400 \mathrm{~N}_{2}\right)$. 
Capítulo III. Metodología y Desarrollo Experimental.

\subsection{TÉCNICAS DE CARACTERIZACIÓN FISICOQUÍMICA APLICADAS A LOS CATALIZADORES.}

- $\quad$ Espectroscopia de resonancia magnética nuclear (RMN)

Se estudiaron los núcleos ${ }^{29} \mathrm{Si}$ y ${ }^{31} \mathrm{P}$ en los catalizadores de los Grupos I y II según sea el caso. A los catalizadores del Grupo III no se les pudo realizar esta prueba por su naturaleza magnética.

Los espectros RMN/MAS de ${ }^{31} \mathrm{P}$ para los materiales del Grupo I se registraron con el equipo Bruker Avance II, utilizando la técnica CP/MAS ${ }^{1} \mathrm{H}-31 \mathrm{P}$. Se empleó un recipiente de muestras de $4 \mathrm{~mm}$ de diámetro y $10 \mathrm{~mm}$ de altura, usando impulsos de $5 \mu \mathrm{s}$, un tiempo de repetición de $4 \mathrm{~s}$, y trabajando a una frecuencia de 121,496 MHz a temperatura ambiente. La velocidad de pico fue de $8 \mathrm{kHz}$ y se recibieron cientos de respuestas de pulso.

Los espectros RMN/MAS de los materiales del Grupo II se realizaron en un espectrómetro Bruker Avance T 9.4 operando a 161,9 MHz para ${ }^{29} \mathrm{Si} \mathrm{y} \mathrm{79,5} \mathrm{MHz}$ para ${ }^{31} \mathrm{P}$. Se utilizó un diámetro de giro de rotor de $4 \mathrm{~mm}$ a $10 \mathrm{kHz}$ y se aplicó un decaimiento Bloch (adquisición de un solo pulso) con un campo de radiofrecuencia de $100 \mathrm{kHz}\left({ }^{31} \mathrm{P}\right)$ y $35 \mathrm{kHz}\left({ }^{29} \mathrm{Si}\right)$ y el ancho de pulso de 10 grados. Debido a la muy pequeña cantidad de núcleos activos de RMN de la muestra, ninguna medición de tiempo de relajación se pudo realizar y se eligió un retraso de reciclado de $15 \mathrm{~s}\left({ }^{31} \mathrm{P}\right)$ y $1 \mathrm{~s}\left({ }^{29} \mathrm{Si}\right)$ basado en diversas pruebas, con un tiempo de duración de 21.120 s (3,7 días) y 642.600s (7,5 días) respectivamente.

En todos los casos, los espectros de RMN de ${ }^{31} \mathrm{P}$ se han referenciado con respecto a una solución $1 \mathrm{M}$ de ácido fosfórico $85 \%$, mientras que lo de ${ }^{29} \mathrm{Si}$ se han referenciado con tetrametilsilano. 
Capítulo III. Metodología y Desarrollo Experimental.

- $\quad$ Espectroscopia Raman por Transformada de Fourier (Raman-TF).

Los espectros Raman se tomaron para los materiales del Grupo II y se registraron en un instrumento Raman Horiba Jobin-Yvon T 64000 con una fuente láser de $\mathrm{Ar}^{+} \mathrm{de}$ $488 \mathrm{~nm}$ de longitud de onda en una configuración macroscópica.

- Espectroscopia Infrarrojo por Transformada de Fourier (IRTF) y Reflectancia Total Atenuada (ATR).

Estos dos análisis se realizaron para determinar la naturaleza de las especies químicas presentes en los materiales en cada paso de la síntesis de los catalizadores.

Los sólidos de los Grupo I y II se analizaron en un espectrofotómetro IR-TF Bruker IFS 66, preparando pastillas en $\mathrm{KBr}$, en el intervalo de longitud de onda de 400$4000 \mathrm{~cm}^{-1}$.

Los materiales del Grupo III se analizaron en un espectrofotómetro Nicolet S50 FTIR acoplado a reflectancia total atenuada (ATR). Para el análisis se pesó 0,1 g de cada muestra, se colocó en la celda de ZnSe a temperatura ambiente, con un barrido de 32 scans y una resolución de $6 \mathrm{~cm}^{-1}$. Los espectros colectados se manipularon con el programa Omnic $5.1 \circledR$.

- $\quad$ Espectrometría de absorción atómica (AAS).

Esta técnica se utilizó para determinar y cuantificar la cantidad de tungsteno (W) soportado sobre los catalizadores y en las pruebas de lavado. Se llevó a cabo en un espectrómetro de absorción atómica Varian AA modelo 240. Los análisis se realizaron a una longitud de onda de 254,9 $\mathrm{nm}$, con un ancho de banda de $0,3 \mathrm{~nm}$, la corriente de la lámpara fue de $15 \mathrm{~mA}$, la amplificación fototubo de $800 \mathrm{~V}$, la altura del quemador fue de $4 \mathrm{~mm}$, y acetileno-nitroso (11: 4). 
Capítulo III. Metodología y Desarrollo Experimental.

- $\quad$ Propiedades texturales

El área superficial específica de todos los sólidos se determinó a partir de las isotermas de adsorción-desorción de $\mathrm{N}_{2}$ a la temperatura del nitrógeno líquido. Las pruebas se realizaron en un equipo de acelerado de área superficial y porosidad Micromeritics ASAP 2020. Las muestras se desgasificaron previamente a $100{ }^{\circ} \mathrm{C}$ durante $2 \mathrm{~h}$.

- $\quad$ Determinación de las propiedades ácidas por titulación potenciométrica con n-butilamina.

Esta prueba se realizó a todos los materiales, incluidos los soportes. El procedimiento realizado consistió en suspender $0,05 \mathrm{~g}$ de cada sólido en $90 \mathrm{~mL}$ de acetonitrilo (Merck) y se agitó durante 3 h. A continuación, la suspensión se valoró con una solución 0,05 $\mathrm{N}$ de n-butilamina en acetonitrilo usando un equipo Metrohm 794 Basic Titrino, donde se midió la variación del potencial de electrodo en $\mathrm{mV}$ (E), utilizando un electrodo de pH combinado, de una sola unión y cuerpo de vidrio (HI 1131B) 211 y un electrodo de doble unión. El punto final de la valoración se obtuvo al alcanzar el potencial de electrodo correspondiente al disolvente puro, es decir cuando el potencial fue constante al seguir agregando n-butilamina.

- $\quad$ Difracción de rayos $X(D R X)$.

Los diagramas de difracción de rayos X de los materiales de los Grupo I y II se obtuvieron en un equipo Phillips PW- 1732 con registrador incorporado, utilizando radiación $\mathrm{Cu} K \alpha(\lambda=1,5417 \AA$ A ) con filtro de níquel, operando el equipo a $20 \mathrm{~mA}$ y $40 \mathrm{kV}$

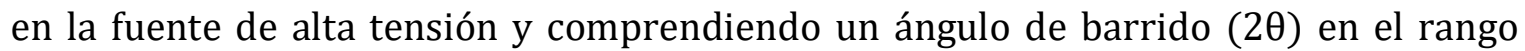
entre $5^{\circ}$ y $60^{\circ}$, y una velocidad de barrido de $2^{\circ}$ por minuto. 
Capítulo III. Metodología y Desarrollo Experimental.

Los diagramas de difracción de rayos X de los materiales del Grupo III se recogieron en un difractómetro PANalytical X-Pert-Pro utilizando un filtro de Ni y radiación $\mathrm{Cu} K \alpha(\lambda=1,54056 \AA$ ). Los espectros se obtuvieron en el intervalo del 0-90

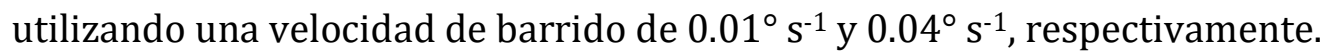

- $\quad$ Microscopia de barrido electrónico (SEM-EDX)

Las imágenes fueron tomadas en un microscopio electrónico de barrido Philips SEM 505, utilizando un voltaje de $25 \mathrm{eV}$ y un aumento desde 500X hasta 10000X. Las muestras fueron metalizadas previamente con oro. Mediante espectroscopia de energía dispersada (EDX) se determinó cualitativamente la presencia de los elementos Fe, Si y W. 
Capítulo III. Metodología y Desarrollo Experimental.

\subsection{EVALUACIÓN CATALÍTICA.}

3.8.1. Reacciones de esterificación del ácido 2-furoico con n-butanol catalizadas por los materiales del Grupo I.

Se escogió como reacción modelo la esterificación del ácido 2-furoico con nbutanol para obtener 2-furoato de n-butilo (Figura 26) y así evaluar la actividad de los materiales en reacciones de esterificación.

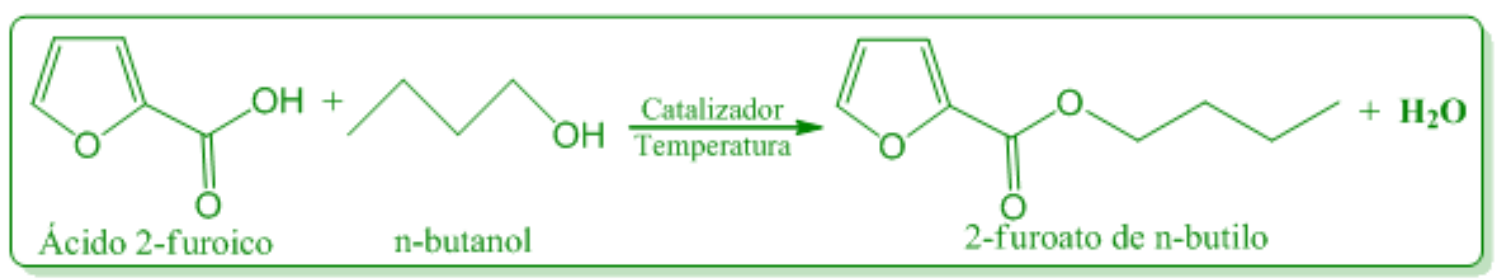

Figura 26. Reacción test: esterificación de ácido 2-furoico con n-butanol para sintetizar 2-furoato de n-butilo.

Para todas las pruebas de optimización se siguió el mismo procedimiento y se utilizó el mismo equipamiento. Un tubo de reacción con un condensador de reflujo de agua fue utilizado como reactor. Se cargaron cantidades predeterminadas de reactivos en el tubo, se agitó a 500 rpm y se llevó a la temperatura predeterminada. Una vez que se alcanzó la temperatura, se añadió el catalizador y se tomó la muestra de tiempo cero. Las muestras fueron tomadas a los de tiempo: 0, 0,5 1, 3, 5, 7 y $24 \mathrm{~h}$. Cada volumen de muestra fue de $10 \mu \mathrm{L}$ y se diluyó a $100 \mu \mathrm{l}$ en etanol. El seguimiento se hizo por cromatografía de gases (CG/FID). Las conversiones se calcularon con base al reactivo límite (el ácido 2-furoico), mediante el método de curva de calibración. El producto fue confirmado por análisis de GC-MS. En cada una de las condiciones estudiadas se hizo un blanco de reacción. Las condiciones estudiadas fueron: 
Capítulo III. Metodología y Desarrollo Experimental.

- $\quad$ Temperaturas de reacción: Se dejaron fijas las cantidades de ácido 2Furoico, n-butanol y catalizador y se varió la temperatura de la siguiente manera: $70,95,110,125$ y $140{ }^{\circ} \mathrm{C}$.

- Relación ácido/alcohol: Se dejó fija la temperatura y la cantidad de catalizador y se varió la relación ácido/alcohol en las siguientes proporciones: 1:2, 1:6, 1:11 y 1:33.

- $\quad$ Cantidad de catalizador: Se dejaron fijas las cantidades de ácido/alcohol y la temperatura, y se varió la cantidad de catalizador, los pesos fueron los siguientes: 50, 100, 150 y $200 \mathrm{mg}$.

\subsubsection{Procedimiento general para la síntesis de 2-furoatos de alquilo.}

Una vez determinadas las condiciones óptimas de reacción, se sintetizó una gran variedad de 2-furoatos de alquilo con diferentes alcoholes: primarios, secundarios y terciarios. En todas las síntesis se utilizaron las mismas cantidades y condiciones: 1 mmol de ácido 2-furoico, 2 mmoles del alcohol correspondiente y $50 \mathrm{mg}$ de catalizador se colocaron en un tubo de reacción. Se calentó a $125{ }^{\circ} \mathrm{C}$ y se dejó reaccionar durante 24 h con agitación constante. Cuando el tiempo de reacción se cumplió, la mezcla de reacción se extrajo con acetona (3 $\mathrm{mL})$, y el catalizador se filtró. La fase orgánica se secó sobre sulfato sódico anhidro y el disolvente se evaporó. Dependiendo del tipo de producto se purificó por recristalización o por separación líquido-líquido. Los productos se identificaron mediante CG/MS.

\subsubsection{Ensayos biológicos de los furoatos de alquilo como compuestos antifouling.}

Como se mencionó en la introducción, durante la presente Tesis Doctoral, se realizó un estudio de actividad biológica con algunos de los compuestos sintetizados, en un trabajo interdisciplinario junto con el grupo de Control de las Incrustaciones Biológicas del "Centro de Investigación y Desarrollo en Tecnología de Pinturas (CIDEPINT)". Dichas pruebas consistieron en analizar la actividad antifouling de los 
Capítulo III. Metodología y Desarrollo Experimental.

ésteres 2-furoato de n-butilo, 2-furoato de n-hexilo y 2-furoato de n-octilo, los cuales presentaron resultados positivos en la inhibición de asentamientos de diferentes especies marinas en placas que contenían pinturas formuladas con los furoatos, comparadas respecto al control. Aquí, se presentará la metodología de elaboración y evaluación de las pinturas.

\subsubsection{Bioensayos de laboratorio.}

Se utilizaron nauplios de Artemia sp. (primer larva característica de los crustáceos) para probar la toxicidad de los furoatos de alquilo. Quistes deshidratados de Artemia sp. se utilizaron para obtener larvas en etapa I, los cuales se incubaron durante $24 \mathrm{~h}$ a $20{ }^{\circ} \mathrm{C}$ bajo iluminación constante y aireación continua en una suspensión en agua de mar²11.

Se prepararon soluciones de 2-furoato de n-butilo, 2-furoato de n-hexilo y 2furoato de n-octilo disolviendo cada compuesto en DMSO, de las cuales se prepararon disoluciones para obtener concentraciones finales de furoato en agua de mar entre 0,08 y $80 \mu \mathrm{g} / \mathrm{ml}$. Posteriormente, cultivos de artemia que contenían entre 50-60 nauplios se expusieron a las soluciones de furoatos durante $24 \mathrm{~h}$, después de lo cual se contó el número de larvas vivas y muertas bajo microscopio estereoscópico. Las larvas de artemia se consideraron muertas cuando no mostraron ningún movimiento durante un período de observación de $30 \mathrm{~s}$. En el presente estudio, las pruebas de toxicidad se realizaron en placas de 24 pocillos múltiples de $2 \mathrm{~mL}$ cada una y se han repetido cuatro veces.

\subsubsection{Preparación de las pinturas.}

Las pinturas se prepararon en un molino de bolas de porcelana a escala de laboratorio $(1,0 \mathrm{~L})$ y se eligieron las condiciones de funcionamiento para lograr una dispersión eficiente. Se usó como ligante la resina colofonia (colofonia WW) y resina colofonía hidrogenada, como plastificante ácido oleico. Las pinturas anfouling se prepararon mediante disolución de las resinas y los plastificantes en tolueno, usando una dispersora de alta velocidad. El molino de bolas se cargó con esta mezcla y 
Capítulo III. Metodología y Desarrollo Experimental.

pigmentos de óxido de zinc y carbonato de calcio, y se dispersó durante $24 \mathrm{~h}$. Posteriormente, las pinturas se filtraron y se fraccionaron en cuatro porciones, una de las cuales se usó como control negativo y las restantes como tratamiento. Para los tratamientos, a las pinturas se les incorporaron 2-furoato de n-butilo, 2-furoato de nhexilo y 2 -furoato de n-octilo al $1 \%$ en peso. Finalmente, las pinturas se dispersaron durante 1 h. La composición de cada pintura se detalla en la Tabla 3.

Tabla 3. Composición de las pinturas expresadas como \% en peso.

\begin{tabular}{cccc}
\hline Componentes & Productos químicos & $\begin{array}{c}\text { Pintura base } \\
(\mathrm{PB})\end{array}$ & $\begin{array}{c}\text { Pinturas AF } \\
(\mathrm{PA})\end{array}$ \\
\hline Pigmentos & Óxido de zinc & 33,2 & 33,2 \\
& Carbonato de calcio & 11,1 & 11,1 \\
\multirow{2}{*}{ Resinas } & Colofonía hidrogenada & 14,9 & 14,9 \\
& Colofonía WW & 12,5 & 12,5 \\
\multirow{2}{*}{ Plastificantes } & Resina de politerpeno & 2,3 & 2,3 \\
& Ácido oleico & 3,8 & 3,8 \\
Solvente & Tolueno & 22,0 & 22,0 \\
Aditivo AF & Furoatos & ---- & 1,0 \\
\hline
\end{tabular}

\subsubsection{Pruebas de campo.}

Se utilizaron probetas acrílicas arenadas y desengrasadas con un área de $4 \times 12$ $\mathrm{cm}^{2}$, para aplicar las pinturas anfouling. Se aplicaron cuatro capas de pintura dejando un tiempo de secado de $24 \mathrm{~h}$ entre cada capa para obtener un espesor seco final de 75 $\pm 5 \mu \mathrm{m}$. Los paneles revestidos se sumergieron en Club Náutico en el puerto de Mar del Plata (Argentina) $\left(38^{\circ} 02^{\prime} 30^{\prime \prime S}-57^{\circ} 32^{\prime} 00^{\prime \prime} \mathrm{W}\right)$.

De igual forma, se sumergieron pobetas sin recubrimiento y otras recubiertas con matriz de pintura sin el agente antifouling, las cuales se usaron como controles. Los experimentos de campo se evaluaron durante 45 días de exposición en el mar en la temporada de verano. El asentamiento de organismos incrustantes se estimó como 
Capítulo III. Metodología y Desarrollo Experimental.

cobertura porcentual en pinturas usando el método de estimación de cuadrícula de puntos $^{212}$. Todas las pruebas fueron realizadas por triplicado. Todos los análisis estadísticos se realizaron con IBM SPSS Statistics. Los cálculos de CL50 con intervalos de confianza del 95\% para cada concentración se realizaron con análisis Probit. Los datos se analizaron estadísticamente mediante SPSS.

\subsubsection{Reacciones de esterificación del ácido 2-furoico con 2-fenoxietanol catalizadas por los materiales del Grupo II.}

Cuando se realizó la síntesis de diferentes ésteres del ácido 2-furoico con los catalizadores del Grupo I, se determinó que el éster 2-furoato de 2-fenoxietilo, no se encontraba descrito en la literatura, por tal motivo, para realizar el estudio de actividad catalítica de los materiales del Grupo II se escogió esta reacción, y así conocer más sobre la síntesis y el comportamiento de este compuesto nuevo. La reacción modelo fue la esterificación del ácido 2-furoico con 2-fenoxietanol para obtener 2furoato de 2-fenoxietilo (Figura 27).

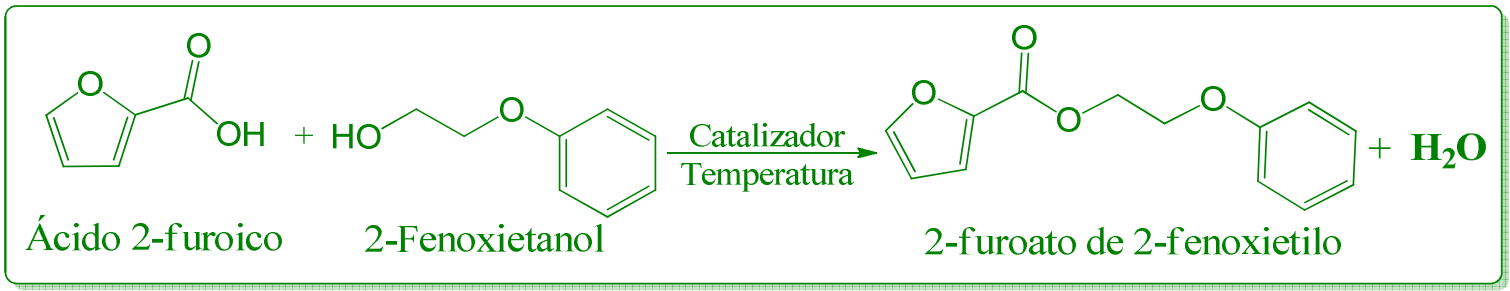

Figura 27. Reacción test: esterificación del ácido 2-furoico con 2-fenoxietanol para sintetizar 2-furoato de 2-fenoxietilo.

Se utilizó un tubo de ensayo como reactor. Se cargaron cantidades predeterminadas de reactivos en el tubo, se agitó a 500 rpm y se llevó a la temperatura predeterminada. Una vez que se alcanzó la temperatura, se añadió el catalizador y se tomó la muestra de tiempo cero. Las muestras fueron tomadas a los de tiempo: 0, 0,5 1, 3, 5, 7 y 24 h. El seguimiento se hizo por cromatografía de gases (CG/FID). Las conversiones se calcularon con base al reactivo límite (el ácido 2-furoico), mediante el método de curva de calibración. El producto fue confirmado por análisis de GC-MS. En 
Capítulo III. Metodología y Desarrollo Experimental.

cada una de las condiciones estudiadas se hizo un blanco de reacción. Las condiciones estudiadas fueron:

- Temperaturas de reacción: se dejaron fijas las cantidades de ácido 2furoico, 2-fenoxietanol y catalizador y se varió la temperatura de la siguiente manera: $95,110,125$ y $140{ }^{\circ} \mathrm{C}$.

- Relación ácido/alcohol: Se dejó fija la temperatura y la cantidad de catalizador y se varió la relación ácido/alcohol en las siguientes proporciones: 1:2, 1:6 y 1:11.

- $\quad$ Cantidad de catalizador: Se dejaron fijas las cantidades de ácido y alcohol y la temperatura y se varió la cantidad de catalizador, los pesos fueron los siguientes: 50, 100 y $150 \mathrm{mg}$.

Dado que el producto es nuevo, se identificó por varias técnicas de caracterización para confirmar su estructura como son: análisis de GC-MS, RMN de ${ }^{1} \mathrm{H}$ y ${ }^{13} \mathrm{C}$ y punto de fusión. Para el análisis de RMN, $30 \mathrm{mg}$ fueron disueltos en 0,4-0,6 mL del solvente deuterado. Los desplazamientos químicos $(\delta)$ están expresados en partes por millón (ppm) con respecto al tetrametilsilano (TMS), mientras que las constantes de acoplamiento (J) están expresadas en Hz.

2-fenoxietil-2-furoato: punto de fusión: $66-68{ }^{\circ} \mathrm{C}$ (etanol); $\mathrm{RMN}$ de ${ }^{1} \mathrm{H}(500 \mathrm{MHz}$, $\left.\mathrm{CDCl}_{3}\right): \delta 4.31(\mathrm{t}, 2 \mathrm{H}, \mathrm{J}=7 \mathrm{~Hz}), 4.68(\mathrm{t}, 2 \mathrm{H}, \mathrm{J}=7 \mathrm{~Hz}), 6.53(\mathrm{dd}, 1 \mathrm{H}, \mathrm{J}=7.5 \mathrm{~Hz}, \mathrm{~J}=7.5$ $\mathrm{Hz}), 6.97(\mathrm{~m}, 3 \mathrm{H}), 7.28(\mathrm{~m}, 3 \mathrm{H}), 7.61(\mathrm{dd}, 1 \mathrm{H}, \mathrm{J}=7.5 \mathrm{~Hz}, \mathrm{~J}=1.5 \mathrm{~Hz}), \mathrm{RMN}$ de ${ }^{13} \mathrm{C}(100$ $\left.\mathrm{MHz}_{\mathrm{CDCl}}\right): \delta 63.25,65.80,111.90,114.69,118.43,121.22,129.53,144.32,146.55$, 158.47,158.59. IEMS: m/z (I \%): 232 (2) $\mathrm{M}^{+}, 139$ (61), 95 (35), 77 (4), 51 (14), 44 (43), 39 (45), 32 (38), 28 (100). 
Capítulo III. Metodología y Desarrollo Experimental.

\subsubsection{Reacciones de esterificación del ácido levulínico con n-butanol catalizadas} por los materiales del Grupo III.

Los catalizadores del Grupo III fueron evaluados en la reacción de esterificación del ácido levulínico con n-butanol para obtener levulinato de n-butilo (Figura 28), ya que éste es un producto interesante para ser estudiado por sus numerosas aplicaciones.

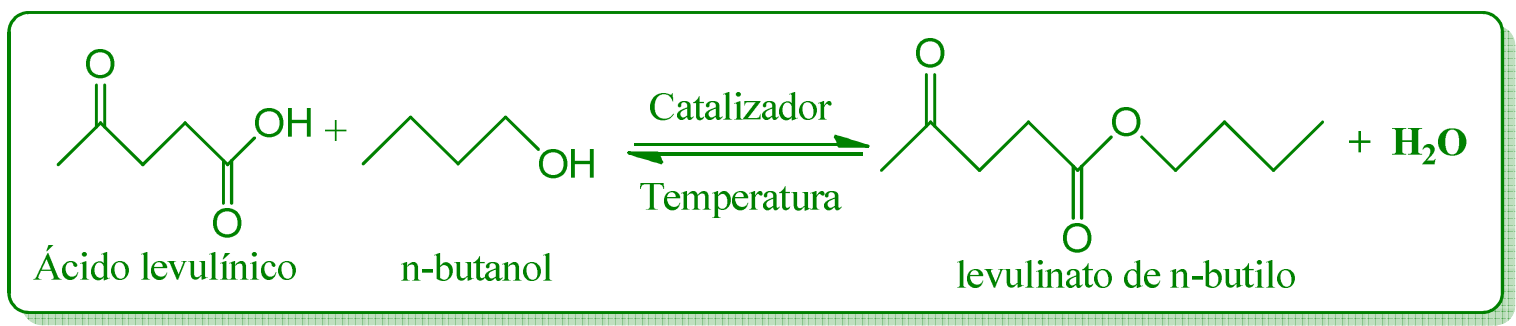

Figura 28. Reacción test: esterificación del ácido levulínico con n-butanol para sintetizar levulinato de n-butilo.

Se utilizó un tubo de ensayo como reactor. Una vez cargadas las cantidades de los reactivos y alcanzada la temperatura predeterminada, se añadió el catalizador y se tomó la muestra de tiempo cero. Los tiempos en los que se tomaron muestras de la reacción fueron $0,0,50,1,2,3,4,5,6$ y 7 h. El rendimiento de la reacción se cuantificó por cromatografía de gases (CG/FID). Cada volumen de muestra fue de $10 \mu \mathrm{L}$ y se diluyó hasta $100 \mu \mathrm{L}$ con etanol. Se estimó la conversión por el método de normalización de áreas siguiendo la desaparición del ácido levulínico como reactivo limitante y la formación de levulinato de n-butilo. Se variaron las siguientes condiciones para determinar las condiciones óptimas de reacción y realizar el test catalítico:

- Temperaturas de reacción: el efecto de la temperatura se estudió en el rango de 40 a $80{ }^{\circ} \mathrm{C}$, con espaciamiento constante de $10^{\circ} \mathrm{C}$.

- Relación ácido/alcohol: las relaciones analizadas fueron 1:2, 1:4, 1,6 y 1:8 y se realizó en cada temperatura. 


\section{Capítulo III. Metodología y Desarrollo Experimental.}

- Cantidad de catalizador: Debido a que el mejor rendimiento de la reacción se logró a $80^{\circ} \mathrm{C}$ y una relación molar ácido/alcohol de 1:2, se escogieron estas condiciones como las mejores para evaluar la cantidad de catalizador, para lo cual se dejaron constantes y se varió el peso de catalizador. Los valores fueron: 25,50 , 100 y 150 mg por mol de ácido levulínico.

\subsubsection{Reutilización de los catalizadores.}

Para evaluar la reutilización de todos los catalizadores preparados durante esta Tesis Doctoral, se llevaron a cabo cuatro experimentos consecutivos, bajo las mismas condiciones de reacción. Después de cada prueba, el catalizador se separó de la mezcla de reacción por filtración o precipitación magnética, según sea el caso, se lavó con tolueno ( 2 × $2 \mathrm{~mL})$, se secó en estufa de vacío a temperatura ambiente, y se volvió a hacer la reacción adaptando las cantidades de los reactivos a la cantidad de catalizador recuperado. Para el primer ensayo se usaron las cantidades y condiciones óptimas que se determinaron para cada reacción. 


\section{Capítulo IV: ANÁLISIS DE RESULTADOS.}


Capítulo IV. Análisis de Resultados.

\subsection{CARACTERIZACIÓN DE LOS MATERIALES DE LOS GRUPOS I Y II.}

\subsubsection{Espectrometría de absorción atómica (EAA).}

El contenido de TPA y TSA en las muestras de los Grupo I y II, se estimó como la diferencia entre la cantidad de W contenida en las soluciones iniciales de los heteropoliácidos incorporadas durante la síntesis de los catalizadores y la cantidad de W en las soluciones obtenidas durante el lavado de los xerogeles, mediante la técnica de espectrometría de absorción atómica.

Los resultados obtenidos para las muestras del Grupo I revelaron que más del 99\% del TPA originalmente agregado durante la síntesis, se incorpora al material final. Igualmente ocurrió con los materiales del Grupo II, donde el contenido de W fue de $22,6 \%(\mathrm{p} / \mathrm{p})$ y $23,2 \%(\mathrm{p} / \mathrm{p})$ para las muestras $\mathrm{TPA} / \mathrm{TiO}_{2}$ y $\mathrm{TSA} / \mathrm{TiO}_{2}$, respectivamente, coincidiendo con la cantidad inicial de $\mathrm{W}$ añadida durante la síntesis donde se agregaron soluciones con concentración de $\mathrm{W}$ de 22,9\% para TPA (p/p) y 23,5\% para TSA (p/p), lo que muestras que casi la totalidad del TPA y del TSA queda firmemente retenido en los sólidos.

\subsubsection{Microscopía de barrido electrónico (SEM).}

La morfología de los materiales sintetizados en el presente trabajo fue estudiada mediante microscopia de barrido electrónico. Las imágenes SEM a 10000 aumentos, de los materiales ZrPEGTPA30T100 y ZrTPA30PEGT100 del Grupo I se muestran en la Figura 29. En ellas puede verse la formación de aglomerados de partículas esféricas con una heterogeneidad en cuanto al tamaño, presentando un amplio rango de distribución de partículas, con valores que oscilan entre los 50 y los $500 \mathrm{~nm}$; estas características se presentan en las muestras independientemente del método de síntesis, indicando que el orden en que se agrega el TPA y el PEG no condiciona la forma y el tamaño final de los materiales. 
Capítulo IV. Análisis de Resultados.
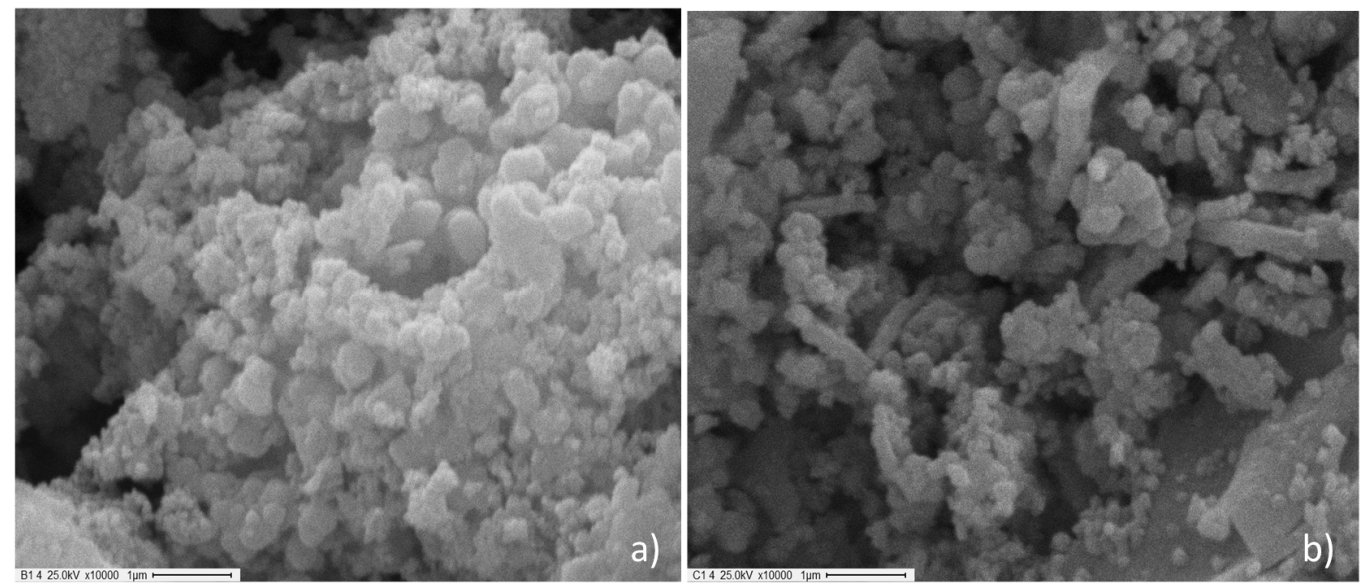

Figura 29. Imágenes SEM de las muestras del Grupo I a) ZrPEGTPA30T100 y b) ZrTPA30PEGT100.

En el caso de los materiales del Grupo II, las imágenes SEM (Figura 30) a 10000 aumentos mostraron que todas las muestras sintetizadas están compuestas de nanopartículas esféricas con un diámetro medio de alrededor de $500 \mathrm{~nm}$. Esta morfología se produce por la presencia de urea durante la preparación de la muestra. Como se reporta en la bibliografía ${ }^{140,213}$, la descomposición de la urea en solución acuosa durante la síntesis sol-gel podría aumentar suavemente el $\mathrm{pH}$, dando lugar a la formación de nanopartículas de $\mathrm{TiO}_{2}$ con un control morfológico, en este caso, esférico.

Por otro lado, las mediciones de EDX revelaron la existencia de las señales de W L $\alpha 1$ y $\mathrm{M} \alpha 1$ en 8.396 y $1.779 \mathrm{KeV}$, respectivamente para la muestra de $\mathrm{TiO}_{2} / \mathrm{TPA}$, mientras que la muestra de $\mathrm{TiO}_{2} / \mathrm{TSA}$ mostró las mismas señales para el $\mathrm{W}$ y una nueva en $1.838 \mathrm{KeV}$ asignado a la línea Si M $\alpha$. Este hecho está estrechamente relacionado con la presencia de POMs o algunos de sus subproductos de degradación en la superficie modificada de $\mathrm{TiO}_{2}$. 


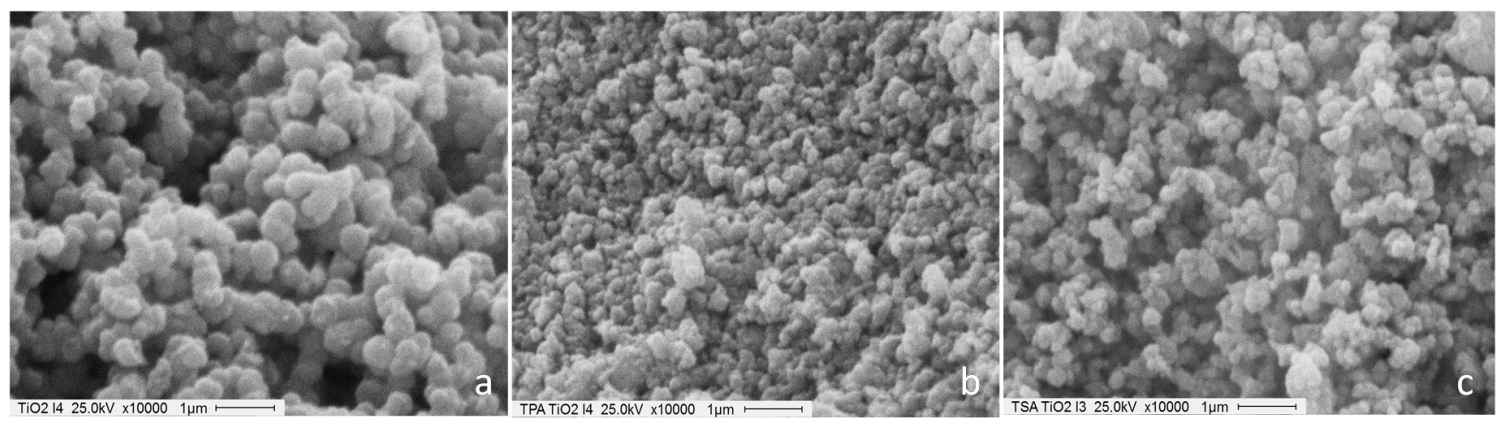

Figura 30. Imágenes SEM de las muestras del Grupo II a) $\mathrm{TiO}_{2}$ b) $\mathrm{TiO}_{2} / \mathrm{TPA}$ y c) $\mathrm{TiO}_{2} / \mathrm{TSA}$.

\subsubsection{Isotermas de adsorción- desorción de nitrógeno.}

Las isotermas de adsorción-desorción a la temperatura del nitrógeno líquido son una de las herramientas fundamentales para determinar las propiedades texturales de los materiales, debido a que la superficie específica y la porosidad juegan un papel importante en el desempeño del catalizador. La IUPAC reconoce tres tipos de poros atendiendo a su diámetro, a saber, microporos (menores a $2 \mathrm{~nm}$ ), mesoporos (entre 2 y $50 \mathrm{~nm}$ ) y macroporos (mayores a $50 \mathrm{~nm}$ ). Así mismo, para unificar criterios y facilitar el análisis de las isotermas, en 1985, Sing y col ${ }^{214}$ proporcionaron una correlación ampliamente aceptada entre la forma de los bucles de histéresis y la geometría y textura del adsorbente que permitió clasificar los tipos comunes de isotermas en seis clases.

De este modo, las isotermas obtenidas tanto para la familia de materiales basados en $\mathrm{ZrO}_{2}$ (Figura 31.a), como para la familia basada en $\mathrm{TiO}_{2}$ (Figura 31.b) pudieron ser clasificadas como tipo IV con bucles de histéresis mayormente tipo H2 y se pudo deducir que todas presentan las características principales asignadas a los materiales mesoporosos. La histéresis se asocia normalmente con la condensación capilar en la estructura de los mesoporos, se suele atribuir a diferentes tamaños de boca de poro y cuerpo de poro (este es el caso de poros en forma de botella de tinta) o a un comportamiento diferente en la adsorción y desorción en poros de paso casi cilíndricos. Sin embargo, según Thommes y col$^{215}$, la forma y la anchura de los bucles 
Capítulo IV. Análisis de Resultados.

de la histéresis en la desorción dependen tanto de los estados termodinámicos del fluido poroso como de fluido bulk y del diámetro de poro. Además, a temperaturas por debajo del punto triple del bulk también dependen fuertemente de la textura y el grado de desorden del material poroso.

En nuestras muestras, la histéresis apenas es visible, atribuibles a sólidos producidos por agregados de partículas esferoidales, característica de la presencia de poros cilíndricos o conos ciegos no uniformes ${ }^{216}$, aunque, en la literatura, la ausencia de la histéresis para materiales como MCM-41 y titania modificada con ácido tungstofosfórico 217,218 se ha atribuido a un arreglo ordenado de los mesoporos presentes en el material.

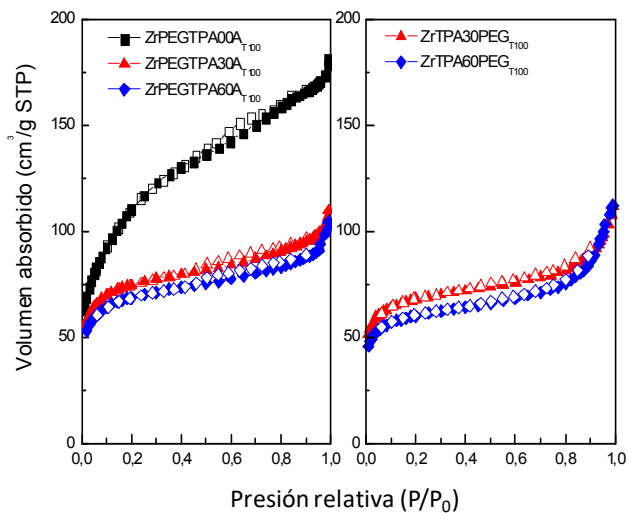

a

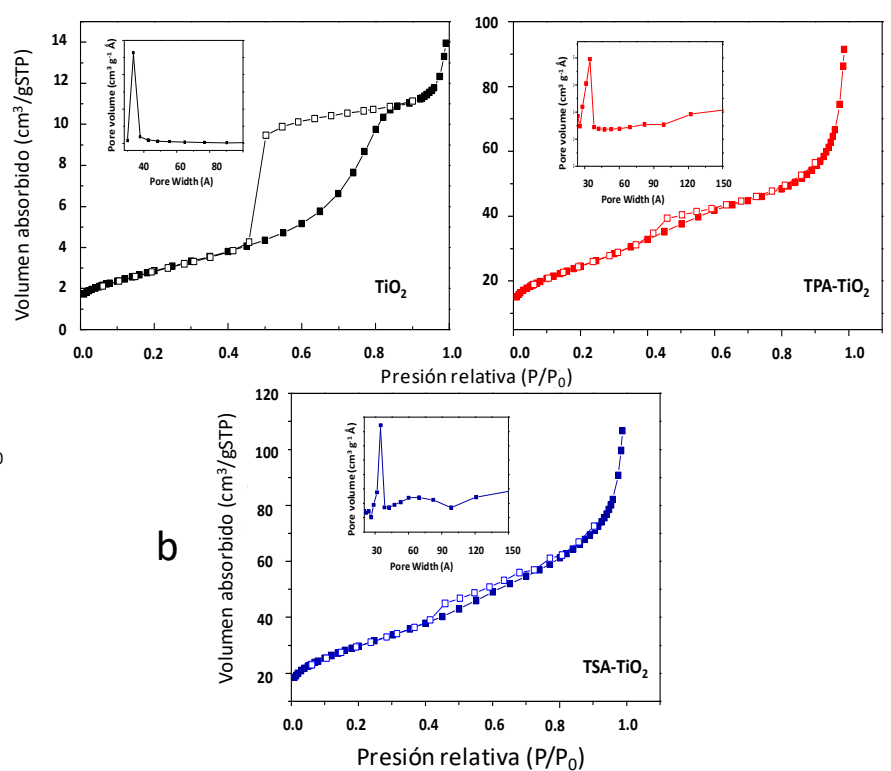

Figura 31. Isotermas de adsorción-desorción a la temperatura del nitrógeno líquido de los Grupos I y II. a) Catalizadores soportados sobre $\mathrm{ZrO}_{2}$ y b) Catalizadores soportados sobre $\mathrm{TiO}_{2}$. 
Capítulo IV. Análisis de Resultados.

Además de clasificar los materiales como mesoporosos según la forma de las isotermas, de este mismo análisis se obtuvieron datos importantes como son el área superficial ( $\mathrm{S}_{\mathrm{BET}}$ ), el diámetro de poro medio ( $\mathrm{D}_{\mathrm{P}}$ ) y la superficie específica de microporos (SMicro) mediante la ecuación de Brunauer-Emmett-Teller (BET) y el método t-plot, respectivamente. Los valores de estos parámetros obtenidos para los materiales soportados sobre $\mathrm{ZrO}_{2}$ y $\mathrm{TiO}_{2}$ se muestran en la Tabla 4.

Analizando primero los valores para la familia de $\mathrm{ZrO}_{2}$, se observa que el valor

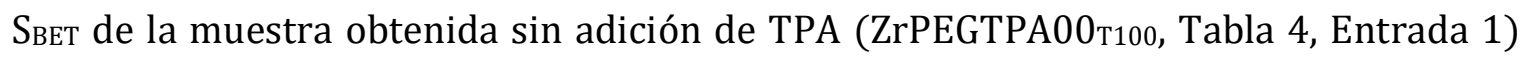
presentó el área superficial específica más alta. Cuando el TPA se añadió junto con el PEG, el SBET disminuyó y la SMicro aumentó (Tabla 4, Entradas 2 y 3). Cuando el TPA se añadió antes del PEG (Tabla 4, Entradas 4 y 5), el SBET disminuyó mucho más y la SMicro fue ligeramente superior. Los sólidos con mayor contenido de TPA (ZrTPA60PEGT100 y ZrTPAPEG60T100 (Tabla 4, Entradas 3 y 5) mostraron el SBET más baja. Esta disminución de la $\mathrm{S}_{\mathrm{BET}}$ ocurre en primer término por el efecto de la disminución de la zirconia en el material final ya que un 30 o un 60\% corresponden al TPA incorporado durante la síntesis. En segundo término, puede atribuirse a una disminución en el grado de reticulación durante la síntesis sol-gel cuando la concentración de ácido se incrementa, de acuerdo con los informes de la literatura que indican un comportamiento similar para la superficie específica de titania mesoporosa obtenida a través del proceso sol-gel ${ }^{175,219}$.

Sin embargo, analizando la familia de catalizadores de $\mathrm{TiO}_{2}$, encontramos que el sólido $\mathrm{TiO}_{2}$ mostró una superficie específica más baja (Tabla 4, Entrada 6) que las muestras $\mathrm{TiO}_{2} / \mathrm{TPA}$ y $\mathrm{TiO}_{2} / \mathrm{TSA}$ (Tabla 4, Entradas 7 y 8). Este valor menor para la muestra libre de heteropoliácidos, es debido a una fuerte interacción del heteropoliácido (TPA o TSA) con los grupos Ti-OH, lo que reduce la sinterización y a su vez, estabiliza la fase anatasa de la titania, que conduce a una mayor superficie a igual temperatura de tratamiento térmico del catalizador ${ }^{220}$. Finalmente, en todos los casos, las aéreas de la familia $\mathrm{TiO}_{2}$ son mucho menores que los de $\mathrm{ZrO}_{2}$, aunque el diámetro de poro es ligeramente mayor. 
Capítulo IV. Análisis de Resultados.

Tabla 4. Área superficial específica (SBET), superficie específica de microporos (SMicro) y diámetro promedio de poro $\left(\mathrm{D}_{\mathrm{p}}\right)$ para las familias de catalizadores de zirconia y titania.

\begin{tabular}{|c|c|c|c|c|}
\hline Entrada & Catalizador & $\begin{array}{c}\mathrm{S}_{\mathrm{BET}} \\
\left(\mathrm{m}^{2} / \mathrm{g}\right)\end{array}$ & $\begin{array}{l}\text { S }_{\text {Micro }}{ }^{\mathrm{a}} \\
\left(\mathrm{m}^{2} / \mathrm{g}\right)\end{array}$ & $\begin{array}{l}\mathrm{DP}^{\mathrm{b}} \\
(\mathrm{nm})\end{array}$ \\
\hline 1 & ZrPEGTPA00T100 & 396 & 6 & 2.8 \\
\hline 2 & ZrPEGTPA30T100 & 243 & 160 & 3.4 \\
\hline 3 & ZrPEGTPA60T100 & 213 & 140 & 3.6 \\
\hline 4 & ZrTPA30PEGT100 & 236 & 135 & 3.5 \\
\hline 5 & ZrTPA60PEGT100 & 198 & 106 & 3.2 \\
\hline 6 & $\mathrm{TiO}_{2}$ & 57 & 35 & 4.1 \\
\hline 7 & $\mathrm{TiO}_{2} / \mathrm{TPA}$ & 115 & 40 & 4.2 \\
\hline 8 & $\mathrm{TiO}_{2} / \mathrm{TSA}$ & 126 & 41 & 4.3 \\
\hline
\end{tabular}

aSuperficie de microporos estimada a partir del método t-plot.

bDiametro medio de poro estimado a partir de $S_{\text {BET. }}$

\subsubsection{Resonancia magnética nuclear de giro de ángulo mágico (RMN/MAS).}

La espectroscopia de RMN/MAS es un poderoso método y posiblemente el más versátil para el análisis de una amplia gama de sistemas, incluyendo materiales inorgánicos, productos farmacéuticos y biomacromoléculas. Las interacciones magnéticas son altamente sensibles al ambiente local, y por tanto, los espectros RMN ofrecen una resolución exquisita que permite la identificación de tipos individuales de núcleos presentes en complejas moléculas.

Sus aplicaciones para el análisis estructural de catalizadores heterogéneos son numerosas y diversas. La técnica ha sido utilizada para sondear los diversos aspectos de la estructura de catalizadores, tales como sustituciones de heteroátomos, distribución de defectos, interacciones fase activa-soporte y efectos de confinamiento, así como la acidez ${ }^{221}$. Ha sido comúnmente utilizada en especies como ${ }^{29} \mathrm{Si},{ }^{31} \mathrm{P},{ }^{1} \mathrm{H},{ }^{19} \mathrm{~F}$, ${ }^{129} \mathrm{Xe}$ y fue la técnica que se utilizó para caracterizar los heteropoliácidos soportados 
Capítulo IV. Análisis de Resultados.

sobre $\mathrm{ZrO}_{2}$ y $\mathrm{TiO}_{2}$. Como se mencionó anteriormente, los materiales $\mathrm{Fe}_{3} \mathrm{O}_{4} @ \mathrm{SiO}_{2}$ no se pudieron analizar debido a su naturaleza magnética.

Los espectros de RMN de compuestos de fósforo se pueden registrar con relativa facilidad ya que el ${ }^{31} \mathrm{P}$ pertenece a los llamados núcleos amigables con spin 1/2, caracterizados por un alto giro magnético y 100\% de abundancia isotópica natural.

La principal diferencia en los espectros RMN ${ }^{31} \mathrm{P}$ entre sólidos y líquidos es la movilidad de las moléculas en una muestra. En el estado líquido, la caída de las moléculas promedia las interacciones que influyen en la forma de la línea (por ejemplo, acoplamientos dipolares y cuadrupolares), de modo que la respuesta de RMN se debe principalmente a cambios químicos y acoplamiento escalar. En el estado sólido, el acoplamiento dipolar, la anisotropía de desplazamiento químico (CSA) y los efectos cuadrupolares no son promedios $\mathrm{y}$, por lo tanto, causan un ensanchamiento significativo de las líneas de resonancia ${ }^{222}$, esto se puede observar en los espectros RMN/MAS ${ }^{31} \mathrm{P}$ obtenidos para el Grupo I, mostrados en la Figura 32, correspondientes a los catalizadores ZrPEGTPA30т100, ZrPEGTPA60т100, ZrTPA30PEGт100 у ZrTPA60PEGT100, los cuales se caracterizan por bandas anchas con un máximo de aproximadamente -14 ppm. Dichas bandas, presentan un ancho de línea aun mayor y un desplazamiento de campo descendente en comparación con el TPA másico (-15.3 ppm), cuando se soportan, esto se puede atribuir a la interacción entre el anión y la matriz de zirconia ${ }^{223,224}$ y se puede suponer que la interacción es del tipo electrostático debido a la transferencia de protones a $\mathrm{Zr}-\mathrm{OH}^{225}$ según:

$$
\mathrm{Zr}-\mathrm{OH}+\mathrm{H}_{3} \mathrm{PW}_{12} \mathrm{O}_{40} \rightarrow\left[\mathrm{Zr}-\mathrm{OH}_{2}{ }^{+}\right]_{n}\left[\mathrm{H}_{3-\mathrm{n}} \mathrm{PW}_{12} \mathrm{O}_{40}\right]^{\mathrm{n}-}
$$

Aunque también cabe la posibilidad de interacciones del tipo enlaces de hidrógeno entre los átomos de oxígeno de las especies de TPA y los grupos hidroxilo de la matriz de la zirconia. 
Capítulo IV. Análisis de Resultados.

En los cuatro espectros RMN/MAS de ${ }^{31} \mathrm{P}$ del Grupo I, además del pico máximo a $14 \mathrm{ppm}$, que evidencia la presencia del anión Keggin $\left[\mathrm{PW}_{12} \mathrm{O}_{40}\right]^{3-}$, se puede ver un hombro a -12 ppm, adjudicado a la especie dimérica $\left[\mathrm{P}_{2} \mathrm{~W}_{21} \mathrm{O}_{71}\right]^{6-226}$. Teniendo en cuenta los resultados de FT-IR y ${ }^{31} \mathrm{P}$ RMN/MAS, puede establecerse que el anión $\left[\mathrm{PW}_{12} \mathrm{O}_{40}\right]^{3-}$ es la especie principal en las muestras. Sin embargo, se transformó parcialmente en los aniones $\left[\mathrm{P}_{2} \mathrm{~W}_{21} \mathrm{O}_{71}\right]^{6-} \mathrm{y}\left[\mathrm{PW}_{11} \mathrm{O}_{39}\right]^{7-}$ durante las etapas de síntesis y secado. Según Pope ${ }^{227}$, la transformación se debe al limitado rango de estabilidad del anión $\left[\mathrm{PW}_{12} \mathrm{O}_{40}\right]^{3-}$ frente a los cambios de $\mathrm{pH}$, sugiriendo que el siguiente esquema de transformación ocurre cuando la concentración de hidroxilo se incrementa:

$$
\left[\mathrm{PW}_{12} \mathrm{O}_{40}\right]^{3-} \Leftrightarrow\left[\mathrm{P}_{2} \mathrm{~W}_{21} \mathrm{O}_{71}\right]^{6-} \Leftrightarrow\left[\mathrm{PW}_{11} \mathrm{O}_{39}\right]^{7-}
$$

Esto puede ser considerado como un camino válido seguido por las especies de TPA durante la síntesis de los catalizadores. Además, se puede observar también que los espectros de las muestras ZrTPA60PEGT100 у ZrPEGTPA60т100 presentan bandas de mayor intensidad comparados con los espectros de las muestras ZrTPA30PEGT100 y ZrPEGTPA30T100 evidenciando la mayor concentración del TPA presente en las dos primeras.

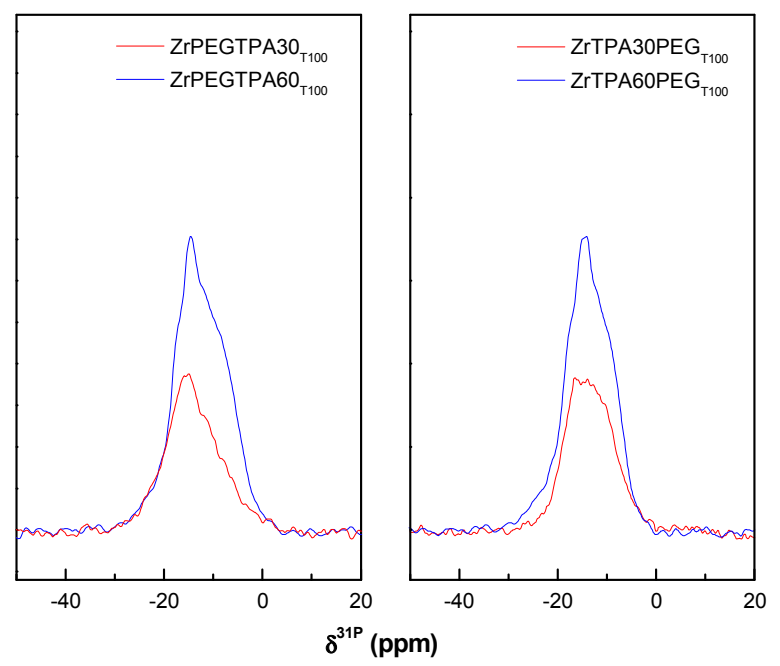

Figura 32. Espectros RMN/MAS de ${ }^{31} \mathrm{P}$ de los catalizadores del Grupo I. ZrPEGTPA30T100, ZrPEGTPA60T100, ZrTPA30PEGT100, y ZrTPA60PEGT100. 
Capítulo IV. Análisis de Resultados.

Por otro lado, a los catalizadores del Grupo II, se les realizaron las mediciones de RMN/MAS de los núcleos ${ }^{31} \mathrm{P}$ y ${ }^{29} \mathrm{Si}$ (Figura 33.a y 33.b respectivamente) revelando que tanto en la muestra $\mathrm{TiO}_{2} / \mathrm{TPA}$ como en la muestra $\mathrm{TiO}_{2} / \mathrm{TSA}$ presentan la presencia de aniones Keggin de estos dos heteropoliácidos. El espectro de ${ }^{31} \mathrm{P}$ del TPA bulk mostrado en la figura 33a.2 exhibió un doblete a -14.7 y -15.0 ppm, correspondiente a la presencia del anión Keggin hidratado del ácido tungstofosfórico 228,229.

Cuando se realizó el espectro de la muestra $\mathrm{TPA}_{\mathrm{TiO}}$, ésta exhibió una señal intensa a -13.5 ppm y también un amplio pico que variaba de 1 a -20 ppm (Figura 33a.1). Según la deconvolución, esta última señal amplia (Figura 33a.3) presentó un máximo a -12 ppm, y no estaba presente en la muestra de $\mathrm{TiO}_{2}$ puro.

Así, las señales a -13.5, -11.2 y -12.0 ppm se asignaron a la presencia del anión Keggin 218,230 y a las especies lacunar $\left[\mathrm{PW}_{11} \mathrm{O}_{39}\right]^{7-}$ y dimérica $\left[\mathrm{P}_{2} \mathrm{~W}_{21} \mathrm{O}_{71}\right]^{6-}$ respectivamente, que como ya se mencionó anteriormente, se forman debido a una descomposición parcial del TPA durante la síntesis en la que la urea se utiliza como agente formador de poro y se forma amoníaco (procedente de la hidrólisis de urea), aumentando ligeramente el pH de la solución. Adicionalmente, la descomposición puede deberse también al tratamiento térmico a $500{ }^{\circ} \mathrm{C}^{213,231,232}$.

Con respecto a las mediciones de $\mathrm{RMN} / \mathrm{MAS}$ de ${ }^{29} \mathrm{Si}$, el anión Keggin $\left[\mathrm{SiW}_{12} \mathrm{O}_{40}\right]^{4-}$ del TSA bulk corresponde a la señal a -84.7 ppm (Figura 33b.2) y dicha señal se desplaza a -85 ppm cuando el TSA es soportado sobre $\mathrm{TiO}_{2}$ (Figura 33b.1), debido nuevamente a la interacción del anión Keggin con la superficie de $\mathrm{TiO}_{2}$.

También se observó la presencia de una señal amplia entre -80 y -120 ppm y centrada en -110 ppm (Figura 33b.2 y 33b.3) que podría ser asignado a especies silicato o especies lacunares (tales como $\left[\mathrm{SiW}_{11} \mathrm{O}_{39}\right]^{8-}$ ) procedentes de una degradación parcial del TSA producida por la temperatura de calcinación ${ }^{233,234}$. 
Capítulo IV. Análisis de Resultados.

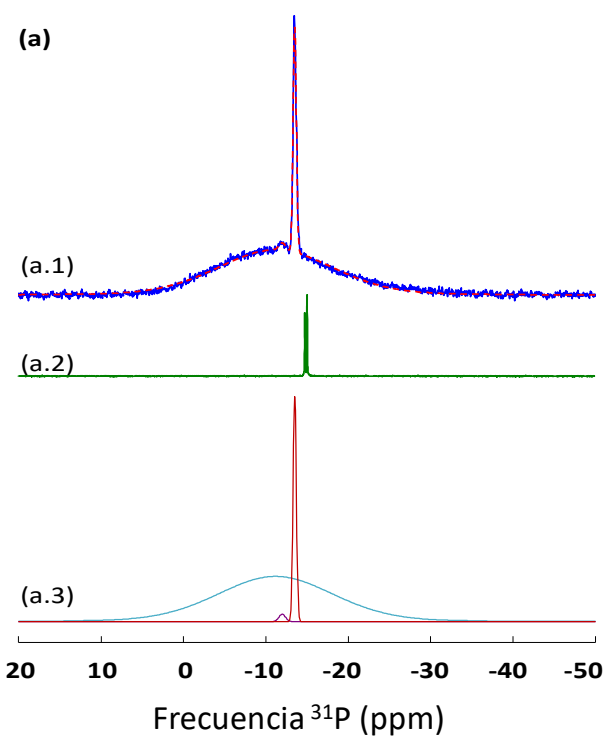

(b)
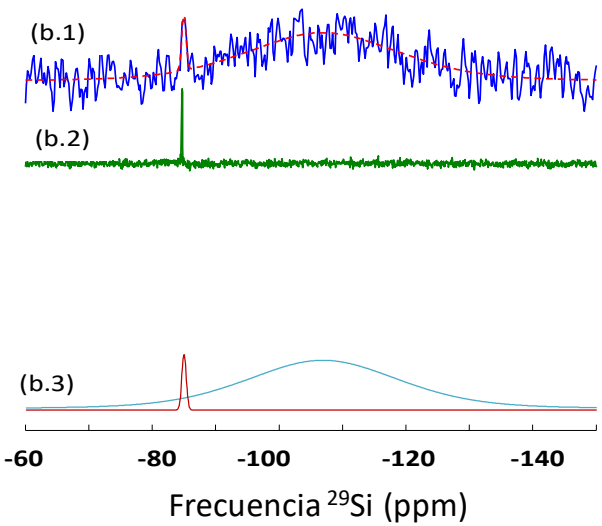

Figura 33. Espectros RMN/MAS del Grupo II. (a) espectros RMN/MAS de ${ }^{31} \mathrm{P}$ de (a.1) $\mathrm{TiO}_{2} / \mathrm{TPA}$, (a.2) TPA Bulk y (a.3) los tres componentes individuales de la simulación mostrados como una línea roja en (a.1). (b) espectros RMN/MAS de ${ }^{29} \mathrm{Si}$ de (b.1) muestras de $\mathrm{TiO}_{2}$ /TSA, (b.2) TSA bulk y (b.3) los dos componentes individuales de la simulación mostrados como una línea roja en (b.1).

\subsubsection{Fuerza ácida por titulación potenciométrica con n-butilamina.}

La acidez es una característica determinante en un catalizador sólido ácido ya que de ello depende principalmente su desempeño y rango de aplicabilidad. En esta oportunidad se estimó por medio de la titulación potenciométrica con n-butilamina, técnica que registra la variación del potencial del electrodo cuando se valora el catalizador ácido con una base.

El potencial inicial (Ei) del electrodo indica la máxima fuerza ácida de los sitios y el área bajo la curva Ei vs mequivalente/g representa el número total de sitios ácidos por gramo de catalizador $\left(\mathrm{N}_{\mathrm{GC}}\right)$. Los sitios ácidos presentes pueden clasificarse considerando la escala de la Tabla 5235,236: 
Capítulo IV. Análisis de Resultados.

Tabla 5. Fuerza de acidez según el potencial medido

\begin{tabular}{cl}
\hline Potencial (E) $\mathrm{mV}$ & \multicolumn{1}{c}{ Grado de fuerza } \\
\hline $\mathrm{Ei}>100$ & Sitios muy fuertes \\
$0<\mathrm{Ei}<100$ & Sitios fuertes \\
$-100<\mathrm{Ei}<0$ & Sitios débiles \\
$\mathrm{Ei}<-100$ & Sitios muy débiles \\
\hline
\end{tabular}

La cantidad de base utilizada en la valoración hasta neutralizar el catalizador, expresada en meq de base/g de sólido, indica el número total de centros ácidos. Este método proporciona una medida semicuantitativa de sitios ácidos y tiene la ventaja de que es indiferente del color del catalizador, por lo que es apropiado para muestras oscuras como son algunos de los catalizadores que se sintetizaron en este trabajo.

Analizando los resultados de la titulación potenciométrica de los materiales del Grupo I, podemos indicar que la muestra no modificada $\mathrm{ZrPEGTPA00}_{\text {T100 }}$ presenta un Ei igual a $140 \mathrm{mV}$, correspondiente a sitios ácidos muy fuertes. Este valor aumentó significativamente en las muestras que contienen TPA, siendo de $394 \mathrm{mV}$ para ZrPEGTPA30T100, $397 \mathrm{mV}$ para ZrPEGTPA60 $_{\text {T100, }} 416 \mathrm{mV}$ para ZrTPA30PEGT100 у 420 $\mathrm{mV}$ para ZrTPA60PEGT100 (Figura 34). La fuerza ácida de los sólidos obtenidos añadiendo el TPA antes del PEG (ZrTPA30PEGT100 y ZrTPA60PEGT100) fue ligeramente superior a la de las preparadas añadiéndolos simultáneamente comparándolas a la misma cantidad de TPA. Sin embargo, la concentración de sitios ácido aumentó ligeramente al aumentar la concentración de TPA indicando que el incremento de la cantidad de TPA utilizado durante la síntesis, no se refleja directamente en la cantidad de sitios ácidos sobre la superficie del catalizador, susceptibles de ser medidos mediante esta técnica.

Es importante destacar la menor fuerza ácida de los compuestos de ácido tungstofosfórico/zirconia en comparación con el TPA másico el cual tiene un Ei de 620 $\mathrm{mV}$, esto podría deberse al hecho de que los protones en $\mathrm{H}_{3} \mathrm{PW}_{12} \mathrm{O}_{40} \cdot 6 \mathrm{H}_{2} \mathrm{O}$ están presentes como especies $\mathrm{H}^{+}\left(\mathrm{H}_{2} \mathrm{O}\right)_{2}$, mientras que en las muestras modificadas están 
Capítulo IV. Análisis de Resultados.

interactuando con el oxígeno de los grupos Zr-OH o en un estado de hidratación más alto $\left(\mathrm{H}^{+}\left(\mathrm{H}_{2} \mathrm{O}\right)_{n}\right)$. Esto está de acuerdo con trabajos previos realizados en nuestro grupo de investigación ${ }^{237}$, donde se informó que en el compuesto $\mathrm{H}_{3} \mathrm{PW}_{12} \mathrm{O}_{40} \cdot 21 \mathrm{H}_{2} \mathrm{O}$, los protones están altamente hidratados, mostrando menor fuerza ácida $(\mathrm{Ei}=538 \mathrm{mV})$ que $\mathrm{H}_{3} \mathrm{PW}_{12} \mathrm{O}_{40} \cdot 6 \mathrm{H}_{2} \mathrm{O}$, mientras que en las sales parcialmente sustituidas $\mathrm{Cs}(\mathrm{K})_{2.9} \mathrm{H}_{0.1} \mathrm{PW}_{12} \mathrm{O}_{40}$ donde los protones no están hidratados mostraron un Ei en el intervalo de 900-1000 mV.

Además, cabe recordar que en las pruebas de RMN/MAS ${ }^{31} \mathrm{P}$, se evidenció que una pequeña parte del heteropoliácido se descompone parcialmente durante la síntesis de los catalizadores, generando especies lacunares y diméricas que aportan menos acidez. En los cuatro catalizadores sintetizados se estableció un comportamiento similar, por lo que se concluye que los valores $\mathrm{N}_{\mathrm{GC}}$ (expresados por gramo de catalizador) no dependen del tiempo transcurrido entre la adición de del PEG y la incorporación de TPA.

Figura 34. Curvas de titulación potentiométrica del Grupo I. Muestras ZrPEGTPA00T100, ZrPEGTPA30T100, ZrPEGTPA60T100, ZrTPA30PEGT100, у ZrTPA60PEGT100.

Pasando a los resultados del Grupo II (Figura 35), la anatasa $\mathrm{TiO}_{2}$, mostró una acidez similar a la de la zirconia $\left(\mathrm{E}_{\mathrm{i}}=150 \mathrm{mV}\right)$. Por su parte, las muestras de $\mathrm{TiO}_{2} / \mathrm{TPA}$ y $\mathrm{TiO}_{2} / \mathrm{TSA}$ mostraron sitios ácidos muy fuertes, con valores de Ei iguales a 378 y 398 $\mathrm{mV}$, respectivamente.

Los mismos, son muy superiores al obtenido para el $\mathrm{TiO}_{2}$, aunque menores que el de los heteropoliácidos másicos (Ei de $620 \mathrm{mV}$ para el TPA y $740 \mathrm{mV}$ para el TSA), presentando el mismo comportamiento que el Grupo I, donde al igual que los protones del TPA, los protones del TSA están presentes como especies $\mathrm{H}^{+}\left(\mathrm{H}_{2} \mathrm{O}\right)_{n}$ y al soportarlo sobre el óxido de titanio, éstos interactúan con el oxígeno de los grupos Ti-OH. 
Capítulo IV. Análisis de Resultados.

Es bien sabido que protones muy ácidos del anión Keggin del TPA podrían interactuar fácilmente con grupos superficiales Ti-OH de la titania, protonándolos y formando especies con la superficie del ácido tales como $\left(=\mathrm{TiOH}_{2}+\right)\left(\mathrm{H}_{2} \mathrm{PW}_{12} \mathrm{O}_{40} 0^{-}\right)$y $\left(=\mathrm{TiOH}_{2}{ }^{+}\right)_{2}\left(\mathrm{HPW}_{12} \mathrm{O}_{40}{ }^{2-}\right)^{230,232}$.

Después de la declaración anterior y aunque las interacciones entre el TSA con el $\mathrm{TiO}_{2}$ no han sido bien descritas en la literatura, es posible sugerir que los protones ácidos del TSA presentan el mismo comportamiento del TPA, interactuando con grupos Ti-OH de la superficie de la titania, formando especies ácidas superficiales $\left(=\mathrm{TiOH}_{2}{ }^{+}\right)_{\mathrm{x}}\left(\mathrm{H}_{4-\mathrm{x}} \mathrm{SiW}_{12} \mathrm{O}_{40} 0^{\mathrm{x}}\right)^{238,239}$.

El TSA también sufrió una degradación parcial, ya que en la prueba RMN de ${ }^{29} \mathrm{Si}$ se encontró una señal amplia entre -100 y -120 ppm, la cual podría deberse a la presencia de especies de sílice amorfa $\mathrm{Q}_{4} \mathrm{o}$ a especies lacunares tales como $\left[\mathrm{SiW}_{11} \mathrm{O}_{39}\right]^{8-}$ siendo una posible causa más de la menor acidez al soportar el heteropoliácido.

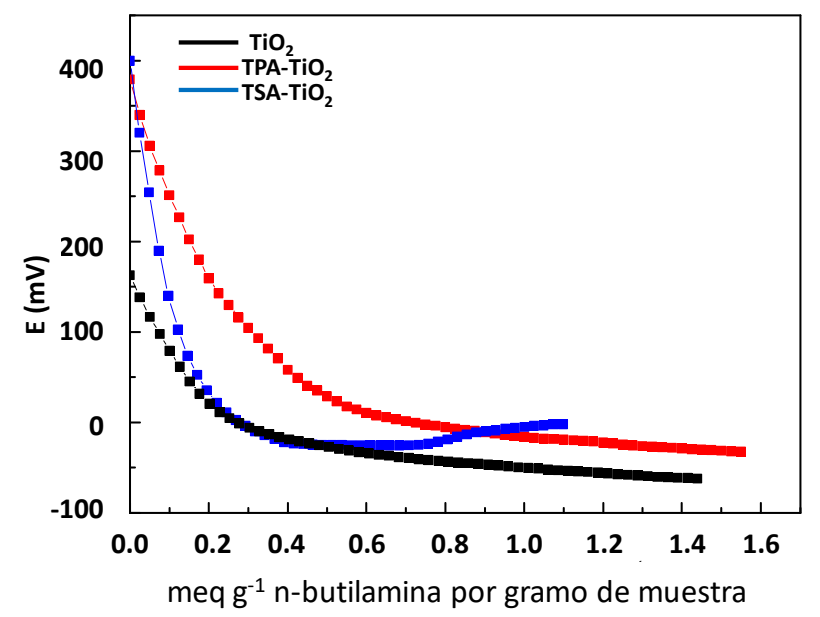

Figura 35. Curvas de titulación potentiométrica del Grupo II.

\subsubsection{Espectroscopia Infrarrojo por Transformada de Fourier (IR-TF).}

La espectroscopia infrarroja es utilizada para establecer grupos funcionales presentes en una muestra, ya que el espectro resultante actúa como una huella digital 
Capítulo IV. Análisis de Resultados.

de cada sustancia química, proporcionando información única sobre la estructura para su identificación.

Analizando el Grupo I, el espectro FT-IR de la muestra ZrPEGTPA00T100 (Figura 36) mostró una banda intensa entre 3600 y $3200 \mathrm{~cm}^{-1}$ y otra a $1600 \mathrm{~cm}^{-1}$, asignada a las vibraciones de estiramiento del agua $(\mathrm{O}-\mathrm{H})$ y a los enlaces $(\mathrm{H}-\mathrm{O}-\mathrm{H})$ y $(\mathrm{O}-\mathrm{H}-\mathrm{O})$ presentes en la estructura del sólido, respectivamente $240-242$. Además, la banda ancha en el intervalo de energía inferior a $850 \mathrm{~cm}^{-1}$, se asignó a la vibración de estiramiento de Zr-O.

Los espectros FT-IR de las muestras ZrPEGTPA30T100 y ZrPEGTPA60T100 mostraron un nuevo conjunto de bandas superpuestas a las bandas de la zirconia sola. La presencia de bandas P-Oa $\left(1081 \mathrm{~cm}^{-1}\right), \mathrm{W}-\mathrm{O}_{\mathrm{d}}\left(982 \mathrm{~cm}^{-1}\right), \mathrm{y} \mathrm{W}-\mathrm{O}_{\mathrm{b}}-\mathrm{W}\left(888 \mathrm{~cm}^{-1}\right)$, corresponden a vibraciones características del anión $\left[\mathrm{PW}_{12} \mathrm{O}_{40}\right]^{3-}$, las cuales se observan mejor en la muestra ZrPEGTPA60T100 por tener una cantidad de TPA mayor ${ }^{242}$. Se observan también, bandas asignadas al anión $\left[\mathrm{PW}_{11} \mathrm{O}_{39}\right]^{7-}$ en el caso de la muestra ZrPEGTPA60T100, esto surge de una comparación con el espectro de la sal sódica del anión lacunar ${ }^{243}$, correspondiente a las bandas a 1100, 1046, 958, 904, 812 y $742 \mathrm{~cm}^{-1}$ (Figura 36).

Los espectros de FT-IR de las muestras ZrTPA30PEGT100 y ZrTPA60PEGT100 muestran las mismas características principales que las de ZrPEGTPA30T100 y ZrPEGTPA60T100, respectivamente. Por lo tanto, de acuerdo con los resultados de FTIR, el orden empleado para la incorporación de PEG durante la síntesis no generó diferencias significativas en las especies de polioxotungstatos presentes en el sólido. Además, los espectros FT-IR de las muestras después de ser lavadas con agua destilada no presentaron ninguna de las bandas características del PEG, tales como las asignadas al estiramiento C-O del grupo éter del PEG 225 a $1099 \mathrm{~cm}^{-1}$, mostrando que la eliminación de la plantilla por extracción con agua era efectiva. 
Capítulo IV. Análisis de Resultados.

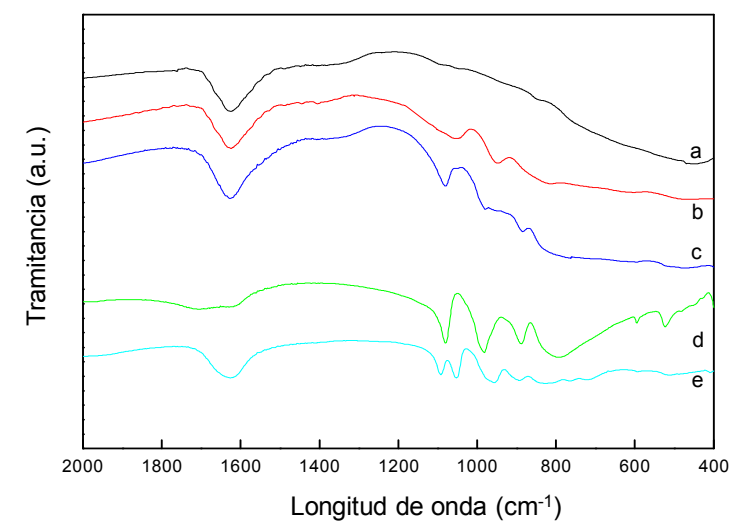

Figura 36. Espectros FT-IR de los catalizadores del Grupo I. ZrPEGTPA00T100 (a), ZrPEGTPA30T100 (b), and ZrPEGTPA60T100 (c); TPA bulk(d), y sal de sodio del anión $\left[\mathrm{PW}_{11} \mathrm{O}_{39}\right]^{7-}(\mathrm{e})$.

Por su parte, los espectros FT-IR del Grupo II, materiales $\mathrm{TiO}_{2}$, $\mathrm{TiO}_{2} / \mathrm{TPA}$, $\mathrm{TiO}_{2} / \mathrm{TSA}$ y TPA y TSA bulk se muestran en la Figura 37. En el espectro de la muestra $\mathrm{TiO}_{2}$ (Figura 37.a) aparecen las bandas centradas en $3380 \mathrm{~cm}^{-1}$ (muy ancho) y 1649 $\mathrm{cm}^{-1}$, asignadas al estiramiento y flexión del agua $\mathrm{O}-\mathrm{H}$ que se ha incorporado a la estructura del sólido ${ }^{241}$. Además, en el intervalo de energía por debajo de $800 \mathrm{~cm}^{-1}$, se observa la banda debida a la vibración de estiramiento Ti-0-Ti.

Los espectros de los materiales $\mathrm{TiO}_{2} / \mathrm{TPA}$ (Figura 37.a) y $\mathrm{TiO}_{2} / \mathrm{TSA}$ (Figura 37.b) muestran características similares a las observadas para la muestra $\mathrm{TiO}_{2}$ en el rango entre 4000 y $1200 \mathrm{~cm}^{-1}$. Además, como resultado de la introducción de TPA en la matriz de titania, un nuevo conjunto de bandas aparece superpuesto a la banda ancha a $800 \mathrm{~cm}^{-1}$ de $\mathrm{TiO}_{2}$, debidas a la presencia de vibraciones de estiramiento $\mathrm{P}-\mathrm{O}_{\mathrm{a}}, \mathrm{W}-\mathrm{O}_{\mathrm{d}} \mathrm{y}$ $\mathrm{W}-\mathrm{O}_{b}-\mathrm{W}$ del anión $\left[\mathrm{PW}_{12} \mathrm{O}_{40}\right]^{3-}$.

De igual forma sucede en la muestra con adición de TSA, donde las nuevas bandas aparecen en los mismos números de onda que los de TSA bulk (Figura 37.b), es decir, a 1020, 982, 926, 884, 778 y $541 \mathrm{~cm}^{-1}$ asignadas al anión $\left[\mathrm{SiW}_{12} \mathrm{O}_{40}\right]^{4-}$ 
Capítulo IV. Análisis de Resultados.

correspondientes a las vibraciones de estiramiento $\mathrm{W}-\mathrm{O}_{\mathrm{d}}, \mathrm{Si}-\mathrm{O}_{\mathrm{a}}, \mathrm{W}-\mathrm{O} \mathrm{b}-\mathrm{W}, \mathrm{W}-\mathrm{O}_{\mathrm{c}}-\mathrm{W}$ y a la vibración de flexión $\mathrm{O}_{\mathrm{a}}-\mathrm{Si}-\mathrm{O}_{\mathrm{a}}+\mathrm{W}-\mathrm{O}-\mathrm{W}$, respectivamente ${ }^{244}$.

El espectro de FT-IR del TPA bulk (Figura 37.a) muestra las bandas a 1081, 982 y $888 \mathrm{~cm}^{-1}$, que ya se habían descrito para los materiales del Grupo I y que están de acuerdo con las descritas en la literatura para el ácido $\mathrm{H}_{3} \mathrm{PW}_{12} \mathrm{O}_{40} 226$.

a)

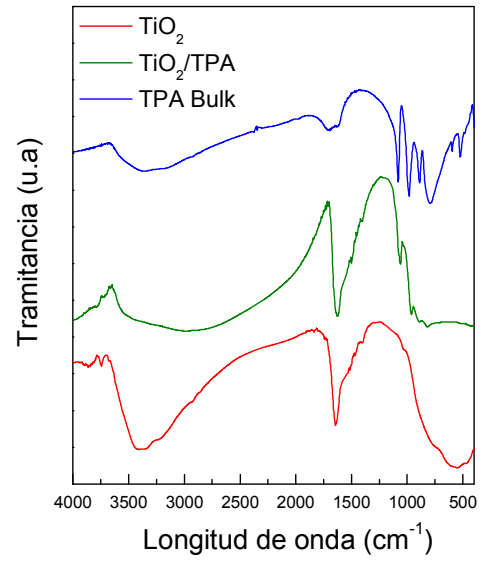

b)

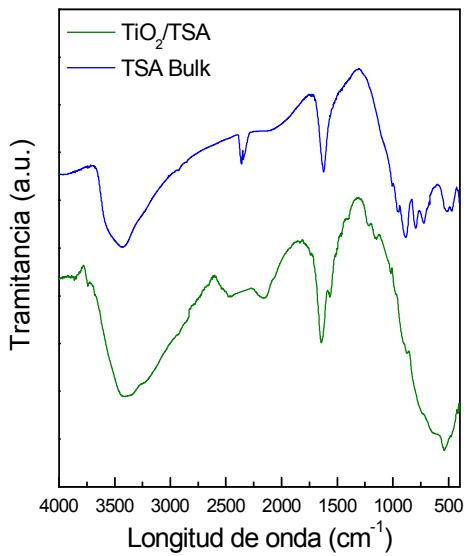

Figura 37. Espectros FT-IR de los materiales del Grupo II a) $\mathrm{TiO}_{2}$, $\mathrm{TiO}_{2} / \mathrm{TPA}$ y TPA bulk, b) $\mathrm{TiO}_{2} / \mathrm{TSA}$ y TSA bulk

\subsubsection{Espectroscopía RAMAN.}

Al igual que la espectroscopia IR, la espectroscopia Raman proporciona vibraciones fundamentales características de cada molécula, que se emplean para elucidar su estructura molecular. Aunque algunas vibraciones pueden ser activas tanto en Raman como en IR, estas dos formas de espectroscopia surgen de diferentes procesos y diferentes reglas de selección.

La caracterización por Raman se utilizó para analizar el Grupo II de los catalizadores debido a que las fases de anatasa y rutilo tienen huellas digitales Raman bien diferenciadas, permitiendo una caracterización sencilla y confiable. La estructura de la anatasa es tetragonal, y su celda unidad está compuesta por dos unidades de $\mathrm{TiO}_{2}$ y su grupo espacial es $D_{4 h}^{19}\left(I 4_{1} / a m d\right)$. Presenta seis modos activos Raman que son $A_{1 g}$ 
Capítulo IV. Análisis de Resultados.

(519 $\left.\mathrm{cm}^{-1}\right), 2 \mathrm{~B} 1 \mathrm{~g}\left(394.4\right.$ y $\left.516.1 \mathrm{~cm}^{-1}\right)$ y $3 \mathrm{Eg}\left(141.3,197 \text { y } 636.7 \mathrm{~cm}^{-1}\right)^{245}$, los cuales estaban presentes en los espectros de las muestras (Figura 38.a).

El TPA másico mostró picos de vibración Raman intensos típicamente asignados al anión Keggin a 1080, 990, 930 y $890 \mathrm{~cm}^{-1}$, que se atribuyen a vibraciones antisimétricas de los enlaces $\mathrm{PO}, \mathrm{W}=0 \mathrm{y}$ WOW respectivamente ${ }^{231}$. Por otro lado, los espectros Raman para el TSA bulk exhibió los picos a $1000 \mathrm{~cm}^{-1}, 976 \mathrm{~cm}^{-1}$ y $926 \mathrm{~cm}^{-1}$ que corresponden a $\mathrm{v}_{\mathrm{s}}(\mathrm{WO})$, $\mathrm{U}_{\mathrm{as}}(\mathrm{WO}) \mathrm{y} \mathrm{v}_{\mathrm{as}}$ (WOW) respectivamente, lo cual coincide muy bien con los del anión Keggin de TSA $233,246$.

Las muestras de $\mathrm{TPA} / \mathrm{TiO}_{2}$ y $\mathrm{TSA} / \mathrm{TiO}_{2}$ mostraron dos interesantes características de Raman. La primera fue un cambio importante del pico Raman más intenso de $\mathrm{TiO}_{2}$ anatasa a $141 \mathrm{~cm}^{-1}$ y atribuido a enlaces Ti-O (Figura 38.b, línea azul). También se encontró un aumento en las señales de TPA y TSA entre 1080 y $900 \mathrm{~cm}^{-1}$ (Figura 38.c) que se asignan a enlaces $\mathrm{W}-0$. Ambos cambios espectrales podrían ser debidos a fuertes interacciones entre el $\mathrm{TiO}_{2}$ y los aniones Keggin como ya se ha descrito en la literatura $232,247$. 
Capítulo IV. Análisis de Resultados.
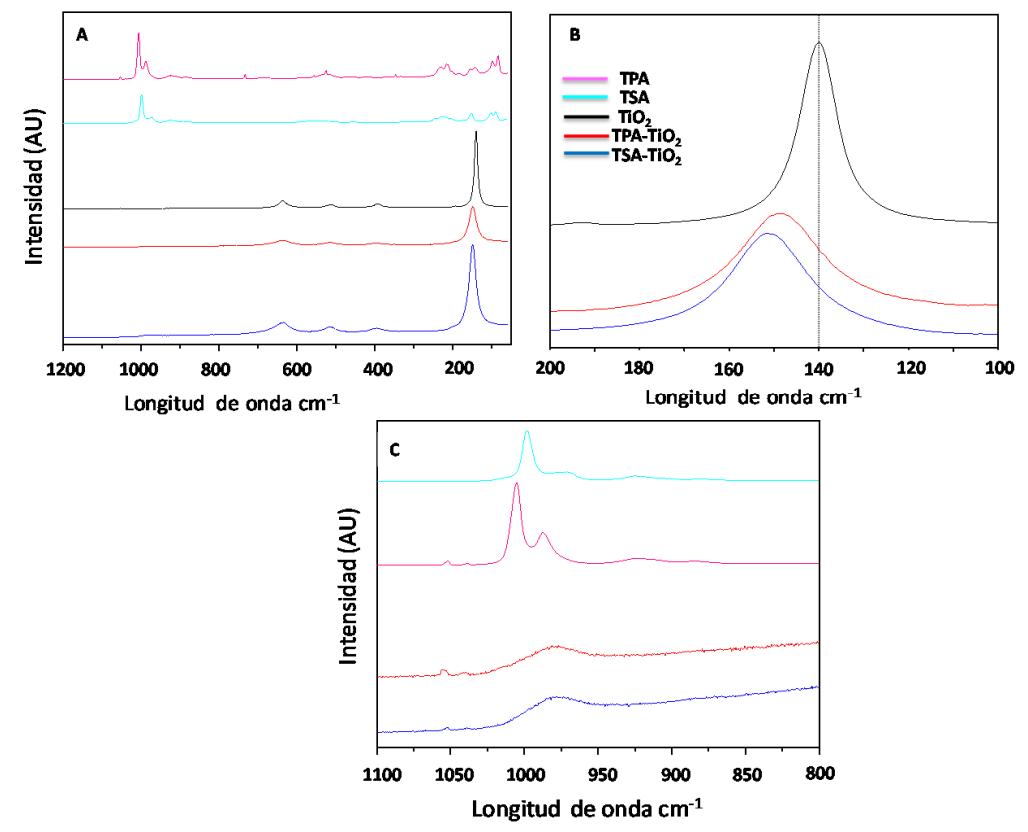

Figura 38. Espectros Raman de las muestras del Grupo II. TPA, TSA, $\mathrm{TiO}_{2}$, $\mathrm{TiO}_{2} / \mathrm{TPA}$ y $\mathrm{TiO}_{2} / \mathrm{TSA}$.

\subsubsection{Difracción de rayos $X(D R X)$.}

El método de difracción de rayos $\mathrm{X}$ es una de las herramientas científicas más poderosas y eficaces para identificar y cuantificar la estructura cristalina de los materiales, ya que permite diferenciar compuestos químicos por su estructura cristalina y no por su composición de elementos químicos. Esto significa que se pueden identificar diferentes fases cristalinas que tienen la misma composición, como es el caso de la titania o la ausencia de cristalinidad en un material ${ }^{248,249}$.

De las muestras del Grupo I, el análisis DRX se le realizó a las muestras

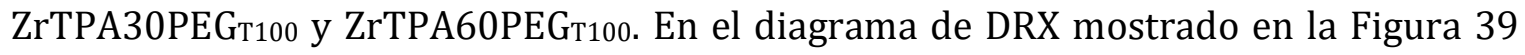
se puede observar que los dos sólidos no presentan una estructura cristalina definida ya que los picos son anchos y distorsionados, donde se destaca un amplio pico alrededor de $2 \theta$ igual a $30^{\circ}$. Así mismo, no se presentan líneas de difracción asignables a TPA u otras fases cristalinas. Esto puede ser debido a una alta dispersión del TPA en la matriz de $\mathrm{ZrO}_{2}$ o a la presencia de especies no cristalinas. 
Capítulo IV. Análisis de Resultados.

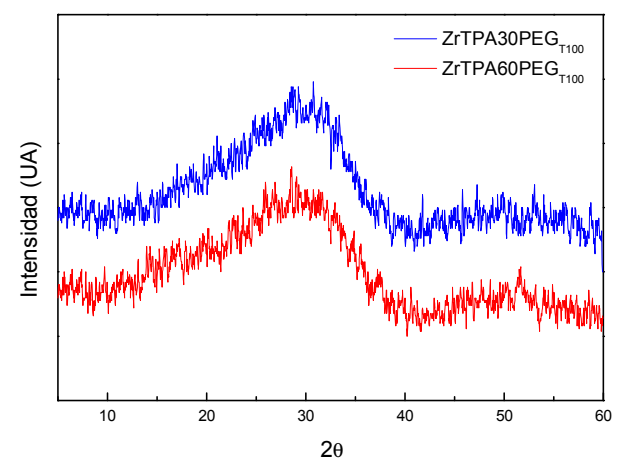

Figura 39. Espectros DRX de las muestras del Grupo I.

Para el caso de los materiales del Grupo II, el análisis de DRX permite diferenciar entre las tres posibles estructuras cristalinas más estables del óxido de titanio. Así, la caracterización por DRX (Figura 40) reveló en todas las muestras los picos correspondientes a $\mathrm{TiO}_{2}$ anatasa a $2 \theta$ igual a $25.3^{\circ}, 37.9^{\circ}, 47.8^{\circ}$ y $54.3^{\circ 232}$. Los picos de los DRX relacionados con TPA o TSA no se encontraron, lo que indica que los heteropoliácidos están altamente dispersos en la matriz de titania o como una fase no cristalina. Sin embargo, las muestras de $\mathrm{TiO}_{2} / \mathrm{TPA}$ y $\mathrm{TiO}_{2} / \mathrm{TSA}$ mostraron un pico más ancho y este hecho está estrechamente ligado a la presencia de heteropoliácidos, ya que estudios previos han evidenciado que la modificación de $\mathrm{TiO}_{2}$ con TPA o TSA retarda la cristalización de la fase de titania²18,220.

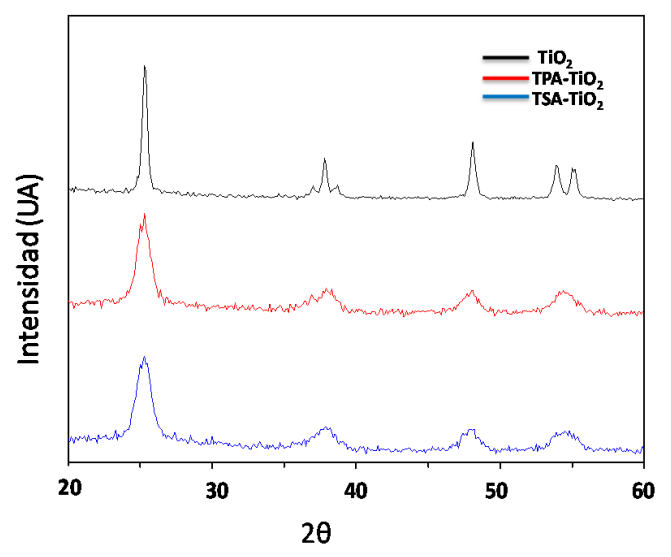

Figura 40. Espectros DRX de las muestras del Grupo II. 
Capítulo IV. Análisis de Resultados.

\subsection{CARACTERIZACIÓN DE LOS MATERIALES DEL GRUPO III.}

\subsubsection{Microscopía de barrido electrónico (SEM).}

Cada uno de los materiales obtenidos durante las pruebas que se realizaron fueron analizados por SEM para determinar y comparar su morfología y tamaño, incluido una muestra de magnetita comercial que se utilizó como patrón de referencia (Figura 41.a).

Inicialmente se analizaron las muestras de magnetita preparadas a través de la mezcla química de sales férricas y ferrosas, precipitándose como $\mathrm{Fe}_{3} \mathrm{O}_{4}$ mediante la adición de amoniaco en el intervalo de pH 11-13. La reacción química de la precipitación de $\mathrm{Fe}_{3} \mathrm{O}_{4}$ es la siguiente:

$$
\mathrm{Fe}^{2+}+2 \mathrm{Fe}^{3+}+\mathrm{O}_{2}+2 \mathrm{OH}^{-} \rightarrow \mathrm{Fe}_{3} \mathrm{O}_{4}+\mathrm{H}_{2} \mathrm{O}
$$

El primer ensayo de síntesis de magnetita incluía la adición de ácido oleico como sustancia protectora para evitar la oxidación de las NPMs, lo que generó varios inconvenientes en la separación y lavado de las mismas al obtenerse un precipitado bastante viscoso. Luego de varios lavados con hexano, finalmente se pudo obtener una muestra para ser analizada por SEM, donde se determinó que no tenían la forma ni el tamaño esperado, ya que como se puede observar en la Figura 41.b, presentan un amplio rango de tamaños, que van desde 10 hasta $100 \mu \mathrm{m}$ aproximadamente y formas bastante irregulares, muy diferentes a la muestra comercial que corresponde a NMPs casi esféricas y de diámetro promedio de 20 nm (Figura 41.a).

De igual forma se analizó la muestra de la prueba dos, la cual no incluyó ácido oleico en su síntesis. Los pasos de precipitar, separar y lavar esta muestra fueron mucho más sencillos y rápidos, pero al analizar la muestra por SEM se determinó que también tienen formas y tamaños irregulares, aunque son más pequeñas que las NPMs de la prueba uno (Figura 41.c). 


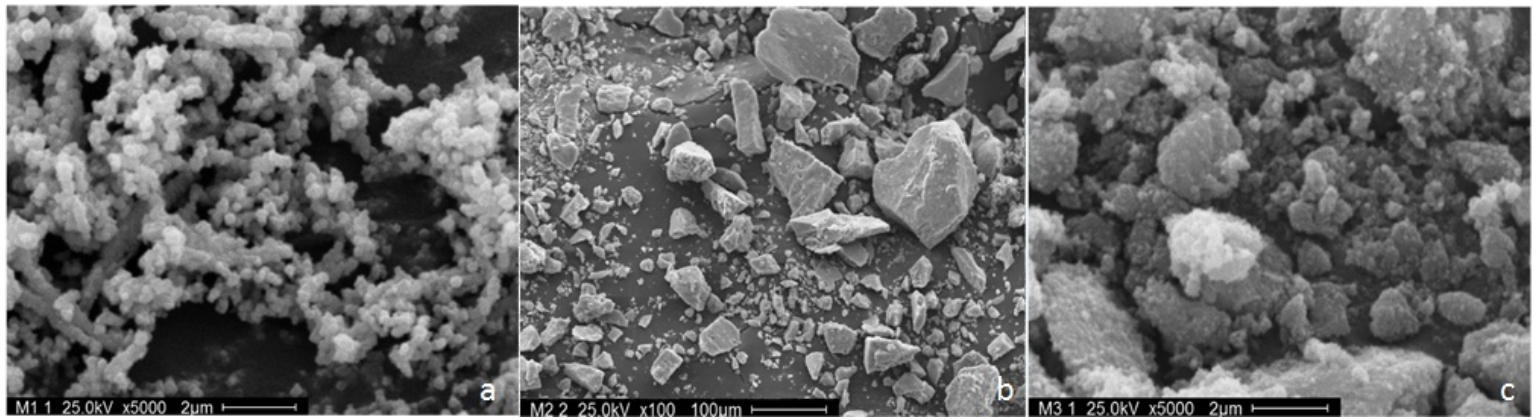

Figura 41. Imágenes $\mathrm{SEM} \mathrm{a}_{\text {) }} \mathrm{Fe}_{3} \mathrm{O}_{4}$ comercial. b) $\mathrm{Fe}_{3} \mathrm{O}_{4}$ prueba 1. c) $\mathrm{Fe}_{3} \mathrm{O}_{4}$ prueba 2.

Hasta el momento, todas las muestras sintetizadas tenían propiedades magnéticas, pero ninguna se parecía morfológicamente a la muestra comercial, razón por la cual se hizo una tercera prueba centrando la atención en que el agua esté libre de iones y oxígeno disuelto, para lo cual se usó agua destilada, desionizada y se aumentó el caudal de nitrógeno, adicionalmente, el amoniaco se agregó lentamente, gota a gota. Los sólidos se dejaron secar a temperatura ambiente. Al analizar las partículas por SEM (Figura 42) se observó con agrado que tenían una forma regular más parecida a las imágenes de la muestra comercial y de un tamaño aun menor, cercano a $10 \mathrm{~nm}$, razón por la que se escogió este procedimiento como el mejor para sintetizar la magnetita.
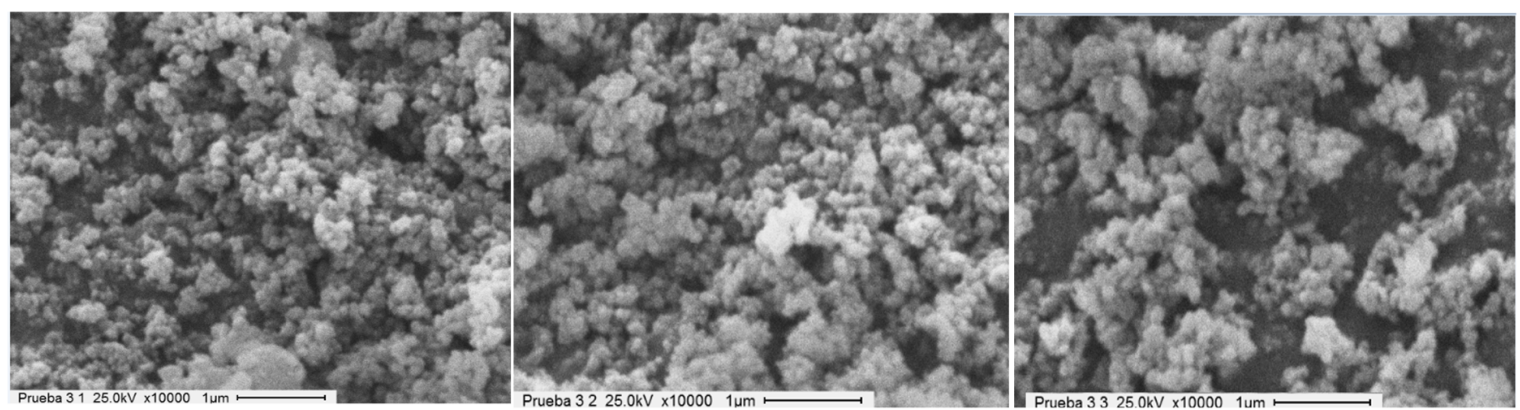

Figura 42. Imágenes $\mathrm{SEM}$ de 3 muestras de $\mathrm{Fe}_{3} \mathrm{O}_{4}$ preparadas con la metodología de la prueba 3.

Luego de determinar la mejor forma de sintetizar las partículas magnéticas, se procedió a estudiar las mejores condiciones que permitieran obtener un adecuado recubrimiento con $\mathrm{SiO}_{2}$. La técnica seleccionada fue el método Stöber a partir de TEOS e hidrólisis básica con amoniaco. Se analizaron condiciones como la mejor relación 
Capítulo IV. Análisis de Resultados.

$\mathrm{Fe}_{3} \mathrm{O}_{4} / \mathrm{SiO}_{2}$, y la relación TEOS/Amoniaco. Como se observa en la Figura 43, esta técnica permite sintetizar partículas esféricas de tamaño uniforme con diámetro promedio de $300 \mathrm{~nm}$.

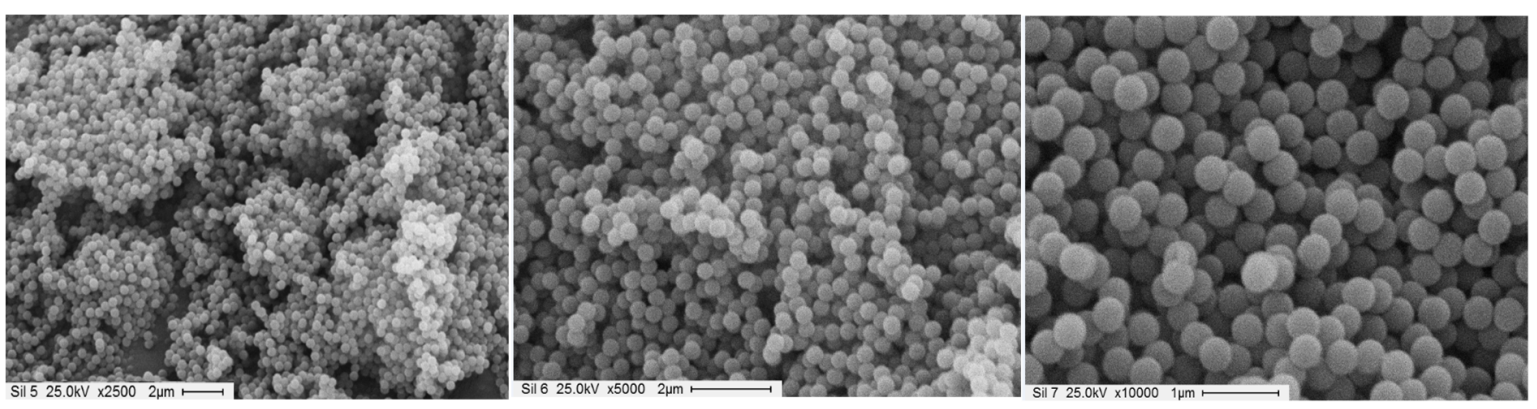

Figura 43. Imágenes SEM a diferentes aumentos de la muestra $\mathrm{Fe}_{3} \mathrm{O}_{4} @ \mathrm{SiO}_{2}$, sintetizada por el procedimiento descrito en la prueba 4.

Posteriormente, estas partículas se dejaron en contacto con $\mathrm{HCl}$ y $\mathrm{HNO}_{3}$ durante 24 h para evaluar su estabilidad en medio ácido, en la cual no se observó disolución significativa de $\mathrm{Fe}_{3} \mathrm{O}_{4}$, por tanto, los recubrimientos de sílice sirven como capas protectoras para inhibir la disolución de los núcleos magnéticos en entornos ácidos y los hace aptos para soportar posteriormente la fase activa.

En busca de encontrar las condiciones de síntesis que permitieran obtener $\mathrm{Fe}_{3} \mathrm{O}_{4} @ \mathrm{SiO}_{2}$ con las propiedades óptimas pasa ser utilizado como soporte, se diseñó una serie de experimentos consecutivos para determinar cuál era la mejor relación $\mathrm{Fe}_{3} \mathrm{O}_{4} / \mathrm{SiO}_{2}$ y la influencia de la misma sobre el tamaño, forma y área superficial de las partículas. Primero se hizo un recubrimiento de las partículas magnéticas utilizando una relación 1:0,5, se separó 3/4 del producto final al que se le hizo un nuevo recubrimiento para una relación 1:1 y finalmente, de este material se separó una parte y se recubrió para una relación 1:2.

En las imágenes SEM de la Figura 44 puede verse que en general se mantiene la forma de esferas para cada una de las relaciones $\mathrm{Fe}_{3} \mathrm{O}_{4} / \mathrm{SiO}_{2}$ ensayadas y cómo su diámetro va aumentando con cada recubrimiento desde $300 \mathrm{~nm}$ en promedio para la relación 1:0.5 hasta $900 \mathrm{~nm}$ para la relación 1:2 (Figura 44.a y c), aunque para la 
Capítulo IV. Análisis de Resultados.

relación 1:0.5 las esferas no son tan definidas y se observan aglomeraciones, debido probablemente, a que se empleó una cantidad de $\mathrm{SiO}_{2}$ inferior a la necesaria para recubrir completamente las NPMs.

Las muestras con relaciones 1:1 y 1:2 fueron las que presentaron mejores características morfológicas (Figura 44.b y d). Aun así, los resultados SBET reportaron áreas muy pequeñas para las 3 muestras y no mostraron diferencias significativas entre ellas (Tabla 6), razón por la cual se escogió la relación 1:1 como la mejor para continuar con la síntesis de los catalizadores.
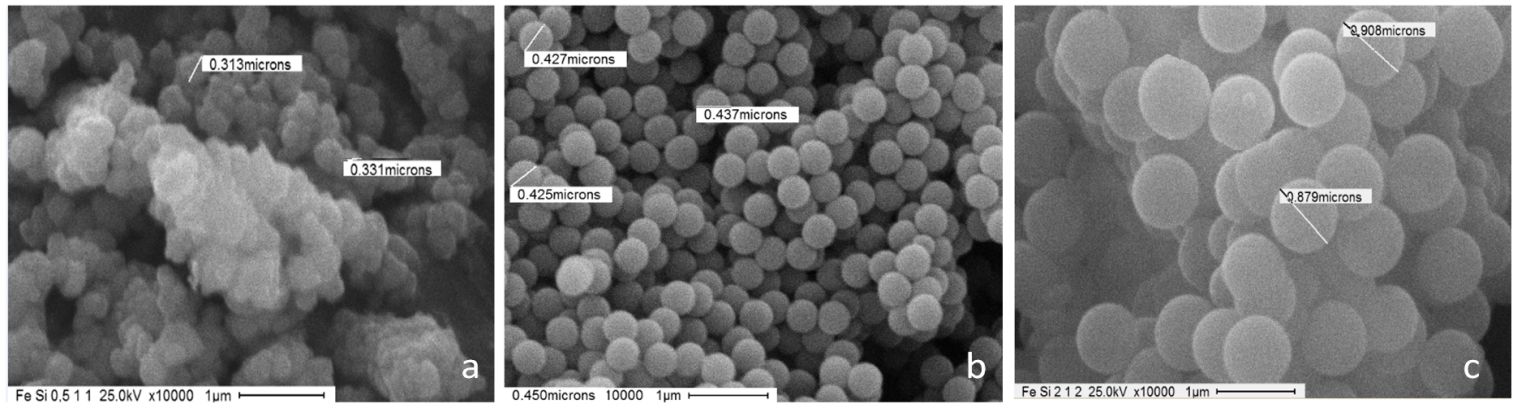

Figura 44. Imágenes SEM de las muestras variando la relación $\mathrm{Fe}_{3} \mathrm{O}_{4} / \mathrm{SiO}_{2}$ a) 1:0.5 b) $1: 1$ c) $1: 2$.

Tabla 6. Resultados de las pruebas EDX y $\mathrm{S}_{\text {BET }}$ para las 3 relaciones $\mathrm{Fe}_{3} \mathrm{O}_{4} / \mathrm{SiO}_{2}$.

\begin{tabular}{|c|c|c|c|c|c|c|c|}
\hline \multirow[b]{2}{*}{ Entrada } & \multirow{2}{*}{$\begin{array}{c}\text { Relación } \\
\mathrm{Fe}_{3} \mathrm{O}_{4} / \mathrm{SiO}_{2} \\
\text { Teórico }\end{array}$} & \multirow{2}{*}{$\begin{array}{c}\text { *Relación } \\
\mathrm{Fe}_{3} \mathrm{O}_{4} / \mathrm{SiO}_{2} \\
\text { Real }\end{array}$} & \multicolumn{2}{|c|}{ Wt \% } & \multirow{2}{*}{$\begin{array}{c}\text { Relación } \\
\mathrm{Fe}_{3} \mathrm{O}_{4} / \mathrm{SiO}_{2} \\
\text { EDX }\end{array}$} & \multirow{2}{*}{$\begin{array}{c}\text { Diámetro } \\
\text { promedio } \\
(\mathrm{nm})\end{array}$} & \multirow{2}{*}{$\begin{array}{c}\text { Área SBET } \\
\mathrm{m}^{2} / \mathrm{g}\end{array}$} \\
\hline & & & $\mathrm{Fe}$ & $\mathrm{Si}$ & & & \\
\hline 1 & $1: 0.5$ & $1: 0.5$ & 56.43 & 43.57 & 1:0.7 & 300 & 6 \\
\hline 2 & $1: 1$ & $1: 1.4$ & 47,17 & 52,83 & $1: 1.1$ & 450 & 7 \\
\hline 3 & $1: 2$ & $1: 4.6$ & 20.96 & 79.04 & $1: 4$ & 900 & 8 \\
\hline
\end{tabular}

*Dado que cada fracción que se toma para el siguiente recubrimiento no es $\mathrm{Fe}_{3} \mathrm{O}_{4}$ solamente, sino que ya contiene $\mathrm{SiO}_{2}$, se hicieron algunos cálculos para corregir las relaciones reales, dando valores de 1:0.54, 1:1.37 y 1:4.6 respectivamente, los cuales son similares a la distribución de elementos obtenida por la técnica EDX (para facilitar la escritura las muestras se mencionaran utilizando las relaciones teóricas). 


\section{Capítulo IV. Análisis de Resultados.}

Por otro lado, se estudió la influencia de la cantidad de amoníaco en la hidrólisis del TEOS y la deposición de $\mathrm{SiO}_{2}$ sobre las NPMs. Se encontró que al utilizar una relación amoniaco/TEOS 6:1 se obtiene un rendimiento del 92\% en peso, esto debido a una disponibilidad suficiente de grupos HO-, que inducen a una hidrólisis rápida del TEOS, lo que produce a una deposición más eficiente de $\mathrm{SiO}_{2}$ sobre la magnetita. Por el contrario, en relaciones menores, como es el caso de 1:1 y 3:1 se alcanzaron rendimientos de 0 y $36 \%$ en peso respectivamente, lo que indica que la insuficiencia de grupos $\mathrm{HO}^{-}$, conduce a una hidrólisis más lenta donde la mayoría del TEOS no se hidroliza y la poca cantidad que si lo hace genera la nucleación de $\mathrm{SiO}_{2}$ que no recubre completamente las NPMs, dando resultado a pequeños nanocompuestos de $\mathrm{Fe}_{3} \mathrm{O}_{4} / \mathrm{SiO}_{2}$.

Finalmente se analizó cual era la mejor forma de soportar el TPA sobre $\mathrm{Fe}_{3} \mathrm{O}_{4} @ \mathrm{SiO}_{2}$. Se estudiaron dos formas de hacerlo, por impregnación e inclusión en una segunda capa de $\mathrm{SiO}_{2}$ mediante hidrólisis ácida catalizada por el mismo TPA y posterior tratamiento térmico a diferentes temperaturas.

Uno de los principales retos de la catálisis heterogénea es lograr que la fase activa no se lixivie del soporte. En el caso de los HPAs, esta dificultad se presenta especialmente en sistemas polares, ya que son solubles en este tipo de sustancias como es el caso de los alcoholes, que es nuestro sistema de reacción. Por este motivo, antes de caracterizar los materiales del Grupo III, primero se hizo un estudio de lixiviación de los mismos para descartar o comprobar este hecho.

En la Figura 45 se muestra los resultados de rendimiento y ciclos de reutilización de los diferentes materiales sintetizados y en la Tabla 7 se especifican los valores de conversión obtenidos. La prueba fue la siguiente, primero se evaluó la posible pérdida de TPA por lixiviación de los catalizadores, para lo cual $100 \mathrm{mg}$ del catalizador se dejaron en contacto con 10 mmoles de n-butanol durante $24 \mathrm{~h}$ a la temperatura de reacción. Transcurrido este tiempo, se retira el catalizador, y al nbutanol se le agrega $1 \mathrm{mmol}$ de ácido levulínico y se dejó reaccionar. Por otra parte, con el catalizador recuperado se realiza la reacción adaptando las cantidades de los reactivos a la cantidad recuperada de catalizador, durante un tiempo de $24 \mathrm{~h}$. 
Capítulo IV. Análisis de Resultados.

Concluido este tiempo, el catalizador se recupera y se repite el ciclo 2 veces más para evaluar su capacidad de reutilización.

Las condiciones de reacción inicialmente utilizadas fueron $1 \mathrm{mmol}$ de ácido levulínico, 10 mmoles de n-butanol, $100 \mathrm{mg}$ de catalizador y una temperatura de $40{ }^{\circ} \mathrm{C}$, durante $24 \mathrm{~h}$. Todos los experimentos se realizaron por duplicado y están con un error dentro del $\pm 2 \%$.

La esterificación del AL con n-butanol se produce incluso en ausencia de catalizador, porque el ácido es capaz de catalizar la reacción, razón por la cual se realiza un blanco de reacción (sin catalizador) en cada etapa del proceso.

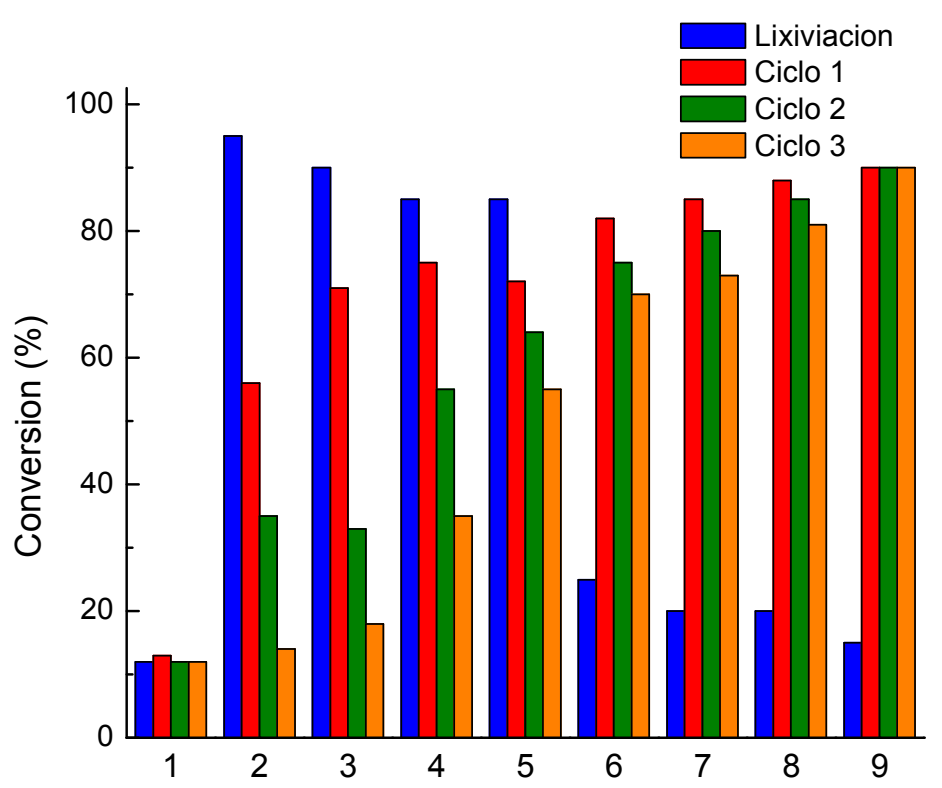

Figura 45. Diagrama de barra de las conversiones alcanzadas durante los diferentes ciclos de reutilización de los materiales del grupo III. 1) Blanco de reacción, 2) $\mathrm{Fe}_{3} \mathrm{O}_{4} @ \mathrm{SiO}_{2}$-TPAsc, 3) $\left.\left.\quad \mathrm{Fe}_{3} \mathrm{O}_{4} @ \mathrm{SiO}_{2} / \mathrm{TPA}_{200}, \quad 4\right) \quad \mathrm{Fe}_{3} \mathrm{O}_{4} @ \mathrm{SiO}_{2} / \mathrm{TPA}_{300}, \quad 5\right)$ $\left.\left.\left.\mathrm{Fe}_{3} \mathrm{O}_{4} @ \mathrm{SiO}_{2} / \mathrm{TPA}_{400 \mathrm{~N}}, 6\right) \mathrm{Fe}_{3} \mathrm{O}_{4} @ \mathrm{SiO}_{2} @ \mathrm{SiO}_{2} / \mathrm{TPAsc}, 7\right) \mathrm{Fe}_{3} \mathrm{O}_{4} @ \mathrm{SiO}_{2} @ \mathrm{SiO}_{2} / \mathrm{TPA}_{200}, 8\right)$ $\left.\mathrm{Fe}_{3} \mathrm{O}_{4} @ \mathrm{SiO}_{2} @ \mathrm{SiO}_{2} / \mathrm{TPA}_{300}, 9\right) \mathrm{Fe}_{3} \mathrm{O}_{4} @ \mathrm{SiO}_{2} @ \mathrm{SiO}_{2} / \mathrm{TPA}_{400 \mathrm{~N}}$. 
Capítulo IV. Análisis de Resultados.

Como se evidencia en la Figura 45 y la Tabla 7, la lixiviación del TPA en los materiales magnéticos se presenta en gran medida, especialmente en los catalizadores sintetizados por el método de impregnación, los cuales dieron rendimientos superiores a $85 \%$ en todas las pruebas de lixiviado (Tabla 7, entradas 2 a 5), indicando que gran parte de la fase activa se disuelve en el solvente durante la reacción y lo continua haciendo durante los diferentes ciclos de reutilización hasta que en el ciclo 3 , toda la fase activa se ha lixiviado, excepto cuando es calcinado a $400{ }^{\circ} \mathrm{C}$ en atmósfera de nitrógeno, para el que se obtiene un rendimiento del 55 \% (Tabla 7, entrada 5). Esto puede ser debido a la pequeña $\mathrm{S}_{\mathrm{BET}}$ determinada para el soporte $\mathrm{Fe}_{3} \mathrm{O}_{4} @ \mathrm{SiO}_{2}$, la cual dio un valor de $20 \mathrm{~m}^{2} / \mathrm{g}$ (Tabla 8, Entrada 6), generando que el TPA no tuviera suficientes puntos a los cuales unirse, haciendo que la interacción soporte-fase activa fuera débil, facilitando la solubilidad del TPA en el medio de reacción.

Tabla 7. Conversiones alcanzadas durante los diferentes ciclos de reutilización de los materiales del grupo III.

\begin{tabular}{cccccc}
\hline Entrada & Catalizador & $\begin{array}{c}\text { Prueba } \\
\text { lixiviación (\%) }\end{array}$ & $\begin{array}{c}\text { Ciclo1 } \\
(\%)\end{array}$ & $\begin{array}{c}\text { Ciclo 2 } \\
(\%)\end{array}$ & $\begin{array}{c}\text { Ciclo 3 } \\
(\%)\end{array}$ \\
\hline 1 & Blanco & 12 & 13 & 12 & 12 \\
2 & $\mathrm{Fe}_{3} \mathrm{O}_{4} @ \mathrm{SiO}_{2} / \mathrm{TPAsc}$ & 95 & 56 & 35 & 14 \\
3 & $\mathrm{Fe}_{3} \mathrm{O}_{4} @ \mathrm{SiO}_{2} / \mathrm{TPA}_{200}$ & 90 & 71 & 43 & 18 \\
4 & $\mathrm{Fe}_{3} \mathrm{O}_{4} @ \mathrm{SiO}_{2} / \mathrm{TPA}_{300}$ & 85 & 75 & 55 & 35 \\
5 & $\mathrm{Fe}_{3} \mathrm{O}_{4} @ \mathrm{SiO}_{2} / \mathrm{TPA}_{400 \mathrm{~N}}$ & 85 & 72 & 64 & 55 \\
6 & $\mathrm{Fe}_{3} \mathrm{O}_{4} @ \mathrm{SiO}_{2} @ \mathrm{SiO}_{2} / \mathrm{TPA} \mathrm{sc}$ & 25 & 82 & 75 & 70 \\
7 & $\mathrm{Fe}_{3} \mathrm{O}_{4} @ \mathrm{SiO}_{2} @ \mathrm{SiO}_{2} / \mathrm{TPA}_{200}$ & 20 & 85 & 80 & 73 \\
8 & $\mathrm{Fe}_{3} \mathrm{O}_{4} @ \mathrm{SiO}_{2} @ \mathrm{SiO}_{2} / \mathrm{TPA}_{300}$ & 20 & 88 & 85 & 81 \\
9 & $\mathrm{Fe}_{3} \mathrm{O}_{4} @ \mathrm{SiO}_{2} @ \mathrm{SiO}_{2} / \mathrm{TPA}_{400 \mathrm{~N}}$ & 15 & 90 & 90 & 90 \\
\hline
\end{tabular}

Condiciones de reacción: $1 \mathrm{mmol}$ de ácido levulínico; 10 mmoles de n-butanol; $100 \mathrm{mg}$ de catalizador; $40{ }^{\circ} \mathrm{C} ; 24 \mathrm{~h}$. 


\section{Capítulo IV. Análisis de Resultados.}

Cabe resaltar que también se realizó la reacción con el soporte únicamente, alcanzando un rendimiento del $12 \%$, equivalente al blanco de reacción, lo cual indica que este no presenta actividad apreciable en la reacción estudiada.

En el caso de los catalizadores sintetizados por el segundo método, donde la fase activa fue incluida dentro de una segunda capa de sílice, se logró disminuir a un muy pequeño porcentaje la lixiviación de la fase activa, especialmente cuando el catalizador es calcinado a $400{ }^{\circ} \mathrm{C}$ en atmósfera de nitrógeno, dando un valor del $15 \%$, muy cercano al obtenido para el blanco de reacción correspondiente al 12\% (Tabla 7, Entrada 1).

Luego, en las pruebas de reutilización, el rendimiento se mantiene constante en 90\% en los 3 ciclos (Tabla 7, Entrada 9). En las restantes muestras del tipo $\mathrm{Fe}_{3} \mathrm{O}_{4} @ \mathrm{SiO}_{2} @ \mathrm{SiO}_{2} / \mathrm{TPA}$ (sin calcinar o calcinadas a temperaturas menores), si bien la lixiviación es más baja, se sigue presentando en todos los ciclos de reacción (Tabla 7, Entradas 6 a 8), lo que indica que la temperatura adecuada para el tratamiento térmico es $400{ }^{\circ} \mathrm{C}$ y en atmósfera inerte de nitrógeno, porque de esta forma se protege la magnetita de ser oxidada por el mismo.

Debido a los resultados obtenidos en esta prueba, el material que se caracterizó ampliamente mediante diferentes técnicas fisicoquímicas fue $\mathrm{Fe}_{3} \mathrm{O}_{4} @ \mathrm{SiO}_{2} @ \mathrm{SiO}_{2} / \mathrm{TPA} \mathrm{T}_{400 \mathrm{~N} 2}$ y se compara con la magnetita $\mathrm{Fe}_{3} \mathrm{O}_{4}$, el soporte $\mathrm{Fe}_{3} \mathrm{O}_{4} @ \mathrm{SiO}_{2}$ y el material $\mathrm{Fe}_{3} \mathrm{O}_{4} @ \mathrm{SiO}_{2} @ \mathrm{SiO}_{2} / \mathrm{TPAsc}$.

Las imágenes SEM de las muestras obtenidas al incluir el TPA dentro de una segunda capa de $\mathrm{SiO}_{2}$ se muestran en la Figura 46. Los catalizadores denominados $\mathrm{Fe}_{3} \mathrm{O}_{4} @ \mathrm{SiO}_{2} @ \mathrm{SiO}_{2} / \mathrm{TPAsc}$ (Figura 46 a y b) y $\mathrm{Fe}_{3} \mathrm{O}_{4} @ \mathrm{SiO}_{2} @ \mathrm{SiO}_{2} / \mathrm{TPA}_{400 \mathrm{~N}}$ (Figura 46 c y d) conservan la forma de esferas uniformes, al igual que lo determinado para el soporte $\mathrm{Fe}_{3} \mathrm{O}_{4} @ \mathrm{SiO}_{2}$, aunque con la presencia de algunos aglomerados. El someter la muestra a calcinación no afecta en forma notoria la morfología del material ni el tamaño, el cual en promedio es de $600 \mathrm{~nm}$, notoriamente mayor que el del soporte $(300 \mathrm{~nm})$. 
Capítulo IV. Análisis de Resultados.

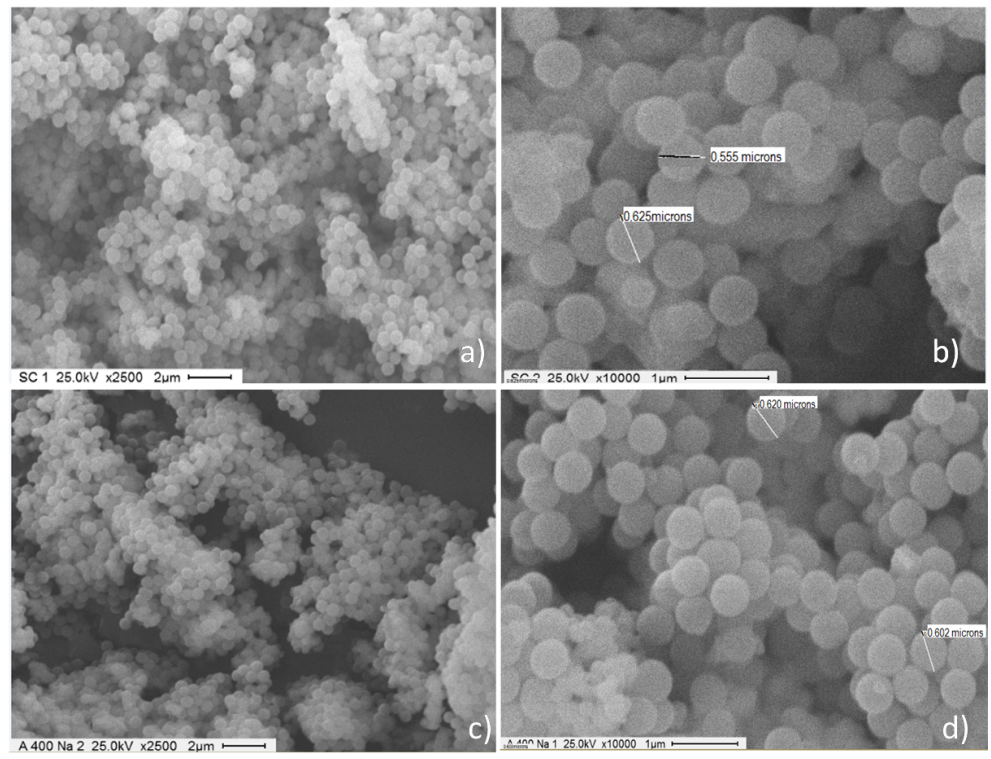

Figura 46. Imágenes SEM a diferentes aumentos del catalizador $\mathrm{Fe}_{3} \mathrm{O}_{4} @ \mathrm{SiO}_{2} @ \mathrm{SiO}_{2} / \mathrm{TPA}$ a) y b) sin calcinar, c) y d) calcinado a $400^{\circ} \mathrm{C}$ en atmósfera de nitrógeno.

\subsubsection{Isotermas de adsorción- desorción de nitrógeno.}

A partir de las isotermas de adsorción-desorción de nitrógeno se estimaron las áreas superficiales aplicando la ecuación de Brunauer-Emmett-Teller (BET). La Tabla 8 muestra los resultados obtenidos de la medida del área superficial y tamaño de poro de los materiales del Grupo III. Los valores determinados para las partículas magnéticas $\mathrm{Fe}_{3} \mathrm{O}_{4}$ evidencian una baja $\mathrm{S}_{\text {BET }}$ correspondiente a $6 \mathrm{~m}^{2} / \mathrm{g}$ (Tabla 8, Entrada 1). Dicha

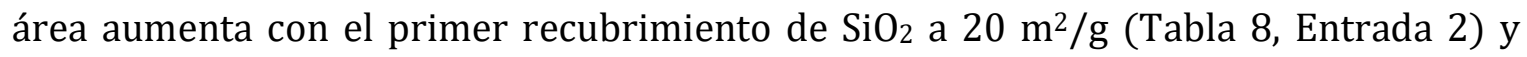
aumenta nuevamente cuando se hace el segundo recubrimiento con $\mathrm{SiO}_{2}$ y la adición del TPA a $65 \mathrm{~m}^{2} / \mathrm{g}$ (Tabla 8, Entrada 3).

La contribución al área total, debida a la presencia de microporos, es de alrededor del 40\% en la muestra $\mathrm{Fe}_{3} \mathrm{O}_{4} @ \mathrm{SiO}_{2}$ y disminuye al 15\% para $\mathrm{Fe}_{3} \mathrm{O}_{4} @ \mathrm{SiO}_{2} @ \mathrm{SiO}_{2} / \mathrm{TPAsc}$ $\mathrm{Al}$ someter el catalizador a tratamiento térmico a $400{ }^{\circ} \mathrm{C}$ en atmósfera de nitrógeno, el S BEt disminuye a $45 \mathrm{~m}^{2} / \mathrm{g}$, disminuyendo también la contribución de microporos (Tabla 8, Entrada 4), debido posiblemente al colapso de los poros más chicos, evidenciado en un aumento del diámetro de poro de 7 a 9 nm (Tabla 8, Entradas 3 y 4). 
Capítulo IV. Análisis de Resultados.

Tabla 8. Área superficial específica ( $\left.\mathrm{S}_{\mathrm{BET}}\right)$ y diámetro promedio de poro $\left(\mathrm{D}_{\mathrm{p}}\right)$ para los materiales del Grupo III.

\begin{tabular}{cccc}
\hline Entrada & Catalizador & $\begin{array}{c}\mathrm{S}_{\mathrm{BET}} \\
\left(\mathrm{m}^{2} / \mathrm{g}\right)\end{array}$ & $\begin{array}{c}\mathrm{DP}^{\mathrm{b}} \\
(\mathrm{nm})\end{array}$ \\
\hline 1 & $\mathrm{Fe}_{3} \mathrm{O}_{4}$ & 6 & - \\
2 & $\mathrm{Fe}_{3} \mathrm{O}_{4} @ \mathrm{SiO}_{2}$ & 20 & 8 \\
3 & $\mathrm{Fe}_{3} \mathrm{O}_{4} @ \mathrm{SiO}_{2} @ \mathrm{SiO}_{2} / \mathrm{TPAsc}$ & 65 & 7 \\
4 & $\mathrm{Fe}_{3} \mathrm{O}_{4} @ \mathrm{SiO}_{2} @ \mathrm{SiO}_{2} / \mathrm{TPA}_{400 \mathrm{~N}}$ & 45 & 9 \\
\hline
\end{tabular}

aSuperficie de microporos estimada a partir del método t-plot.

bDiametro medio de poro estimado a partir de SBET.

Analizando la forma y ciclos de histéresis de las isotermas de adsorcióndesorción mostradas en la Figura 47, puede verse que al igual que los catalizadores de los Grupos I y II, las isotermas obtenidas para los catalizadores del Grupo III, son de tipo IV, características de sólidos mesoporosos, evidenciado también en el diámetro de poro.

Sin embargo los distintos ciclos de histéresis sugieren que la incorporación de sílice y TPA a las partículas de $\mathrm{Fe}_{3} \mathrm{O}_{4}$ modifican las propiedades texturales, razón por la cual aumenta significativamente su área superficial y la cantidad y el tamaño de los poros (Tabla 8).

Así, la gráfica resultante para las partículas magnéticas de $\mathrm{Fe}_{3} \mathrm{O}_{4}$ no presenta histéresis y para la muestra $\mathrm{Fe}_{3} \mathrm{O}_{4} @ \mathrm{SiO}_{2}$ es apenas perceptible, cuando se agrega la segunda capa de sílice y TPA la histéresis aumenta significativamente. Los bucles de histéresis tanto en el catalizador sin calcinar como calcinado son tipo H2. 
Capítulo IV. Análisis de Resultados.

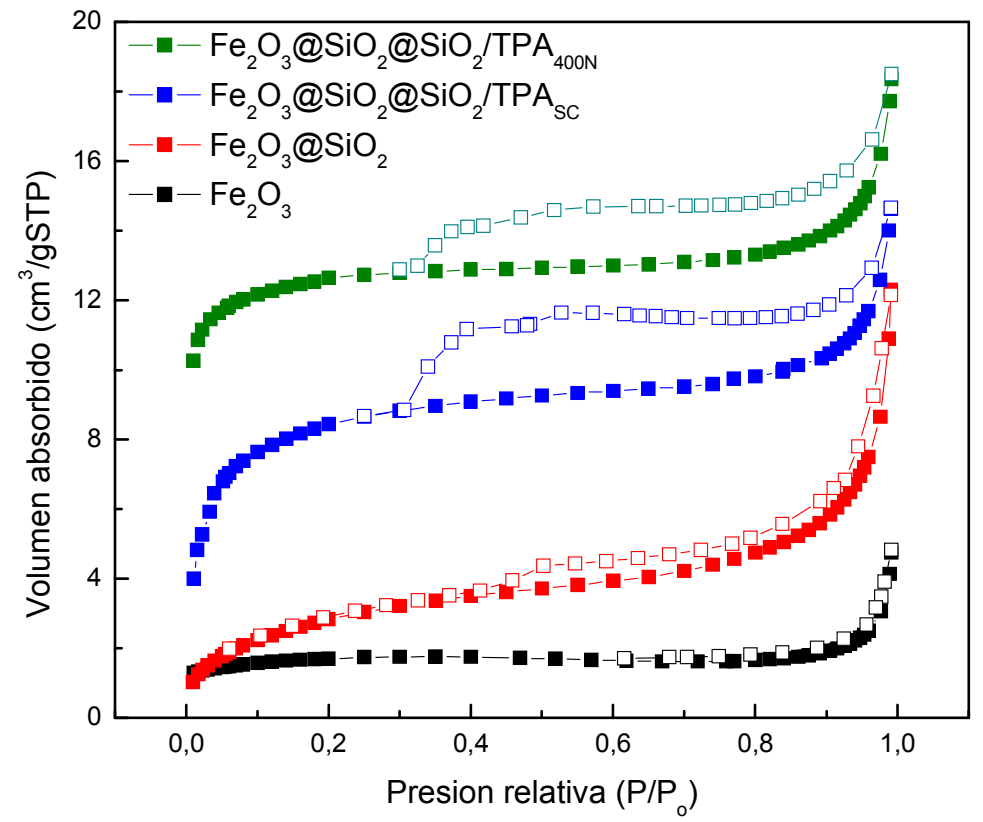

Figura 47. Isotermas de adsorción-desorción a la temperatura del nitrógeno líquido de las diferentes fases durante la síntesis de los catalizadores del Grupo III.

\subsubsection{Espectroscopia Infrarroja con Transformada de Fourier acoplada a Reflectancia Total Atenuada (FTIR-ATR).}

Los espectros FTIR-ATR de los materiales TPA másico, $\mathrm{Fe}_{3} \mathrm{O}_{4} @ \mathrm{SiO}_{2}$ y $\mathrm{Fe}_{3} \mathrm{O}_{4} @ \mathrm{SiO}_{2} @ \mathrm{SiO}_{2} / \mathrm{TPA} \mathrm{A}_{400 \mathrm{~N} 2}$ se muestra en la Figura 48. En el espectro de la muestra $\mathrm{Fe}_{3} \mathrm{O}_{4} @ \mathrm{SiO}_{2}$, las bandas características de la sílice aparecen tapando las correspondientes al $\mathrm{Fe}_{3} \mathrm{O}_{4}$.

Se puede ver una banda ancha e intensa a $1080 \mathrm{~cm}^{-1}$ que se debe a los enlaces de estiramiento asimétricos de $\mathrm{Si}-\mathrm{O}-\mathrm{Si}$ en el tetraedro $\mathrm{SiO}_{4}$. La banda a $793 \mathrm{~cm}^{-1}$ se asigna al tramo simétrico Si-O-Si. La banda de absorción a $960 \mathrm{~cm}^{-1}$ corresponde a estiramientos del enlace $\mathrm{Si}-\mathrm{OH}$, y la banda a $564 \mathrm{~cm}^{-1}$ es una indicación de la presencia de Si-O-Fe según lo reportado en la literatura ${ }^{204}$. Estas mismas bandas están presentes en la muestra $\mathrm{Fe}_{3} \mathrm{O}_{4} @ \mathrm{SiO}_{2} @ \mathrm{SiO}_{2} / \mathrm{TPA}_{400 \mathrm{~N}}$. 
Capítulo IV. Análisis de Resultados.

Como se mencionó anteriormente, las bandas del anión con estructura tipo Keggin del TPA son: $1080 \mathrm{~cm}^{-1}$ propia del enlace P-Oa, $964 \mathrm{~cm}^{-1}$ del enlace $\mathrm{W}=\mathrm{Od}, \mathrm{y}$ 891 y 814 cm-1 de enlaces W-Oc-W. En la muestra $\mathrm{Fe}_{3} \mathrm{O}_{4} @ \mathrm{SiO}_{2} @ \mathrm{SiO}_{2} / \mathrm{TPA} 400 \mathrm{~N} 2$, dichas bandas se encuentran solapadas por las bandas de la sílice que aparecen en las mismas longitudes de onda y son más intensas y anchas 208,250 .

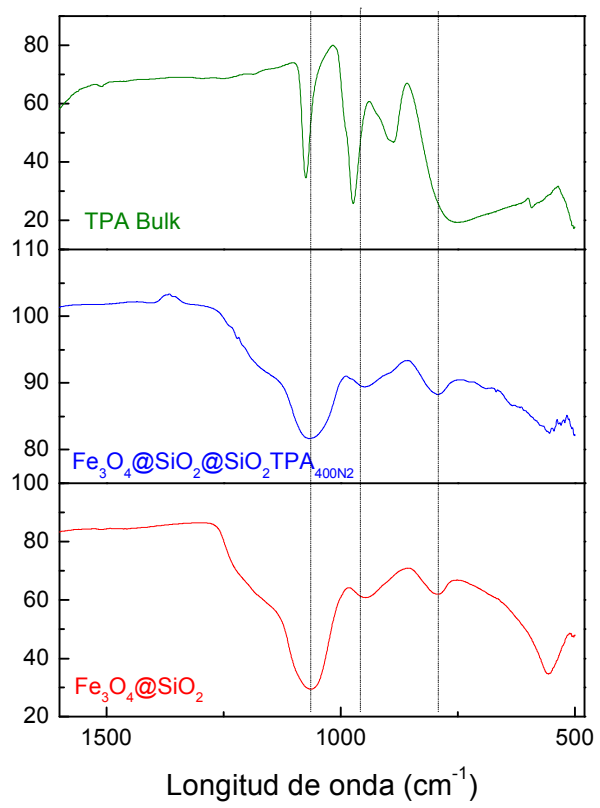

Figura 48. Espectros IRFT-ART de las muestras del Grupo III, $\mathrm{Fe}_{3} \mathrm{O}_{4} @ \mathrm{SiO}_{2}$ (Linea roja), $\mathrm{Fe}_{3} \mathrm{O}_{4} @ \mathrm{SiO}_{2} @ \mathrm{SiO}_{2} / \mathrm{TPA}_{400 \mathrm{~N} 2}$ (Línea azul) y TPA másico (Línea verde).

Basándonos en esta información, concluimos que las NPMs de $\mathrm{Fe}_{3} \mathrm{O}_{4}$ en suspensión en una solución etanol/amoniaco y TEOS se pueden recubrir de forma rápida y efectiva con sucesivas capas de sílice, las cuales, protegen y proporcionan sitios adecuados (grupos Si-OH) para la posterior inmovilización del TPA.

\subsubsection{Difracción de Rayos $X(D R X)$.}

Las propiedades magnéticas de las NPMs dependen de su tamaño, distribución de tamaños, forma y pureza de fase cristalina, así, la presencia de impurezas en forma de fases secundarias distintas de la fase requerida afecta dichas propiedades. Durante la síntesis de NPMs de magnetita por la técnica de coprecipitación, suelen obtenerse otras 
Capítulo IV. Análisis de Resultados.

fases como maghemita o hematita, dependiendo de las condiciones del proceso, y el estudio por DRX permite establecer si hay mezcla de fases y de ser así, en qué proporción.

En la Figura 49 se muestran los diagramas de DRX de $\mathrm{Fe}_{3} \mathrm{O}_{4} @ \mathrm{SiO}_{2}$ y $\mathrm{Fe}_{3} \mathrm{O}_{4} @ \mathrm{SiO}_{2} @ \mathrm{SiO}_{2} / \mathrm{TPA} \mathrm{T}_{400 \mathrm{~N} 2}$, en los cuales prevalecen los picos de difracción característicos de $\mathrm{Fe}_{3} \mathrm{O}_{4}$ a valores de $2 \theta$ iguales a $18,4^{\circ}, 30,2^{\circ}, 35,6^{\circ}, 43,3^{\circ}, 53,6^{\circ}, 57,1^{\circ}$ y $62,6^{\circ}$, atribuidos a los planos (111), (220), (311), (400), (422), (511) y (440), respectivamente, de la estructura cúbica de espinela inversa correspondiente a la fase de magnetita.

Basándose en el hecho de que en el momento de la síntesis de las NPMs aparece un precipitado negro (característico de la síntesis de $\mathrm{Fe}_{3} \mathrm{O}_{4}{ }^{200}$ ) justo después de mezclar la solución de las sales de hierro con la solución de amoniaco, se demuestra que el pH desempeñó un papel importante en la formación de esta única fase, siendo favorecida por un pH por encima de 11 y una atmósfera inerte (burbujeo con nitrógeno), que ayudan a prevenir la oxidación del hierro.

Además, se evidencia que el recubrimiento con $\mathrm{SiO}_{2}$ y la calcinación en atmósfera inerte, protege a la magnetita de oxidarse, ya que en la muestra $\mathrm{Fe}_{3} \mathrm{O}_{4} @ \mathrm{SiO}_{2} @ \mathrm{SiO}_{2} / \mathrm{TPA} 400 \mathrm{~N} 2$, los picos de difracción son exactamente los mismo, aunque un poco menos definidos y más anchos debido a una mayor cantidad de $\mathrm{SiO}_{2}$.

Esto indica que la sílice está en una forma amorfa y posiblemente sus picos pequeños y anchos están dominados por los picos agudos de la magnetita. Aun así, se observa un hombro ancho entre 25 y $30^{\circ}$ característico de la sílice amorfa. Por último, no se observan los picos de difracción característicos del TPA debido a una gran dispersión de la fase activa sobre la superficie del soporte $251,252$. 
Capítulo IV. Análisis de Resultados.

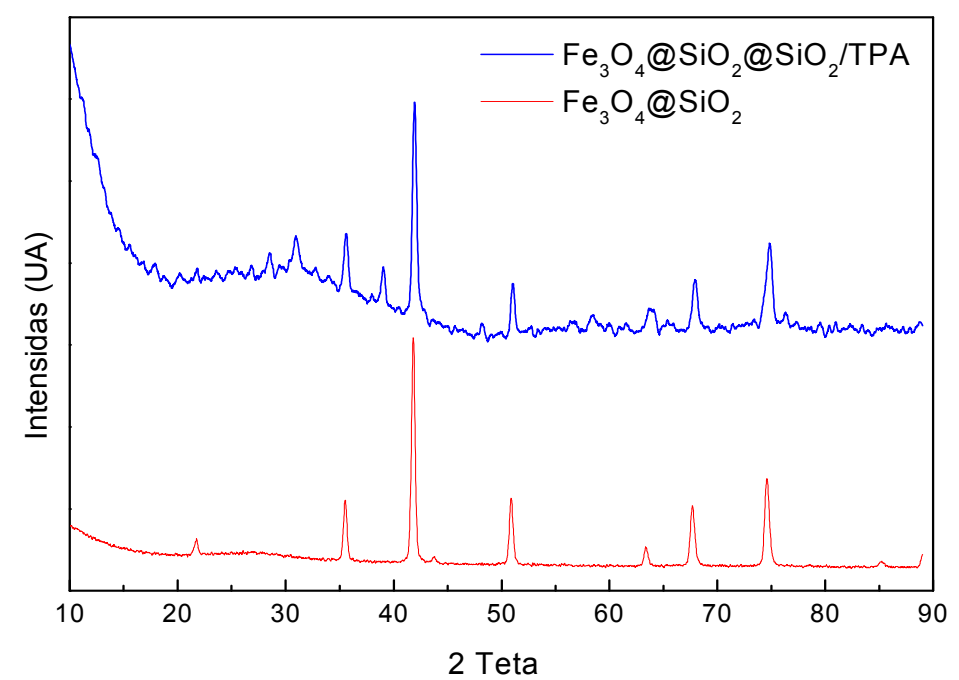

Figura 49. Espectros DRX de las muestras del Grupo III, $\mathrm{Fe}_{3} \mathrm{O}_{4} @ \mathrm{SiO}_{2}$ (Linea roja) y $\mathrm{Fe}_{3} \mathrm{O}_{4} @ \mathrm{SiO}_{2} @ \mathrm{SiO}_{2} / \mathrm{TPA}_{400 \mathrm{~N} 2}$ (Línea azul).

\subsubsection{Estudio por magnetometría de vibración.}

Las propiedades magnéticas tienen su origen en la existencia de polos magnéticos en los átomos, como resultado del movimiento de los electrones. Al someter un material a un campo magnético externo, éste tiende a alinear estos dipolos con el campo, con la consiguiente aparición de momentos magnéticos inducidos en el material. Se ha mencionado anteriormente que muchas de las propiedades magnéticas de las nanopartículas dependen directamente de su composición, recubrimiento y tamaño de partícula y esto hace que sea de gran importancia para los materiales tipo "núcleo/envoltura" estudiar su comportamiento magnético ${ }^{253}$. Una forma de medir dichas propiedades es a partir de las curvas de magnetización o de histéresis como también son conocidas, las cuales, para construirlas se grafica la magnetización (momento magnético total por unidad de volumen, M) en función del campo aplicado (H) a una determinada temperatura.

Las curvas de magnetización para los materiales $\mathrm{Fe}_{3} \mathrm{O}_{4}, \mathrm{Fe}_{3} \mathrm{O}_{4} @ \mathrm{SiO}_{2}$ y $\mathrm{Fe}_{3} \mathrm{O}_{4} @ \mathrm{SiO}_{2} @ \mathrm{SiO}_{2} / \mathrm{TPA} 400 \mathrm{~N} 2$ se realizaron con un barrido de -10.000 a +10.000 
Capítulo IV. Análisis de Resultados.

Oersted (Unidad de intensidad de campo magnético del sistema cegesimal, Oe) a $300 \mathrm{~K}$. Las curvas resultantes se muestran en la Figura 50.

La dependencia del campo magnético aplicado para estos sistemas confirma la respuesta ferromagnética de estos materiales. Se puede observar que las curvas $\mathrm{Fe}_{3} \mathrm{O}_{4}$ y $\mathrm{Fe}_{3} \mathrm{O}_{4} @ \mathrm{SiO}_{2}$ pasan por el origen (Figura 50.a líneas azul y roja), correspondientes a sólidos que no presentan coercitividad o remanencia, lo que indica su comportamiento superparamagnético, permitiendo que puedan dispersarse fácilmente cuando el campo magnético aplicado es retirado ${ }^{189,254}$. Los valores de magnetización de saturación (Ms) para estos dos materiales fueron 87 y $49 \mathrm{emu} / \mathrm{g}$, respectivamente. La disminución en el valor de $\mathrm{Ms}_{\mathrm{s}}$ para $\mathrm{Fe}_{3} \mathrm{O}_{4} @ \mathrm{SiO}_{2}$ puede atribuirse a la deposición de $\mathrm{SiO}_{2}$ no magnético en la superficie de $\mathrm{Fe}_{3} \mathrm{O}_{4}$, con la consecuente menor cantidad de magnetita en un mismo peso de muestra (se pesó $10 \mathrm{mg}$ para cada análisis) ${ }^{252}$.

Sin embargo, cuando se hace el segundo recubrimiento de $\mathrm{SiO}_{2}$ en el que se agrega el TPA, muestra $\mathrm{Fe}_{3} \mathrm{O}_{4} @ \mathrm{SiO}_{2} @ \mathrm{SiO}_{2} / \mathrm{TPA}_{400 \mathrm{~N} 2}$ (Figura 50.a, línea verde), el valor de Ms disminuye considerablemente a $15 \mathrm{emu} / \mathrm{g}$, evidenciando que la capa de $\mathrm{SiO}_{2}$ es mucho más gruesa, con la consecuente menor cantidad de magnetita por unidad de peso. Adicionalmente, se puede observar un leve bucle de histéresis indicando que el material presenta una pequeña remanencia, debido probablemente a un aumento significativo en el tamaño de las partículas, a una menor cristalinidad o cambios en la estructura superficial, hecho que se evidenció en el análisis de los DRX, donde se observó que el recubrimiento $\mathrm{SiO}_{2}$ /TPA no es cristalino, afectando el comportamiento magnético del polvo sintetizado, reduciendo la máxima magnetización y aumentando ligeramente la fuerza coercitiva192,200. Aun así, su magnetización es suficiente para separar fácilmente el sólido del medio de reacción con un imán convencional, que para nuestro caso es el objetivo.

Finalmente se estudió y comparó el comportamiento magnético del material $\mathrm{Fe}_{3} \mathrm{O}_{4} @ \mathrm{SiO}_{2} @ \mathrm{SiO}_{2} / \mathrm{TPA}$ sin calcinar, calcinado y luego de dos ciclos de reacción para analizar si la temperatura de calcinación y el medio de reacción tenían algún efecto sobre sus propiedades magnéticas. Las curvas resultantes se muestran en la figura 50.b 
Capítulo IV. Análisis de Resultados.

y en ellas se puede observar que el valor de Ms se mantiene en $15 \mathrm{emu} / \mathrm{g}$ y se mantienen el mismo ciclo de histéresis indicando que las capas de $\mathrm{SiO}_{2}$ protegen a la magnetita del efecto de la temperatura y del medio de reacción.
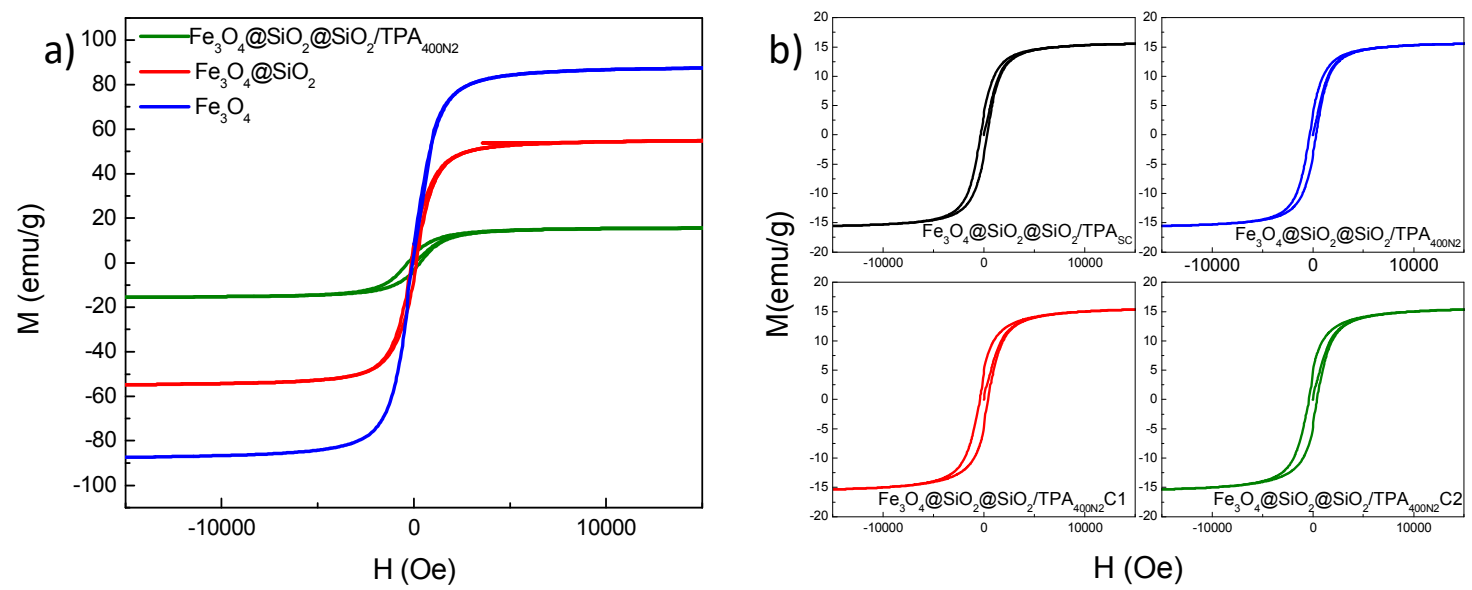

Figura 50. a) Curvas de magnetización para los materiales magnéticos en las diferentes etapas de síntesis del catalizador, $\mathrm{Fe}_{3} \mathrm{O}_{4}$ (Línea azul), $\mathrm{Fe}_{3} \mathrm{O}_{4} @ \mathrm{SiO}_{2}$ (Línea roja) y $\mathrm{Fe}_{3} \mathrm{O}_{4} @ \mathrm{SiO}_{2} @ \mathrm{SiO}_{2} / \mathrm{TPA} 400 \mathrm{~N} 2$ (Línea verde), b) Curvas de magnetización para el catalizador luego de varios ciclos de reacción, $\mathrm{Fe}_{3} \mathrm{O}_{4} @ \mathrm{SiO}_{2} @ \mathrm{SiO}_{2} / \mathrm{TPAsc}$ (Línea negra), $\mathrm{Fe}_{3} \mathrm{O}_{4} @ \mathrm{SiO}_{2} @ \mathrm{SiO}_{2} / \mathrm{TPA}_{400 \mathrm{~N} 2}$ (Línea azul), $\mathrm{Fe}_{3} \mathrm{O}_{4} @ \mathrm{SiO}_{2} @ \mathrm{SiO}_{2} / \mathrm{TPA}_{400 \mathrm{~N} 2} \mathrm{C} 1$ (Línea roja) y $\mathrm{Fe}_{3} \mathrm{O}_{4} @ \mathrm{SiO}_{2} @ \mathrm{SiO}_{2} / \mathrm{TPA}_{400 \mathrm{~N} 2} \mathrm{C} 2$ (Línea verde).

\subsubsection{Fuerza ácida por titulación potenciométrica con n-butilamina.}

La acidez de los materiales del Grupo III se determinó mediante titulación potenciométrica con n-butilamina. Las curvas obtenidas para el soporte $\mathrm{Fe}_{2} \mathrm{O}_{4} @ \mathrm{SiO}_{2}$, el catalizador $\mathrm{Fe}_{3} \mathrm{O}_{4} @ \mathrm{SiO}_{2} @ \mathrm{SiO}_{2} / \mathrm{TPA} 400 \mathrm{~N} 2$ y una muestra del catalizador luego del primer ciclo de reacción, denominada $\mathrm{Fe}_{3} \mathrm{O}_{4} @ \mathrm{SiO}_{2} @ \mathrm{SiO}_{2} / \mathrm{TPA}_{400 \mathrm{~N}_{2}} \mathrm{C} 1$ se muestran en la Figura 51. El soporte $\mathrm{Fe}_{2} \mathrm{O}_{4} @ \mathrm{SiO}_{2}$ mostró sitios muy fuertes según la clasificación de la Tabla 5, marcando un valor de Ei de $110 \mathrm{mV}$. Dicho valor aumentó significativamente luego

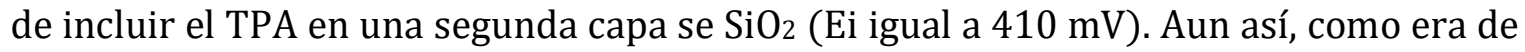
esperarse, al incluir el TPA en el material $\mathrm{Fe}_{2} \mathrm{O}_{4} @ \mathrm{SiO}_{2}$, disminuyó la fuerza de los sitios ácidos comparado con el valor registrado para el TPA másico el cual presenta un valor 
Capítulo IV. Análisis de Resultados.

Ei de $620 \mathrm{mV}$. Ésta disminución es atribuida a la interacción del TPA con el soporte, en este caso, indica una fuerte interacción entre los protones del $\mathrm{H}_{3} \mathrm{PW}_{12} \mathrm{O}_{40} \cdot 6 \mathrm{H}_{2} \mathrm{O}$ y los oxígenos de los grupos $\mathrm{Si}-\mathrm{OH}$, lo que se traduce en la ausencia de lixiviación durante la reacción ${ }^{255}$.

Analizando la curva de titulación potenciométrica de $\mathrm{Fe}_{3} \mathrm{O}_{4} @ \mathrm{SiO}_{2} @ \mathrm{SiO}_{2} / \mathrm{TPA}_{400 \mathrm{~N} 2} \mathrm{C} 1$, vemos que es muy similar a la del catalizador fresco, aunque presenta un valor de Ei de $395 \mathrm{mV}$, el cual es ligeramente menor en comparación con valor Ei del catalizador sin utilizar $(410 \mathrm{mV})$, mostrando que es muy poca la variación del material durante la reacción, lo que concuerda con los resultados de conversión obtenidos durante las diferentes reutilizaciones del catalizador, los cuales se mantienen constantes hasta en 4 ciclos de uso, exhibiendo una excelente actividad en reacciones de esterificación.

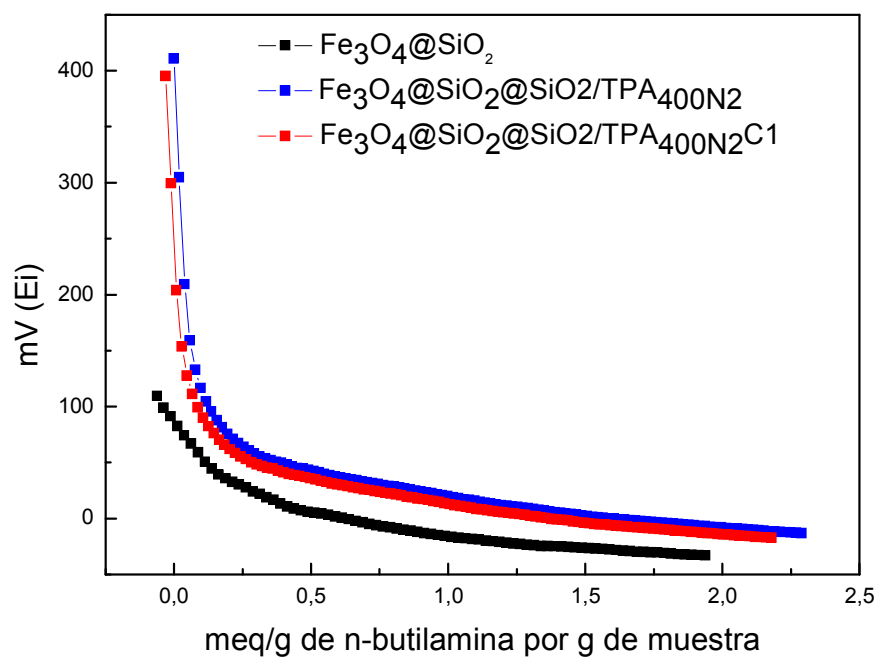

Figura 51. Curvas de titulación potentiométrica para los materiales del Grupo III. 
Capítulo IV. Análisis de Resultados.

\subsection{ENSAYOS CATALÍTICOS.}

\subsubsection{Evaluación catalítica de los catalizadores del Grupo I.}

Se eligió la reacción de ácido 2-furoico con n-butanol para obtener 2-furoato de n-butilo como reacción modelo de esterificación de Fischer para estudiar la actividad catalítica de las muestras ZrTPA30PEGT100, ZrPEGTPA60T100, ZrPEGTPA30T100 у ZrTPA60PEGT100, ya que ésta es una reacción de gran interés en la actualidad debido a las posibles aplicaciones del 2-furoato de n-butilo y porque representa un aporte a las investigaciones sobre valorización de residuos de biomasa.

Se hizo inicialmente una comparación de los cuatro catalizadores, determinando cuál presentaba el mejor rendimiento y continuar con este para realizar las pruebas de optimización de las condiciones de reacción.

Las condiciones para la comparación fueron $1 \mathrm{mmol}$ del ácido 2-furoico, 33 mmoles de n-butanol y 200 mg de los catalizadores ZrTPA30PEGT100 y ZrPEGTPA30T100 y $100 \mathrm{mg}$ de los catalizadores ZrPEGTPA60т100 y ZrTPA60PEG la prueba a una cantidad igual de TPA, a una temperatura de $140{ }^{\circ} \mathrm{C}$.

Es importante destacar que el 2-furoato de n-butilo es el único producto detectado en todas las reacciones realizadas en el trabajo, indicando que el rendimiento de este producto es igual a la conversión alcanzada (selectividad del $100 \%$ de 2-furoato de n-butilo).

De igual forma, antes de intentar un trabajo catalítico detallado, se realizó la reacción del ácido 2-furoico con n-butanol en ausencia de catalizador, ya que es conocido que en reacciones de esterificación es posible que el ácido orgánico sea capaz de catalizar la reacción por sí mismo como lo reportó Kuwahara y $\operatorname{col}^{256}$ quienes mostraron que en ausencia de catalizador el ácido levulínico puede esterificarse con etanol a $70{ }^{\circ} \mathrm{C}(1,8 \%$ en $10 \mathrm{~h})$. Esto posibilitará también, determinar cuánto de la conversión final es debida a la presencia del catalizador. 
Capítulo IV. Análisis de Resultados.

Este comportamiento pudo evidenciarse durante la prueba, ya que bajo las mismas condiciones experimentales mencionadas anteriormente, se detectó una conversión del 10\% a las 24 h (Tabla 9, Entrada 1), lo que indica que si bien, el ácido 2furoico cataliza la reacción de esterificación en una pequeña cantidad, desde un punto de vista práctico la reacción no está teniendo lugar en un grado importante en ausencia de un catalizador. Los perfiles de reacción de los cuatro catalizadores y del blanco de reacción se muestran en la Figura 52. Las conversiones del ácido 2-furoico después de 24 h de reacción se listan en la Tabla 9.

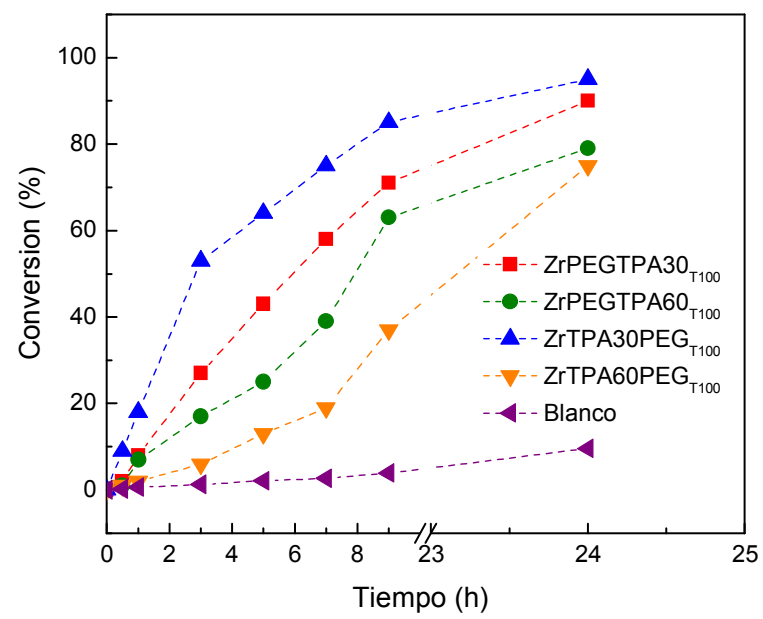

Figura 52. Conversión del ácido 2-furoico en función del tiempo para los diferentes catalizadores del Grupo I. Condiciones de reacción: ácido 2-furóico, 1 mmol; n-butanol, 33 mmoles; 100 mg de catalizador para ZrPEGTPA60т100 у ZrTPA60PEGT100 у 200 mg para ZrPEGTPA30T100 y ZrTPA30PEGT100; correspondiente a 0,17 mmoles de fase activa, $140{ }^{\circ} \mathrm{C} ; 24$ h; agitación.

Como se muestra en la Figura 52, la reacción se aceleró significativamente en presencia de los catalizadores ácidos sólidos comparadas con el blanco de reacción, especialmente, se observa que la conversión, aumenta más rápidamente cuando se emplearon los catalizadores ZrTPA30PEGT100 y ZrPEGTPA30T100 en comparación con los sólidos que tienen $60 \%$ de concentración de TPA. La conversión obtenida a las 24 horas con los dos catalizadores mencionados, son similares (95\% y 90\%, respectivamente, como se muestra en la Tabla 9, Entradas 2 y 4), lo que mostraría que 
Capítulo IV. Análisis de Resultados.

la actividad catalítica es independiente del tiempo transcurrido entre que se agrega el PEG y la incorporación del TPA.

Un comportamiento similar se observó para los catalizadores ZrTPA60PEGT100 y ZrPEGTPA60т100 (75\% у 79\%, respectivamente, Tabla 9, Entradas 3 у 5). Estos resultados concuerdan con que, los materiales obtenidos presentan similares valores de acidez, independientemente del orden de agregado del TPA, como por ejemplo para el caso de ZrTPA30PEGT100 y ZrPEGTPA30T100 (Ei = 394 y $416 \mathrm{mV}$, respectivamente) o de ZrTPA60PEGT100 y ZrPEGTPA60T100 (Ei = 397 y $420 \mathrm{mV}$, respectivamente). Los valores de acidez también son similares para las series conteniendo 30 y $60 \%$ de TPA.

El mayor rendimiento obtenido usando las muestras ZrTPA30PEGT100 y ZrPEGTPA30T100 puede ser atribuido, al hecho de que estos materiales tienen un número mayor de sitios ácidos por gramo de TPA (NGTPA) que los sólidos ZrTPA60PEGT100 y ZrPEGTPA60T100 (Tabla 9). Teniendo en cuenta estos resultados, se decidió seguir con las pruebas de optimización de las condiciones de reacción solo con los dos catalizadores que presentaron mejores rendimientos, ZrTPA30PEGT100 y ZrPEGTPA30T100.

Tabla 9. Propiedades ácidas $(\mathrm{mV})$ y conversiones de reacción (\%) para el blanco de reacción y los catalizadores del Grupo I.

\begin{tabular}{cccc}
\hline Entrada & Catalizador & $\begin{array}{c}\mathrm{Ei} \\
(\mathrm{mV})\end{array}$ & $\begin{array}{c}\text { Conversión } \\
(\%)\end{array}$ \\
\hline 1 & Blanco & - & 10 \\
2 & ZPEGTPA30T100 & 394 & 90 \\
3 & ZPEGTPA60T100 $_{\mathrm{T}}$ & 397 & 79 \\
4 & ZTPA30PEGT100 $_{\mathrm{T}}$ & 416 & 95 \\
5 & ZTPA60PEGT100 $_{\mathrm{T}}$ & 420 & 75
\end{tabular}

Condiciones de reacción: ácido 2-furóico, $1 \mathrm{mmol}$; n-butanol, $33 \mathrm{mmoles} ; 100 \mathrm{mg}$ de catalizador para ZrPEGTPA60T100 y ZrTPA60PEGT100 y $200 \mathrm{mg}$ para ZrPEGTPA30T100 y ZrTPA30PEGT100; $140{ }^{\circ} \mathrm{C} ; 24$ h; agitación. 
Capítulo IV. Análisis de Resultados.

Se continuó con el estudio de la influencia de la temperatura sobre la síntesis de 2-furoato de n-butilo usando los catalizadores ZrTPA30PEGT100 y ZrPEGTPA30T100. Los resultados se ilustran en la Figura 53.a y b. Para estimar la temperatura óptima, se ensayaron cinco temperaturas $\left(70,95,110,125\right.$ y $\left.140{ }^{\circ} \mathrm{C}\right)$. Cuando la reacción se realizó a $70{ }^{\circ} \mathrm{C}$ no se detectó formación apreciable de producto.

Se encontró que la formación de 2-furoato de n-butilo se incrementa para temperaturas superiores a los $70{ }^{\circ} \mathrm{C}$. Por ejemplo, mientras que a $110{ }^{\circ} \mathrm{C}$ para un tiempo de reacción de 24 h, utilizando el catalizador ZrTPA30PEGT100, la conversión fue tan sólo del $25 \%$, en el mismo tiempo, a $125{ }^{\circ} \mathrm{C}$ la conversión fue del 93\% (Figura 53.a).

De forma similar ocurrió con el catalizador ZrPEGTPA30T100, el cual presentó una conversión de $22 \%$ a $110{ }^{\circ} \mathrm{C}$, mientras que a 125 y $140{ }^{\circ} \mathrm{C}$ la conversión fue de 80 y 90\%, respectivamente (Figura 53.b). Esto evidencia que la reacción debe llevarse a cabo a una temperatura relativamente alta para alcanzar el umbral de la energía de activación.

Así mismo, debido a que las reacciones de esterificación se dan en equilibrio, temperaturas por encima de los $100^{\circ} \mathrm{C}$ hacen que el agua generada durante la reacción se elimine por evaporación, desplazando el equilibrio hacia la formación del éster y aumentando significativamente el rendimiento. Esto se ve reflejado en los altos porcentajes que se consiguen cuando la reacción se hace a las temperaturas de $125 \mathrm{y}$ $140{ }^{\circ} \mathrm{C}$ respectivamente.

También se puede observar en la Figura 53 que no hay una diferencia significativa de conversión entre estas dos últimas temperaturas, especialmente con el catalizador ZrTPA30PEGT100 (Figura 53.a), por esa razón se escogió la temperatura de $125{ }^{\circ} \mathrm{C}$ como la óptima para seguir este estudio, ya que implica un ahorro de energía. 
Capítulo IV. Análisis de Resultados.
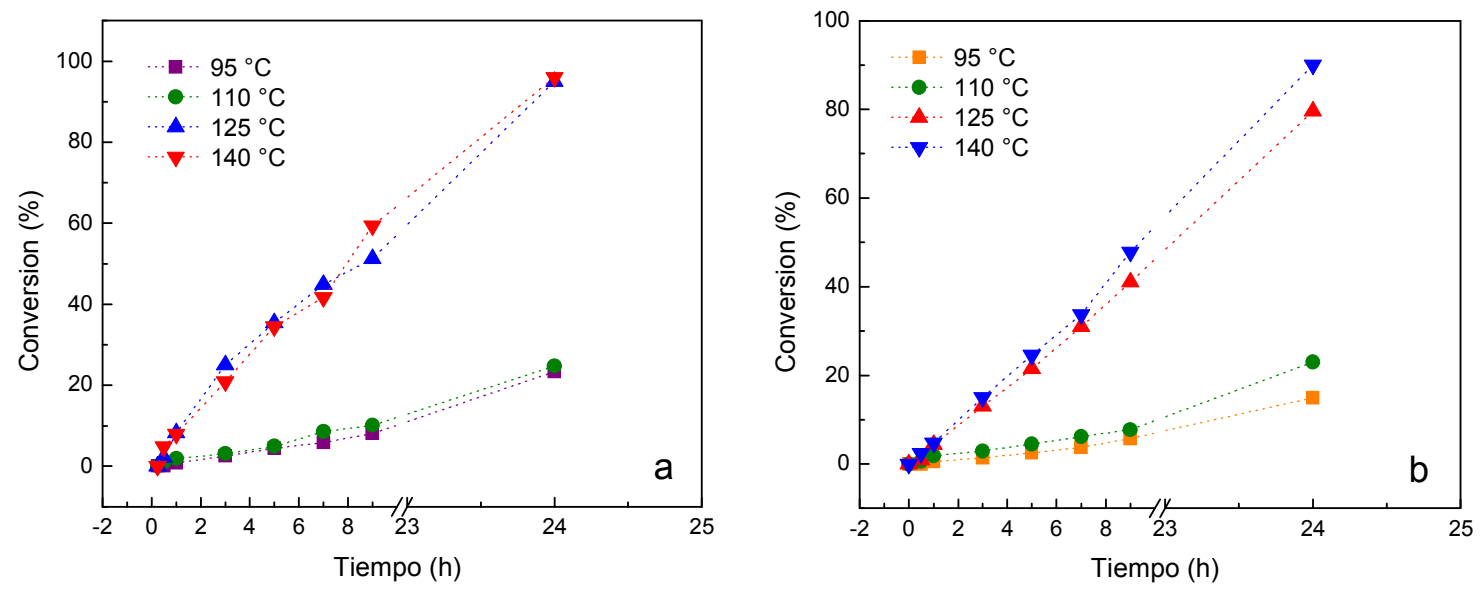

Figura 53. Porcentaje de conversión (\%) del ácido 2-furoico a 2-furoato de n-butilo en función de la temperatura. a) ZrTPA30PEGT100 b) ZrPEGTPA30T100. Condiciones de reacción: ácido 2-furoico, 1 mmol; n-butanol, 33 mmoles; 200 mg de catalizador; 24 h; agitación.

La siguiente prueba que se realizó fue determinar el efecto de la cantidad de catalizador, sobre el rendimiento de 2-furoato de n-butilo en la reacción de esterificación estudiada, los resultados se muestran en la Figura 54 a y b para los catalizadores ZrTPA30PEGT100 у ZrPEGTPA30T100, respectivamente, donde las cantidades utilizadas fueron 50, 100, 150 y $200 \mathrm{mg}$.

Se puede ver que la conversión aumentó del $65 \%$ al $90 \%$ cuando la cantidad de ZrTPA30PEGT100 aumentó de 50 a 100 mg (Figura 54.a). No obstante, no se observó un cambio significativo de conversión cuando se utilizaron cantidades superiores de catalizador, ya que con 200 mg alcanzó un máximo de 95\% en las mismas 24 horas.

Se obtuvo un resultado bastante similar empleando el catalizador ZrPEGTPA30T100 (Figura 54.b). Así, $100 \mathrm{mg}$ es la cantidad adecuada según estos resultados. 
Capítulo IV. Análisis de Resultados.
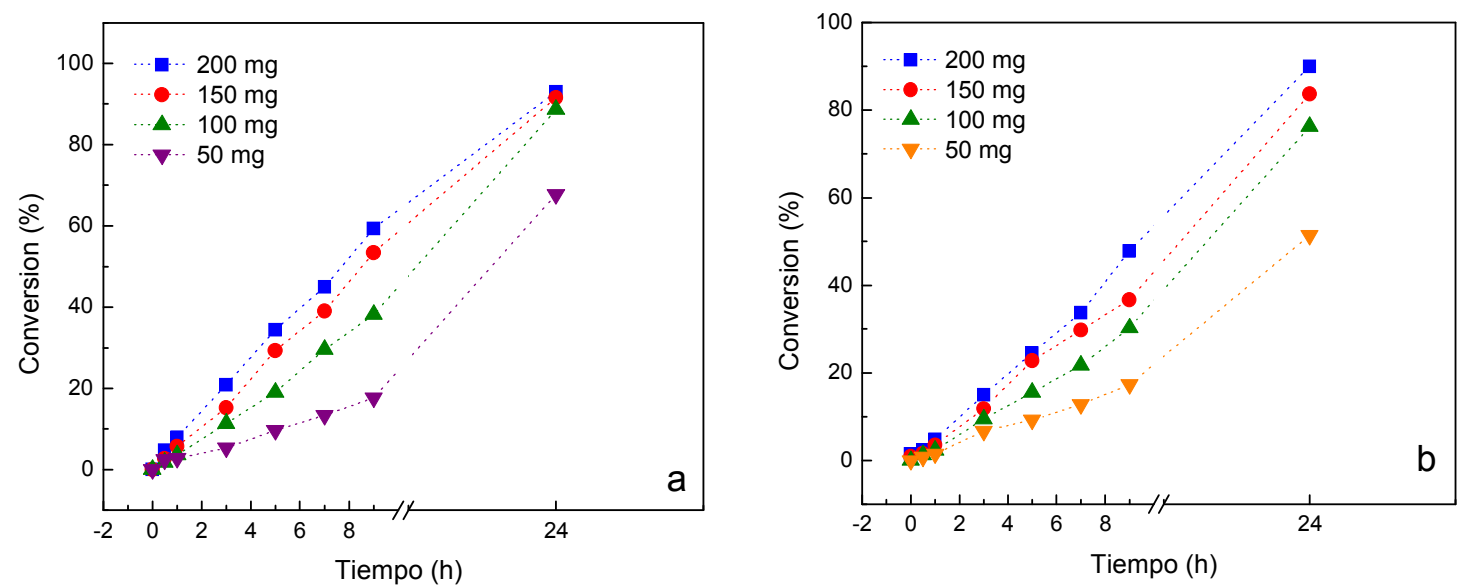

Figura 54. Porcentaje de conversión (\%) de ácido 2-furoico a 2-furoato de n-butilo en función de la cantidad de catalizador. a) ZrTPA30PEGT100, b) ZrPEGTPA30T100. Condiciones de reacción: ácido 2 -furoico, $1 \mathrm{mmol}$; n-butanol, 33 mmoles, $125{ }^{\circ} \mathrm{C}$; 24 h; agitación.

Por último, se estudió el efecto de la relación molar ácido furoico/n-butanol en la conversión del ácido 2-furóico a 2-furoato de n-butilo. Se dejó constante la cantidad de ácido furoico (1 mmol) y se variaron las moles de n-butanol, 2, 6, 11 y $33 \mathrm{mmol}$ respectivamente. Los resultados se muestran en la Tabla 10.

Tabla 10. Efecto del radio molar ácido 2-furoico/n-butanol.

\begin{tabular}{ccc}
\hline Entrada & $\begin{array}{c}\text { Radio molar } \\
\text { acid:alcohol }\end{array}$ & $\begin{array}{c}\text { Conversión } \\
(\%)\end{array}$ \\
\hline 1 & $1: 2$ & 82 \\
2 & $1: 6$ & 63 \\
3 & $1: 11$ & 36 \\
4 & $1: 33$ & 18
\end{tabular}

Condiciones de reacción: ácido 2-furoico, 1 mmol; catalizador ZrTPA30PEGT100 50 mg; $125^{\circ} \mathrm{C} ; 10$ h; agitación. 


\section{Capítulo IV. Análisis de Resultados.}

Se los porcentajes de conversión mostrados en la Tabla 10, se puede observar que aunque las reacciones de esterificación se ven favorecidas por un exceso de alcohol para desplazar el equilibro hacia los productos, en este sistema de reacción una relación molar ácido 2-furoico/n-butanol 1:2 es suficiente para mejorar el rendimiento del éster (Tabla 10, Entrada 1), obteniendo una conversión del ácido 2-furoico de 82\% en $10 \mathrm{~h}$, alcanzando así un rendimiento mayor en menos tiempo.

Cuando se trabaja con un exceso de alcohol, éste hace las veces de solvente, pero dado que la conversión de sustrato en función de la cantidad de n-butanol mostró una relación 1:2 de reactivos es la óptima, al reducir la cantidad de alcohol, se llega a un proceso libre de disolvente, que además favorece también la velocidad de reacción, aumentándola notablemente y permitiendo que se haga incluso con menor cantidad de catalizador, ya que como se describe en las condiciones de la Tabla 10, la reacción se realizó con $50 \mathrm{mg}$ de catalizador. Si se utiliza una cantidad menor de n-butanol para sintetizar 2-furoato de n-butilo, sin sacrificar el rendimiento de la reacción, serán menor la cantidad de desechos, y aunque el alcohol en exceso se puede recuperar para reutilizar, esto implica pasos adicionales como purificación, que aumentan el costo del proceso, siendo una razón más para utilizar la relación molar 1:2 en los próximos experimentos.

Esto representa un resultado excelente en términos de la reducción del factor E, y la disminución del uso de sustancias auxiliares. El factor E, propuesto por Roger A. Sheldon ${ }^{257}$, es un cálculo matemático sencillo que compara la cantidad de residuos generados por kg de producto, siendo una herramienta útil para evaluar rápidamente la cantidad de residuos generados durante un determinado proceso. Por su parte, la disminución del uso de sustancias auxiliares como los solventes, es un principio muy relacionado con el de economía atómica (principio 2 de la Química Verde).

Este mejor rendimiento con una relación menor ácido/alcohol, se debe probablemente a que la velocidad de reacción depende de la concentración de los reactantes, alcanzando así bajo estas condiciones su máximo. También es lógico pensar que el alcohol puede ser adsorbido sobre la superficie del catalizador, compitiendo con 
Capítulo IV. Análisis de Resultados.

el ácido 2-furoico por los sitios ácidos, al disminuir las moles de alcohol, aumenta la probabilidad de adsorción del ácido, además, los reactivos y el catalizador están en estrecha proximidad, aumentando la probabilidad de choque entre moléculas favoreciendo la velocidad de la reacción.

En la Tabla 11 se muestra un resumen de algunas de las condiciones de reacción evaluadas durante este estudio con el catalizador ZrTPA30PEGT100, de la cual se concluye que las condiciones óptimas son: una relación molar ácido/alcohol 1:2, $50 \mathrm{mg}$ de catalizador y $125^{\circ} \mathrm{C}$ (Tabla 11, Entrada 10).

Tabla 11. Síntesis de 2-furoato de n-butilo utilizando ZrTPA30PEGT100 como catalizador, variando las condiciones de reacción. 24 h.

\begin{tabular}{rrccc}
\hline Entrada & $\begin{array}{c}\text { Temperatura } \\
\left({ }^{\circ} \mathrm{C}\right)\end{array}$ & $\begin{array}{c}\text { Cantidad de } \\
\text { catalizador }(\mathrm{mg})\end{array}$ & $\begin{array}{c}\text { Relación ácido/alcohol } \\
(\mathrm{moles})\end{array}$ & $\begin{array}{c}\text { Rto } \\
\%\end{array}$ \\
\hline 1 & 125 & 50 & $1: 33$ & 68 \\
2 & 125 & 100 & $1: 33$ & 90 \\
3 & 125 & 150 & $1: 33$ & 92 \\
4 & 125 & 200 & $1: 33$ & 93 \\
5 & 95 & 200 & $1: 33$ & 23 \\
6 & 110 & 200 & $1: 33$ & 25 \\
7 & 140 & 200 & $1: 33$ & 95 \\
8 & 125 & 50 & $1: 11$ & 77 \\
9 & 125 & 50 & $1: 6$ & 93 \\
10 & 125 & 50 & $1: 2$ & 97 \\
\hline
\end{tabular}

\subsubsection{Prueba de reutilización de los catalizadores del Grupo I.}

La reutilización de los catalizadores ZrTPA30PEGT100 y del ZrPEGTPA30T100 se estudió haciendo sucesivas reacciones de esterificación entre el ácido 2-furoico y el nbutanol. Al final de cada paso el catalizador se separó por filtración, se lavó con n- 
Capítulo IV. Análisis de Resultados.

butanol, se secó en una estufa de vacío a $40{ }^{\circ} \mathrm{C}$ y se volvió a utilizar adaptando las cantidades de los reactivos a la cantidad de catalizador recuperado.

Los resultados mostraron que ambos catalizadores pueden ser reutilizados en cuatro ocasiones sin pérdida apreciable de su actividad catalítica (el rendimiento fue del 95\% en los cuatro casos).

Con el fin de evaluar la posible solubilización de la fase activa del catalizador se realizó una prueba adicional. Se pesó $100 \mathrm{mg}$ del catalizador ZrTPA30PEGT100 y se sometió a reflujo en $3 \mathrm{~mL}$ de n-butanol durante $24 \mathrm{~h}$ a $125{ }^{\circ} \mathrm{C}$. Transcurrido este tiempo, el catalizador se filtró y se secó al vacío hasta peso constante, después se hicieron tres reacciones, una con el catalizador luego del reflujo, otra con el alcohol refluido en ausencia de catalizador y un blanco de reacción. Después de $10 \mathrm{~h}$, el rendimiento de 2-furoato de n-butilo con el alcohol refluido fue sólo del $6 \%$, un valor bajo comparado con el 51\% obtenido con el catalizador ZrTPA30PEGT100 y levemente mayor que el $4 \%$ que se obtuvo en el blanco de reacción, descartando así un posible lixiviado del catalizador.

\subsubsection{Síntesis de furoatos de alquilo.}

Finalmente en esta parte del trabajo, para explorar el potencial de este sistema catalítico, se hizo la esterificación del ácido 2-furoico con diversos alcoholes (primarios, secundarios, terciarios y bencílicos). La esterificación de los compuestos seleccionados se ensayó usando en todos los casos las mismas condiciones de reacción determinadas para el 2-furoato de n-butilo (1 mmol de ácido 2-furoico, $2 \mathrm{mmoles}$ del alcohol correspondiente y $50 \mathrm{mg}$ de catalizador, se agitó a $125{ }^{\circ} \mathrm{C}$ durante $24 \mathrm{~h}$ ) se utilizaron alternamente los catalizadores ZrTPA30PEGT100, y ZrPEGTPA30т100, ya que fueron los sólidos que dieron los rendimientos más altos en la síntesis de 2-furoato de n-butilo. Los rendimientos obtenidos se muestran en la Tabla 12. Se señala que en todas las reacciones los productos de interés fueron los únicos compuestos obtenidos en cada síntesis, no se produjeron reacciones secundarias competitivas y los productos de reacción fueron aislados y purificados por recristalización y separación líquido- 
Capítulo IV. Análisis de Resultados.

líquido según sea el caso, para separar los reactivos que quedaron sin reaccionar. No fue necesaria una purificación adicional. Los productos fueron identificados por cromatografía de gases/espectrometría de masas (CG/MS).

Durante esta prueba se determinó que un factor importante para el rendimiento de la reacción es la estructura del alcohol, ya que se presenta un componente de impedimento estérico que afecta su reactividad, se sabe que esto también es un factor decisivo para la esterificación de Fischer catalizada por ácido como ya lo han reportado otros estudios ${ }^{258}$. El impedimento estérico aumenta con el tamaño molecular, induciendo la repulsión entre los átomos de las moléculas. Este obstáculo repulsivo disminuye la densidad en la región intermolecular y perturba la unión ${ }^{259}$. Así, es mayor la reactividad de alcoholes primarios y bencílicos (Tabla 12, Entradas 3-7, 11 y 12) que la de alcoholes secundarios (Tabla 12, Entradas 9, 10, 14 y 15) y casi nula para alcoholes terciarios (Tabla 12, Entrada 8, 16).

La diferencia de rendimiento entre alcoholes primarios y secundarios se atribuye a efectos estéricos, la presencia de grupos voluminosos, como por ejemplo difenilcarbinol (Tabla 12, Entrada 15) muy cerca del centro de reacción, hace más lenta la tasa de esterificación. Otros ejemplos son: el mentol (un alcohol secundario), el cual es una molécula bastante voluminosa y el trifenilmetanol (un alcohol terciario) con lo que se obtuvieron solo trazas o no se detectó ningún producto (Tabla 12, Entradas 14 y 16). En resumen, el orden de reactividad hacia la esterificación de ácido 2-furoico con alcoholes es la siguiente: Alcoholes primarios $>$ alcoholes secundarios $>$ alcoholes terciarios.

Por último, se hicieron ensayos con alcoholes de menor punto de ebullición como es el caso del metanol y el etanol a su temperatura de reflujo (69 y $78{ }^{\circ} \mathrm{C}$, respectivamente), donde como era de esperarse, no se obtuvo ninguna conversión de sustratos, ya que como se había analizado cuando se estudió el efecto de la temperatura en la reacción, es necesaria una temperatura, por encima de los $100{ }^{\circ} \mathrm{C}$ para que tenga lugar la reacción. 
Capítulo IV. Análisis de Resultados.

Tabla 12. Efecto de la naturaleza del alcohol sobre la conversión alcanzada en la esterificación del ácido 2-furoico.

\begin{tabular}{|c|c|c|c|c|}
\hline Entrada & Alcohol & Catalizador & Producto & Conv. (\%) \\
\hline $1^{\mathrm{a}}$ & $\mathrm{H}_{3} \mathrm{C}_{-\mathrm{OH}}$ & ZrTPA30PEGT100 & $\mathrm{O}$ & - \\
\hline $2^{b}$ & $H_{3} C^{\prime}$ & ZrTPA30PEGT100 & 0 & - \\
\hline 3 & & ZrTPA30PEGT100 & & 97 \\
\hline 4 & & $\begin{array}{l}\text { ZrTPA30PEGT100 } \\
\text { ZrPEGTPA30T100 }^{\text {ZrPT }}\end{array}$ & & $\begin{array}{l}95 \\
90\end{array}$ \\
\hline 5 & & ZrTPA30PEGT100 & & 89 \\
\hline 6 & & $\begin{array}{l}\text { ZrTPA30PEGT100 } \\
\text { ZrPEGTPA30T100 }^{\mathrm{T}}\end{array}$ & & $\begin{array}{l}99 \\
98\end{array}$ \\
\hline 7 & & ZrTPA60PEGT100 & & 65 \\
\hline 8 & $\mathrm{CH}_{3}$ & $\mathrm{ZrPEGTPA30}_{\mathrm{T} 100}$ & & 25 \\
\hline 9 & & ZrTPA30PEGT100 & & 60 \\
\hline 10 & & ZrTPA30PEGT100 & & Trazas \\
\hline
\end{tabular}


Capítulo IV. Análisis de Resultados.

Continuación de la tabla 12.

Errada Catalizador

aLa reacción fue realizada a $65^{\circ} \mathrm{C}$.

bLa reacción fue realizada a $78^{\circ} \mathrm{C}$.

Condiciones de las reacciones: ácido 2-furoico, $1 \mathrm{mmol}$; alcohol, $2 \mathrm{mmoles}$; libres de solvente, catalizador, $50 \mathrm{mg}$. Agitación constante durante $24 \mathrm{~h}$ a $125^{\circ} \mathrm{C}$. 
Capítulo IV. Análisis de Resultados.

\subsubsection{Resultados de las pruebas antifouling.}

\subsubsection{Ensayos de laboratorio.}

Para mostrar la utilidad de estos compuestos, se estudió una de sus posibles aplicaciones: su actividad como repelentes o inhibidores del asentamiento de especies marinas, mediante su empleo en pinturas fabricadas con ésteres de furoato como agente activo. Los ésteres evaluados fueron 2-furoato de n-butilo, 2-furoato de n-hexilo y 2-furoato de n-octilo, donde se comparó la influencia del largo de la cadena carbonada en la actividad presentada.

Para ello se inició realizando una prueba de toxicidad de los furoatos en nauplios de Artemia sp. Los resultados arrojados por esta prueba mostraron que al exponer los nauplios a las soluciones de furoatos, se vio afectada la actividad larval incluso a partir de bajas concentraciones (Figura 55). Se observó, que para los 3 compuestos analizados, la toxicidad es inversamente proporcional al largo de la cadena carbonada, siendo el 2-furoato de n-butilo el compuesto que presentó mejor actividad, con un valor de concentración letal 50 (CL50) de 0,092 $\mathrm{g} / \mathrm{mL}$ (Tabla 13, Entrada 1). Aun así, los tres compuestos fueron activos y por lo tanto, se procedió a realizar pruebas de campo, estudiando su actividad incluidos en pinturas antifouling.

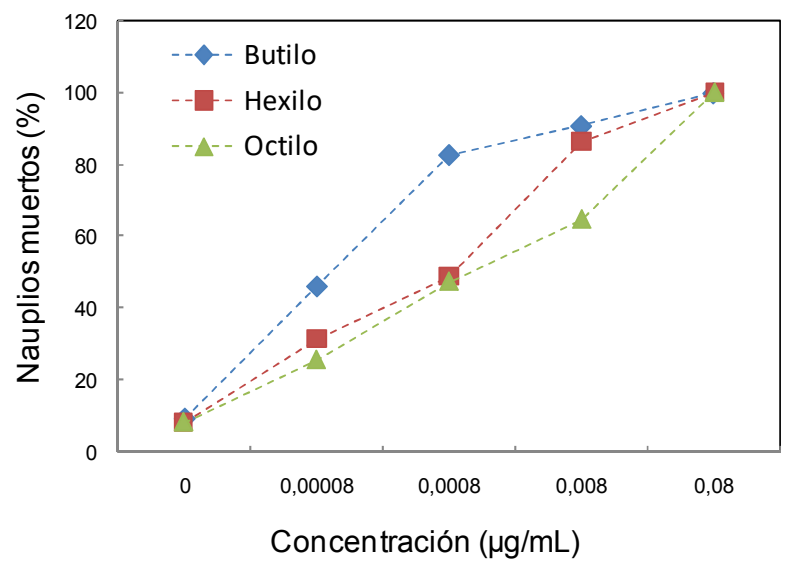

Figura 55. Ensayo de toxicidad de los furoatos a diferentes concentraciones contra Artemia sp. 
Capítulo IV. Análisis de Resultados.

Tabla 13. Concentración letal cincuenta para cada compuesto.

\begin{tabular}{ccc}
\hline Entrada & Antiincrustante & CL50 $(\mu \mathrm{g} / \mathrm{mL})$ \\
\hline 1 & 2-Furoato de butilo & 0,092 \\
2 & 2-Furoato de hexilo & 0,454 \\
3 & 2-Furoato de octilo & 0,903 \\
\hline
\end{tabular}

\subsubsection{Pruebas de campo.}

A continuación se realizaron experimentos de campo en el Puerto de Mar del Plata, con el objetivo de evaluar la actividad antofouling de las pinturas formuladas con los furoatos en condiciones ambientales en la época de verano, para lo cual se utilizaron probetas acrílicas recubiertas con las pinturas antifouling, sin los agentes y sin pintura, estas dos últimas como placas control.

Después de 45 días expuestos en el mar, las tres pinturas formuladas con los furoatos mostraron una fuerte actividad antifouling comparada con el control. Se detectó una gran reducción en el asentamiento de todas las especies incrustantes. En particular, las pinturas que contenían los furoatos inhibieron por completo el asentamiento de especies conspicuas del puerto de Mar del Plata como Hydroides elegans, Botryllus sp. y Polydora sp.

Sin embargo, se detectaron algunas diferencias en el efecto antifouling entre los 3 tratamientos. Las pinturas que contenían los compuestos 2-furoato de n-butilo y el 2furoato de n-hexilo tuvieron rendimientos y porcentajes de cobertura similares, a diferencia de la pintura que contenía 2-furoato de n-octilo, cuyos rendimientos fueron significativamente más bajos. Los resultados se muestran en la Figura 56.

Los dos primeros tratamientos inhibieron el asentamiento del anfípodo Corophium sp. y especies de algas como Enteromorpha sp. y Griffithsia sp. y redujeron en abundancia el asentamiento de Ectocarpus sp. 
Capítulo IV. Análisis de Resultados.

En el caso del 2-furoato de n-octilo, aunque demostró un buen rendimiento comparado con el control, este compuesto afectó la adherencia de estas especies solo disminuyendo el porcentaje de cobertura y, en el caso particular de Ectocarpus sp., no se observó ningún efecto relacionado con los paneles de control. Por otro lado, ninguno de los tratamientos presentó actividad contra la especie Bugula sp. ya que fue registrada en los tres revestimientos, aunque en menor porcentaje para los tratamientos 2-furoato de n-butilo y el 2-furoato de n-hexilo.

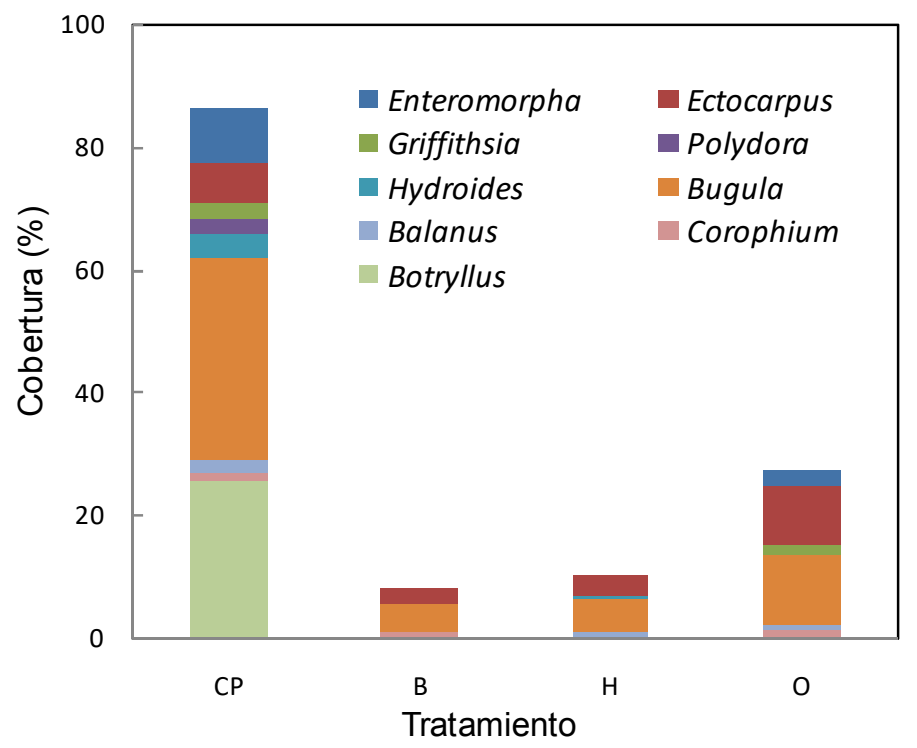

Figura 56. Cobertura de los paneles pintados luego de 45 días de inmersión en el mar (puerto de Mar del Plata). CP: control de pintura; B: furoato de n-butilo; $\mathrm{H}$ : furoato de n-hexilo y 0: furoato de n-octilo.

Los resultados obtenidos de estos experimentos indican claramente que los tres furoatos tienen actividad anfouling. Este resultado positivo de los furoatos evaluados podría ser debido a la presencia del anillo furano de las moléculas, ya que es bien sabido que dicha fracción, presente en muchos metabolitos generados por especies marinas, es un resto funcional con un fuerte impedimento para el asentamiento y crecimiento de organismos marinos y, como tal, tiene una aplicación potencial como tecnología para pinturas antifouling para seguir siendo estudiado. 
Capítulo IV. Análisis de Resultados.

Analizando las posibles razones por las cuales este tipo de moléculas presenta propiedades biológicas, lo primero que se considera es el papel de la lipofilia (comportamiento de toda molécula que tiene afinidad por los lípidos) en la acción anfouling.

Si este fuera el caso, en función de su naturaleza lipófila, es posible que interactúen con la membrana celular y permeen su lisis celular (proceso de ruptura de la membrana celular de células o bacterias que produce la salida del material intracelular, provocado por lisinas) ${ }^{260}$. Pero debido a que el tamaño de la cadena de carbono es un factor importante que contribuye a la lipofilia, es decir, a medida que aumenta el tamaño de la cadena de carbono, las moléculas se vuelven más solubles en lípidos, y en este caso, el 2-furoato de n-butilo, que tiene la cadena más corta, fue el que presentó mejor rendimiento en relación con los otros dos compuestos de cadena más larga, se descartaría esta premisa.

En este sentido, se centró la investigación en la naturaleza del biofilm formado en cada revestimiento antifouling, pero este parámetro fue descartado porque no se detectaron diferencias significativas ni en la abundancia, ni en la composición específica.

De este modo, hasta ahora, no está claro un mecanismo por el cual el rendimiento del 2-furoato de n-butilo fue mejor en relación con las otras moléculas. Aun así, teniendo en cuenta que el ácido furoico y sus ésteres se pueden obtener a partir de biomasa vegetal con un buen rendimiento y fácil purificación aplicando técnicas de Química Verde y muestran bioactividad en ensayos de campo, se pueden considerar como candidatos prometedores para la tecnología antifouling y se seguirán haciendo estudios que permitan deducir el alcance y el mecanismo de acción de este tipo de moléculas. 
Capítulo IV. Análisis de Resultados.

\subsubsection{Evaluación catalítica de los catalizadores del Grupo II.}

Mediante una revisión bibliográfica sobre el compuesto 2-furoato de 2fenoxietilo, se determinó que era un compuesto que no había sido sintetizado anteriormente pues no se encontró registro de él en ninguna base de datos. Por esta razón se escogió la reacción de esterificación del ácido 2-furoico con 2-fenoxietanol como reacción modelo para estudiar la actividad catalítica de los materiales $\mathrm{TiO}_{2} / \mathrm{TPA}$ y $\mathrm{TiO}_{2} / \mathrm{TSA}$. La evaluación de la conversión alcanzada por los dos catalizadores y el soporte $\mathrm{TiO}_{2}$ se realizó bajo las siguientes condiciones: $1 \mathrm{mmol}$ de ácido 2-furoico, 10 mmol de 2-fenoxietanol y $50 \mathrm{mg}$ de catalizador calentando a $125^{\circ} \mathrm{C}$.

Mediante cromatografía de gases (GC/FID) se siguió tanto la aparición y aumento del pico correspondiente a 2-furoato de 2-fenoxietilo, como la disminución del pico correspondiente al ácido 2-furoico. Un perfil de las reacciones de esta prueba se muestra en la Figura 57 y los resultados más significativos de las conversiones alcanzadas variando las condiciones de reacción se detallan en la Tabla 14. Cabe resaltar que el 2-furoato de 2-fenoxietilo fue el único producto de la reacción, así que el rendimiento es igual a la conversión.

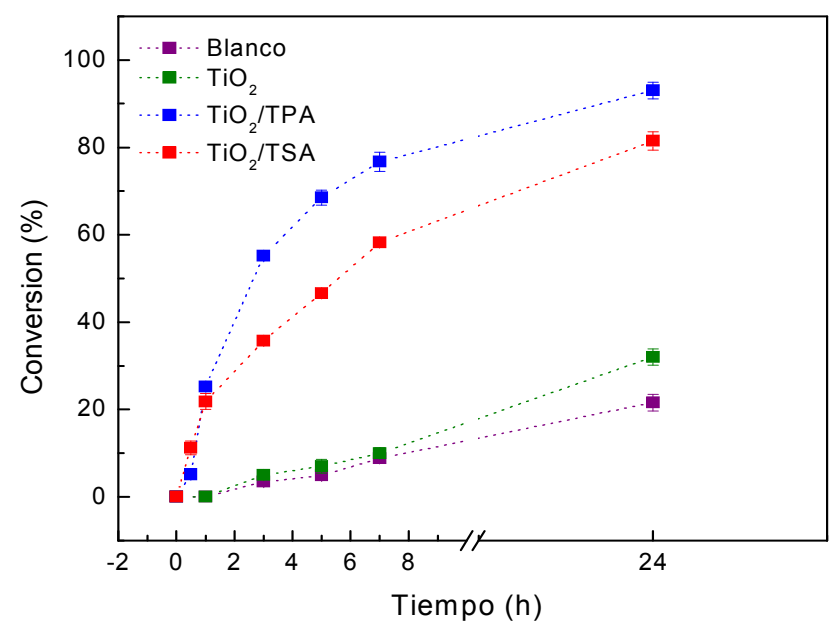

Figura 57. Conversión del ácido 2-furoico en función del tiempo para los diferentes catalizadores del Grupo II. Condiciones de reacción: ácido 2-furóico, $1 \mathrm{mmol}$; 2fenoxietanol, 10 mmoles; 50 mg de catalizador; 24 h; Agitación. 
Capítulo IV. Análisis de Resultados.

En la Figura 57 se puede ver que la muestra de $\mathrm{TiO}_{2} / \mathrm{TPA}$ exhibió la mayor actividad catalítica, alcanzándose una conversión del ácido 2-furoico del 76\% después de 7 h de reacción (Tabla 14, Entrada 5), mientras que, en el mismo tiempo, la muestra de $\mathrm{TiO}_{2}$ /TSA exhibió un porcentaje de conversión del 57\% (Tabla 14, Entrada 3). Se destaca que en ambos casos la conversión fue significativamente mayor que la alcanzada por la reacción en ausencia de catalizador, la cual fue solo del 15\% (Tabla 14, Entrada 1).

Al igual que en la reacción de esterificación del ácido 2-furoico con n-butanol, la reacción es catalizada por la presencia del ácido orgánico, pero no es una acidez suficiente para lograr una conversión significativa. Así mismo, la reacción con el soporte $\mathrm{TiO}_{2}$ dio un rendimiento del 17\% (Tabla 14, Entrada 2), ligeramente superior al blanco de reacción, lo que nos indica que los rendimientos presentados por las muestras $\mathrm{TiO}_{2} / \mathrm{TPA}$ y $\mathrm{TiO}_{2} / \mathrm{TSA}$ es debida al incremento de la acidez resultante de la incorporación de los heteropoliácidos en la matriz $\mathrm{TiO}_{2}$.

Por otro lado, a pesar de que la muestra de $\mathrm{TiO}_{2} / \mathrm{TSA}$ presentaba una ligera fuerza ácida, Ei, superior y una superficie específica mayor que el $\mathrm{TiO}_{2} / \mathrm{TPA}$, presentó un rendimiento bastante menor (19\% menos), esto es debido a que este último posee un mayor número de sitios ácidos tales como $\left(=\mathrm{TiOH}_{2}{ }^{+}\right)\left(\mathrm{H}_{2} \mathrm{PW}_{12} \mathrm{O}_{40}{ }^{-}\right)$y $\left(=\mathrm{TiOH}_{2}{ }^{+}\right)_{2}\left(\mathrm{HPW}_{12} \mathrm{O}_{40}{ }^{2-}\right)$, hecho que podría explicar su mejor efecto catalítico en comparación con la muestra de $\mathrm{TiO}_{2} / \mathrm{TSA}$. Dado que la muestra de $\mathrm{TiO}_{2} / \mathrm{TPA}$ mostró la actividad catalítica más alta, se eligió como el catalizador a ser evaluado bajo diferentes condiciones experimentales tales como temperatura, cantidad de catalizador y relación molar 2-furoico/2-fenoxietanol para encontrar las condiciones óptimas de reacción.

Seguidamente, se estudió el efecto de la relación molar ácido 2-furoico/2fenoxietanol sobre el rendimiento de la reacción a $125{ }^{\circ} \mathrm{C}$ (los perfiles de reacción se muestran en la Figura 58.a). Cuando la relación molar ácido: alcohol fue de 1:2 (Tabla 14, Entrada 6), el rendimiento de la reacción fue de un 91\% de conversión en 7 horas, un valor muy superior a los obtenidos en relaciones molares de 1:5 y 1:10 (77\% y 76\% de conversión respectivamente, Tabla 14, Entradas 4 y 5). 
Capítulo IV. Análisis de Resultados.

Tal como se explicó para los catalizadores de zirconia, el aumento de la conversión al disminuir la relación de los reactivos se debe probablemente al hecho de que un contenido mayor de alcohol actúa como disolvente, disminuyendo la concentración del ácido y la probabilidad de contacto entre el ácido furoico y el catalizador. También podría deberse a que el alcohol se adsorbe sobre el catalizador y compite con la adsorción del ácido. Esto comprueba una vez más, que si bien un exceso de alcohol, ayuda a desplazar el equilibrio de la reacción hacia la formación del éster, un exceso mucho mayor termina siendo contraproducente. Nuevamente este hecho permite que la reacción se lleve a cabo en condiciones libres de disolvente y aumentando así el factor $\mathrm{E}$, haciendo el proceso más eco-eficiente.

En segundo término, se evaluó el efecto de la temperatura de reacción, utilizando una relación molar 1:2 (Los perfiles de la reacción se muestran en la Figura 58.b). Debido a que previamente, en el estudio realizado en la reacción de esterificación del ácido 2 -furoico con n-butanol se determinó que esta reacción es fuertemente afectada por la temperatura y que se da en temperaturas superiores a los $100{ }^{\circ} \mathrm{C}$, se escogió estudiar esta reacción a 95, 110,125 y $140{ }^{\circ} \mathrm{C}$.

Como era de esperarse, a $95{ }^{\circ} \mathrm{C}$ el rendimiento fue bajo ya que el porcentaje de conversión fue de alrededor del 21\% después de 7 horas de reacción (Tabla 14, Entrada 8). Cuando la temperatura se elevó a $110{ }^{\circ} \mathrm{C}$, la conversión aumentó significativamente a 77\% (Tabla 14, Entrada 7) y la conversión continuó en aumento cuando la temperatura fue $125^{\circ} \mathrm{C}$, siendo de $91 \%$ en el mismo tiempo, sin embargo, la conversión que se alcanzó a los $140{ }^{\circ} \mathrm{C}$ no fue muy superior siendo de 95\% (Tabla 14, Entradas 6 y 9).

Dado que las reacciones de esterificación son reversibles y producen agua como subproducto, temperaturas superiores a los $100{ }^{\circ} \mathrm{C}$, ayudan a desplazar el equilibrio hacia la formación del éster por la evaporación del agua, lo que explica la mayor conversión a temperaturas de $110^{\circ} \mathrm{C}$ y superiores. 
Capítulo IV. Análisis de Resultados.
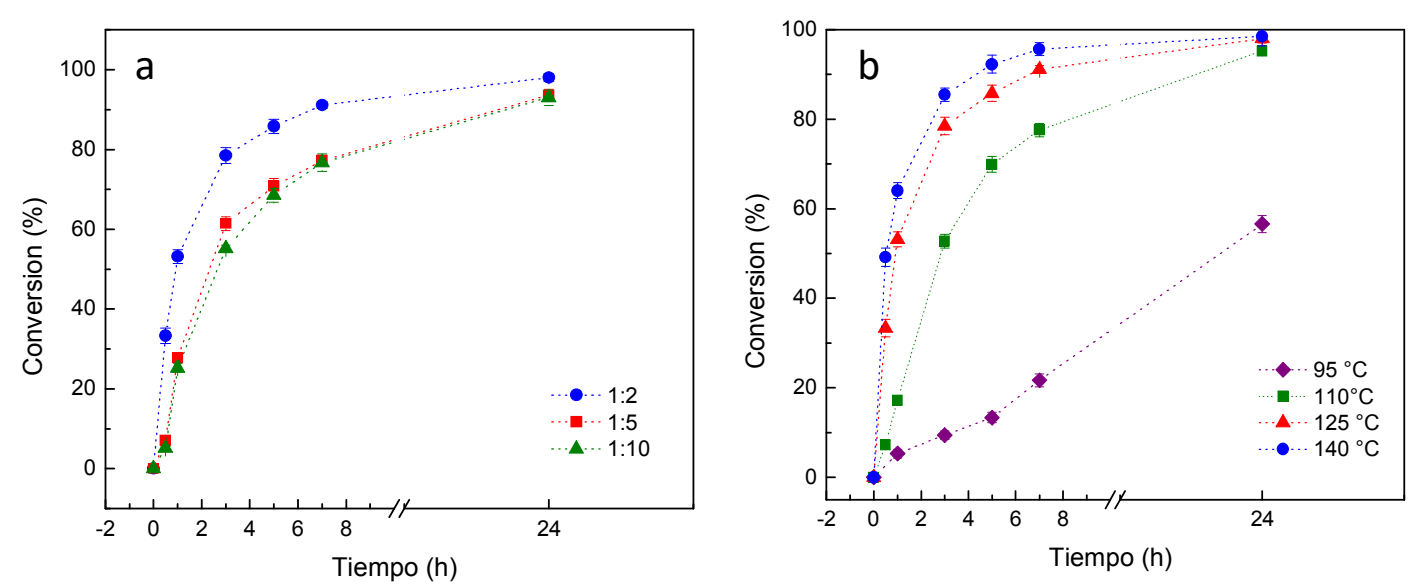

Figura 58. Porcentaje de conversión (\%) del ácido 2-furoico a 2-furoato de 2fenoxietilo en función del tiempo para a) Relación molar ácido 2-furoico/2fenoxietanol. b) Temperatura. Para el catalizador $\mathrm{TiO}_{2} /$ TPA. 50 mg de catalizador; 24 h; Agitación.

Por último, se estudió el efecto de la cantidad de catalizador sobre el rendimiento de la reacción, fijando la relación molar de los reactivos en 1:2 y la temperatura en 125 ${ }^{\circ} \mathrm{C}$. Las cantidades de catalizador escogidas fueron 25, 50 y $100 \mathrm{mg}$ y los porcentajes de conversión de ácido 2-furoico fueron de 80, 91 y 90\% después de 7 h (Tabla 14, Entradas 10, 6 y 11 respectivamente).

Un aumento en la cantidad de catalizador no mejoró la conversión o la velocidad de reacción, lo que sugiere que en las condiciones ensayadas para la síntesis de 2furoato de 2-fenoxietilo, la cantidad de $50 \mathrm{mg}$ es la que permite optimizar la síntesis del éster empleando la menor cantidad de catalizador.

En resumen, se encontró que las condiciones óptimas de reacción para la esterificación del ácido 2-furoico con 2-fenoxietanol son similares a las que se encontraron para la esterificación del mismo ácido con n-butanol, una relación molar de 1:2, 50 mg de catalizador y una temperatura de $125{ }^{\circ} \mathrm{C}$ (Tabla 14, Entrada 6). 
Capítulo IV. Análisis de Resultados.

Tabla 14. Actividad catalítica en la conversión (\%) de ácido 2-furoico en 2-furoato de 2fenoxietilo bajo diferentes condiciones experimentales para los catalizadores del Grupo II.

\begin{tabular}{cccccc}
\hline Entrada & Catalizador & $\begin{array}{c}\text { Temperatura } \\
\left({ }^{\circ} \mathrm{C}\right)\end{array}$ & $\begin{array}{c}\text { Cantidad de } \\
\text { catalizador }(\mathrm{mg})\end{array}$ & $\begin{array}{c}\text { Relación molar } \\
\text { ácido/alcohol (mmol) }\end{array}$ & $\begin{array}{c}\text { Conv. }^{\text {a }} \\
(\%)\end{array}$ \\
\hline 1 & Blanco & 125 & - & $1: 10$ & 15 \\
2 & $\mathrm{TiO} 2$ & 125 & 50 & $1: 10$ & 17 \\
3 & $\mathrm{TiO}_{2} / \mathrm{TSA}$ & 125 & 50 & $1: 10$ & 57 \\
4 & $\mathrm{TiO}_{2} / \mathrm{TPA}$ & 125 & 50 & $1: 10$ & 76 \\
5 & $\mathrm{TiO}_{2} / \mathrm{TPA}$ & 125 & 50 & $1: 5$ & 77 \\
6 & $\mathrm{TiO}_{2} / \mathrm{TPA}$ & 125 & 50 & $1: 2$ & 91 \\
7 & $\mathrm{TiO}_{2} / \mathrm{TPA}$ & 110 & 50 & $1: 2$ & 77 \\
8 & $\mathrm{TiO}_{2} / \mathrm{TPA}$ & 95 & 50 & $1: 2$ & 21 \\
9 & $\mathrm{TiO}_{2} / \mathrm{TPA}$ & 140 & 50 & $1: 2$ & 95 \\
10 & $\mathrm{TiO}_{2} / \mathrm{TPA}$ & 125 & 25 & $1: 2$ & 80 \\
11 & $\mathrm{TiO}_{2} / \mathrm{TPA}$ & 125 & 100 & $1: 2$ & 90 \\
\hline
\end{tabular}

${ }^{a}$ Conversión de ácido 2-furoico en 2-furoato de 2-fenoxietanol después de $7 \mathrm{~h}$ de reacción.

Se llevó a cabo un experimento para seguir simultáneamente la desaparición de ácido 2-furoico y la formación de 2-furoato de 2-fenoxietilo por GC (Figura 59). Está claro que el ácido 2-fuorico desaparece al mismo tiempo e igual proporción molar que el 2-furoato de 2-fenoxietilo inicia su formación, no observándose la formación de otros subproductos. 


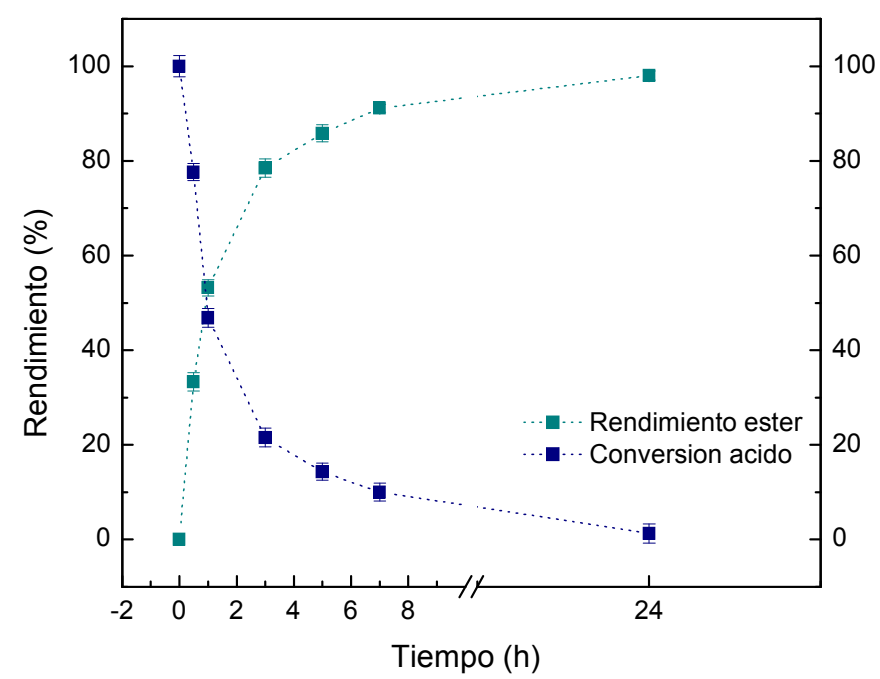

Figura 59. Desaparición del ácido 2-fuórico y formación de 2-furoato de 2-fenixietilo bajo prueba catalítica en las condiciones óptimas.

El producto de reacción se aisló y purificó por recristalización en etanol, obteniendo un sólido blanco que se caracterizó por RMN de ${ }^{1} \mathrm{H}$ y ${ }^{13} \mathrm{C}$ y espectrometría de masas confirmando que el compuesto obtenido es 2-furoato de 2-fenoxietilo (sección 3.8.4), el cual tiene un punto de fusión relativamente bajo, $65-68{ }^{\circ} \mathrm{C}$, es soluble en solventes orgánicos e insoluble en agua.

\subsubsection{Prueba de reutilización del catalizador.}

Debido a que una de las ventajas de los catalizadores heterogéneos es su reutilización, es importante evaluar que el catalizador $\mathrm{TiO}_{2}$ /TPA cumpla con esta condición. Para esto se estudió la conversión del ácido 2-furoico durante varios ciclos usando las condiciones óptimas de relación molar, temperatura y cantidad de catalizador durante $24 \mathrm{~h}$.

Los resultados obtenidos (Tabla 15) muestran que en el segundo ciclo la conversión disminuyó de 98 a 92\%, lo que puede ser debido, ya sea a una pérdida de actividad catalítica causada por el envenenamiento de los sitios activos del catalizador o al lixiviado del TPA, siendo este último la causa más probable. 
Capítulo IV. Análisis de Resultados.

Para comprobarlo, se hizo un experimento en el que en un tubo de reacción se agregó 50 mg de catalizador y 2 mmoles de 2-fenoxietanol, se dejaron en agitación y calentamiento a 125 grados durante 7 h, cumplido el tiempo, se filtró el catalizador y al alcohol recuperado se le agregó $1 \mathrm{mmol}$ de ácido furoico y se realizó la reacción. Como experimento control, se realizó un blanco de reacción. El resultado mostró que, en la primera prueba, la conversión fue ligeramente superior con respecto al experimento de control realizado en ausencia de catalizador, los valores obtenidos fueron 19 y $11 \%$ respectivamente después de 7 h de reacción.

Esta elevación de la conversión se relaciona con la presencia de TPA lixiviado en el 2-fenoxietanol. Para determinar qué porcentaje de TPA se lixivió, se realizó una prueba para medir la cantidad de tungsteno (W) en el alcohol, en la cual el catalizador se dejó en contacto con el 2-fenoxietanol a las condiciones óptimas de reacción determinadas, posteriormente el alcohol se filtró y se analizó por absorción atómica, dando un valor por debajo del límite de detección, lo que indica que la cantidad de TPA lixiviada es muy baja.

Al hacerse un tercer ciclo de reacción, nuevamente la conversión disminuyó a $85 \%$ (Tabla 15) y en el cuarto ciclo se mantuvo casi contante con un valor de $84 \%$. Esto podría ser debido a que las moléculas de TPA débilmente ancladas fueron lixiviadas en los dos primeros ciclos, quedando en el sólido aquellas moléculas de heteropoliácido fuertemente ancladas.

Tabla 15. Prueba de reutilización del catalizador. Conversiones obtenidas para cada ciclo de reacción.

\begin{tabular}{ccccc}
\hline Ciclo & Ciclo 1 & Ciclo 2 & Ciclo 3 & Ciclo 4 \\
\hline Conversión (\%) & 98 & 92 & 85 & 84 \\
\hline
\end{tabular}


Capítulo IV. Análisis de Resultados.

\subsubsection{Evaluación catalítica de los catalizadores del Grupo III.}

La mayoría de los procesos industriales actuales para la síntesis de ácido levulínico (LA) y levulinatos de alquilo utilizan ácidos minerales convencionales como catalizadores en cada uno de los pasos, entre ellos se destacan el ácido sulfúrico y el ácido clorhídrico ${ }^{261}$, lo que significa inconvenientes importantes relacionados con el uso de sustancias altamente corrosivas y tóxicas, y la dificultad en la separación y el reciclaje que lo convierten en un proceso ambientalmente hostil. Por estas razones, éste estudio se centra en proporcionar un catalizador heterogéneo que facilite el proceso y el rendimiento de la reacción.

Para ello, se eligió como reacción de estudio la esterificación de Fischer del AL con n-butanol para sintetizar levulinato de n-butilo, utilizando como catalizadores los materiales del Grupo III. El levulinato de n-butilo es un producto de interés por sus aplicaciones como aromatizante en alimentos y aditivo en combustibles y se puede obtener de derivados de biomasa ${ }^{262}$.

Como se explicó en la sección 4.2.1. Figura 45 y Tabla 7, la primera prueba que se le realizó a los materiales del Grupo III fue un estudio de lixiviación y reutilización donde se determinó que el catalizador $\mathrm{Fe}_{3} \mathrm{O}_{4} @ \mathrm{SiO}_{2} @ \mathrm{SiO}_{2} / \mathrm{TPA}_{400 \mathrm{~N} 2}$ fue el que presentó los mejores resultados de actividad catalítica y de reutilización y por esta razón, las pruebas para optimizar las condiciones de reacción se realizaron con este catalizador, con el propósito de maximizar el rendimiento a levulinato de n-butilo. A continuación, se presentan los resultados obtenidos.

Para optimizar las condiciones de reacción, se planteó un diseño de experimentos de 3 variables las cuales fueron temperatura, relación molar de reactivos y carga de catalizador.

La Tabla 16 resume los resultados más sobresalientes obtenidos de las conversiones alcanzadas según las diferentes variables analizadas. Más adelante analizaremos cada una de ellas detalladamente. 
Capítulo IV. Análisis de Resultados.

Es importante destacar que a temperaturas bajas $\left(40\right.$ y $\left.50{ }^{\circ} \mathrm{C}\right)$, relaciones molares altas ácido/alcohol (1:6 y 1:10) y cortos tiempos de reacción se produce la deshidratación intermolecular del alcohol formándose di-butil éter ${ }^{263}$ en una cantidad no mayor al 10 \%, aun así el producto principal de esta reacción es el levulinato de nbutilo y a temperaturas superiores es el único producto formado en todas las relaciones molares estudiadas, siendo la conversión de la reacción igual al rendimiento.

La primera prueba que se hizo para determinar las condiciones óptimas fue estudiar el efecto de la cantidad de catalizador en un rango entre 25 y $150 \mathrm{mg}$ de catalizador manteniendo las otras condiciones constantes, relación molar de reactivos 1:2 y una temperatura de $80{ }^{\circ} \mathrm{C}$ durante $5 \mathrm{~h}$, los perfiles de reacción se muestran en la Figura 60.

Se determinó que la velocidad de reacción es directamente proporcional a la cantidad de catalizador, debido al aumento proporcional del número de sitios activos. Así, con 25 mg se alcanzó un rendimiento del 82\% y con cantidades de 50, 100 y 150 mg se alcanzan rendimientos de 95, 98 y 100 \%, respectivamente (Tabla 16, Entradas 17-20). Valores significativamente cercanos, por lo que se escogió una carga de $50 \mathrm{mg}$ por mol de AL como la cantidad de catalizador óptima.

De igual forma, el blanco de la reacción dio un rendimiento de $25 \%$ en 5 h, ya que como se había mencionado anteriormente, la acidez del ácido levulínico alcanza a catalizar la reacción, y se ve favorecida además por un aumento en la temperatura, pues a $40{ }^{\circ} \mathrm{C}$ había dado un rendimiento del $12 \%$ en $24 \mathrm{~h}$, aun así, es un valor menor comparado con el rendimiento que se obtuvo en presencia del catalizador $\mathrm{Fe}_{3} \mathrm{O}_{4} @ \mathrm{SiO}_{2} @ \mathrm{SiO}_{2} / \mathrm{TPA} 400 \mathrm{~N}$. 
Capítulo IV. Análisis de Resultados.

Tabla 16. Resultados catalíticos durante la esterificación del ácido levulínico con nbutanol sobre el catalizador $\mathrm{Fe}_{3} \mathrm{O}_{4} @ \mathrm{SiO}_{2} @ \mathrm{SiO}_{2} / \mathrm{TPA}_{400 \mathrm{~N}}$ en diferentes condiciones de reacción durante $7 \mathrm{~h}$.

\begin{tabular}{|c|c|c|c|c|}
\hline Entrada & $\begin{array}{c}\text { Cantidad de } \\
\text { catalizador }(\mathrm{mg})\end{array}$ & $\begin{array}{l}\text { Relación molar } \\
\text { (mmol) }\end{array}$ & $\begin{array}{c}\text { Tempratura } \\
{ }^{\circ} \mathrm{C}\end{array}$ & $\begin{array}{c}\text { Rendimiento } \\
\text { (\%) }\end{array}$ \\
\hline 1 & 50 & $1: 8$ & \multirow{4}{*}{40} & 17 \\
\hline 2 & 50 & $1: 6$ & & 18 \\
\hline 3 & 50 & $1: 4$ & & 22 \\
\hline 4 & 50 & $1: 2$ & & 35 \\
\hline 5 & 50 & $1: 8$ & \multirow{4}{*}{50} & 29 \\
\hline 6 & 50 & $1: 6$ & & 32 \\
\hline 7 & 50 & $1: 4$ & & 38 \\
\hline 8 & 50 & $1: 2$ & & 45 \\
\hline 9 & 50 & $1: 8$ & \multirow{4}{*}{60} & 51 \\
\hline 10 & 50 & $1: 6$ & & 55 \\
\hline 11 & 50 & $1: 4$ & & 56 \\
\hline 12 & 50 & $1: 2$ & & 73 \\
\hline 13 & 50 & $1: 8$ & \multirow{4}{*}{$70^{1}$} & 86 \\
\hline 14 & 50 & $1: 6$ & & 86 \\
\hline 15 & 50 & $1: 4$ & & 93 \\
\hline 16 & 50 & $1: 2$ & & 91 \\
\hline 17 & 25 & $1: 2$ & \multirow{7}{*}{$80^{1}$} & 82 \\
\hline 18 & 50 & $1: 2$ & & 95 \\
\hline 19 & 100 & $1: 2$ & & 98 \\
\hline 20 & 150 & $1: 2$ & & 100 \\
\hline 21 & 50 & $1: 4$ & & 93 \\
\hline 22 & 50 & $1: 6$ & & 85 \\
\hline 23 & 50 & $1: 8$ & & 74 \\
\hline
\end{tabular}

1 Tiempo de reacción 5 h. 


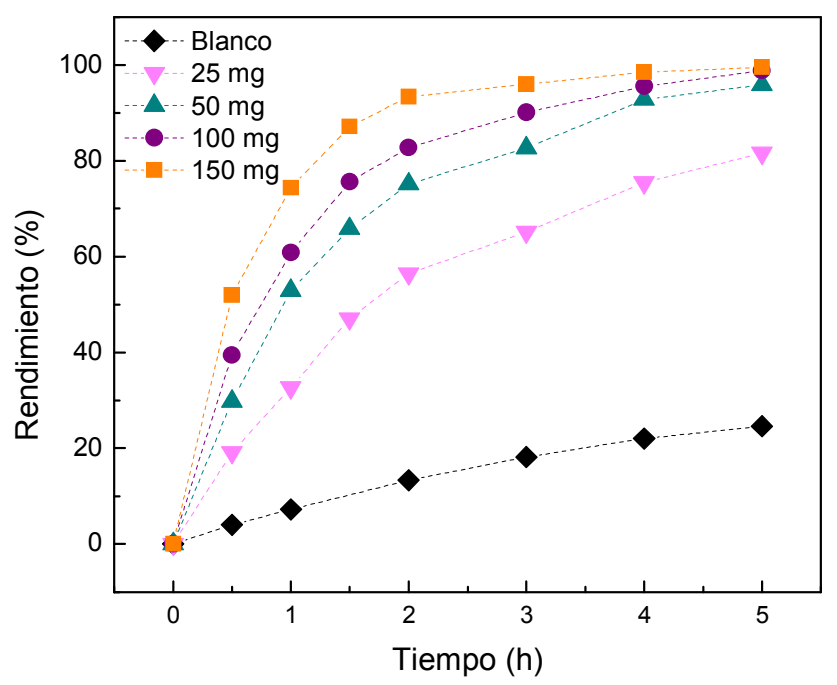

Figura 60. Influencia de la cantidad de catalizador en la conversión del ácido levulínico a levulinato de n-butilo con $\mathrm{Fe}_{3} \mathrm{O}_{4} @ \mathrm{SiO}_{2} @ \mathrm{SiO}_{2} / \mathrm{TPA}_{400 \mathrm{~N}}$ como catalizador. Condiciones de reacción: relación molar de reactivos 1:2; $80^{\circ} \mathrm{C} ; 5 \mathrm{~h}$.

El efecto de la temperatura sobre la conversión del AL a levulinato de n-butilo se estudió en un intervalo de temperatura entre 40 y $80{ }^{\circ} \mathrm{C}$ (Figura 61). No solo se observó un aumento importante del rendimiento de la reacción cuando se aumentó la temperatura, sino que también aumentó la velocidad de reacción consiguiendo un rendimiento del $95 \%$ en 5 horas a $80{ }^{\circ} \mathrm{C}$, comparado con el $35 \%$ en 7 horas que se alcanzó cuando se hizo a $40^{\circ} \mathrm{C}$.

Este comportamiento sugiere un mecanismo controlado cinéticamente. Además, como se ha explicado para las reacciones de esterificación del ácido furoico, la reacción de esterificación es una reacción en equilibrio que genera agua como uno de los productos, al aumentar la temperatura, el agua se va eliminando del sistema, desplazando el equilibrio hacia la formación del éster.

Analizando la Figura 61 puede observarse que a temperaturas de 40 y $50{ }^{\circ} \mathrm{C}$, la reacción es lenta y hay un aumento importante de la velocidad y el rendimiento de la reacción cuando se hace a 70 y $80^{\circ} \mathrm{C}$. 


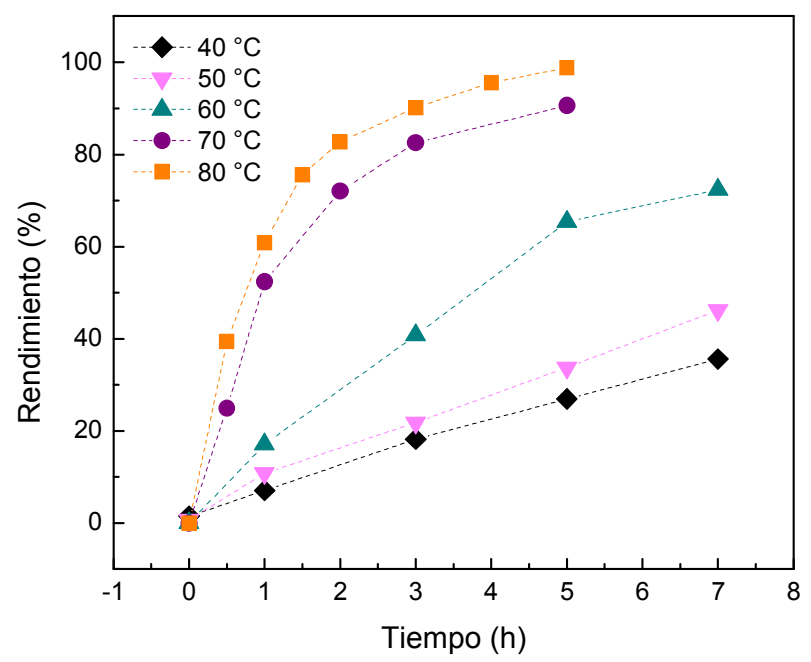

Figura 61. Influencia de la temperatura en la conversión de AL a levulinato de n-butilo con $\mathrm{Fe}_{3} \mathrm{O}_{4} @ \mathrm{SiO}_{2} @ \mathrm{SiO}_{2} / \mathrm{TPA}_{400 \mathrm{~N}}$ como catalizador. Condiciones de reacción: relación molar de reactivos 1:2; $50 \mathrm{mg}$ de catalizador; $7 \mathrm{~h}$.

Otra forma de desplazar el equilibrio hacia la formación de productos es con un exceso de alcohol, pero en la prueba de relación molar de reactivos (Figura 62), se encontró que aunque es así, un exceso demasiado grande, tiene el efecto contrario. Éste mismo efecto ya se había observado en las reacciones de esterificación del ácido 2furoico y además concuerda con lo publicado en la literatura donde se reporta que una relación molar baja del alcohol con el ácido levulínico, en el intervalo de 2 a 5 son las que favorecen el sistema.

Tales soluciones concentradas son justificadas por el hecho de que un sistema demasiado diluido podría implicar limitaciones de transferencia de masa del ácido al catalizador y favorecer la adsorción del alcohol con la consecuente deshidratación intermolecular del mismo para formar el éter corresponciente ${ }^{263}$. En nuestro caso, la mejor relación fue de 1:2, la cual favorece la velocidad de reacción, la selectividad y permite que se realice en condiciones libre de solvente, con la ventaja adicional de mejorar la eco-compatibilidad del proceso. 
Capítulo IV. Análisis de Resultados.

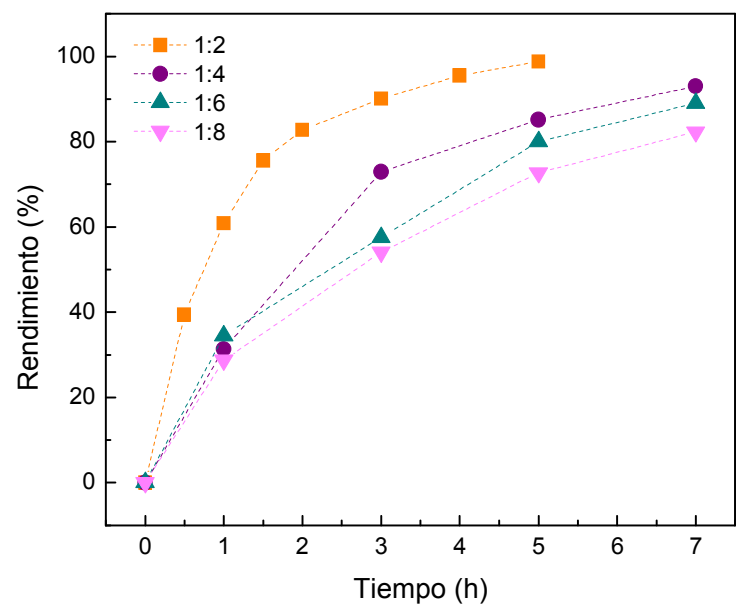

Figura 62. Influencia de la relación molar de reactivos en la obtención de levulinato de n-butilocon $\mathrm{Fe}_{3} \mathrm{O}_{4} @ \mathrm{SiO}_{2} @ \mathrm{SiO}_{2} / \mathrm{TPA}_{400 \mathrm{~N}}$ como catalizador. Condiciones de reacción: Temperatura $80^{\circ} \mathrm{C}, 100 \mathrm{mg}$ de catalizador, $7 \mathrm{~h}$.

Así, el catalizador $\mathrm{Fe}_{3} \mathrm{O}_{4} @ \mathrm{SiO}_{2} @ \mathrm{SiO}_{2} / \mathrm{TPA} 400 \mathrm{~N}$ demostró ser eficiente en la reacción de eterificación del ácido levulínico con n-butanol, alcanzando conversiones altas en cortos tiempos y condiciones más suaves de reacción, comparado con las reportadas en la literatura ${ }^{92-99}$, además de ser selectivo hacia levulinato de n-butilo. Las condiciones óptimas determinadas fueron una relación molar 1:2, una temperatura de $80{ }^{\circ} \mathrm{C}$ y $50 \mathrm{mg}$ de catalizador por mol de ácido (Tabla 16, Entrada 18). 


\section{Capítulo V: \\ CONCLUSIONES Y \\ PERSPECTIVAS.}




\section{Capítulo V. Conclusiones y Perspectivas.}

En el presente trabajo de Tesis Doctoral se propusieron como principales objetivos sintetizar y caracterizar materiales basados en heteropoliácidos tipo Keggin, específicamente ácido tungstofosfórico y ácido tungstosilísico inmovilizados sobre diferentes materiales: óxido de zirconio $\left(\mathrm{ZrO}_{2}\right)$, óxido de titanio $\left(\mathrm{TiO}_{2}\right)$ y óxidos de hierro magnético $\left(\mathrm{Fe}_{3} \mathrm{O}_{4}\right)$ encapsulado en óxido de silicio $\left(\mathrm{SiO}_{2}\right)$, y evaluarlos catalíticamente en diferentes reacciones de esterificación de ácidos derivados de biomasa para obtener productos de valor agregado, aplicando metodologías sintéticas que cumplan con la mayor cantidad posible de los principios de la Química Verde.

Cumpliendo con los objetivos propuestos, se logró sintetizar una gran variedad de materiales, a través de reacciones sol-gel, entre los que se destacan 4 materiales de ácido tungstofosfórico inmovilizado en óxido de zirconia, 2 materiales de ácido tungstofosfórico y tungstosilísico inmovilizados sobre óxido de titania y ácido tungstofosfórico inmovilizado sobre magnetita encapsulada en óxido de silicio y tratamiento térmico a diferentes temperaturas. Los mismos fueron caracterizados ampliamente, permitiendo conocer sus propiedades fisicoquímicas y texturales, realizando un importante aporte a las áreas de materiales y catálisis. Además, se evaluó el desempeño de los mismos como catalizadores ácidos en la síntesis de diferentes furoatos de alquilo y levulinato de n-butilo, productos de interés por sus aplicaciones como agentes aromatizantes y fragancias, aditivos de combustibles y como productos intermedios en la industria farmacéutica, presentándose como una oportunidad de aprovechar y valorizar residuos de biomasa a partir de reacciones eco-eficientes.

La metodología desarrollada involucró la mayor cantidad de postulados de la Química Verde como partir de materias primas renovables al utilizar derivados de biomasa como reactivos, economía atómica al realizar las reacciones en condiciones libre de solvente, baja toxicidad tanto de los reactivos como de los productos, procesos catalíticos heterogéneos en remplazo de los catalizadores homogéneos, minimizando la generación de residuos y productos secundarios nocivos, cumpliendo de esta manera el objetivo de rediseñar un proceso y mejorarlo para que conduzca a tecnologías limpias y de menor impacto ambiental. 


\section{Capítulo V. Conclusiones y Perspectivas.}

Analizando los catalizadores del Grupo I, ácido tungstofosfórico incluido en óxido de zirconia $\left(\mathrm{ZrO}_{2}\right)$, el material ZrTPA30PEGT100, un sólido mesoporoso y de numerosos sitios ácidos donde la estructura tipo Keggin prevalece, fue el mejor catalizador para la esterificación del ácido 2-furoico con n-butanol. El catalizador se mostró activo, estable y reutilizable para la reacción de esterificación no sólo con el nbutanol sino también con una amplia gama de alcoholes. La estructura del alcohol es un factor importante en la conversión al producto de esterificación. El orden de reactividad para la esterificación con ácido 2-furóico utilizando materiales compuestos de ácido tungstofosfórico/zirconia fue el siguiente: alcoholes primarios $>$ alcoholes secundarios $>$ alcohol terciario, demostrando que la reacción depende fuertemente de un efecto estérico de la estructura del alcohol. Se estudió el efecto de varios parámetros tales como la masa del catalizador, la relación molar de ácido 2-furóico nbutanol y la temperatura de reacción. Adicionalmente, se logró realizar la reacción en condiciones libres de solvente, alcanzando excelentes resultados que nos permiten decir que es un procedimiento sencillo y con una baja toxicidad relativa del catalizador como ventajas notables de este método. Finalmente, estos catalizadores ácidos sólidos pueden ser recuperados y reutilizados al menos tres veces con una pérdida insignificante en su actividad.

Además, sumado a los objetivos iniciales, se hizo un estudio de actividad antifouling de tres ésteres sintetizados los cuales fueron 2-furoato de n-butilo, 2furoato de n-hexilo y 2-furoato de n-octilo. Los tres compuestos presentaron resultados positivos tanto en ensayos de laboratorio, como en pruebas de campo luego de 45 días expuestos en el mar, en la inhibición del asentamiento de diferentes especies marinas, en placas con pinturas formuladas con los furoatos mencionados, donde se destacó el rendimiento mostrado por el 2-furoato de n-butilo. Estos resultados preliminares indican que el uso de ésteres de furoato en pinturas pueden ser una nueva alternativa prometedora antifouling, no solo para la industria de navíos, sino también para estructuras acuícolas sumergidas, igualmente, representan una nueva actividad biológica para los ésteres del ácido 2-furoico, y abre nuevas posibilidades en términos de explorar la actividad biológica de análogos sintéticos. 


\section{Capítulo V. Conclusiones y Perspectivas.}

Por su parte, luego de analizar los catalizadores del Grupo II, conformados por ácido tungstofosfórico (TPA) y tungstosilísico (TSA) incluidos en óxido de titanio $\left(\mathrm{TiO}_{2}\right)$ (denominados $\mathrm{TiO}_{2} / \mathrm{TPA}$ y $\mathrm{TiO}_{2} / \mathrm{TSA}$ ), la caracterización reveló que la mayor parte los heteropoliácidos, ya sea TSA o TPA podrían estar presentes en el soporte como aniones Keggin exhibiendo sitios muy ácidos tales como $\left(=\mathrm{TiOH}_{2}+\right)\left(\mathrm{H}_{2} \mathrm{PW}_{12} \mathrm{O}_{40^{-}}\right)$ y $\left(\mathrm{TiOH}_{2}{ }^{+}\right)_{2}\left(\mathrm{HPW}_{12} \mathrm{O}_{40}{ }^{2-}\right)$ para $\mathrm{TiO}_{2} / \mathrm{TPA}$ y $\left(\mathrm{TiOH}_{2}{ }^{+}\right)_{\mathrm{x}}\left(\mathrm{H}_{4-\mathrm{x}} \mathrm{SiW}_{12} \mathrm{O}_{40}{ }^{-\mathrm{x}}\right)$ para $\mathrm{TiO}_{2} / \mathrm{TSA}$. La conversión obtenida, que se evaluó en la esterificación del ácido 2-fuórico con 2fenoxietanol para conducir a la formación de 2-furoato de 2-fenoxietilo mostró que el material $\mathrm{TiO}_{2}$ /TPA presentó la mayor actividad catalítica, debido a la presencia de una mayor cantidad de sitios ácidos en la superficie del sólido, tal como se determinó por titulación potenciométrica. La cantidad de catalizador, temperatura y relación molar ácido:alcohol fueron evaluados como variables. Las dos últimos, fueron las variables más importantes. Temperaturas superiores a los $100 \circ \mathrm{C}$ permiten evaporar el agua generada en la reacción, desplazando el equilibrio a la formación del éster mejorando la actividad catalítica. Por otra parte, se encontró una relación molar ácido:alcohol con bajo contenido de alcohol (1:2) como la óptima ya que un contenido alto de alcohol, actúa como disolvente, diluyendo reactivos, produciendo un efecto perjudicial en el contacto entre el ácido y el catalizador. A bajo contenido de alcohol, la reacción se puede denominar libre de disolvente. Se destaca que el compuesto 2-furoato de 2fenoxietilo fue sintetizado y caracterizado por primera vez.

Finalmente, se logró incluir el TPA en materiales compuestos por magnetita encapsulada en óxido de silicio $\left(\mathrm{Fe}_{3} \mathrm{O}_{4} @ \mathrm{SiO}_{2}\right)$, catalizadores del Grupo III. El seguimiento y estandarización de la síntesis se hizo analizando el tamaño y morfología de las NPMs por imágenes SEM, determinando que son esferas uniformes y que no se ven afectada por factores como medio ácido o temperatura si se calcinan en atmósfera inerte. Se analizaron factores importantes como la relación $\mathrm{Fe}_{3} \mathrm{O}_{4} / \mathrm{SiO}_{2}$ siendo la relación 1:1 la que presentó mejores características y la relación TEOS/amoniaco determinando que una relación 1:6 favorece la hidrólisis del TEOS y el recubrimiento

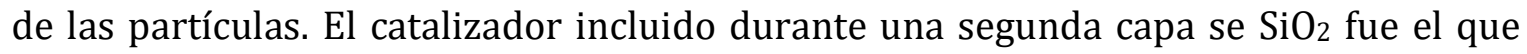
presentó mejor rendimiento catalítico y hasta cuatro ciclos de reacción consecutivas 


\section{Capítulo V. Conclusiones y Perspectivas.}

sin pérdida apreciable de actividad por envenenamiento o lixiviación de la fase activa, además de ser fácil de separar del medio de reacción mediante precipitación magnética. Este catalizador mostró ser activo en la síntesis de levulinato de n-butilo a partir de ácido levulínico y n-butanol, producto de interés en la valorización de biomasa, con un rendimiento del $95 \%$ y una selectividad del $100 \%$ a $80{ }^{\circ} \mathrm{C}$.

En el futuro se espera continuar con estudios de inmovilización de diferentes heteropoliácidos como los tipo Preysler en materiales magnéticos, debido a las ventajas que estos presentan como facilidad de separación y fácil manejo durante la reacción y se seguirán sintetizando ésteres del ácido 2-furoico para continuar con los estudios de actividad anfouling por medio de metodologías que minimicen el impacto ambiental negativo.

A continuación se presentan los diversos trabajos publicados y participaciones en congresos durante el desarrollo de la Tesis Doctoral.

\section{TRABAJOS PUBLICADOS O ACEPTADOS EN REVISTAS PERIÓDICAS (con referato):}

1. "Single-step synthesis of 4-phenyl and 3,4-dihydro-4-phenyl coumarins using a recyclable Preyssler heteropolyacid catalyst under solvent-free reaction conditions".

Angélica M. Escobar, Diego M. Ruiz, Juan C. Autino. Gustavo P. Romanelli. 2015. Research on Chemical Intermediates 41, 12 (2015) 10109-10123. 18.1.2.

2. "Biomass valorization derivatives: Clean esterification of 2-furoic acid using tungstophosphoric acid/zirconia composites as recyclable catalyst".

Angélica Escobar, Ángel Sathicq, Luis Pizzio, Mirta Blanco, Gustavo Romanelli. 2015. Process Safety and Environmental Protection 98 (2015) 176-186.

3. "Valorization of biomass derivatives: Keggin heteropolyacidssupported on titania as catalysts in the suitable synthesis of 2-phenoxyethyl-2-furoate". 


\section{Capítulo V. Conclusiones y Perspectivas.}

Angélica M. Escobar Caicedo, Julián A. Rengifo-Herrera, Pierre Florian, Mirta N. Blanco, Gustavo P. Romanelli, Luis R. Pizzio. Journal of Molecular Catalysis A: Chemical 425 (2016) 266-274.

\section{TRABAJOS PRESENTADOS EN CONGRESOS.}

1. IV Jornadas de Ingeniería Química Sustentable. "Valorización de derivados de biomasa: esterificación de ácido 2-furoico usando ácido tungstofosfórico soportado sobre óxido de zirconia como catalizador". Angélica María Escobar Caicedo, Gabriel Sathicq, Mirta N. Blanco, Luis R. Pizzio, Gustavo P. Romanelli. Universidad Tecnológica Nacional. Facultad Regional Avellaneda. Villa Domínico, Buenos Aires, Argentina. 23, 24 y 25 de Septiembre 2014. Participante. Ponente oral.

2. XXII Jornadas de Jóvenes Investigadores "Ciencia para el desarrollo de los Pueblos" de la Asociación de Universidades Grupo Montevideo. "Catalizadores heterogéneos con estructura tipo keggin de ácido tungstofosfórico soportado sobre zirconia preparada por el método sol-gel, evaluados en reacciones de esterificación del ácido furoico con diferentes alcoholes". Angélica María Escobar Caicedo. Valparaíso, Chile. 29 de septiembre al 1 de Octubre 2014. Presentación póster.

3. $31^{\circ}$ Congreso Latinoamericano de Química CLAQ-2014. XXVII Congreso Peruano de Química. "Valorización de derivados de biomasa: esterificación ecocompatible de ácido 2-furoico". Angélica M. Escobar, Ángel G.Sathicq, Luis R. Pizzio , Mirta N. Blanco, Gustavo P. Romanelli. Lima, Perú. 14 al 17 de Octubre 2014. Presentación póster.

4. $30^{\circ}$ Congreso Argentino de Química 2014. "Heteropoliácidos como catalizadores ecocompatibles en la síntesis de moléculas de interés para la industria farmacéutica y la valorización de biomasa”. Angelica M. Escobar, Romina Frenzel, María Dolores Morales, Toa Rivera, Gabriel Sathicq, Mirta Blanco, Luis Pizzio, Gustavo Romanelli. Buenos Aires, Argentina. 22 al 24 de octubre 2014. Presentación póster. 


\section{Capítulo V. Conclusiones y Perspectivas.}

5. XIX Congreso Argentino de Catálisis. VII Congreso de Catálisis del Mercosur. "Ácido tungstofosfórico soportado sobre óxido de titanio como catalizador en la síntesis de 2-furoato de 2-fenoxietilo en condiciones libre de solvente". Angélica M. Escobar Caicedo, Julián Rengifo Herrera, Luis R. Pizzio, Mirta N. Blanco, Gustavo P. Romanelli. Bahía Blanca, Buenos Aires. 21 al 23 de Septiembre de 2015. Presentación poster.

6. III Jornadas en Ciencias Aplicadas "Dr. Jorge J. Ronco". "Valorización de derivados de biomasa: esterificación de ácido 2- furoico usando ácido tungstofosfórico soportado sobre óxido de zirconia como catalizador". Angelica Escobar, Angel Sathicq, Luis Pizzio, Mirta Blanco, Gustavo Romanelli. La Plata, Buenos Aires, 20 y 21 de octubre 2015. Ponente oral, trabajo completo publicado.

7. V Jornadas de Tesistas de la Facultad de Ciencias Exactas de La Plata. "Catalizadores heterogéneos con estructura tipo Keggin de ácido tungtofosfórico soportados sobre zirconia preparados por el método sol-gel, evaluados en reacciones de esterificación de diferentes alcoholes”. Angélica Escobar, Mirta Blanco, Gustavo Romanelli. La Plata, Buenos Aires, 28 al 30 de octubre 2015. Presentación Poster.

8. XXXI Congreso Argentino de Química. "Valorización de desechos de biomasa: optimización de la síntesis de alquilfuroatos y dihidropirimidonas catalizada por un heteropoliácido de estructura tipo Preyssler incluido en sílice”. Omar M. Portilla, Eliana R. Nope, Angélica M. Escobar, Romina Frenzel, Gabriel Sathicq, Gustavo Romanelli. Buenos Aires, Octubre 2016. Presentación poster.

9. II Jornadas de Jóvenes Investigadores. "Nuevos materiales magnéticos basados en heteropoliácido tipo Keggin y su aplicación en reacciones de esterificación del ácido levulínico paravalorización de residuos de biomasa”. Angélica Escobar, Mirta Blanco, Jose. J. Martinez, Jairo A. Cubillos, Luis Pizzio, Gustavo Romanelli. Junio 2017. Presentación oral.

10. XX Congreso Argentino de Catálisis. "Estudio cinético de la esterificación del ácido levulínico con n-butanol utilizando ácido tungstofosfórico soportados sobre 
Capítulo V. Conclusiones y Perspectivas.

nanopartículas de Fe304 encapsuladas con sílice como catalizador reciclable”. Escobar Caicedo Angélica M. Blanco Mirta N. Martínez Zambrano José J. Cubillos Lobo Jairo A. Pizzio Luis R. Romanelli Gustavo P. Córdoba. Noviembre 2017. Presentación poster. 


\section{REFERENCIAS BIBLIOGRÁFICAS.}

1. Carson R. Silent Spring. (Harcourt HM, ed.). Boston; 1962.

2. Sanjay Kumar Sharma AM. Green Chemestry for Environmental Sustainability; 2010.

3. Paul Anastas JW. Green Chemistry: Theory and Practice. (Press OU, ed.). New York; 1998.

4. Manley JB, Anastas PT, Cue BW. Frontiers in Green Chemistry: meeting the grand challenges for sustainability in R\&D and manufacturing. $J$ Clean Prod. 2008;16(6):743-750. doi:10.1016/j.jclepro.2007.02.025.

5. Tuck CO, Perez E, Horvath IT, Sheldon R a., Poliakoff M. Valorization of Biomass: Deriving More Value from Waste. Science (80- ). 2012;337(6095):695-699. doi:10.1126/science.1218930.

6. Audsley E, Annetts JE. Modelling the value of a rural biorefinery-part I: the model description. Agric Syst. 2003;76(1):39-59. doi:10.1016/S0308521X(02)00038-0.

7. Cherubini F. The biorefinery concept: Using biomass instead of oil for producing energy and chemicals. Energy Convers Manag. 2010;51(7):1412-1421. doi:10.1016/j.enconman.2010.01.015.

8. Italian rubbish sent to the Netherlands for processing. DutchNews.nl. www.dutchnews.nl/news/archives/2011/12/italian_rubbish_sent_to_the_ne.ph p. Published 2011.

9. Deswarte FEI, Clark JH, Hardy JJE, Rose PM. The Fractionation of valuable wax products from wheat straw using C02. Green Chem. 2006;8(0):39-42. doi:10.1039/B514978A.

10. Clark JH. Green chemistry: today (and tomorrow). Green Chem. 2006;8(1):1721. doi:10.1039/B516637N.

11. Lichtenthaler FW, Peters S. Carbohydrates as green raw materials for the chemical industry. Comptes Rendus Chim. 2004;7(2):65-90. doi:10.1016/j.crci.2004.02.002.

12. FitzPatrick M, Champagne P, Cunningham MF, Whitney RA. A biorefinery 
processing perspective: Treatment of lignocellulosic materials for the production of value-added products. Bioresour Technol. 2010;101(23):8915-8922. doi:10.1016/j.biortech.2010.06.125.

13. Zhang ML, Fan YT, Xing Y, Pan CM, Zhang GS, Lay JJ. Enhanced biohydrogen production from cornstalk wastes with acidification pretreatment by mixed anaerobic cultures. Biomass and Bioenergy. 2007;31(4):250-254. doi:10.1016/j.biombioe.2006.08.004.

14. Shackley S, Carter S, Knowles T, et al. Sustainable gasification - biochar systems ? A case-study of rice-husk gasification in Cambodia, Part I : Context, chemical properties, environmental and health and safety issues. Energy Policy. 2012;42:49-58. doi:10.1016/j.enpol.2011.11.026.

15. (IBP) JGL (ECOPETROL); RG y MER (YPF (Grupo RGJH (ExxonMobil); JE (PETROPERU); EF. Manual de Biocombustibles.; 2009.

16. Ritter SK. Lignocellulose: A Complex Biomaterial. Genome Management Information System/ORNL. http://cen.acs.org/articles/86/i49/LignocelluloseComplex-Biomaterial.html. Published 2008.

17. Jonoobi M, Oladi R, Davoudpour $\mathrm{Y}$, et al. Different preparation methods and properties of nanostructured cellulose from various natural resources and residues: a review. Cellulose. 2015;22(2):935-969. doi:10.1007/s10570-0150551-0.

18. Scheller HV, Ulvskov P. Hemicelluloses. Annu Rev Plant Biol. 2010;61(1):263289. doi:10.1146/annurev-arplant-042809-112315.

19. Alvira P, Ballesteros M, Negro MJ. Bioresource Technology Pretreatment technologies for an efficient bioethanol production process based on enzymatic hydrolysis: A review. Bioresour Technol. 2010;101(13):4851-4861. doi:10.1016/j.biortech.2009.11.093.

20. Menon V, Rao M. Trends in bioconversion of lignocellulose: Biofuels, platform chemicals \& biorefinery concept. Prog Energy Combust Sci. 2012;38(4):522-550. doi:10.1016/j.pecs.2012.02.002.

21. Zakzeski J, Bruijnincx PCA, Jongerius AL, Weckhuysen BM. The Catalytic Valorization of Ligning for the Production of Renewable Chemicals. Chem Rev. 
2010;110:3552-3599. doi:10.1021/cr900354u.

22. Lee JM, Jameel H, Venditti RA. Bioresource Technology A comparison of the autohydrolysis and ammonia fiber explosion ( AFEX ) pretreatments on the subsequent enzymatic hydrolysis of coastal Bermuda grass. Bioresour Technol. 2010;101(14):5449-5458. doi:10.1016/j.biortech.2010.02.055.

23. Jian Luo MC and TGGBP for BPS in GC for S (2013). Pretreatment of Lignocellulosic Biomass Using Green Ionic Liquids. In: T. Gu (ed.), ed. Green Biomass Pretreatment for Biofuels Production. SpringerBriefs; 2013:127.

24. Gallezot P. Process options for converting renewable feedstocks to bioproducts. Green Chem. 2007;9(4):295. doi:10.1039/b615413a.

25. Oh SJ, Park J, Na JG, Oh YK, Chang YK. Production of 5-hydroxymethylfurfural from agarose by using a solid acid catalyst in dimethyl sulfoxide. RSC $A d v$. 2015;5(59):47983-47989. doi:10.1039/C5RA02911B.

26. Hao W, Li W, Tang X, et al. Catalytic transfer hydrogenation of biomass-derived 5-hydroxymethyl furfural to the building block 2,5-bishydroxymethyl furan. Green Chem. 2016;18(4):1080-1088. doi:10.1039/C5GC01221J.

27. Zeitsch KJ. The Chemistry and Technology of Furfural and Its Many By-Products. (Elsevier, ed.).; 2000.

28. Furfural Market Will Be Worth \$1,200.9 Billion By 2020: New Report By Grand View Research, Inc. Grand View Research. 1. https://globenewswire.com/news-

release/2015/01/15/697629/10115694/en/Furfural-Market-Will-Be-Worth-1200-9-Billion-By-2020-New-Report-By-Grand-View-Research-Inc.html.

Published 2015.

29. H. J. Brownlee and C. S. Miner. Ind. Eng. Chem. 40 (1948) 201-204.-20.

30. Yang W, Li P, Bo D, Chang $\mathrm{H}$. The optimization of formic acid hydrolysis of xylose in furfural production. Carbohydr Res. 2012;357:53-61. doi:10.1016/j.carres.2012.05.020.

31. Otomo R, Tatsumi T, Yokoi T. Catalysis Science \& Technology the conversion of various types of saccharides. Catal Sci Technol. 2015. doi:10.1039/C5CY00719D.

32. Dias AS, Pillinger M, Valente AA. Dehydration of xylose into furfural over micro- 
mesoporous sulfonic acid catalysts. J Catal. 2005;229(2):414-423. doi:10.1016/j.jcat.2004.11.016.

33. Martínez JJ, Nope E, Rojas H, Cubillos J, Sathicq ÁG, Romanelli GP. Dehydration of xylose to furfural and its valorization via different multicomponent reactions using sulfonated silica with magnetic properties as recyclable catalyst. Catal Letters. 2014;144(7):1322-1331. doi:10.1007/s10562-014-1267-8.

34. Hui-Ling Li, Shuai-Yang Wang, Wen-Ju Wang, Jun-Li Ren, Feng Peng, b Run-Cang Sun LL. One-Step Heterogeneous Catalytic Process for the Dehydration of Xylan into Furfural One-Step Heterogeneous Catalytic Process for the Dehydration of Xylan into Furfural. BioResources. 2016;8:3200-3211. doi:10.15376/biores.8.3.3200-3211.

35. Hoydonckx HE, Van Rhijn WM, Van Rhijn W, De Vos DE, Jacobs PA. Furfural and Derivatives. In: Ullmann's Encyclopedia of Industrial Chemistry. Weinheim, Germany: Wiley-VCH Verlag GmbH \& Co. KGaA; 2007. doi:10.1002/14356007.a12_119.pub2.

36. Mariscal R, Maireles-Torres P, Ojeda M, Sádaba I, López Granados M. Furfural: a renewable and versatile platform molecule for the synthesis of chemicals and fuels. Energy Environ Sci. 2016;9(4):1144-1189. doi:10.1039/C5EE02666K.

37. Carrington HC, Haworth WN, Hirst EL. Sucrose and Other Disaccharides. Sir James Irvine's “Correction.” J Am Chem Soc. 1933;55(3):1084-1090. doi:10.1021/ja01330a033.

38. Corma Canos A, Iborra S, Velty A. Chemical routes for the transformation of biomass into chemicals. Chem Rev. 2007;107(6):2411-2502. doi:10.1021/cr050989d.

39. Pérez HI, Manjarrez N, Solís A, Luna H, Ramírez MA. Microbial biocatalytic preparation of 2-furoic acid by oxidation of 2-furfuryl alcohol and 2furanaldehyde with Nocardia corallina. African J Biotechnol. 2009;8(10):22792282.

40. Online Edition: "Specifications for Flavourings." Food and Agriculture Organization.

41. Klostergaard H. Notes - Esterification with Trapping Phase. J Org Chem. 
1958;23(1):108-110. doi:10.1021/jo01095a616.

42. Zanetti JE, Beckmann CO. ESTERS OF FUROIC ACID. J Am Chem Soc. 1926;48(4):1067-1069. doi:10.1021/ja01415a028.

43. Polucci P, Magnaghi P, Angiolini M, et al. Alkylsulfanyl-1,2,4-triazoles, a New Class of Allosteric Valosine Containing Protein Inhibitors. Synthesis and Structure-Activity Relationships. J Med Chem. 2013;56(2):437-450. doi:10.1021/jm3013213.

44. Xu X, Sun C, Yang D, Bu H, Wang J, Xu Y. Synthesis and Insecticidal Activities of cis -Configuration Nitenpyram Analogues with Benzoyl Hydrazines. J Heterocycl Chem. 2013;50(4):945-948. doi:10.1002/jhet.1546.

45. Won J-E, Kim H-K, Kim J-J, et al. Effective esterification of carboxylic acids using (6-oxo-6H-pyridazin-1-yl)phosphoric acid diethyl ester as novel coupling agents. Tetrahedron. 2007;63(51):12720-12730. doi:10.1016/j.tet.2007.10.011.

46. Chakraborti AK, Singh B, Chankeshwara S V., Patel AR. Protic Acid Immobilized on Solid Support as an Extremely Efficient Recyclable Catalyst System for a Direct and Atom Economical Esterification of Carboxylic Acids with Alcohols. J Org Chem. 2009;74(16):5967-5974. doi:10.1021/jo900614s.

47. Chiarotto I, Feroci M, Sotgiu G, Inesi A. The dual role of ionic liquid BmimBF4, precursor of $\mathrm{N}$-heterocyclic carbene and solvent, in the oxidative esterification of aldehydes. Tetrahedron. 2013;69(37):8088-8095. doi:10.1016/j.tet.2013.06.014.

48. D'Souza MJ, Boggs ME, Kevill DN. Correlation of the rates of solvolysis of 2furancarbonyl chloride and three naphthoyl chlorides. J Phys Org Chem. 2006;19(3):173-178. doi:10.1002/poc.1010.

49. Martín-Muñoz MG, Fierros M, Rodriguez-Franco MI, Conde S. Mucor miehei lipase catalyzed transesterifications on aromatic and heteroaromatic substrates. A general survey. Tetrahedron. 1994;50(23):6999-7008. doi:10.1016/S00404020(01)81352-1.

50. Jackson L. Global invasive species programme. Marine biofouling: An assessment of risks and management initiatives. Global Invasive Species Programme and UNEP Regional Seas Srogramme. 
http://www.issg.org/gisp_publications_reports.htm. Published 2008. Accessed January 1, 2016.

51. Bixler GD, Bhushan B. Biofouling: lessons from nature. Philos Trans R Soc A Math Phys Eng Sci. 2012;370(1967):2381-2417. doi:10.1098/rsta.2011.0502.

52. Adeleye AS, Oranu EA, Tao M, Keller AA. Release and detection of nanosized copper from a commercial antifouling paint. Water Res. 2016;102:374-382. doi:10.1016/j.watres.2016.06.056.

53. Qi SH, Zhang S, Yang LH, Qian PY. Antifouling and antibacterial compounds from the gorgonians Subergorgia suberosa and Scripearia gracillis. Nat Prod Res. 2008;22(2):154-166. doi:10.1080/14786410701642441.

54. Molnar JL, Gamboa RL, Revenga C, Spalding MD. Assessing the global threat of invasive species to marine biodiversity. Front Ecol Environ. 2008;6(9):485-492. doi:10.1890/070064.

55. Chambers LD, Stokes KR, Walsh FC, Wood RJK. Modern approaches to marine antifouling coatings. Surf Coatings Technol. 2006;201(6):3642-3652. doi:10.1016/j.surfcoat.2006.08.129.

56. Willemsen PR. Biofouling un european aquaculture: Is there an easy solution? In: Eur. Aquac. Soc. Spec. Publ. Vol 35. ; 2005:82-87.

57. Ten Hallers-Tjabbes CC. Environmentally Sound and Safe Removal of Harmful Anti-Fouling Systems and of Cleaning Ships' Hulls. Report for the Project: EUROMED Cooperation on Maritime Safety and Prevention of Pollution from Ships; 2007.

58. Qian P-Y, Xu Y, Fusetani N. Natural products as antifouling compounds: recent progress and future perspectives. Biofouling. 2010;26(2):223-234. doi:10.1080/08927010903470815.

59. Satheesh S, Ba-Akdah MA, Al-Sofyani AA. Natural antifouling compound production by microbes associated with marine macroorganisms ??? A review. Electron J Biotechnol. 2016;21:26-35. doi:10.1016/j.ejbt.2016.02.002.

60. Ytreberg E, Bighiu MA, Lundgren L, Eklund B. XRF measurements of tin, copper and zinc in antifouling paints coated on leisure boats. Environ Pollut. 2016;213:594-599. doi:10.1016/j.envpol.2016.03.029. 
61. Saleh A, Molaei S, Sheijooni Fumani N, Abedi E. Antifouling paint booster biocides (Irgarol 1051 and diuron) in marinas and ports of Bushehr, Persian Gulf. Mar Pollut Bull. 2016;105(1):367-372. doi:10.1016/j.marpolbul.2016.02.037.

62. Rocha J, Peixe L, Gomes NCM, Calado R. Cnidarians as a source of new marine bioactive compounds - An overview of the last decade and future steps for bioprospecting. Mar Drugs. 2011;9(10):1860-1886. doi:10.3390/md9101860.

63. Qi SH, Zhang S, Qian PY, Xiao ZH, Li MY. Ten new antifouling briarane diterpenoids from the South China Sea gorgonian Junceella juncea. Tetrahedron. 2006;62(39):9123-9130. doi:10.1016/j.tet.2006.07.049.

64. Acevedo MS, Puentes C, Carreño K, et al. Antifouling paints based on marine natural products from Colombian Caribbean. Int Biodeterior Biodegrad. 2013;83:97-104. doi:10.1016/j.ibiod.2013.05.002.

65. Fusetani N. Antifouling marine natural products. Nat Prod Rep. 2011;28(2):400410. doi:10.1039/C0NP00034E.

66. Omae I. General Aspects of Tin-Free Antifouling Paints. Chem Rev. 2003;103(9):3431-3448. doi:10.1021/cr030669z.

67. Stewart M, Miles WH, Depree C. Antifouling activity of synthetic ??hydroxybutenolides. Int Biodeterior Biodegrad. 2014;88(January):176-184. doi:10.1016/j.ibiod.2013.10.019.

68. Stewart M, Depree C, Thompson KJ. Antifouling Sesterterpenes from the New Zealand Marine Sponge Semitaspongia bactriana. Nat Prod Commun. 2009;4(3):331-336.

69. Li YX, Wu HX, Xu Y, Shao CL, Wang CY, Qian PY. Antifouling Activity of Secondary Metabolites Isolated from Chinese Marine Organisms. Mar Biotechnol. 2013;15(5):552-558. doi:10.1007/s10126-013-9502-7.

70. Raveendran T V., Limna Mol VP, Parameswaran PS. Natural Product Antifoulants from the octocorals of Indian waters. Int Biodeterior Biodegrad. 2011;65(1):265-268. doi:10.1016/j.ibiod.2010.11.013.

71. Lewkowski J. Synthesis, chemistry and applications of 5-hydroxymethyl-furfural and its derivatives. Arkivoc. 2005;2001(1):17-54. 
doi:10.3998/ark.5550190.0002.102.

72. Antal MJ, Mok WSL, Richards GN. Mechanism of formation of S ( hydroxymethyl ) -2-furalde- hyde from D-fructose and sucrose *. Carbohydr Res. 1990;199:91109.

73. T. Werpy GP. Top Value Added Chemicals from Biomass Volume I-Results of Screening for Potential Candidates from Sugars and Synthesis Gas.; 2004.

74. Bozell JJ, Petersen GR. Technology development for the production of biobased products from biorefinery carbohydrates-the US Department of Energy's “Top 10" revisited. Green Chem. 2010;12(4):539. doi:10.1039/b922014c.

75. Morone A, Apte M, Pandey RA. Levulinic acid production from renewable waste resources: Bottlenecks, potential remedies, advancements and applications. Renew Sustain Energy Rev. 2015;51:548-565. doi:10.1016/j.rser.2015.06.032.

76. Timokhin B V, Baransky VA, Eliseeva GD. Levulinic acid in organic synthesis. Russ Chem Rev. 1999;68(1):73-84. doi:10.1070/RC1999v068n01ABEH000381.

77. Levulinic Acid Market Analysis And Segment Forecasts To 2020. Grand View Research. http://www.grandviewresearch.com/industry-analysis/levulinicacid-market. Published 2015.

78. v. Grote AF, Kehrer E, Tollens B. Untersuchungen über die Lävulinsäure oder $\beta$ Acetopropionsäure. I. Ueber Darstellung und Eigenschaften der Lävulinsäure. Justus Liebig's Ann der Chemie. 1881;206(1-2):207-225. doi:10.1002/jlac.18812060111.

79. Conrad M. XLI. Ueber Acetsuccinsäureester und dessen Derivate. Justus Liebig's Ann der Chemie. 1877;188(1-2):217-226. doi:10.1002/jlac.18771880111.

80. Sah, P. P. T.; Ma S-Y. Levulinic acid and its esters. J Am Chem Soc. 1930;52:4880-4883.

81. Schuette HA, Cowley MA. Levulinic acid. II. The vapor pressures of its alkyl esters (C 1 --C 6). J Am Chem Soc. 1931;53(9):3485-3489. doi:10.1021/ja01360a039.

82. Fitzpatrick SW. The Biofine Technology: A "Bio-Refinery" Concept Based on Thermochemical Conversion of Cellulosic Biomass. In: Joseph J. Bozell MKP, ed. Feedstocks for the Future Renewables for the Production of Chemicals and Materials. ; 2006:271-287. doi:10.1021/bk-2006-0921.ch020. 
83. Hayes DJ, Fitzpatrick S, Hayes MHB, Ross JRH. The Biofine Process- Production of Levulinic Acid, Furfural, and Formic Acid from Lignocellulosic Feedstocks. In: Biorefineries-Industrial Processes and Products. Weinheim, Germany: WileyVCH Verlag GmbH; 2008:139-164. doi:10.1002/9783527619849.ch7.

84. Hayes DJ. An examination of biorefining processes, catalysts and challenges. Catal Today. 2009;145(1-2):138-151. doi:10.1016/j.cattod.2008.04.017.

85. Online Edition: "Specifications for Flavourings." Food and Agriculture Organization. $\quad$ http://www.fao.org/food/food-safety-quality/scientificadvice/jecfa/jecfa-flav/details/en/c/1111/. Published 2002.

86. Erner WE. Synthetic liquid fuel and fuel mixtures for oil-burning devices. 1982.

87. Maheria KC, Kozinski J, Dalai A. Esterification of levulinic acid to n-butyl levulinate over various acidic zeolites. Catal Letters. 2013;143(11):1220-1225. doi:10.1007/s10562-013-1041-3.

88. Dharne S, Bokade V V. Esterification of levulinic acid to n-butyl levulinate over heteropolyacid supported on acid-treated clay. J Nat Gas Chem. 2011;20(1):1824. doi:10.1016/S1003-9953(10)60147-8.

89. Nandiwale KY, Niphadkar PS, Deshpande SS, Bokade V V. Esterification of renewable levulinic acid to ethyl levulinate biodiesel catalyzed by highly active and reusable desilicated H-ZSM-5. J Chem Technol Biotechnol. 2014;89(10):1507-1515. doi:10.1002/jctb.4228.

90. Pasquale G, Vázquez P, Romanelli G, Baronetti G. Catalytic upgrading of levulinic acid to ethyl levulinate using reusable silica-included Wells-Dawson heteropolyacid as catalyst. Catal Commun. 2012;18:115-120. doi:10.1016/j.catcom.2011.12.004.

91. Ciptonugroho W, Al-shaal MG, Mensah JB, Palkovits R. One pot synthesis of WO x / mesoporous-ZrO 2 catalysts for the production of levulinic-acid esters. J Catal. 2016;340:17-29. doi:10.1016/j.jcat.2016.05.001.

92. Manzer LE. Biomass derivatives: A sustainable source of chemicals. ACS Symp Ser. 2006;921:40-51. doi:doi:10.1021/bk-2006-0921.ch004.

93. Fagan, P.J., Manzer LE. Preparation of levulinic acid esters and formic acid esters from biomass and olefins. 2006. 
94. Zhang Z, Dong K, Zhao Z. Efficient conversion of furfuryl alcohol into alkyl levulinates catalyzed by an organic-inorganic hybrid solid acid catalyst. ChemSusChem. 2011;4(1):112-118. doi:10.1002/cssc.201000231.

95. Lange JP, van de Graaf WD, Haan RJ. Conversion of furfuryl alcohol into ethyl levulinate using solid acid catalysts. ChemSusChem. 2009;2(5):437-441. doi:10.1002/cssc.200800216.

96. Demmacarà P, Ciriminna R, Shiju NR, Rothenberg G, Pagliaro M. Enhanced heterogeneous catalytic conversion of furfuryl alcohol into butyl levulinate. ChemSusChem. 2014;7(3):835-840. doi:10.1002/cssc.201301027.

97. Tominaga K. Preparation of levulinates from carbohydrates and alcohols with nonvolatile catalysts. 2016.

98. Saravanamurugan S, Buu ON Van, Riisager A. Conversion of mono- and disaccharides to ethyl levulinate and ethyl pyranoside with sulfonic acidfunctionalized ionic liquids. ChemSusChem. 2011;4(6):723-726. doi:10.1002/cssc.201100137.

99. Peng L, Lin L, Zhang J, Shi J, Liu S. Solid acid catalyzed glucose conversion to ethyl levulinate. Appl Catal A Gen. 2011;397(1-2):259-265. doi:10.1016/j.apcata.2011.03.008.

100. Hu X, Lievens C, Larcher A, Li C. Bioresource Technology Reaction pathways of glucose during esterification : Effects of reaction parameters on the formation of humin type polymers. Bioresour Technol. 2011;102(21):10104-10113. doi:10.1016/j.biortech.2011.08.040.

101. Misono M. Recent progress in the practical applications of heteropolyacid and perovskite catalysts: Catalytic technology for the sustainable society. Catal Today. 2009;144(3-4):285-291. doi:10.1016/j.cattod.2008.10.054.

102. Weinstock IA, Cowan JJ, Barbuzzi EMG, Zeng H, Hill CL. Equilibria between $\alpha$ and $\beta$ Isomers of Keggin Heteropolytungstates. J Am Chem Soc. 1999;121(19):46084617. doi:10.1021/ja982908j.

103. Kazushi arata. Solid Superacids. AdV Catal. 1990;37:165-211. doi:10.1002/9783527619528.ch4g.

104. Hill C. Introduction : Polyoxometalates s Multicomponent Molecular Vehicles To. 
Chem Rev. 1998;98(1):1-2.

105. Keggin JF. The Structure and Formula of 12-Phosphotungstic Acid. Proc R Soc A Math Phys Eng Sci. 1934;144(851):75-100. doi:10.1098/rspa.1934.0035.

106. Dawson B. The structure of the 9(18)-heteropoly anion in potassium 9(18)-

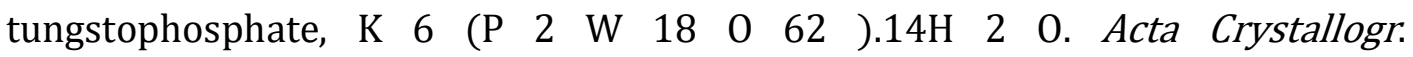
1953;6(2):113-126. doi:10.1107/S0365110X53000466.

107. Evans HT. THE CRYSTAL STRUCTURES OF AMMONIUM AND POTASSIUM MOLYBDOTELLURATES. J Am Chem Soc. 1948;70(3):1291-1292. doi:10.1021/ja01183a521.

108. Dexter DD, Silverton J V. A new structural type for heteropoly anions. The crystal structure of (NH4)2H6(CeMo12042).12H2O. J Am Chem Soc. 1968;90(13):3589-3590. doi:10.1021/ja01015a067.

109. Kozhevnikov I V. Catalysis by heteropoly acids and multicomponent polyoxometalates in liquid-phase reactions. Chem Rev. 1998;98(1):171-198. doi:10.1021/cr960400y.

110. Polyoxometalate. WOW. http://www.wow.com/wiki/Polyoxometalate.

111. Filippov AP, Kovalenko AS, Il'in VG. Formation of nanoperiodic structures based on keggin and lacunar anions of phosphotungstic acid and cationic surfactants. Theor Exp Chem. 1998;34(4):229-234. doi:10.1007/BF02523254.

112. Pope MT. Structural chemistry of actinide polyoxometalates. Struct Chem Inorg Actin Compd. 2007:341-361. doi:10.1016/B978-044452111-8/50010-7.

113. Brown GM, Noe-Spirlet MR, Busing WR, Levy HA. Dodecatungstophosphoric acid hexahydrate, $(\mathrm{H} 502+) 3(\mathrm{PW} 120403-)$. The true structure of Keggin's 'pentahydrate' from single-crystal X-ray and neutron diffraction data. Acta Crystallogr Sect B Struct Crystallogr Cryst Chem. 1977;33(4):1038-1046. doi:10.1107/S0567740877005330.

114. Kozhevnikov I V., Sinnema A, van Bekkum H. Proton sites in Keggin heteropoly acids from170 NMR. Catal Letters. 1995;34(1-2):213-221. doi:10.1007/BF00808336.

115. Mizuno N, Misono M. Heterogeneous Catalysis. Chem Rev. 1998;98(150):199218. doi:10.1002/anie.201410738. 
116. Okuhara T, Nakato T. Catalysis by porous heteropoly compounds. Catal SurV From Japan. 1998;2:31-44. doi:10.1016/S0926-860X(01)00830-4.

117. Feumi-Jantou C, Fournier M, Rabia C, Hervé G, Launay S. Polyoxometalates Catalyst Materials : X-Ray Thermal Stability Study of Phosphorus-containing Heteropolyacids. J Mater Chem. 1992;2(9):971-978.

118. Kozhevnikov I V, Kozhevnikov I V. Sustainable heterogeneous acid catalysis by heteropoly acids. J Mol Catal. 2007;262(August 2006):86-92. doi:10.1016/j.molcata.2006.08.072.

119. Misono M. Catalysis of Heteropoly Compounds (Polyoxometalates). Vol 176.; 2013. doi:10.1016/B978-0-444-53833-8.00004-1.

120. Micek-Ilnicka A. The role of water in the catalysis on solid heteropolyacids. J Mol Catal A Chem. 2009;308(1-2):1-14. doi:10.1016/j.molcata.2009.04.003.

121. Ghosh AK, Moffat JB. Acidity of heteropoly compounds. J Catal. 1986;101(2):238245. doi:10.1016/0021-9517(86)90249-6.

122. Pearson RG. Hard and Soft Acids and Bases. J Am Chem Soc. 1963;85(22):35333539. doi:10.1021/ja00905a001.

123. Izumi Y, Matsuo K, Urabe K. Efficient homogeneous acid catalysis of heteropoly acid and its characterization through ether cleavage reactions. I Mol Catal. 1983;18(3):299-314. doi:10.1016/S0304-5102(83)80004-2.

124. Misono M. Acid catalysts for clean production. Green aspects of heteropolyacid catalysts. Comptes Rendus I Acad des Sci Ser Ii Fasc C-Chimie. 2000;3(6):471475. doi:10.1016/S1387-1609(00)01165-8.

125. Kozhevnikov I V., Matveev KI. Homogeneous catalysts based on heteropoly acids (review). Appl Catal. 1983;5(2):135-150. doi:10.1016/0166-9834(83)80128-6.

126. Morin P, Hamad B, Sapaly G, et al. Transesterification of rapeseed oil with ethanol. I. Catalysis with homogeneous Keggin heteropolyacids. Appl Catal A Gen. 2007;330(1-2):69-76. doi:10.1016/j.apcata.2007.07.011.

127. Kamiya Y, Okuhara T, Misono M, Miyaji A, Tsuji K, Nakajo T. Catalytic chemistry of supported heteropolyacids and their applications as solid acids to industrial processes. Catal Surv from Asia. 2008;12(2):101-113. doi:10.1007/s10563-0089043-7. 
128. Yadav JS, Satyanarayana M, Balanarsaiah E, Raghavendra S. Phosphomolybdic acid supported on silica gel: a mild, efficient and reusable catalyst for the synthesis of 2,3-unsaturated glycopyranosides by Ferrier rearrangement. Tetrahedron Lett. 2006;47(34):6095-6098. doi:10.1016/j.tetlet.2006.06.084.

129. Kozhevnikova EF, Kozhevnikov I V. A calorimetric study of the acidity of bulk and silica-supported heteropoly acid H3PW12040. J Catal. 2004;224(1):164169. doi:10.1016/j.jcat.2004.03.001.

130. Robles-Dutenhefner PA, da Silva KA, H. Siddiqui MR, Kozhevnikov I V, Gusevskaya E V. Hydration and acetoxylation of monoterpenes catalyzed by heteropoly acid. J Mol Catal A Chem. 2001;175(1-2):33-42. doi:10.1016/S13811169(01)00217-5.

131. Miyaji A, Ohnishi R, Okuhara T. Skeletal isomerization of n-heptane over PdH4SiW12040 supported on SiO2: comparative study with typical bifunctional catalysts. Appl Catal A Gen. 2004;262(2):143-148. doi:10.1016/j.apcata.2003.11.041.

132. Kaur J, Griffin K, Harrison B, Kozhevnikov IV. Friedel-Crafts Acylation Catalysed by Heteropoly Acids. J Catal. 2002;208(2):448-455. doi:10.1006/jcat.2002.3592.

133. Oliveira CF, Dezaneti LM, Garcia FAC, et al. Esterification of oleic acid with ethanol by 12-tungstophosphoric acid supported on zirconia. Appl Catal A Gen. 2010;372(2):153-161. doi:10.1016/j.apcata.2009.10.027.

134. Rivera TS, Sosa A, Romanelli GP, Blanco MN, Pizzio LR. Tungstophosphoric acid/zirconia composites prepared by the sol-gel method: An efficient and recyclable green catalyst for the one-pot synthesis of 14-aryl-14Hdibenzo[a,j]xanthenes. Appl Catal A Gen. 2012;443-444:207-213. doi:10.1016/j.apcata.2012.08.001.

135. Satam JR, Parghi KD, Jayaram R V. 12-Tungstophosphoric acid supported on zirconia as an efficient and heterogeneous catalyst for the synthesis of bis(indolyl)methanes and tris(indolyl)methanes. Catal Commun. 2008;9(6):1071-1078. doi:10.1016/j.catcom.2007.10.009.

136. Chai S, Wang H, Liang Y, Xu B. Sustainable production of acrolein : gas-phase dehydration of glycerol over 12-tungstophosphoric acid supported on $\mathrm{ZrO} 2$ and 
SiO 2. Green Chem. 2008;10(July 2015):1087-1093. doi:10.1039/b805373a.

137. Qu X, Guo Y, Hu C. Preparation and heterogeneous photocatalytic activity of mesoporous H3PW12040/ZrO2 composites. J Mol Catal A Chem. 2007;262(12):128-135. doi:10.1016/j.molcata.2006.08.026.

138. Bai B, Zhao J, Feng X. Preparation and characterization of supported photocatalysts: HPAs/TiO2/SiO2 composite. Mater Lett. 2003;57(24-25):39143918. doi:10.1016/S0167-577X(03)00240-4.

139. Ortiz-Islas E, Lopez T, Gomez R, Picquart M, Aguilar DH, Quintana P. Crystallinity effect in the textural properties of titania-TPA catalysts. Appl Surf Sci. 2005;252(3):853-857. doi:10.1016/j.apsusc.2005.02.066.

140. Rengifo-Herrera JA, Blanco MN, Pizzio LR. Visible light absorption of TiO2 materials impregnated with tungstophosphoric acid ethanol-aqueous solution at different $\mathrm{pH}$ values. Evidence about the formation of a surface complex between Keggin anion and TiO 2 surfaces. Mater Res Bull. 2014;49(1):618-624. doi:10.1016/j.materresbull.2013.09.043.

141. Ladera RM, Fierro JLG, Ojeda M, Rojas S. TiO2-supported heteropoly acids for low-temperature synthesis of dimethyl ether from methanol. $J$ Catal. 2014;312:195-203. doi:10.1016/j.jcat.2014.01.016.

142. Frenzel R, Sathicq ÁG, Blanco MN, Romanelli GP, Pizzio LR. Carbon-supported metal-modified lacunary tungstosilicic polyoxometallates used as catalysts in the selective oxidation of sulfides. J Mol Catal A Chem. 2015;403:27-36. doi:10.1016/j.molcata.2015.02.021.

143. Pinto T, Dufaud V, Lefebvre F. Isomerization of n-hexane on heteropolyacids supported on SBA-15. 1. Monofunctional impregnated catalysts. Appl Catal A Gen. 2014;483:103-109. doi:10.1016/j.apcata.2014.07.003.

144. Marcì G, García-López E, Vaiano V, Sarno G, Sannino D, Palmisano L. Keggin heteropolyacids supported on $\mathrm{TiO} 2$ used in gas-solid (photo)catalytic propene hydration and in liquid-solid photocatalytic glycerol dehydration. Catal Today. May 2016. doi:10.1016/j.cattod.2016.04.037.

145. Lv G, Deng L, Lu B, Li J, Hou X, Yang Y. Efficient dehydration of fructose into 5hydroxymethylfurfural in aqueous medium over silica-included heteropolyacids. 
J Clean Prod. November 2016. doi:10.1016/j.jclepro.2016.11.053.

146. Munnik P, de Jongh P, de Jong K. Recent Developments in the Synthesis of Supported Catalysts. Chem Rev. 2015:150619062952001. doi:10.1021/cr500486u.

147. van Honschoten JW, Brunets N, Tas NR. Capillarity at the nanoscale. Chem Soc Rev. 2010;39(3):1096-1114. doi:10.1039/b909101g.

148. Kahlweit M. Ostwald ripening of precipitates. Adv Colloid Interface Sci. 1975;5(1):1-35. doi:10.1016/0001-8686(75)85001-9.

149. Kaluza S, Behrens M, Schiefenhövel N, et al. A Novel Synthesis Route for $\mathrm{Cu} / \mathrm{ZnO} / \mathrm{Al} \quad 20 \quad 3$ Catalysts used in Methanol Synthesis: Combining Continuous Consecutive Precipitation with Continuous Aging of the Precipitate. ChemCatChem. 2011;3(1):189-199. doi:10.1002/cctc.201000329.

150. Pierre AC, Pajonk GM. Chemistry of aerogels and their applications. Chem Rev. 2002;102(11):4243-4265. doi:10.1021/cr0101306.

151. Graham T. XXXV.-On the Properties of Silicic Acid and other Analogous Colloidal Substances. JChem Soc. 1864;17:318-327. doi:10.1039/JS8641700318.

152. Verwey E, Overbeek J. Theory of the stability of lyophobic colloids. J Phys Colloid Chem. 1947;51(3):631-636. doi:10.1038/162315b0.

153. Derjaguin B V, Voropayeva TN, Titiyevskaya a S. Surface forces and the stability of colloids and disperse systems. J Colloid Sci. 1964;19:113-135. doi:10.1016/0095-8522(64)90023-6.

154. Flory J. Molecular Size Distribution in Three Dimensional Polymers. I. Gelation. J Am Chem Soc. 1941;63(11):3083-3090. doi:10.1021/ja01856a061.

155. Stockmayer WH. Theory of Molecular Size Distribution and Gel Formation in Branched Polymers II. General Cross Linking. J Chem Phys. 1944;12(4):125. doi:10.1063/1.1723922.

156. Frisch HL, Hammersley JM. Percolation Processes and Related Topics. J Soc Ind Appl Math. 1963;11(4):894-918. doi:10.1137/0111066.

157. Schwarz J a., Contescu C, Contescu A. Methods for Preparation of Catalytic Materials. Chem Rev. 1995;95(3):477-510. doi:10.1021/cr00035a002.

158. Piconi C, Maccauro G. Zirconia as a ceramic biomaterial. Biomaterials. 
1999;20(1):1-25. doi:10.1016/S0142-9612(98)00010-6.

159. Schuster B, Fujara F, Merk B, Neumann R, Seidl T, Trautmann C. Response behavior of $\mathrm{ZrO} 2$ under swift heavy ion irradiation with and without external pressure. Nucl Instruments Methods Phys Res Sect B Beam Interact with Mater Atoms. 2012;277:45-52. doi:10.1016/j.nimb.2011.12.060.

160. Hofmann MKGN, Berthold C. Ageing behavior of 3Y-TZP dental ceramics in water, acetic acid and orthophosphoric acid at $80^{\circ} \mathrm{C}$. http://www.geo.unituebingen.de/studium/studentische-projekte/wissenschaftlichespraesentieren-ss-2013-und-ws-201314/geowissenschaften/martinhofmann.html. Published 2014.

161. Chuah GK. An Investigation into the Preparation of High Surface Area Zirconia. Catal Today. 1999;49(1-3):131-139. doi:10.1016/S0920-5861(98)00417-9.

162. Grant C. Bailey VCFH. Sulfate-treated zirconia-gel catalyst. 1962.

163. Guldhe A, Singh P, Ahmad F, Singh B, Bux F. Biodiesel synthesis from microalgal lipids using tungstated zirconia as a heterogeneous acid catalyst and its comparison with homogeneous acid and enzyme catalysts. Fuel. 2017;187:180188. doi:10.1016/j.fuel.2016.09.053.

164. Sarish S, Devassy BM, Böhringer W, Fletcher J, Halligudi SB. Liquid-phase alkylation of phenol with long-chain olefins over WO x/ZrO2 solid acid catalysts. J Mol Catal A Chem. 2005;240(1-2):123-131. doi:10.1016/j.molcata.2005.06.046.

165. Farhadi S, Zaidi M. Polyoxometalate-zirconia (POM/ZrO2) nanocomposite prepared by sol-gel process: A green and recyclable photocatalyst for efficient and selective aerobic oxidation of alcohols into aldehydes and ketones. Appl Catal A Gen. 2009;354(1-2):119-126. doi:10.1016/j.apcata.2008.11.024.

166. Zhu S, Zhu Y, Gao X, Mo T, Zhu Y, Li Y. Production of bioadditives from glycerol esterification over zirconia supported heteropolyacids. Bioresour Technol. 2013;130:45-51. doi:10.1016/j.biortech.2012.12.011.

167. Sosa AA, Rivera TS, Blanco MN, Pizzio LR, Romanelli GP. Tungstophosphoric Acid Supported on Zirconia: A Recyclable Catalyst for the Green Synthesis on Quinoxaline Derivatives under Solvent-Free Conditions. Phosphorus Sulfur Silicon Relat Elem. 2013;188(8):1071-1079. 
doi:10.1080/10426507.2012.710678.

168. Kirk-Othmer, ed. Titanium compounds, inorganic. In: Encyclopedia of Chemical Technology, Index to Volumes 1 - 26. 5th Editio. New York: Wiley; 2001.

169. Mo S Di, Ching WY. Electronic and optical properties of three phases of titanium dioxide: Rutile, anatase, and brookite. Phys Rev B. 1995;51(19):13023-13032. doi:10.1103/PhysRevB.51.13023.

170. Dambournet D, Belharouak I, Amine K. Tailored preparation methods of TiO2 anatase, rutile, brookite: Mechanism of formation and electrochemical properties. Chem Mater. 2010;22(3):1173-1179. doi:10.1021/cm902613h.

171. Hanaor DAH, Sorrell CC. Review of the anatase to rutile phase transformation. $J$ Mater Sci. 2011;46(4):855-874. doi:10.1007/s10853-010-5113-0.

172. Reyes-Coronado D, Rodríguez-Gattorno G, Espinosa-Pesqueira ME, Cab C, de Coss R, Oskam G. Phase-pure TiO(2) nanoparticles: anatase, brookite and rutile. Nanotechnology. 2008;19(14):145605. doi:10.1088/0957$4484 / 19 / 14 / 145605$.

173. Chaturvedi A, Joshi MP, Mondal P, Sinha AK, Srivastava AK. Growth of anatase and rutile phase TiO2 nanoparticles using pulsed laser ablation in liquid: Influence of surfactant addition and ablation time variation. Appl Surf Sci. 2017;396:303-309. doi:10.1016/j.apsusc.2016.10.133.

174. Zaban A, Aruna ST, Tirosh S, Gregg BA, Mastai Y. The Effect of the Preparation Condition of TiO 2 Colloids on Their Surface Structures. J Phys Chem B. 2000;104(17):4130-4133. doi:10.1021/jp993198m.

175. Phonthammachai N, Chairassameewong T, Gulari E, Jamieson AM, Wongkasemjit S. Structural and rheological aspect of mesoporous nanocrystalline $\mathrm{TiO} 2$ synthesized via sol-gel process. Microporous Mesoporous Mater. 2003;66(23):261-271. doi:10.1016/j.micromeso.2003.09.017.

176. Feng C, Xu G, Liu X. Photocatalytic degradation of imidacloprid by composite catalysts H 3PW12040/La-TiO2. J Rare Earths. 2013;31(1):44-48. doi:10.1016/S1002-0721(12)60232-4.

177. Marcì G, García-López E, Palmisano L. Photo-assisted degradation of 2-propanol in gas-solid regime by using $\mathrm{TiO} 2$ impregnated with heteropolyacid 
H3PW12040. Catal Today. 2009;144(1-2):42-47. doi:10.1016/j.cattod.2008.11.010.

178. Alsalme A, Kozhevnikova EF, Kozhevnikov I V. Heteropoly acids as catalysts for liquid-phase esterification and transesterification. Appl Catal A Gen. 2008;349(12):170-176. doi:10.1016/j.apcata.2008.07.027.

179. ZHAO Y, QIU Z, HUANG J. Preparation and Analysis of Fe304 Magnetic Nanoparticles Used as Targeted-drug Carriers. Chinese J Chem Eng. 2008;16(3):451-455. doi:10.1016/S1004-9541(08)60104-4.

180. Mirzababaei SN, Gorji TB, Baou M, Gorji-Bandpy M, Fatouraee N. Investigation of magnetic nanoparticle targeting in a simplified model of small vessel aneurysm. J Magn Magn Mater. 2017;426:126-131. doi:10.1016/j.jmmm.2016.11.044.

181. Sun B, Ni X, Cao Y, Cao G. Electrochemical sensor based on magnetic molecularly imprinted nanoparticles modified magnetic electrode for determination of $\mathrm{Hb}$. Biosens Bioelectron. 2017;91:354-358. doi:10.1016/j.bios.2016.12.056.

182. Liu C, Du X, He Q, et al. Preparation of pyridyl disulfide-functionalized magnetic nanoparticles and application in traceless isolation of thiol-containing proteins. Mater Lett. 2017;186:386-389. doi:10.1016/j.matlet.2016.10.044.

183. Azimi N, Rahimi M. Magnetic nanoparticles stimulation to enhance liquid-liquid two-phase mass transfer under static and rotating magnetic fields. J Magn Magn Mater. 2017;422:188-196. doi:10.1016/j.jmmm.2016.08.092.

184. Carmona-Carmona AJ, Palomino-Ovando MA, Hernández-Cristobal O, SánchezMora E, Toledo-Solano M. Synthesis and characterization of magnetic opal/Fe304 colloidal crystal. J Cryst Growth. 2017;462:6-11. doi:10.1016/j.jcrysgro.2016.12.105.

185. Wan $\mathrm{H}, \mathrm{Wu} \mathrm{Z}$, Chen $\mathrm{W}$, et al. Heterogenization of ionic liquid based on mesoporous material as magnetically recyclable catalyst for biodiesel production. $J$ Mol Catal A Chem. 2015;398:127-132. doi:10.1016/j.molcata.2014.12.002.

186. Tan KA, Morad N, Teng TT, Norli I, Panneerselvam P. Removal of Cationic Dye by Magnetic Nanoparticle (Fe304) Impregnated onto Activated Maize Cob Powder and Kinetic Study of Dye Waste Adsorption. APCBEE Procedia. 2012;1:83-89. 
doi:10.1016/j.apcbee.2012.03.015.

187. Mathew DS, Juang RS. An overview of the structure and magnetism of spinel ferrite nanoparticles and their synthesis in microemulsions. Chem Eng J. 2007;129(1-3):51-65. doi:10.1016/j.cej.2006.11.001.

188. Weiss P. L'hypothèse du champ moléculaire et la propriété ferromagnétique. J Phys Théorique Appliquée. 1907;6(1):661-690. doi:10.1051/jphystap:019070060066100.

189. Sorensen CM. Magnetism. In: Klabunde KJ, ed. Nanoscale Materials in Chemistry. New York, USA: John Wiley \& Sons, Inc.; 2001:169. doi:10.1002/0471220620.fmatter_indsub.

190. Paradela RP. Preparación y caracterización de nanopartículas magnéticas biocompatible. 2013. http://ruc.udc.es/handle/2183/11554.

191. Castellanos MJR. Procesos de imanación en la nanoescala mediante microscopía de fuerzas magnéticas.

192. Jahagirdar AA, Dhananjaya N, Monika DL, et al. Structural, EPR, optical and magnetic properties of $\alpha$-Fe 203 nanoparticles. Spectrochim Acta - Part A Mol Biomol Spectrosc. 2013;104:512-518. doi:10.1016/j.saa.2012.09.069.

193. Wells AF. Química Inorgánica Estructural. Barcelona: Reverté; 1978.

194. Gupta AK, Naregalkar RR, Vaidya VD, Gupta M. Recent advances on surface engineering of magnetic iron oxide nanoparticles and their biomedical applications. Nanomedicine. 2007;2(1):23-39. doi:10.2217/17435889.2.1.23.

195. Wu W, Wu Z, Yu T, Jiang C, Kim W-S. Recent progress on magnetic iron oxide nanoparticles: synthesis, surface functional strategies and biomedical applications. Sci Technol Adv Mater. 2015;16(2):023501. doi:10.1088/14686996/16/2/023501.

196. Faraji M, Yamini Y, Rezaee M. Magnetic Nanoparticles: Synthesis, Stabilization, Functionalization, Characterization, and Applications. Iran Chem Soc. 2010;7(1):1-37.

197. Majewski P, Thierry B. Functionalized Magnetite Nanoparticles Synthesis,Properties, and Bio-Applications. Crit Rev Solid State Mater Sci. 2007;32(3):203-215. doi:10.1080/10408430701776680. 
198. Perez De Berti IO, Cagnoli M V, Pecchi G, et al. Alternative low-cost approach to the synthesis of magnetic iron oxide nanoparticles by thermal decomposition of organic precursors. Nanotechnology. 2013;24(17):175601. doi:10.1088/0957$4484 / 24 / 17 / 175601$.

199. Babes L, Jacques J, Jeune L, Jallet P. Synthesis of Iron Oxide Nanoparticles Used as MRI Contrast Agents : A Parametric Study. J Colloid Interface Sci. 1999;212:474482.

200. Faiyas APA, Vinod EM, Joseph J, Ganesan R, Pandey RK. Dependence of pH and surfactant effect in the synthesis of magnetite (Fe304) nanoparticles and its properties. J Magn Magn Mater. 2010;322(4):400-404. doi:10.1016/j.jmmm.2009.09.064.

201. Shen YF, Tang J, Nie ZH, Wang YD, Ren Y, Zuo L. Preparation and application of magnetic Fe304 nanoparticles for wastewater purification. Sep Purif Technol. 2009;68(3):312-319. doi:10.1016/j.seppur.2009.05.020.

202. Stöber W, Fink A, Bohn E. Controlled growth of monodisperse silica spheres in the micron size range. J Colloid Interface Sci. 1968;26(1):62-69. doi:10.1016/0021-9797(68)90272-5.

203. Chae SS, Hwang BH, Jang WS, et al. Homogeneous liquid crystal alignment on inorganic-organic hybrid silica thin films derived by the sol-gel method. Soft Matter. 2012;8(5):1437. doi:10.1039/c1sm06592k.

204. Du GH, Liu ZL, Xia X, Chu Q, Zhang SM. Characterization and application of Fe304/SiO2 nanocomposites. J Sol-Gel Sci Technol. 2006;39(3):285-291. doi:10.1007/s10971-006-7780-5.

205. Goksu EI, Hoopes MI, Nellis BA, et al. Silica xerogel/aerogel-supported lipid bilayers: Consequences of surface corrugation. Biochim Biophys Acta Biomembr. 2010;1798(4):719-729. doi:10.1016/j.bbamem.2009.09.007.

206. Mariela A. Agotegaray VLL. Microemulsion method. In: Silica-Coated Magnetic Nanoparticles: An Insight into Targeted Drug Delivery and Toxicology. SpringerBriefs; 2017:42.

207. Liu X, Guan Y, Ma Z, Liu H. Surface modification and characterization of magnetic polymer nanospheres prepared by miniemulsion polymerization. Langmuir. 
2004;20(23):10278-10282. doi:10.1021/la0491908.

208. Rafiee E, Eavani S. H3PW12040 supported on silica-encapsulated $\gamma$-Fe2O3 nanoparticles: a novel magnetically-recoverable catalyst for three-component Mannich-type reactions in water. Green Chem. 2011;13(8):2116. doi:10.1039/c1gc15291b.

209. Jang JH, Lim HB. Characterization and analytical application of surface modi fi ed magnetic nanoparticles. Microchem J. 2010;94(2):148-158. doi:10.1016/j.microc.2009.10.011.

210. Deng YH, Wang CC, Hu JH, Yang WL, Fu SK. Investigation of formation of silicacoated magnetite nanoparticles via sol-gel approach. Colloids Surfaces A Physicochem Eng Asp. 2005;262(1-3):87-93. doi:10.1016/j.colsurfa.2005.04.009.

211. Koutsaftis A, Aoyama I. Toxicity of four antifouling biocides and their mixtures on the brine shrimp Artemia salina. Sci Total Environ. 2007;387(1-3):166-174. doi:10.1016/j.scitotenv.2007.07.023.

212. Foster MS, Harrold C, Hardin DD. Point vs. photo quadrat estimates of the cover of sessile marine organisms. J Exp Mar Bio Ecol. 1991;146(2):193-203. doi:10.1016/0022-0981(91)90025-R.

213. Rengifo-Herrera JA, Blanco MN, Pizzio LR. Photocatalytic bleaching of aqueous malachite green solutions by UV-A and blue-light-illuminated TiO2 spherical nanoparticles modified with tungstophosphoric acid. Appl Catal B Environ. 2011;110:126-132. doi:10.1016/j.apcatb.2011.08.034.

214. Sing KSW, Everett DH, Haul R a. W, et al. Reporting physisorption data for gas/solid systemwith special reference to the determination of surface areaand porosity. Pure Appl Chem. 1985;54(11):2201-2218. doi:10.1351/pac198557040603.

215. Thommes M, Köhn R, Fröba M. Sorption and pore condensation behavior of pure fluids in mesoporous MCM-48 silica, MCM-41 silica, SBA-15 silica and controlledpore glass at temperatures above and below the bulk triple point. Appl Surf Sci. 2002;196(1-4):239-249. doi:10.1016/S0169-4332(02)00062-4.

216. Leofanti G, Padovan M, Tozzola G, Venturelli B. Surface area and pore texture of 
catalysts. Catal Today. 1998;41(1-3):207-219. doi:10.1016/S09205861(98)00050-9.

217. Ajaikumar S, Pandurangan A. Esterification of alkyl acids with alkanols over MCM-41 molecular sieves: Influence of hydrophobic surface on condensation reaction. $J$ Mol Catal A Chem. 2007;266(1-2):1-10. doi:10.1016/j.molcata.2006.10.010.

218. Fuchs VM, Soto EL, Blanco MN, Pizzio LR. Direct modification with tungstophosphoric acid of mesoporous titania synthesized by urea-templated sol-gel reactions. J Colloid Interface Sci. 2008;327(2):403-411. doi:10.1016/j.jcis.2008.08.045.

219. Khalil KMS, Baird T, Zaki MI, El-Samahy AA, Awad AM. Synthesis and characterization of catalytic titanias via hydrolysis of titanium (IV) isopropoxide. Colloids Surfaces A Physicochem Eng Asp. 1998;132(1):31-44. doi:10.1016/S0927-7757(97)00156-8.

220. Kumbar SM, Shanbhag GV, Lefebvre F, Halligudi SB. Heteropoly acid supported on titania as solid acid catalyst in alkylation of p-cresol with tert-butanol. $J \mathrm{Mol}$ Catal A Chem. 2006;256(1-2):324-334. doi:10.1016/j.molcata.2006.05.024.

221. Polenova T, Gupta R, Goldbourt A. Magic angle spinning NMR spectroscopy: A versatile technique for structural and dynamic analysis of solid-phase systems. Anal Chem. 2015;87(11):5458-5469. doi:10.1021/ac504288u.

222. Potrzebowski MJ, Kaźmierski S, Kassassir H, Miksa B. Phosphorus-31 NMR Spectroscopy of Condensed Matter. Annu Reports NMR Spectrosc. 2010;70(C):35-114. doi:10.1016/S0066-4103(10)70005-3.

223. Mastikhin VM, Kulikov SM, Nosov AV, Kozhevnikov IV, Mudrakovsky IL, Timofeeva MN. 1H and 31P MAS NMR studies of solid heteropolyacids and H3PW12040 supported on SiO2. J Mol Catal. 1990;60(1):65-70. doi:10.1016/0304-5102(90)85068-S.

224. López-Salinas E, Hernández-Cortéz J., Schifter I, et al. Thermal stability of 12tungstophosphoric acid supported on zirconia. Appl Catal A Gen. 2000;193(12):215-225. doi:10.1016/S0926-860X(99)00431-7.

225. Jung D-H, Koan Ko Y, Jung H-T. Aggregation behavior of chemically attached 
poly(ethylene glycol) to single-walled carbon nanotubes (SWNTs) ropes. Mater Sci Eng C. 2004;24(1-2):117-121. doi:10.1016/j.msec.2003.09.006.

226. Massart R, Contant R, Fruchart JM, Ciabrini JP, Fournier M. Phosphorus-31 NMR studies on molybdic and tungstic heteropolyanions. Correlation between structure and chemical shift. Inorg Chem. 1977;16(11):2916-2921. doi:10.1021/ic50177a049.

227. Pope M. Heteropoly and Isopoly Oxometalates. Springer-Verlag; 1983.

228. Lefebvre F. MAS NMR Study of H3PW12040 Supported. 1992;(756):756-757.

229. Essayem N, Tong YY, Jobic H, Vedrine JC. Characterization of protonic sites in H3PW12O40 and Cs1.9H1.1PW12040: a solid-state 1H, 2H, 31P MAS-NMR and inelastic neutron scattering study on samples prepared under standard reaction conditions. Appl Catal A Gen. 2000;194:109-122. doi:10.1016/S0926860X(99)00359-2.

230. Edwards JC, Thiel CY, Benac B, Knifton JF. Solid-state NMR and FT-IR investigation of 12-tungstophosphoric acid on TiO2. Catal Lett. 1998;51(1-2):7783. doi:10.1023/A:1019045319788.

231. Holclajtner-Antunović I, Bajuk-Bogdanović D, Popa A, Uskoković-Marković S. Spectroscopic identification of molecular species of 12-tungstophosphoric acid in methanol/water solutions. Inorganica Chim Acta. 2012;383:26-32. doi:10.1016/j.ica.2011.10.035.

232. Gelover S, Mondragón P, Jiménez A. Titanium dioxide sol-gel deposited over glass and its application as a photocatalyst for water decontamination. $J$ Photochem Photobiol A Chem. 2004;165(1-3):241-246. doi:10.1016/j.jphotochem.2004.03.023.

233. Sawant DP, Vinu A, Mirajkar SP, et al. Silicotungstic acid/zirconia immobilized on SBA-15 for esterifications. J Mol Catal A Chem. 2007;271(1-2):46-56. doi:10.1016/j.molcata.2007.02.029.

234. Brahmkhatri V, Patel A. Synthesis and characterization of 12-tungstosilicic acid anchored to MCM-41 as well as its use as environmentally benign catalyst for synthesis of succinate and malonate diesters. Ind Eng Chem Res. 2011;50(24):13693-13702. doi:10.1021/ie201447y. 
235. Cid R, Pecchi G. Potentiometric method for determining the number and relative strength of acid sites in colored catalysts. Appl Catal. 1985;14:15-21. doi:10.1016/S0166-9834(00)84340-7.

236. Fuchs VM, Pizzio LR, Blanco MN. Synthesis and characterization of aluminum or copper tungstophosphate and tungstosilicate immobilized in a polymeric blend. Eur Polym J. 2008;44(3):801-807. doi:10.1016/j.eurpolymj.2007.12.017.

237. Pizzio LR, Blanco MN. Isoamyl acetate production catalyzed by H3PW12040 on their partially substituted Cs or K salts. Appl Catal A Gen. 2003;255(2):265-277. doi:10.1016/S0926-860X(03)00565-9.

238. Guo Y, Yang Y, Hu C, et al. Preparation, characterization and photochemical properties of ordered macroporous hybrid silica materials based on monovacant Keggin-type polyoxometalates. J Mater Chem. 2002;12(10):3046-3052. doi:10.1039/b110873p.

239. Guo Y-H, Hu C-W. Porous Hybrid Photocatalysts Based on Polyoxometalates. J Clust Sci. 2003;14(4):505-526. doi:10.1023/B:JOCL.0000010921.07093.b2.

240. Patel S, Purohit N, Patel A. Synthesis, characterization and catalytic activity of new solid acid catalysts, H3PW12040 supported on to hydrous zirconia. J Mol Catal A Chem. 2003;192(1-2):195-202. doi:10.1016/S1381-1169(02)00416-8.

241. Rubio J, Oteo JL, Villegas M, Duran P. Characterization and sintering behaviour of submicrometre titanium dioxide spherical particles obtained by gas-phase hydrolysis of titanium tetrabutoxide. J Mater Sci. 1997;32(3):643-652. doi:10.1023/A:1018579500691.

242. van Veen JAR, Veltmaat FTG, Jonkers G. A method for the quantitative determination of the basic, acidic, and total surface hydroxy content of TiO2. $J$ Chem Soc Chem Commun. 1985;(23):1656. doi:10.1039/c39850001656.

243. Rocchiccioli-Deltcheff C, Thouvenot R, Franck R. Spectres IR et Raman d'hétéropolyanions $\alpha$ - XM12040n- de structure de type Keggin (X = BIII, SiIV, GeIV, PV, AsV et M = WVI et MoVI). Spectrochim Acta Part A Mol Spectrosc. 1976;32(3):587-597. doi:10.1016/0584-8539(76)80121-3.

244. Blanco MN, Pizzio LR. Properties of mesoporous tungstosilicic acid/titania composites prepared by sol-gel method. Appl Surf Sci. 2010;256(11):3546- 
3553. doi:10.1016/j.apsusc.2009.12.105.

245. Li Bassi A, Cattaneo D, Russo V, et al. Raman spectroscopy characterization of titania nanoparticles produced by flame pyrolysis: The influence of size and stoichiometry. J Appl Phys. 2005;98(7). doi:10.1063/1.2061894.

246. ??olovi?? MB, Bajuk-Bogdanovi?? D V., Avramovi?? NS, et al. Inhibition of rat synaptic membrane $\mathrm{Na}+/ \mathrm{K}+$-ATPase and ecto-nucleoside triphosphate diphosphohydrolases by 12-tungstosilicic and 12-tungstophosphoric acid. Bioorganic Med Chem. 2011;19(23):7063-7069. doi:10.1016/j.bmc.2011.10.008.

247. Li J, Kang W, Yang X, et al. Mesoporous titania-based H3PW12040 composite by a block copolymer surfactant-assisted templating route: Preparation, characterization, and heterogeneous photocatalytic properties. Desalination. 2010;255(1-3):107-116. doi:10.1016/j.desal.2010.01.007.

248. Leng Y. X-Ray Diffraction Methods. In: Materials Characterization. Introduction Tu Microscopic and Spectroscopic Methods. Singapore: John Wiley \& Sons, Ltd; :45-77. doi:10.1002/9780470823002.ch2.

249. Sakurai K, Mizusawa M. X-ray diffraction imaging of anatase and rutile. Anal Chem. 2010;82(9):3519-3522. doi:10.1021/ac9024126.

250. Yuan J, Yue P, Wang L. A study on the magnetically supported heteropolyacid nanophase catalysts. Powder Technol. 2010;202(1-3):190-193. doi:10.1016/j.powtec.2010.04.020.

251. Khosroshahi ME, Ghazanfari L. Preparation and characterization of silica-coated iron-oxide bionanoparticles under N2 gas. Phys E Low-Dimensional Syst Nanostructures. 2010;42(6):1824-1829. doi:10.1016/j.physe.2010.01.042.

252. Zhang Z, Zhang F, Zhu Q, Zhao W, Ma B, Ding Y. Magnetically separable polyoxometalate catalyst for the oxidation of dibenzothiophene with H2O2. $J$ Colloid Interface Sci. 2011;360(1):189-194. doi:10.1016/j.jcis.2011.04.045.

253. Maleki B, Eshghi H, Khojastehnezhad A, et al. Silica coated magnetic $\mathrm{NiFe}<\mathrm{inf}>2</ \mathrm{inf}>0<\mathrm{inf}>4</ \mathrm{inf}>$ nanoparticle supported phosphomolybdic acid; Synthesis, preparation and its application as a heterogeneous and recyclable catalyst for the one-pot synthesis of tri- and tetra-substituted imidazoles unde. $R S C A d v$. 2015;5(80):64850-64857. doi:10.1039/C5RA10534J. 
254. Ghasemzadeh MA, Abdollahi-Basir MH, Babaei M. Fe 304 @SiO 2 -NH 2 coreshell nanocomposite as an efficient and green catalyst for the multi-component synthesis of highly substituted chromeno[2,3-b]pyridines in aqueous ethanol media. Green Chem Lett Rev. 2015;8(3-4):40-49. doi:10.1080/17518253.2015.1107139.

255. Rafiee E, Khodayari M. Synthesis and characterization of a green composite of H3PW12040 and starch-coated magnetite nano particles as a magneticallyrecoverable nano catalyst in Friedel-Crafts alkylation. J Mol Catal A Chem. 2015;398:336-343. doi:10.1016/j.molcata.2015.01.005.

256. Kuwahara Y, Kaburagi W, Nemoto K, Fujitani T. Esterification of levulinic acid with ethanol over sulfated Si-doped ZrO2 solid acid catalyst: Study of the structure-activity relationships. Appl Catal A Gen. 2014;476:186-196. doi:10.1016/j.apcata.2014.02.032.

257. Sheldon RA. Atom efficiency and catalysis in organic synthesis*. Pure Appl ChemPure Appl Chem. 2000;72(7):1233-1246. doi:10.1351/pac200072071233.

258. Osiglio L, Romanelli G, Blanco M. Alcohol acetylation with acetic acid using borated zirconia as catalyst. J Mol Catal A Chem. 2010;316(1-2):52-58. doi:10.1016/j.molcata.2009.09.021.

259. Liu Y, Lotero E, Goodwin J. Effect of carbon chain length on esterification of carboxylic acids with methanol using acid catalysis. J Catal. 2006;243(2):221228. doi:10.1016/j.jcat.2006.07.013.

260. Badireddy AR, Hernandez-Delgadillo R, Sánchez-Nájera RI, Chellam S, CabralRomero C. Synthesis and characterization of lipophilic bismuth dimercaptopropanol nanoparticles and their effects on oral microorganisms growth and biofilm formation. J Nanoparticle Res. 2014;16(6):2456. doi:10.1007/s11051-014-2456-5.

261. Yan K, Jarvis C, Gu J, Yan Y. Production and catalytic transformation of levulinic acid: A platform for speciality chemicals and fuels. Renew Sustain Energy Rev. 2015;51:986-997. doi:10.1016/j.rser.2015.07.021.

262. Alexandre Démolis, Nadine Essayem and FR. Synthesis and Applications of Alkyl Levulinates. ACS Sustain Chem Eng. 2014;2:1338-1352. doi:10.1021/sc500082n. 
263. Patil CR, Niphadkar PS, Bokade VV, Joshi PN. Esterification of levulinic acid to ethyl levulinate over bimodal micro-mesoporous H/BEA zeolite derivatives. Catal Commun. 2014;43:188-191. doi:10.1016/j.catcom.2013.10.006. 